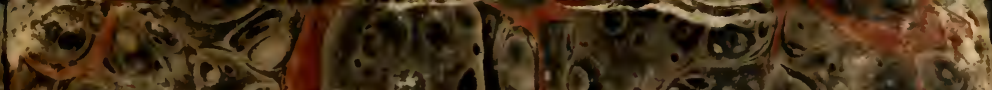

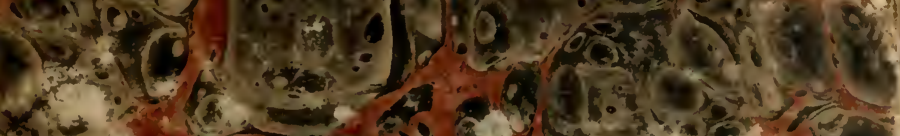

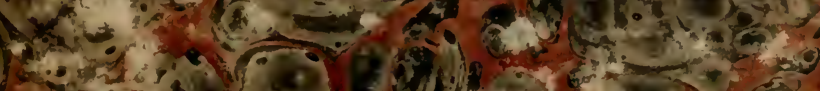

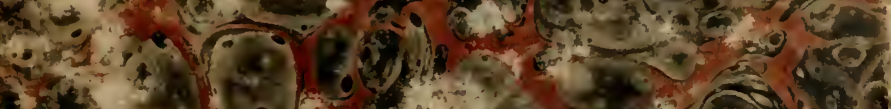

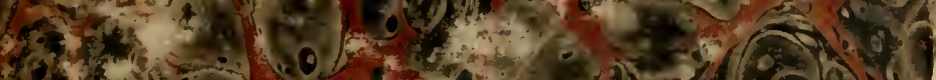

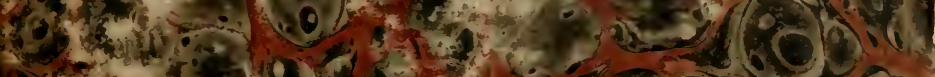

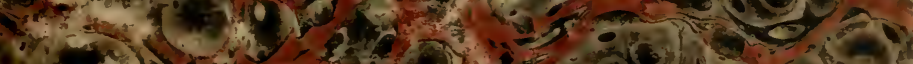
(1)

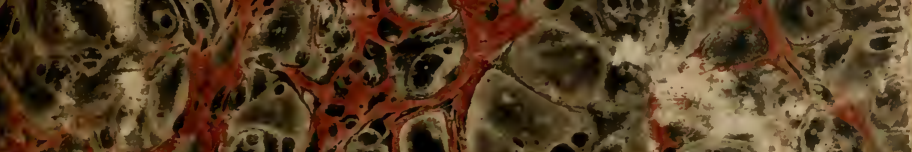

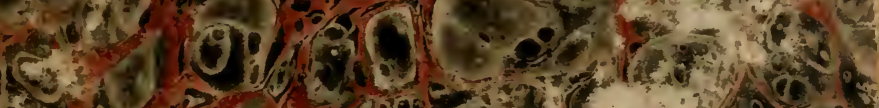

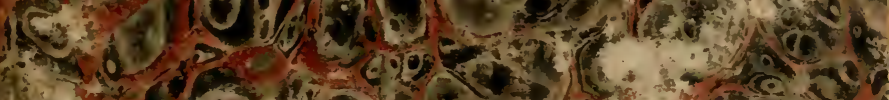

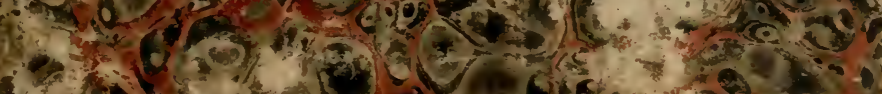

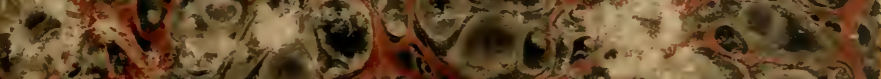

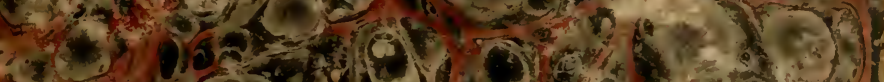
5.

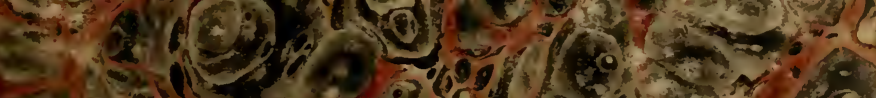

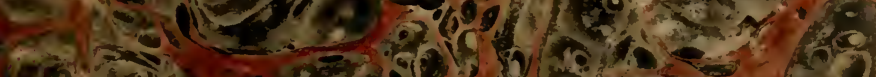
(1)



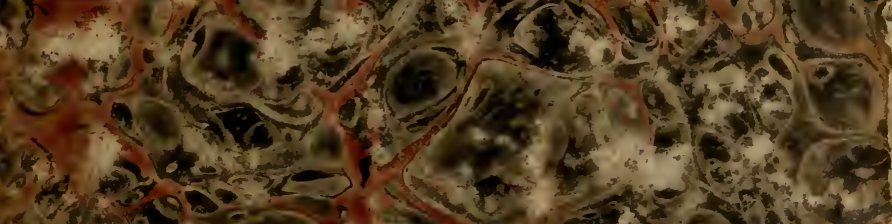
(x)

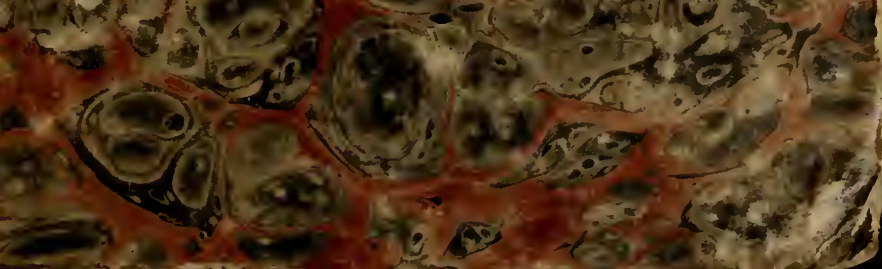




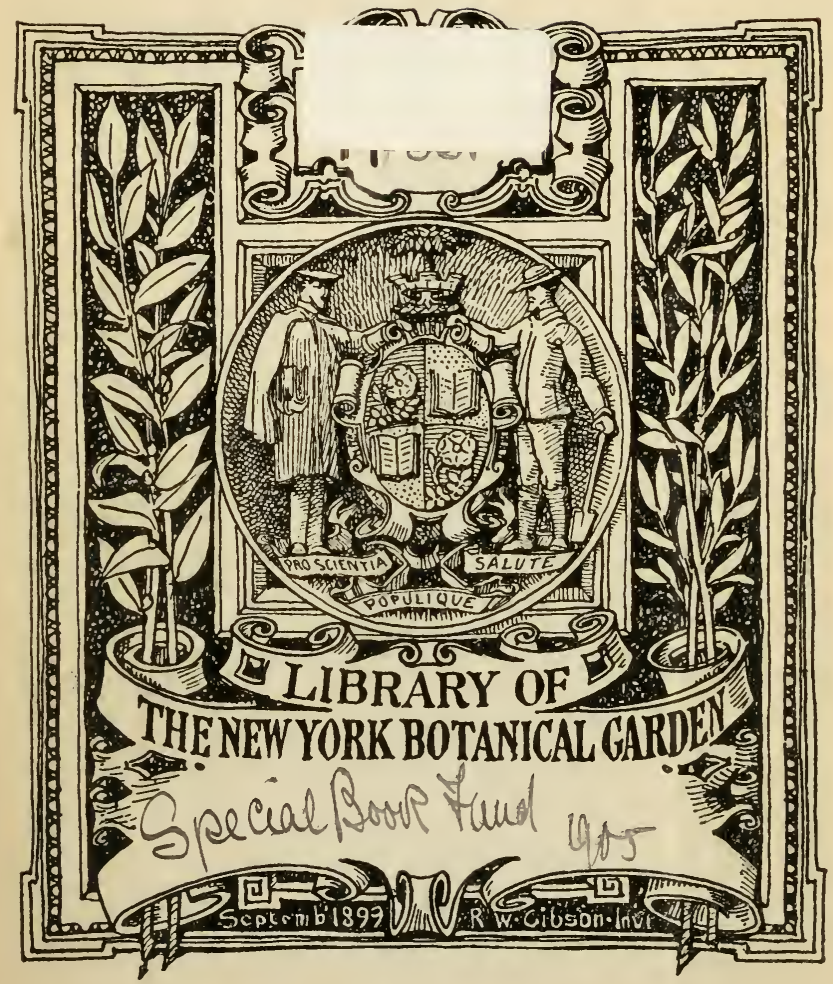


DR. ERNST ZICKENDRATH.

Moskau, Nishny Bahn; Flattform KUTSCHINO.

Д-рт Әрнеть Васнльеэить ЦИКЕНДРАТО.

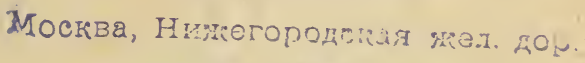
платџорма Iіни:оо. 
$\begin{array}{llllllllll}\mathbf{P} & \mathbf{R} & \mathbf{O} & \mathbf{D} & \underline{\mathbf{n}} & \mathrm{O} & \mathbf{M} \boldsymbol{I} & \mathrm{U} & \mathrm{S}\end{array}$

\section{FLORAE MOSQUENSIS.}

\section{A U C T O R E}

\section{HENRICO DE MARTIUS}

Medicinae ac Cimpurgiae Doctore, Societatis Imperialis naturae scrutatorum Mosquensis MEMERO ORDINARIO ETC.

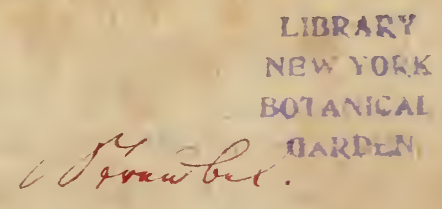

\section{EDITIO ALTERA.}

\section{I P S I A E}

IN COMAERCIO. INDUSTRIAE

$$
1817 \text {. }
$$




$$
\begin{gathered}
+2 k 321 \\
. M 35 \\
1817
\end{gathered}
$$

Relinguamus aliquid ne frustra vixisse videamur. 


\section{EX C E L L E N T IS S I M O}

A C

\section{ILLUSTRISSIMO DOMINO}

\section{ALEXANDRO CRIGHTON}

Augustissimi Imperatoris et Autocratoris onnivm Russorum

Consiliario Status actuali

et Arciriatro

Medicinae et Cimiturgae

D O $\mathrm{T}$ O $\mathrm{R}$

SUMMO ReRUM MEDiCARUM CIVILIUM

IN S P E C T O R I

Consmin Medici Membro

Ofinis Sanctie Anne

EQurti

Societatis Imperialis Naturae Scrutatorua

Mospuensts

pluriemQue altarum Membo

E.TC. 


\section{HOC OPUSCULUM}

SUMMAE VENERATIONIS TESTIHONIUM

SACAUM ESSE VUL.T

A U C T O R. 


\section{LISR ARY}

NBW YORK

BOTANICAL

UARDEN

\section{P R A E F A T I O.}

pus, quum non prorsus inutile ac su. pervacaneum milii viderer suscipere, novam Prodromi Florae Mosquensis editionem curare coepi. Nam prior libelli editio, quae propriis meis sumptibus anno 1812. e typographia Lubyana in lucem prodiit, fato aeque diro, atque herbarium meum, cujus jacturam etiamnum aegre fero, bibliotheca reliquisque omnibus, quas haberem rebus mobilibus, deperditis, post Franco-Gallorum invasionem, magno incendio urbis capitalis veteris Russici Imperii flammis est correpta at- 
que deleta. Novam cur retardarem edi. tionem, varia mihi impedimenta erant, imprimis tamen desiderio in patria dilectissima huius laboris suscipiendi, non potui a me impetrare ut resisterem.

Quibus, quae scrutatori harum regionum sese opponant obstacula innumerabilia, non ignotum est, hurum me virorum eo facilius veniam impetraturum spero, si omni adhibita diligentia, ac saepius et saepissime repetitis ad plantas inquirendas excursionibus, quaedam plantarum oculis meis furte evaserint. Quarum quidem numerum perquam exiguum fore propterea sperare possum, quod norem annorum otium ad hunc laborem perficiendum conferre non haesitavi, omnique Jove ac tempore, propiori. bus ac remotioribus hujus tractus regionibus perscrutandis maxime laetatus sum. 
Antecessorem me habere egregium, Vi. rum praenobilissimum Equitem STEPHAN, cujus magna de Flora Russica merita sunt et satis nota, lubens profiteor. Ceterum quorundam amicorum nomina, qui et ipsi Botanices eruditi cultores in opere perficiendo imprimis mesustentavere, publice quoque grato animo pronuntiare officium mihi sanctissimum est. Ex intimo enim animo Clarissimo Henning, pharmacopolae meritissimo, qui per duo decennia regiones mosquenses perscrutatus est; Clarissimo D. Londes, beate defuncto, nec non amicissimis D. MÜLLER et D. GoldBACH, sacra pectoris vota voveo. Summis tamen laudibus me publice nunc extollere posse magna in me merita Viri Illustris HoffManN, professoris mosquensis, qui laborem plurimis impedimentis obnoxium et doctrina sua 
et studio honestissimo adjuvit, imprimis laetor.

Catalogo vero, non nisi, quarum copiam habere plantarum et quas videre potui, nomina inserui*). E contrario plurium plantarum nomina haud enumeravi, quarum Flora Illustris Stephan fecit mentionem, quas ut invenirem et viderem, omni cura adhibita, nunquam mihi contigit. Quod ad eas attinet plantas, quae minus occurrunt, plura ubi proveniunt loca, tempus, quo florescunt,

*) Scillae amoenae e. g. rernali tempore a rusticis in mercatu florum magna copia venalis circumfertur; dicitur etiam in regiono mosquenei absque cura et cultura provenire. Sic reterente lllustri PALLAS Alisma Damasonium, Hippophä̈ Rhamonides etc. non procul ab Urbe crescunt. Quas cam in loco natali nunquam invenire possem, earurs nomina in $\mathrm{Ca}$. talogo omitti posse non dubitari. Tiumicisbucephalophori antem, licet persuasu difncile sit, Clarisaimus Henning plus triginta exemplaria recentia, ripae Jausae depromta, mecum communicavit. 
solitas, quas habent varietates, simul adnotavi.

Ad singulas quod attinet plantarum species, ea harum womina eligere ausus sum, quae iis maxime mihi viderentur convenire. Ajuga genevensis, Circaea lutetiana, Iris sibirica, Lavatera thuringiaca, aliaeque plantae permultae, tam in majori Imperii Rassici parte, quam in aliis terris et regionibus crebrius proveniunt, quam ut nomina a loco nativitatis repetita potuissent retinere.

\section{Desideriis tironum studii Botanices} ut succurrerem, eorum habuirationemlibrorum, in quibus singularum plantarum optimae occurrunt, et imprimis accuratae imagines. Prodromi tamen hujus Florae Mósquensis hunc etiam esse volui finem primarium, ut studii botanici cultoribus 


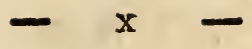

sit comes in excursionibus instituendis non inutilis.

Sequenti anno, Deo favente, Floram Mosquensem majorem tribus tomis, quae usus, quam plantae praebere possunt, primariam habeat rationem, Virorum doctorum subjicere me posse judicio spero.

A U C TOF:

Budissae,

die 28. Decembris

2816. 


\section{AUCTORES CITATI.}

Allione, flora pedemontana o. enumeratio methodice stirpium indigenarum Pedemontii. Augustae Taurinorum. 1785. fol.

Amman, stirpium rariorum in imperio rutheno sponte provenientium icones et descriptiones. Petropoli. 17j̄9, 4. Barreliere, plantae per Hispaniam. Italiam et Galliam observatae. Parisiis. 1714. fol. Batsch, elenchus fungorum. Halac. $1780-1789.4$. Bauhin, pinax theatri botanici. Basileae. 1623.4 . Blackwell, herbarium selectum emendatum et auctum 8. collectio stirpium officinalium. Norimbergae.1757 1773. fol.

Bocco, museo di piante rare della Sicilia, Malta, Corsica, Italia, Piemonte e Germania. Venezia. I697. 8. Bolton, history of all the british proper ferns. London 3792. 4.

Bulliard, herbier de la France, ou collection complette des plantes indigenes de ce Royaume. Paris. 1780 . fol. Bulliard, histoire des champignoris de la France. Paris. 1798. fol.

Buxbaum, plantarum minus cognitarum Cent, V. Petropoli. 1728.4.

Cavanilles, classis monadelphia. Madrit. 1785-1790. 4. Columina, ecphrasis stirpium minus cognitarum. Romae. 1616.4 .

Curtis, flora Londinensis, or plates in the environs of London. Londini. 1777-1785. fol. Curtis, the botanical magazine. London. 2787. 8. Decandolle, flore française. Paris, 1805. 
Decandollo, plantarum historia succulentarum s, histoire des plantes grasses. Paris. 1799 . fol.

Dickson, plantarum cryprogamicarum Brittanniae. Fasc. IV. Londini. $3785 \div-180 x .4$.

Dillenius, hisioria muscorum. Oxoniae. 1745. 4. Dillwyn, syzopsis of the british confervae. London. $1800-1802.4$.

Dodonaeus, stirpium historiae pemptaçes sex. Antwerpiae. 1616. fol.

Du Hamel du Monceau, trailé des arbres, fruitiers, contenant lcur figure, leur description, leur culture, etc. Paris. 1768. 4 .

Ehrhart, herbae Linneanae XVI. Docades. 1787-1793. fol.

Ehrhart, calamariae, çramina et tripetaloideae Linnea. nae. XIV. Decades. $1789-1793$. fol.

Ehrhart, plantarum cryptoganicarum decades. fol. Gmolin, flora sibirice. Petropoli. 174?-1769, 4.

Haller, historia stirpium indigenarum Helvetiae. Beranae. 1768 . fol.

Haller, de allii genere naturali libellus. Gottingae. 1745. 4 .

Hayno et Drewes, getrcue Darstellung und Beschreibung der in der Arzneikunde gebräuchlichen Gewächse. Berlin, 1802. 4.

Hedwig, species muscorum frondosorum. Iipsias. 1801. 4.

Hermann, paradisus batarus, continens plus centum plantas aori incisas. Lugduni. 1693.4.

Hoffmann, Dcutschlands Flora. 1795-1804. 12. Hoffmann, historia salicum. Lipsiae. 1787. toil. Hoffinann, descriptio lichenum. Lipsiae. 1790 - 1801. fol. Hoppe, lateinisches Taschenbuch für die anfanger dieser Wissenschaft und der Apothekerliunst. $1799^{\circ}-$ 18.5. 8 .

Host, icones et descriptiones graminum austriacorum. Vicnuae. $1802-8805$. fol. 
Nouttuyn, des Ritters von Linné vollatåndiges PAnnzen. system. Nïrnberg. 1777-1788. 8.

Jacquin, fora anstriaca. Viennac. $1773-1778$. fol. Jacquin, hortus botanicus Vindobonensis. Vindobonae. 1770- 1776. fol.

Jacquin, icones plantarum rariorum. Viennee. $2780-$ 1795. fol.

Jacquin, collectanea al Botanicam, Chemiam et Mistoriam naturalem spectantia. Viennae. 1786-1793. 4. Ferner, Beschreibung und Abbildung der Bäume und Gesträuche von Würtemberg. Stuttgard. 1788. 4. Finiphof, botanicon in originali. Halae. $1757-1764$. Fnorr, thesaurus rei herbariae hortensisque universalis. Norimbergae. 1772. fol.

Krocker flora silesiaca renovata emondata. Vratislavias. $1787-1790.8$.

Lamarc, flore française ou description de toutes les plantes, gui croissent naturellement en France. Pa. ris. 1795. 8.

Lambert, description of the genus Pinus. London.1824. Leers, flcra herbormensis. Herbornae. 1775. 8

Linné, flora lapponica. Loudini, 1792. 8.

Linne, hortus Cliffortianus. Ainstelaedaini, 1737. fol. Lobel, icones plantarum. Antwerpiae. 158i. 4. Loesel, flora prussica. Regiomonti. 1703. 4. Marschall a Bieberstein, flora taurico-caucasica. Charkoviae. 1808. 8 :

Micheli, nova plantarum genera, Florentiae. 1729. 4. Iiller, illustratio systematis sexualis Linnaei. Londini. 1777. fol.

Miller, figures of the most beautiful, useful-and uncommon plants, described in the garderers diction. ry. London. 2760 . fol.

Mönch, enumeratio plantarum indigenarum Hassiae. Cassellis. 1777. 8. Morison, historia plantarum universalis. Oxoniae.1680 16g9. fol. 
Oeder, Muillor, Vahl, flora danica. Havniae. $1764-$ 1800. fol.

Pallas, flora rossica. Petropoli. I784 - 1788. fol.

Persoon, synopsis fungorum methodica. Gottingae. 1801. 8 .

Persoon, icones et descriptiones fungorum. Lipsiae. 1800.4 .

Persoon, icones pictae rariorum fungorum.' Parisiis. 1804. 4.

persoon, observationes mycolngicae. Lipsiae. 1796 1797. 8 .

Petiver, herbarii britannici Raji catalogus. Londini. 1764. fol.

Plenk, icones plantarum medicinalium. Vindobonae. 1788 - 1789. fol.

Pluknet, almagestum botanicum. Londini. 16944 .

Pluknet, pliytographia. Londini. 1690. 4.

Rebentisch, prodromus florae neomarchicae. Berolini. 180\%. 4 .

Ihivin, ordo plantarum flore irregulari tetrapetalo. Lipsiae. 1691. fol.

Rivin, ordo plantar am flore irregulari pentapetalo. Lipsiae. 1699. fol.

Fömer, Archiv für die Botanik. Leipzig. 1796 1805. 4 .

Roth, tentamen florae germanicae. Lipsiae, 1788 I789. 8.

Ruppe, flora jenensis. Jenae. 17458 .

Sabbati, hortus Romanus. Romae. $1772-1777$. fol. Schäffer, icones fungoıum Ratisbonensium. Ratisbonae. $1765-1770.4$.

Scheuchzer, agrostographia s. graminum, juncorum, cyperorum etc. historia. Tiguri. 1719.40 Schkuhr, botanisches Handbuch. Wien. 279I - 1803.8. Schkuhr, Besclıreibung und Abbildung der Riedgräser.

Nittenberg, 1801. 8 . 
Schkuhr, kryptogamische Gewächse, Leipzig. '1804 1805. 4 .

Schmidel, icones et analyses plantarum. Norimbergao. 1762. fol.

Schrader, spicilegium florae germanicae. Hannoverae. 1794. 8 .

Schrader, commentatio super Veronicis spicatis. Gottin. gae. 1803.8 .

Schrader, systematische Sammlung cryptogamischer Gewächse. Göttingen, 2796. 8.

Schrank, baiersche Flora. München. 1789. 8. Schreber, Bescreibung, der Gräser, nebst ihren Abbildungen nach der Natur. Leipzig, 1769. fol. Smith, plantarum icones hactenus ineditae. Londini. 1789- 1791. fol.

Sinith et Sowerby, english botany or colowred figure of british plants. London. $2790-2805.8$. Sole, menthae britannicae. Bathiae. 1798. fol. Sowerby, colored figures of english fungi. London. 1797. fol.

Sprengel, florac halensis tentamen. Halae, 18068 . Stephan, enumeratio stirpium agri Mcsquensis. Lipsiao. 1792. 8.

Stephan, icones plantarum Mosquensium, ad historiam plantarum sponte circa Mosquam crescentium illu. strandum. Mosquae. 1795. fol.

Sturm, Deutschland Flora in Abbildungen nach dex Natur. Nürnberg. $1798-1806.12$.

Tode, fungi meklenburgenses. Luneburgi. 1790. 4. Usteri, Annalen der Botanil. Zürich. 179r.

Usteri, neue Annalen der Botanik. Zürich. 1794. 4. Vaillant, botanicon parisiense si denombrement des plantes qui so trourent aux environs de Paris. Lugduni. 1757. fol.

Vaucher, histoire des conferres d'eau douce. Genève. 1803.4 . 


\section{- XVI}

Viborg, botanisk-nekonomisk, aflandeling on Bygget. riobenliavn. 1738. 4.

Villars, histoire des plantes de Datuphinés. Grenoblé. $1786-1788.8$.

VWaldstein et Kitaibel, icones et descriptiones plantarum rariorum Hungariae. Viennae. 1802. fol.

WTeigel, observationes botanicae. Gryphiswaldae. 1772.8. Willdenow, enumeratio plantarum horti betanici Bero. linensis. Berolini. 1809. 8\%.

Zorn, icones plantarum medicinalium. Norimbergae. $1779-1782.8$.

Abhandlungen der Halleschen naturforschenden Gesellschaft. Dessau. 1783.8.

Acta academiae scientiarum Petropolitanae. Petropoli. $1728-1776.4$.

Memoires de la societé Imperiale des Naturalistes à Moscou, Moscotl. 1806. q.

\section{O R R I G E N D A.}

pag. 33. lin. 6. loc. Jasjone leg. Iasione.

- 33. - 1. - fructicasus leg. fruticosus,

- 1I6. - 19. - ABABIS - ARABIS.

- r28. - 3. - Astragulus - Astragalus.

- 171. - 12. - pedurículatus - pedunculata.

- 178. - 19. - Aloides - Aloides. 


\section{PARS PRIMA}

\section{PLANTAE PHAENOGAMAE.}




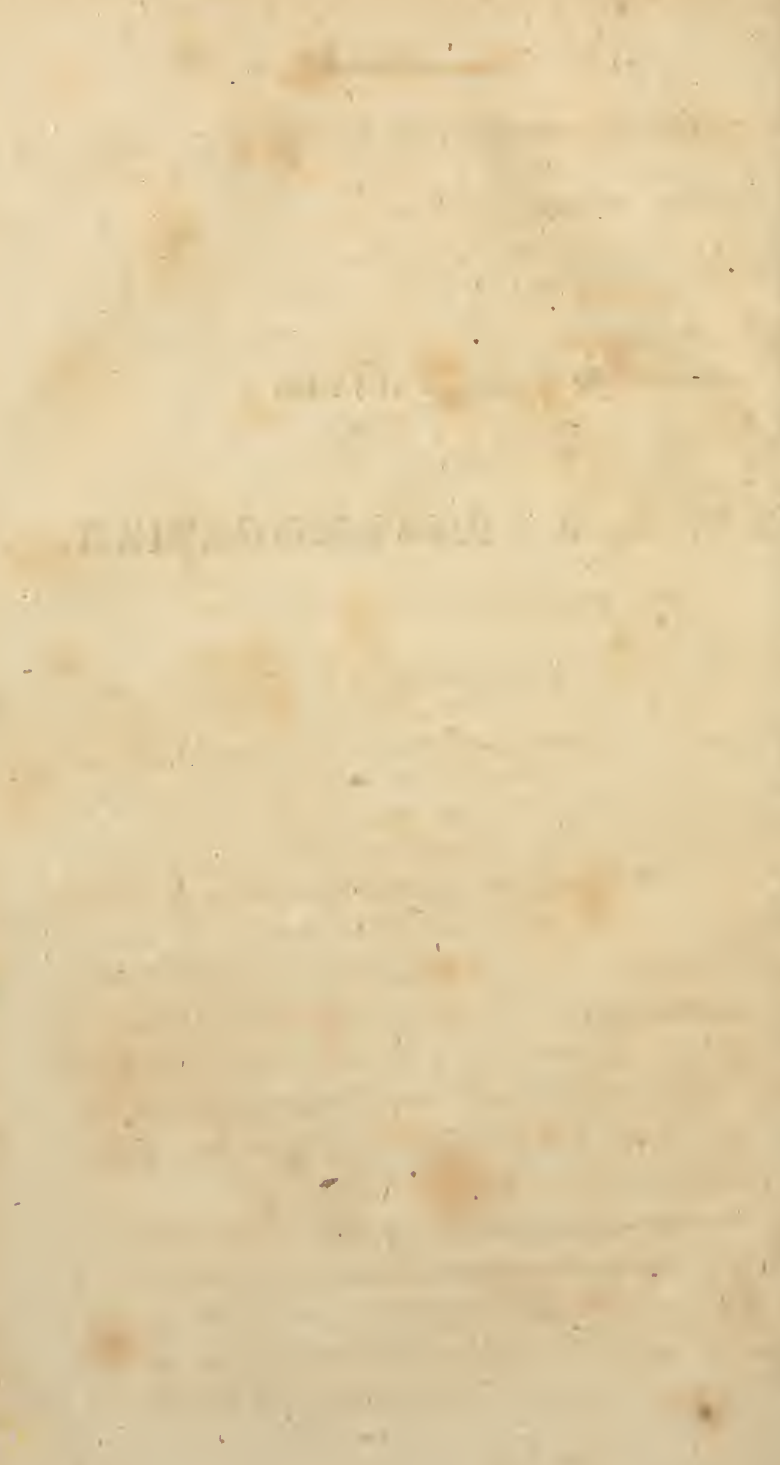




\section{O N A N D R I A. MIONOGYNIA.}

1. Hipuris. Calyx margo bilobus. Corolla nulla. Stigma simplex. Nux monosperma.

1. H. vulgaris: foliis verticillatis numerosis linearibus acutis. Flor. dan. t. 87. (habitat in sic dictis tribus montibus. Jun.)

b. Hippuris minor: foliis superioribus linearibus octonis senisve, inferioribus lineari-lanceolatis quaternis senisque. (ibidem Henning.)

\section{I G Y N I A.}

2. Caleitriche. Calyx diphyllus. Corolla nulla. Capsula bilocularis tetrasperma.

2. C. verna: foliis superioribus ovalibus, floribus, androgynis. Fl. dan. t. 1乞9. (in lacubus, fossis, paludibusque. Mai. Jun.)

2. C. intermedia: foliis superioribus ovalibus, caulinis linearibus apice bifidis. Schliukr.t. 1. f.e. (cum antecedente. Jun. Jul.)

3. C. autumnalis: foliis omnibus linearibus apice bifidis, floribus hermaphroditis. Loes. pruss. to 38. (cum priori. Sept.)

4. C. cespitosa: [minima] foliis lineari-lanceolatis utrinque attenuatis, apice obtusis integris, 


\section{- $4-$}

caulibus cespitosis ramosissimis reptantibus. (in fossis exsicatis, ad vias in orbitis. Jun. Aug.) 3. Buitum. Calyx trifidus. Corolla nulla. Semen unum calyce baccato immersum.

1. B. virgatum: glomerulis florum axillaribus, foliis subhastato-lanceolatis inaequaliter dentatis. Mill. sexual. Linn. t. 2. (in locis incultis. Jun.)

\section{I A N D R I A.}

\section{MONOGYNIA.}

4. Syringa. Calyx quadridentatus, Corolla hypocrateriformis quadrifida. Capsula bilocularis, bivalvis. Semen margine membranaceo.

1. S.vulgaris: foliis ovato-cordatis, floribus caeruleis. Schkuhr. t. 2. (in hortis et sepibus. Mai.)

b. Syringa rosea: corollis roseis.

c. Syringa alba: corollis albis.

5. Cincaea. Calyx bipartitus basi tubulosus. Corolla dipetala. Capsula infera bilocularis non dehiscens, loculis monospermis.

1. C. pubescens: [lutetiana] caule erecto, foliis ovatis denticulatis opacis pubescentibus. Fl. dan. t. 210. et t. 256. (in montibus passerinis et nemoribus Kuskowae. Jun. Jul.)

£. C. alpina: caule ramosissimo depresso, foliis cordatis dentatis nitidis glabris. Engl. bot. t. 1057. (in montibus passerinis, Gorenli et ILunzowa. Jul. Aug.) 


\section{$-5$}

6. Veroxica. Calyx quadrifidus vel quinquefidus. Corolla rotata quadripartita, lacinia infima angustiore. Capsula bilocularis.

* Spica racemove terminali.

1. V. spicata: spicis terminalibus, tota pubescens, foliis oppositis lanceolatis obtusis basi attenuatis crenatis. $F l$. dan. t. 52 (in sylvis. Jun. Jul.)

b. Veronica rosea: corollis roseis.

2. V. longifolia: spicis terminalibus, tota pubescens, foliis oppositis ternis quaternisve lanceolatis acuminatis, basi cordatis, duplicatoserratis. Schrader veron. spic. t. 2. f. 1. (in collibus siccis. Jun. Jul.)

3. V. maritima: spicis terminalibus, tota pubcscens, foliis ternis quaternis quinisve linearilanceolatis acuminatis duplicato - serratis, basi ova. tis. Fl.dañ.t. 374. (in pratis humidis. Jul. Aug.)

4. V. serpyllifolia: racemo terminali solitario, bracteis ellipticis, caulibus diffusis, foliis ellipticis obtusis crenatis glabris. $\mathrm{Fl}$. dail t. 492. (ad vias et in pratis. Mai. Jun.)

** Spicis racemisve axillaribus.

5. V.officinalis: racemis axillaribus pedunculatis, floribus inferioribus distantibus, foliis oppositis obovato-oblongis annuis cauleque procumbente hirtis. Fl.'dan. t. 248. (in sylvis. Jun.)

6. V. Beccabunga: racemis axillaribus oppositis, foliis ovato - oblongis serratis petiolatis glabris. Fl.dan. t. 511. (ad fontes rivulosque. Jun. Jul.) 7.V. Anagallis: racemis axillaribus oppositis, foliis oblongo-lanceolatis amplexicaulibus ser. 


\section{$-6-$}

ratis glabris. Fl. dan. t. 903. (ad fossas rivulosque. Jul.)

8. V. scutellata: racemis axillaribus alternis, pedunculis patentissimis, foliis lineari-lanceolatis sessilibus remote denticulatis glabris: $F l$. dan. t. 209. (in pratis humidis, inundatis, paludibus. Jun. Jul.)

b. Veronica parmularia: racemis lateralibus alternis, foliis lineari-lanceolatis retrorsum perspicueque denticulatis pilosis. Poiteal et Iurpin. flor. paris. t. 14. (in paludosis.)

9. V. Chamacdrys: racemis axillaribus, foliis ovatis grosse inaequaliter obtuse serratis, inferioribus petiolatis, caule adscendente bifariam piloso. Fl.dan. t. 448. (in pratis, vallis, aggeribus. Jun. Sept.)

10. $V$. austriaca: racemis axillaribus, foliis linearibus pinnatifidis bipinnatisve, bracteis pedicellis longioribus. Jacyu. austr. IV. t. 329. (in pratis circa Gorenki. Jun. Jul. Londes.)

11. V. Teucrium: [latifolia.] racemis axillaribus longissimis, foliis inferioribus oblongis, superioribus ovato-oblongis obtusiusculis rugosis dentatis, caule adscendente. Rivin. t. 95. (ad sylvarum margines. Jul. Aug.)

*** Pedunculis unifloris.

12. V. agrestis: floribus solitariis pedunculatis, foliis cordatis petiolatis, caule pubescente. $F$. dan. t. 449. (in arvis et agris. Mai.)

13. $V$. arvensis: floribus solitariis foliisque cordatis subsessilibus, caule hirto. Fl. dan. t. 515 . 


\section{$-7-$}

(circa nosocomium militare et versus sylvam St. Annae. Mai.)

24. V. triphyllos: floribus solitariis pedunculatis, foliis digitato - partitis, caule patulo. $F l$. dan.

t. 627. (in agris frequens. Mai.)

35. V. verna: floribus solitariis subsessilibus, foliis digitato-partitis, summis indivisis, caule stricto. Fl. dan. t. 252. (in graminosis siccis. Mai.)

7. Gratrola. Calyx quinquepartitus. Corolla irregularis resupinata. Stamina quatuor: binasterilia. Stigma bilamellatum. Capsula bilocularis.

1. G. officinalis: foliis lanceolatis trinerviis apice serratis, pedunculis unifloris, calycibus bibra. cteatis. Fl. dan. t. 363. (ad Occam fluvium. Jun. Stephan.)

8. Utricularia. Calyx diphyllus aequalis. Corolla personata calcarata. Capsula unilocularis circumscissa.

1. U,vulgaris: nectario conico, labio superiorelateribus reflexo longitudine palati, scapo stricto. Fl. dan. t. 133. (in aquis stagnantibus. Aug.)

2. U. minor: nectario carinato. Fl. dan, t. 128. (cum priore, rarius. Aug.)

9. Lrcopus. Calyx tubulosus quinquefidus. Coxolla tubulosa subaequalis quadrifida, lacinia superiore latiore emarginata. Semina quaterna, retusa.

1. L. vulgaris: [europaeus] foliis ovato-lanceolatis villosis sinuato-serratis. Fl. dan. t. I081. (ad ripas, fossas, paludes. Jul. Aug.) 


\section{$-8-$}

10. Salvia. Calyx subcampanulatus bilabiatus: labio superiore tridentato. Corolla ringens. Filamenta transverse pedicello affixa.

3. S. pratensis: foliis cordato-oblongis crenatis, summis amplexicaulibus, verticillis subnudis, corollis galea glutinosis. Engl. bot. t. 2.53. (in pratis ad ripam Occae. Jul. Aug.)

b. Salvia rubra: corollis formosissimis coccineis.

2. S. glutinosa: villoso-viscosa, foliis cordatosagittatis grosse serratis acuminatis. Moris. hist. III. t. 13. f. 18 (in sylva umbrosissima circa pagum Dolmatowa, solo lutoso. Jul. Henning.)

\section{I G Y N I A.}

12. Anthoxanthum. Calyx gluma bivalvis uniflora. Corolla duplex bivalvis: exterior aristata, interior minima mutica. Semen corollae interiori adnatum.

1. A. odoratum: spica oblonga ovata, flosculis subpedunculatis arista longioribus. $F l$, dan. $t$. 666. (in pratis et sylvis. Jun.)

\section{T R I A N D R I A.}

\section{MONOGYNIA.}

12. Valeriana. Calyx nullus, nisi margo involutus germen coronans et deinde in pappum transiens. Corolla monopetala quinquefida, hasi gibba vel calcarata supera, Semen unicum pappo plumoso coronatum. 
1. V. officinalis: foliis omnibus pimatis lanceolatis serratis. Fl. dan. t. 570. (in nemoribus et umbrosis humidis. Jun. Jul.)

13. Gradrolus. Spatha bivalvis. Corolla sexpartita: laciniis limbi inaequalibus, tubo subcurvato. Stamina adscendentia

1. G. communis: corollis subringentibus secundis, laciniis spathulatis, spathis tubo longioribus, foliis ensiformibus nervosis. Fl. Lond. t. 86. (ad colles et monticulos circa Kunzowa rarius. Jun.)

14. Inis, Corolla sexpartita: laciniis alternis re. flexis. Stigmata petaliformia.

1. J. paludosa: [Pseud-Acorus.] imberbis, foliis ensiformibus, laciniis corollae interioribus stigmate minoribus, Fl. dan. t. 494. (in paludosis. Jul.)

2. J. pratensis: [sibirica.] imberbis, foliis linearibus, scapo subtrifloro tereti, germinibus trigonis. Jacqu. austr. I. t. 3. (in pratis uliginosis. Jun.)

15. Rirmcirospora. Squamae paleaceae, infimae vacuae. Corolla nulla. Semen unicum coronatum stylo persistente indurato, basi latitudine seminis.

1. $R$. alba: [Schoenus albus] spicis corymbosofasciculatis, culmo foliisque setaceis. Fl. dan.t. 327. (in paludibus turfosis circa Gorenki. Jul. Londes.)

16. Scrrpus. Squamae paleaceae undique imbricatae. Corolla nulla. Semen unicum nudum, vel setis e receptaculo ortis obvallatum. 
1. S. palustris: culmo tereti nudo, vaginis muticis lanceolatis acutis, spica solitaria ovali, squaınis lanceolatis acutis, stigmatibus duobus, radice repente. Fl. Ilan. t. 273. (in fossis et paludibus. Jun. Aug.)

b. Scirpus nanus: culmo brevissimo vix palmari. Fl. dan. t. 167. (in ruderatis et inundatis. Jun. Jul.)

2. S. ovatus: [capitatus] culmo subcompresso nudo filiformi, spica ovata terminali nuda, floribus diandris, stylo bifido. Moris hist. III. t. 10. f. 34. (in humidis. Jun. Jul.)

3. S. adicularis: culıno fliformi tetragono, vaginis obliquis muticis, spica solitaria ovata, squanis duabus infimis majoribus, radice repente nuda filiformi. $F l$. dan, t. 287. (ad lacuum ripas. Jun. Jul.)

4. S. caricinus: [Carex uliginosa] culmo compresso superne triquetro, vaginis foliiferis, spica composita disticha, involucro monophyllo brevi. Host. gram. III, t. 57 (in pratis turfosis. Jun.)

5. S. lacustris: culmo tereti nudo, umbella decomposita terminali, spicis oblongis, involucro diphyllo. Host, gram. III. t. 61. (in lacubus, stagnis, piscinis, paludibusque. Jul.)

6. S. sylvaticus: culmo triquetro folioso, umbella supradecomposita, pedunculis propriis tristachyis, spicis ovatis, squamis mucronatis, involucro subtriphyllo umbella longiore. Host, gram. III. t, 68. (in nemorosis humentibus. Jul.) 
17. Errophonum. Squamae paleaceae undique imbricatae. Corolla nulla. Semen unum lana longissima cinctum.

2. F. vaginatum: culmis yaginatis trigonis, spica solitaria terminali scariosa ovato-oblonga. Host. gram. I. t. 39. (in frigidis uliginosis turfosis, praecipue circa pagum Butirki. Mai.)

2. E, latifolium: [polystachion] culmis foliosis teretibus, foliis planis, spicis pedunculatis, seminibus ovatis, Engl. bot. t. 563. (in pratis uliginosis. Jun.)

3. E. angustifolium: culmis foliosis teretibus, foliis canaliculato - triquetris, spicis pedunculatis, seminibus ovatis. Fl. Lond.t. 9. (cum priori. Jun.)

18. NArDUs. Calyx nullus. Corolla bivalvis. Stigma simplex.

3. N. stricta: spica setarea recta secunda. Host. gram. II. t. 4. (in asperis sterilibus nurlis, circa Butirki, Kuskowa, Sokolniki. Mai.)

\section{I G Y N I A.}

19. PAnicum. Calyx bivalvis biflorus, valvulis valde inaequalibus, flosculo altero hermaphro. dito, altero neutro.

Hermaphroditi: Calyx nullus. Corolla bivalvis mutica vel apice aristata. Stamina terna, Styli bini. Semen corolla cartilaginea corticatum.

Neutri: Calyx nullus, Corolla uni-seu bivalvis, 
1. P. Glaucum: [flavescens] spica cylindracea, involucellis bifloris fasciculato - pilosis hispidis, corollis hermaphroditis transversim undulatis. Host. gram. II. t, 16. (in agris, cultis et hortis. Jun. Jul.)

2.' $P$. viride: spica cylindracea, involucellis bifloris fasciculato - pilosis hispidis, corollis hermaphroditis laeviusculis, vaginis foliorum pubescentibus. Hust. gram. II. to- 14 . (in arvis maxime arenosis, in agris post messem. Jul. Aug.)

3. Crus galli: spicis alternis conjugatisque, spiculis subdivisis, glumis aristatis hispidis, rachi quinquangulari. Host. gram. II. t. 19. (in hortis, agris et cultis. Jul. Aug.)

b. Panicum aristanum: aristis longissimis. Moris. hist. III. s. 8. t. 4. f. 15. (ad ripas Jausae. Jun.)

c. Panicum muticum: aristis subnullis. (in agris cum priore.)

4. P. miliaceum: panicula laxa flaccida, foliorum vaginis hirtis, glumis mucronatis nervosis, Host. gram. Il. t. 20. (in cultis. Jul. Aug.);

20. Piraranis. Calyx bivalvis uniflorus, valvulis subaequalibus corolla majoribus. Corolla duplex; exterior univalvis vel bivalvis; interior bivalvis. Semen corolla interiori corticatum.

2. Ph. canariensis: panicula subspicata ovata, glumis calycinis navicularibus apice integerrimis, corolla exteriori bivalvi. Host. gram. II. t. 38. (circa domos in plateis frequens. Jun. Jul) 


\section{$-\quad 15$}

8. Ph. arundinacea: panicula patente golomerata, glumis calycinis obtuse carinatis, corolla exteriore bivalvi brevissima pilosa. Host. gram. II. t. 33. (ad ripas lacuum et fluminum. Jun. Jul.) b. Phalaris picta: foliis viride-albis striatis. (in hortis Jun. Jul.)

21. PhLeum. Calyx bivalvis uniflorus, valvulis subaequalibus mucronato-subaristatis. Corolla bivalvis mutica calyce inclusa. Semen liberum corolia tectum.

1. Ph. pratense: racemo spicato cylindraceo, calycibus truncatis mucronato - aristatis carina ciliatis, aristis calyce brevioribus. Host. gram. III. t. 9. (in pratis et pascuis. Mai. Aug.)

2. Ph. nodosum: [bulbosum] spica cylindrica, culmo adscendente, foliis obliquis, radice bulbosa. Fl dan. t. 330. (in pascuis et collibus siccioribus circa Kuskiowa et Zarizina. Jun. Jul)

22. Alopecurus. Calyx bivalvis uniforus, valvulis basi connatis. Corolla univalvis basi aristata. Semen liberum corolla tectum.

I. A. pratensis: culmo erecto glabro, panicula subspicata cylindracea obtusa, glumis calycinis infra medium connatis acutis villosis. Host. gram. I. t. 31. (in pratis. Jun. Aug.)

2. A agrestis: [myosuroides] culno erecto scabriusculo, spica simplici gracili (purpurascente), glumis nudiusculis basi connatis carina dilatatis. Host. gram. III.t. 12. (in pratis editioribus, agris, hortisque. Jun.)

5. A. geniculatus: culmo adscendente, panicula suhspicata cylindracea obtusa, glumis calycinis 
basi connatis obtusis subvillosis corollaque apice crenulatis. Fl. dan. t. 564. (in aquis stagnantibus et páludibus. Jun. Jul.)

b. Alopecurus bulbosus: radice bulbosa.

23. Bechmannia, Calyx bivalvis, biflorus, valvulis navicularibus. Corolla bivalvis, valvula exteriore apice subaristata. Semen liberum corolla tectum.

1. B. erucaejormis: [Phal tris erucaeformis] panicula secunda lineari. Host. gram. III. t. 6. (ad lacuum ripas, in paludibus, pratisque uliginosis Jun. Jul.)

24. Mirliur. Calyx bivalvis, uniflorus, ventricosus. Corolla bivalvis calyce inclusa, valvula majore sub apice aristata, interdum mutica. Semen corolla corticatum.

2. M. effusum: panicula verticillata patentissima, floribus ovatis muticis, vaginis aequalibus glabris. Fl. dan. $\mathrm{t}$ 1143. (in nemoribus umbrosis circa Gorenki et Zarizina. Jun.)

25 Agrostrs Calyx bivalvis, uniflorus, compressus. Corolla bivalvis calyce plerumque minor, valvula majori aristata seu mutica.

1. A. Spica venti: panicula verticillata patula, arista longissima subflexuosa infra apicem petali exterioris. Fl. dan. t. 853. (inter segetes et in pratis Jul.)

2. A. vulgaris: [tenella] panicula patente, ramulis divaricatis laeviusculis, flosculis muticis, calycibus aequalibus, ligula brevissima truncata. Smith.-icon pl.III. t. 54. (in pratis, pascuis, nemoribus, collibusque. Jul.) 
3. A. alba: [hispida] panicula verticillata patente, ramis patulis calycibusque aequalibus hispidis, flosculis muticis, ligula oblonga. Engl.bot. t. 1189. (in pratis, pascuis et nemoribus, Jun。 Jul.)

4. A. gigantea: [compressa] paniculae parte superiore patentissima, calycibus hispidis, petalo exteriore glabro, dorso superne subaristato, culmo erecto. Fioth. (ad ripas fluviorum. Jul.) 26. Trichodiun. Calyx bivalvis, uniflorus. Cotolla univalvis calyce minor aristata vel mutica. Semen liberum corolla tectum.

1. T. caninum: [Agrostis canina] paniculae ramis trichotomis hispidulis, ramulis divergentibus flexuosis, calycibus acutis, arista dorsali infra medium proveniente. Fl.dan.t. 161. (in pratis, pascuis, nemoribus. Jun. Jul.)

27. Arra. Galyx bivalvis biflorus absque interjecto rudimento tertii flosculi. Corolla bivalvis supra basin aristata vel mutica. Semen liberum corolla tectúm.

2. A. cristata: panicula subspicata, glumis acuminatis, flosculis calycem excedentibus, foliis ciliatis. Host. gram. II. t. 75. (in collibus, pascuisque siccis. Jun. Jul.)

2. A. caespitosa: panicula patentissima, flosculis calycem subaequantibus, arista recta brevi, foliis planis profunde sulcatis. Host. gram. II. t. 42. (in pratis et nemoribus humidis. Jun.)

3. A. flexuosa: panicula patente, ramis flexuosis, flosculis calycem subaequantibus, arista geri- 
culata calycem excedente, foliis setaceis. Host. gram. II. t. 43. (in sylvis nemoribusque siccis, Jul.)

4. A. canescens: panicula conferto-patula, flosculis calyce minoribus, arista medio annulata calyce breviore, foliis setaceis. Mroris. hist. III. 1. 5. f. 10. (in pascuis, arvisque siccis sterilibus apricis. Jul,)

5. A. praecox: foliis setaceis, vaginis angulatis, floribus paniculato-spicatis, flosculis basi aristatis. Engl. bot. t. 1296. (in arenosis et inundatis. Mai.)

6. A. aquatica: panicula patente, floribus muticis laevibus calyce longioribus, foliis planis. Host. gram. II. t. 41. (ad lacus et flumina. Jun.)

28. Mielica. Calyx bivalvis, biflorus, cum rudimento tertii floris. Corolla bivalvis mutica. Semen liberum corolla cartilaginea tectum.

1. M. nutans: petalis imberbibus, panicula racemosa secunda, spiculis nutantibus ovatis trifloris, flosculo tertio imperfecto. Host. gram. II. t. 10. (in nemoribus umbrosis. Jun. Sept.)

2. M. uniflora: [Lobelii] petalis imberbibus, panicula simplici secunda, ramis horizontalibus, spiculis erectis ovatis biforis, altero imperfecto. Vill. delph. II.t. 3.f.3. (in Saloolniki. Jul. Aug.)

3. M. caerulea: panicula coarctata, pedunculis flexuosis, floribus erectis conico-cylindricis, glumis internis quaternis laxiusculis acuminatis, binis fertilibus. Host. gram. II. t. 8. (in pratis, pascuis, sylvis et nemoribus humidis. Aug.) 


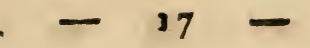

29. Hoccus. Hermaphroditi: Calyx gluma biseu triflora. Corolla gluma sub apice aristata. Stamina terna. Styli bini. Semen unicum.

Masculi: Calyx gluma bivalvis, Corolla bivalvis. Stamina terna.

1. H. avenaceus: [Avena elatior] panicula aequali, glumis bifloris, flosculo hermaphrodito superiore submutico, masculi arista geniculata, culmi geniculis glabris, radice nodosa. Host. gram. II. t. 49. (in pratis, pascuis, pomariis. Jun. Aug.)

2. H. mollis: panicula aequali, glumis bifloris, flosculo hermaphrodito inferiore mutico, masculi arista geniculata calycem excedente, radice repente. Host. gram. I. t. 3. (in nemoribus, arvis, pratis, agrisque arenosis. Jun. Jul.)

3. H. odoratus: panicula patula, glumis trifloris muticis, flosculis confertis, hermaphrodito intermedio diandro apice villoso, masculis triandris, margine villoso-ciliatis, dorso sublaevibus. Host. gram. I. t. 5. (in pascuis, arvisque liumentibus, in Perowa, Kuskowa, Archangelsk. Jun. Jul.)

50. PoA. Calyx bivalvis multiflorus. Corolla bivalvis, valvulis subovatis acutiusculis muticis. Semen liberum corolla tectum.

1. P. aquatica: panicula aequali diffusa ramosissima, spiculis linearibus quinque usque novemfloris, flosculis obtusis liberis septemnervibus, radice repente. Host. gram. II. t. 6o. (in lacubus, fluviis, fossis et paludibus, Jun. Jul.) 
2. P. fluitans: [Festuca fluitans] panicula secunda divaricata, spiculis linearibns appressis septemvel undecimfloris, flosculis obtusis liberis septemnervibus, radice repente. Host. gram. II. t. 77. (in stagnis, fossis, paludibus. Jun. Sept.)

5. P. bulbosa: panicula ovata, spiculis quadrifloris ovatis, glumis interioribus villo connexis, culmo subnudo basi bulboso, foliis serrulatis. Host. gram. II. t. 65. (in collibus apricis circa Jiunzowa et in montibus passerinis. Mai. Jun.) 4. P. trivialis: panicula aequali diffusa, spiculis oblongo-ovatis subtrifloris, flosculis basi villo connexis quinquenervibus, culmo vaginisque scabriusculis, ligula oblonga, radice fibrosa. Host. gram. II. t. 62. (in pratis et pascuis. Jul. Sept.)

5. P. strigosa: panicula coarctata diffusa, spiculis oratis subtrifloris, culmo erecto laevi, foliis angustis caespitosis. Hoff $m$. (in siccioribus elatis. iNai, Jun.)

6. P.pratensis: panicula aequali diffusa, spiculis quinquefloris glabris, culmo erecto tereti. $F l$. Lonc. t. 2. (in pascuis, pratis et nemoribus. Jul. Aug.)

7. P. angusrifolia: panicula aequali diffusa, spiculis quadrifloris pubescentibus, culmo erecto tercti. Host. gram, II, t. 61. (cum praecedente. Jul. Aug.)

8. P. sudetica: panicula aequali diffusa . spiculis ovato-lanceolatis subtrifloris, flosculis liberis, vaginis ancipitibus, ligula brevi, radice repente. 
Host. gram. III. t. 13. (in sylvarum locis humidis prope Gorenki. Londes; nec non in montibus passerinis. Goldbach. Jun. Jul.)

9. P. annua: panicula subsecunda divaricata, spiculis oblongo - ovatis quinque - vel septemfloris, flosculis liberis, culmo subcompresso, radice fibrosa. Hest. gram. II. t. 64. (ad vias, in cultis et ruderatis. INai. Sept.)

10. P. compressa: panicula subsecunda diffusa, spiculis oblongo - ovatis quinque - seu septemfloris, basi villo connexis, culmo compresso, radice repente. Host. gram. II. t. 70. (in muris, viis, pascuis siccis. Jun. Jul.)

12. P. palustris: panicula diffusa, spiculis subtrifloris pubescentibus, foliis planis demum involutis sultus scabris. Leers, herb. t. 6.f. 2. (ad ripas, in humidis sylvaticis, etiamque in siccis. Ju1. Jul.)

22. P. nemoralis: panicula subsecunda diffusa attenuata, spiculis lanceolatis subtrifloris, flosculis liberis, ligula brevissima truncata, culmo subcompresso vaginisque glabris, radice subrepente. Ilost. gram. II. t. 71. (in nemorosis et dumetis frequens. Jun. Jul.)

13. P. distans: [retroflexa] panicula aequali divaricata, ramis fructiferis deflexis, spiculis linearibus subquinquefloris, flosculis obtusis liberis obsolete quinquenervibus, radice fibrosa. Host. gram. II. t. 63. (juxta canalem haud procul a ponte sic dicto fabrorum. Goldbach; nec non in miontibus passerinis. Henning. Jun.) 


\section{$-20$}

31. Brrza. Calyx bivalvis multiflorus. Corolla bivalvis ventricosa, valvulis cordatis obtusis muticis. Semen corollae adnatum.

1. P. media: spiculis ovatis, calyce flosculis breviore. Host. gram. II. t. 29. (in pratis pascuisque siccioribus. Jun. Aug.)

32. Dactruss. Calyx bivalvis multiflorus, valvula majori altero latere convexa latiori, altero depressa angustiori. Corolla bivalvis, valvulis lanceolatis muticis. Semen corollae adnatum.

1. D. glomerata: panicula secunda glomerata, spiculis tri-quadriflorisve, foliis carinatis. Host. gram. IT. t. 94. (in pratis, hortis, nemoribus. Jun. Aug.)

33. Crnosunus. Calyx bivalvis, bi-vel quinqueflorus. Corolla bivalvis, valvula exteriore nutica seu aristata. Semen corollae aduatum. Spiculae involucro disticho glumaceo stipatae.

1. C. cristatus: racemo spicato lineari, spiculis muticis, foliis linearibus. Fl. dan. t. 238. (in pratis, pascuis, hortisque. Jul. Aug.)

34. Festuca. Calyx bivalvis multiflorus. Corolla bivalvis, valvulis lanceolatis : exteriore mutica vel apice aristata. Semen corollae adnatum.

1. F. ovina: panicula patente, spiculis oblongis aristatis, culmo tctragono, foliis setaceis, ligula biaurita. Host. gram. II. t. 34. (in siccioribus sterilibus. Jun. Jul.)

2. F. duriuscula: panicula patente, flosculis arista longioribus, radice fibrosa. Host. gram. II. 


\section{$-\quad 21$}

t. 83. (in pratis, pascuis, collibus et nemoribus. Mai, Jul.)

3. F. rubra: panicula patente, flosculis arista longioribus, radice repente. Host. gram. II. t. 82. (in sterilibus siccis. Jun.)

4. F. pratensis: panicula patente ramosa, spiculis linearibus muticis multifloris, foliis linearibus, radice fibrosa. (in pratis et graminosis. Jun. Jul.)

5. F. elatior: panicula patente ramosissima, spiculis ovato - lanceolatis subaristatis qquadriquinqueflorisve, foliis lineari-lanceolatis, radice repente. Schreb. gram. I. t. 2. (in pratis, fluviorumque ripis. Jul, Aug.)

6. F. decumbens: panicula erecta, spiculis sub. ovatis muticis, calyce flosculis majore, culmu decumbente. Fl. ،lan. t. 262. (in nemoribus, arvisque. Jul.)

35. Bronus. Calyx bivalvis multiflorus, Corolla livalvis, valvulis lanceolatis, exteriore sub apice aristata. Semen corollae adnatum.

2. B. secalinus: panicula fructifera apice nutante, spiculis oblongo-ovatis compressis nudis, flosculis demum distinctis remotiusculis, aristis flexuosis gluma brevioribus, foliis subpilosis. Host. gram. I. t. 12. (inter. segetes. Jun. Aug.)

2. B. multiflorus: panicula apice nutante, spiculis lanceolatis compressis nudis, flosculis imbricatis, aristis rectis gluma longioribus, foliis villosis. Weig. obs, t, 1, f. 1, (cum praecedente. Jul. Aug.) 
3. B. mollis: panicula erecta, spiculis oblongoovatis subcompressis pubescentibus, flosculis imbricatis, corollae gluma exteriori apice bifida, aristis rectis glumam aequautibus, foliis mollissime pubescentibus. Host. gram. I. t. 19. (in pratis, pascuis, viis, muris(jue. Jun.)

4. B. inermis: panicula erecta, spiculis linearibus subteretibus nudis, flosculis inbricatis muticis vel brevissime aristatis, foliis glabriusculis. Host. gram. I. t. 9. (in pascuis, hortisque, ad vias et sepes. Jun. Jul.)

5. B. sterilis: panicula apice nutante, spiculis scabris lineari-lanceolatis, dein flosculorum remotione compressis et superne latioribus, aristis rectis gluma longioribus, foliis pubescentibus. Leers. herb. t. 11. f. 4. (in muris, ruderatis, dumetis, viisque. Jul.)

6. B. tectorum: panicula apice nutante, spiculis compressis foliisque pubescentibus, flosculis demum remotiusculis, aristis rectis glumam aequantibus. Host. gram. I. t. 15. (in muris, viis, ruderatis, collibusque. Jun.)

7. B. arvensis: panicula demum nutante, spiculis lanceolatis compressis nudis, flosculis imbricatis, aristis rectis glumam aequantibus, foliis villosis. Fl. dan. to 293. (inter segetes, ad sepes et vias. Jun. Jul.)

8. B. giganteus: [strigosus] panicula apice nutante, spiculis lanceolatis compressis nudis, flosculis imbricatis, aristis flexuosis glunia longioribus, foliis nudis, Host. gram. I. t. 6. (in 


\section{- 23}

remoribus et umbrosis humidiusculis, montibus passerinis. Jul. Aug.)

36. Avera Calyx bivalvis inultiflorus. Corolla bivalvis, valvulis lanceolatis, exteriore dorso aristata. Semen plerumque corolla corticatuın.

1. A. sativa: panicula aequali, spiculis bifloris, flosculis calyce minoribus basi nudis, altero aristato, radice fibrosa annua. Blackiw. t. 422. (culta. Jul.)

2. A. strigosa: panicula secunda, spiculis subtrifloris, flosculis calycem aequantibus triaristatis, arista dorsali longissima geniculata, reliquis duabus terminalibus brevibus rectis, radice $f_{i}$ brosa annua. Host. gram. II. t. 56. (inter segetes. Jul )

3. A. fatua: panicula aequali, spiculis subtrifioris, flosculis calyce minoribus basique pilusis, sadice fibrosa annua. Schreb. gram. I. t. 15. (inter segetes. Jul.)

4. A. pratensis: subspicata, spiculis quinquefloris. Vaill. paris. t. 18.f. 1. (ad sepes, in pratis, arvis, viisque. Jun.)

37. Arundo. Calyx bivalvis uni-seu multiflorus. Corolla bivalvis pilis persistentibus cincta. Semen liberum corolla tectum.

2. A. Phragmites: calycibus subquinqueloris, flosculis calycem excedentibus. Scheuchz. gram. t. 3. f. 14. (in lacubus et Auviis. Jul.)

2. A. Epigejos: panicula stricta patente, calycibus unifloris acuminatis, arista dorsali recta pilis breviore, pilis calycem subaequantibus. 
Engl.bot. t. 402. (in collibus, nemoribusque aridis. Jul. Aug.)

3. A. sylvatica: [Agrostis arundinacea] panicula patente, calycibus unifloris acutis, pilis brevissimis, arista dorsali geniculata, calycem excedente. Schrad. germ. t. 4. f. 7. (in sylvaticis et nemorosis humidiusculis. Jul. Aug.)

38. Loutum. Calyx univalvis lateralis fixus solitarius multiflorus. Corolla bivalvis. Semen corolla corticatum.

1. L. perenne: spica mutica, spiculis calyce longioribus, radice perenni. Schreb. gram. II. t. 37. (in pascuis et pratis, ad vias et agrorum versuras. Jun. Jul.)

b. Lolium latum: spica lata secunda, Roth. (ad vias frequens. Jul.)

2. L. temulentum: spica aristata, spiculis calyce minoribns, radice annua. Sclireb. gram. II. t. 36. (inter segetes, nec non in hortis. Jul.)

39. Exymús. Calyx lateralis bivalvis aggregatus multiflorus.

1. E. caninus: spica nutante arcta, spiculis rectis involucro destitutis, infimis geminis. Buxb. cent. IV. t. 50. (ad sepes et in dumetis. Jul.)

40. Horderum. Calyx uniflorus ternus: flosculo intermedio hermaphrodito, lateralibus masculis vel neutris.

Hermaphroditi: Calyx corollaque bivalvis. Sta. mina terna. Styli bini. Semen singulum corolla eorticatum. 


\section{$-\quad 25$}

Masculi vel Neutri: Calyx corollaque bivalvis. Stamina terna vel nulla.

1. H. vulgare: flosculis omnibus hermaphroditis aristatis, seminibus quadrifariam positis, culmis erectis. (cultum. Jul.)

2. H. hexastichum: flosculis omnibus hermaphroditis aristatis, seminibus sexfariam positis. $V i$ bor o. cereal. t. 2. (cultum. Jul.)

3. H. murinum: glumis calycinis intermediis lineari-lanceolatis ciliatis, exterioribus setaceis scabris, flosculis lateralibus masculis. Host. gram. I. t. 32. (in ruderatis, versuris, viisque. Jun, Aug.)

41. Secale. Calyx oppositus bivalvis biflorus, valvulis aequalibus muticis seu aristatis. Corolla bivalvis : valvula' exteriore longissime aristata. Semen liberuin corolla tectum.

I. S. cereale: calycibus aristisque scabris, Blackw. t. 408. et 424. (cultum. Jul.)

b. Secale aestivum: radice annua, semino minori.

42. Trixicum. Calyx oppositus bivalvis solitarius multiflorus, valvulis subaequalibus. Corolla bivalvis, valvulis lanceolatis muticis vel apice aristatis. Semen corollae adnatum.

1. T. aestivum: calycibus quadrifloris ventricosis glabris imbricatis aristatis. Hall. in nov. comment. Gotting. 1774. t. 1. f. 1. (cultum. Jul.)

2. T. hyhernum: calycibus quadrifloris ventricosis laevibus imbricatis submuticis. Hall. ibid. V. t. 1. f. 2. (ut antecedens, Jul.) 


\section{$-26$}

3. T. repens: spica disticha, glumis calycinis subquinqueverviis quadri-octoflorisve, flosculis muticis aristatisve, radice repente. Sclireb. gram. II. t. 26. (in agris hortisque. Jun. Aug.)

\section{T E T R A N D I A. IM O N O G Y N I A.}

43. Scabiosa. Calyx communis polyphyllus; proprius duplex superus. Corolla quadri - vel quinquefida. Semen singulum calyce coronatum. Reoeptaculum paleaceum sive nudum.

1. S. Succisa: corollulis quadrifidis aequalibus, caule simplici, ramis approximatis, foliis lanceolato-ovatis. $F l$. dan.t. 279. (in pascuis pratisque humidiusculis Aug.)

b. Succisar osca: corollulis roseis. (cum praecedente.)

2. S. arvensis: corollulis quadrifidis radiantihus, foliis pinnatifidis incisis, caule hispido. Fl.dan. t. 447. (in agris, pratis, pascuisque. Jul. Aug.) 3. S. sylvatica: corollulis quadrifidis radiantibus, foliis omnibus indivisis ovato - oblongis serratis, caule hispido. Jacqu. austr. t. 36z. (in sylvaticis. Jul.)

4. S. columbaria: corollulis quinquefidis radiantibus, foliis radicalibus ovatis crenatis, caulinis pinnatis setaceis. $\mathrm{Fl}$. dan. t. 314 . (in arenosis ad pagum Katschanowa. Jun.)

5. S. ochroleuca: corollulis quinquefidis radiantibus, foliis bipinnatis linearibus. Jacyu. austr. 
t. 439. (in collibus graminosis, vallo magn urbano versus monasterium St. Simeonis. Jul. Aug.)

44. Asperiula. Calyx margo obsoletus quadridentatus superus. Corolla infundibuliformis. Semina bina globosa.

1. A. odurata: foliis octonis lanceolatis, corymbis terminalibus pedunculatis, seminibus echinato-hispidis. Fl. dan. t. 562. (in sylvis, umbrosis. Jul.)

2. A. Aparine: foliis octonis lineari-lanceolatis, margine caulisque tetragoni angulis scaberrimis, fructibus globoso-didymis glabris. Marsch. flor. caucas. n. 257. (locis uliginosis et umbro-. sis inter densam herbam luxuriat. Jun. Jul.)

45. Galium. Calyx margo obsoletus superus. Corolla rotata. Semina bina globosa.

$$
\text { * fructibus glabris. }
$$

r. G. rubioides: foliis quaternis ovato-lanceolatis aequalibus trinerviis subtus scabris, caule erecto, fructibus glabris. Buxb. cent. II. t. 29 . (in arvis, vallis, umbrosis: versus monasterium magnum s. d. virginum; in Kuskowa Ihunzowa, et alibi. Jul. Aug.)

2. G. hyssopifolium: foliis quaternis inaequalibus lineari-lanceolatis obtusis glabris. Hoff mann. (in pascuis sylvaticis montosis. Jul. Aug.)

3. G. palustre: foliis quaternis abovatis inaequalibus, caulibus difrusis. Fl. clan. t. 423. (in paludijus ac fossis Juni) 


\section{$-\quad 28$}

4. G. trifidum: foliis qquaternis linearibus, caule procumbente scabro, corollis trifidis. $F l$. dan. t. 48 (circa Kupawna. Stephan.)

5. G. montanum: foliis subquaternis linearibus laevibus, caule debili scabro, seminibus glabris. Vill. delph. II. t. 7. (in collibus sylvaticis; in Kunzowa. Jun. Jul.)

6. G. verum: foliis octonis linearibus sulcatis, ramis floriferis brevibus. Blackw. t. 435. (in pratis, arvis, viis, nemoribus. Jun. Jul.)

b. Galium luteum: corollulis saturate luteis, (in aggeribus, vallisque.)

7. G. Mollugo: foliis octonis ovato-linearibus subserratis patentissimis mucronatis, caule flaccilo, ramis patentibus. Fl. dan, t. 45.5. (in versuris agrorum, marginibusque nemorum. Jun. Sept.)

b. Galium pubescens: (in pratis, ad sepes, viasque. Jun. Jul.) flores citrini et albi.

3. G. glaucum: foliis octonis senisve linearibus, floribus corymbosis, corollis campanulatis, caule rereti laevi. Jacqu. austr. t. 81. (in apricis et montosis. Jun. Jul.)

9. G. sylvaticum: foliis octonis lanceolatis laevibus subtus scabris, floralibus binis, panicula terminali, pedunculis capillaribus, caule tereti laevi, geniculis tumidis, (in sylvis. Jun. Jul.)

10. G. uliginosum: foliis senis lanceolatis retrorsum serrato-aculeatis mucronatis rigidis, corollis fructu majoribus. Petiv: herb. 3o. f. 6. (in pascuis aquosis sterilibus. Jun. Jul.) 


\section{$-59-$ \\ ** fructibus hispidis.}

11. G. boreale: foliis quaternis lanceolatis trinerviis glabris, caule erecto, seminibus hispidis. Fl. dan.t. 1024 . (in pratis, nemoribusque. Jul.) 12. G. scabrum: [asperum] foliis senis octonisve linearibus scabris mucronatis, infini is minutissinis ellipticis, pedunculis trichotomis ternisve, caule sublaevi depresso adscendente, basi tomentoso. Jacyu. austr. t. 422. (in sylvaticis montium passerinorum. Jul.)

13. G. Aparine: foliis octonis lanceolatis, carinis scabris retrorsum aculeatis, geniculis villosis, fructibus hispidis. Fl. dan. t. 495. (in cultis et ruderatis. Jun. Aug.)

46. Plantago. Calyx quadrifidus. Corolla quadrifida, limbo reflexo. Stamina longissima. Capsula bilocularis circumscissa.

1. P. major: foliis ovatis glabris, scapo tereti, spica flosculis imbricatis. $F l$, dan. t, 461. (in viis et ruderatis, Jul. Aug.)

2. P. media: foliis ovato-lanceolatis pubescentibus, spica cylindrica, scapo tereti, Fl. dan, t. 581. (in pascuis, pratisque siçcioribus. Jun. Jul.)

3. P. lanceolata: foliis lanceolatis, spica subovata nuda, scapo angulato. $F l$. dan. t. 437. (in pascuis, viis et nemoribus. Jun. Jul.)

4. P. sylvatica: [altissima] foliis lanceolatis quinquenerviis dentatis, spica oblongo-cylindrica, scapis angulatis bipedalibus. Lirock. siles. (in sylvaticis, siccisque umbrosis. Jul Aug.) 
47. Majaxthenum. Calyx nullus. Corolla rotata quadrifida. Bacca maculata trilocularis.

1. M. bifolium: [Convallaria bifolia.] foliis cordatis petiolatis. $F l$. dan. t. 29a. (in nemorosis et sylvaticis humidis. Jun.)

48. Cenvunculus. Calyx quadrifidus. Corolla quadrifida patens. Stamina brevia. Capsula unilocularis circumscissa polysperma.

1. C. minimus : foliis alternis ovatis, floribus sessilibus. Fl. dan. t. 177. (in arenosis humidiusculis. Jul. Aug.)

49. Parietarta. Hermaphroditi: Calyx quadrifidus. Corolla nulla. Stamina quaterna. Stylus singulus. Semen unum superum elongatum.

Feminei: Calyx quadrifidus, Corolla nulla. Stamina nulla. Stylus singulus. Semen unum superum elongatum.

1.P. officinalis: foliis oblongo-ovatis acuminatis pellucido-punctatis, pedunculis dichotomis, calycibus diphyllis $F l$. dan. t. 521 . (in ruderatis glarecso-arenosis, ad Semenova. Jul. Müller.)

5o. Sanguisorba. Calyx diphyllus inferus. Corolla rotata quadrifida supera. Capsula bilocularis.

1. S. officinalis: spicis ovatis, staminibus corolla brevioribus. Fl. dan, t. 97. (in pratis siccioribus, circa Kupawna, Kunzowa et Semenowa. Jun. Jul.)

51. Trapa. Calyx quadripartitus. Corolla quadripetala. Nux monosperma quadrispinosa, qua calycis foliola fuere. 


\section{$-31$}

1. T. natans : rucibus quadricornibus, spinis patentilus. Plenk. pl.med. II. (in stagnis et fossis limosis, versus Archangelsk. Jun.)

52. Alchemilla. Calyx octofidus. Corolla nulla. Stylus e basi germinis. Semen singulum.

1. A. vulgaris: foliis reniformibus novemlobis acute dentatis glabris, corymbis terminalibus. Fl. dan. t. 693. (in pratis et sylvis herbidis. IMai, Jun.)

2. A. pubescens: [hybrida] foliis lobatis sericeis acuie serratis, caule petiolisque longis dense pilosis. (in pascuis et sterilioribus. Mai. Aug.)

\section{I G Y N I A.}

53. Cuscura, Calyx quadrifidus. Corolla monopetala. Capsula bilocularis.

2. C. vulgaris: [europaea] floribus subsessilibus, corolla subtetrandra fauce nuda, stigmatibus acutis. Fl. dan. t. 299. (in urtica dioica linoque usitatissimo parasitica. Jul. Aug )

54. Potamogeton, Calyx nullus. Petala quaterna. Stylus nullus. Semina quatuor.

1. P. ustars: foliis natantibus petiolatis ellipticis acutis basi rotuntatis subcordatis. Fl. dan, t. 2025. (in lacubus, stagnis et fluminibus. Jun. Jul.)

2. P. perfoliatum: foliis cordatis amplexicaulibus. Fi. dan. t. 196. (in lacubus fluviisque. Jul.)

3. P. lucens: foliis lanceolatis planis in petiolos desinentibus. Fl. dan. t. 195. (in stagnis, la. subus, fluviisque. Juk. Jul.) 
4. P. crispum: foliis lanceolatis alternis oppositisve undulatis serratis. $\mathrm{Fl}$. dan. t. 927. (in fossis et rivulis. Jul. Aug.)

5. P. gramineum: foliis lineari-lanceolatis alternis sessilibus stipula latioribus. Fl. dan. t. 222. (in fossis stagnisque. Jul.)

6. P. pusillum: foliis linearibus oppositis alternisque distinctis basi patentibus, caule tereti. Engl. bot. t. 215. (in stagnis et fossis Jul.)

55. Sagina. Calyx tetraphyllus. Corolla tetrapetala vel nulla. Capsula quadrilocularis quadrivalvis polysperma.

1. S. procumbens: ramis procumbentibus. Engl. bot. t. 880. (in pascuis sterilibus, in muris, hortisque. Jun. Aug.)

\section{P E N T A N D R I A.}

\section{IM O N O G Y N I A.}

56. Mrosotrs. Calyx quinquefidus. Corolla hypocrateriformis quinquefida emarginata, fauce clausa fornicibus convexis.

1. M. palustris: [scorpioides] seminibus laevibus, caule subsimplici, foliis lanceolatis obtusis glabriusculis. $F l$. dan. t. 583. (in humidis et paludosis. Jun. Sept.)

b. Myosotis scabra: foliis cauleque scabris. (in inundatis. Jul. Aug )

2. M. sylvatica: seminibus lacvibus, caule elongato hirsuto, foliis.lineari-lanceolatis, racemo conjugato. Ehrhart. herb. (in sylvaticis. Jul. Aug.) 
3. M. arvensis: seminibus laevibus, caule basi ramosissimo, foliis obovato-lanceolatis hirtis, racemo nudo, corolla connivente. Bulliard. t. 355. (in pratis, agris et arvis. Jun. Aug.) 4. M. collina: calycibus magis patulis, caule ramoso subnudo, foliis cespitosis. Ehrh. herb. t. 32. (in collibus agrisque apricis siccissimis. Jun. Jul,)

5. M. sparsiflora: seminibus laevibus, caule ramoso diffuso, foliis lanceolatis acutis hispidis, racemis simplicibus elongatis, floribus ramosissimis, calycibus acutis. (ad sepes et circa domos frequenter. Jun. Aug.)

6. M. Lappula: seminibus aculeis glochidibus, foliis lanceolatis pilosis. Fl. dan.t. 692. (in argillosis, ruderatis, murisque. Mai. Aug.)

57. Lithospenmur. Calyx quinquepartitus. Corolla infundibuliformis fauce perforata nuda. Semina quatuor.

1. L. arvense: scminibus rugosis, corollis vix calycem superantibus, foliis lanceolatis hirtis basi angustatis. Fl, dan. t, 456. (in agris et arvis. Jun.)

53. Cynogrossum. Calyx quinquepartitus. Corolla infundibuliformis seu rotata, fauce clausa fornicibus. Semina quaterna compressa, interiore tantum latere stylo affixa.

1. C. officinale: staminibus corolla brevioribus, foliis lato - lanceolatis basi attenuatis cano - pubescentilus sessilibus, laciniis calycinis oblon- 
gis. Fl.dan. t. 1147. (in ruderatis, sepulcris, viisque 'Jun. Jul.)

59. Pulmonaria. Calyx quinquefidus prismatico-pentagonus. Corolla infundibuliformis fauce pervia. Semina quaterna.

2. P. angustifolia : calycibus longitudine tubi corollae, foliis oblongo-lanceolatis, radicalibus petiolatis, caulinis sessilibus $F l$. dan. t. $48 j$. (in nemoribus et umbrosis. Mai.)

8. P. officinalis: calycibus longitudine tubi cozollae, foliis radicalibus ovato-cordatis scabris, caulinis ovatis sessilibus. $\mathrm{Fl}$. dan. t. 482." (cum praecedente. Mai.)

b. Pulmonaria maculati: foliis albo-maculaiis. (cum prioribus, rarius.)

6o. Sympirytur. Calyx quinquepartitus. Corolla tubuloso-clavata, fauce clausa fornicibus lanceolatis.

1. S. officinale: [album] foliis ovato-lanceolatis decurrentibus. Fl. dan, t. 664. (in nemoribus es umbrosis. Jun )

\&. S. patens: [purpureum] calycibus patentibus. Itniph. crnt. II. (in humidis, umbrosisque. Jun. Jul.)

61. Buhago. Calyx quinquepartitus. Corolla rotata fauce fornicibus basi subappendiculatis clausa. Autherae exsertae. Semina quaterna.

1. B. officinalis: foliis omnibus alternis, calycibus patentibus (corollis azureis) Engl.bot. t. 36. (in cultis, oleraceisque. Jun. Sept.)

b. Borago alba: corollis albis. (in hortis.) 


\section{$-35$}

62. Asperugo. Calyx quinquefidus, fructiferus, compressus, lamellis plano-parallelis sinuatis. Corolla rotata fauce fornicibus obtusis clausa. Semina quatcrna.

1. A. procumbens: calycibus fructus compressis. Fl. dan.t. 552. :(in ruderatis pinguibus. Mai. $*$ Jun.)

63. Lycopsis. Calyx quinquepartitus. Corolla infundibuliformis: tubo incurvato, fauce fornicibus obtusis clausa. Semina quaterna.

1. L. arvensis: foliis lanceolatis hispidis, calycicibus florescentibus erectis. Fl. dan, t. 4.35. (in arvis. Jun. Jul.)

64. Echrum. Calyx quinquepartitus. Corolla tubulosa: limbo inaequali, fauce pervia. Semina quaterna.

1. E. vulgare: caule herbaceo tuberculato-hispido, foliis lineari-lanceolatis, hispidis spicis lateralibus approximatis, staminibus corolla loṇgioribus. Fl, dan. t. 445. (in agris et siccioribus. Jun.)

65. Axdrosace. Involucrum umbellae. Calyx quinquefidus, Corolla hypocrateriformis: tubo ovato, ore glanduloso. Capsula unilocularis polysperma apice quinquefariam dehiscens.

1. A. septentrionalis: foliis lanceolatis dentatis glabris, perlunculis strictis involucro multoties longioribus, corollis calyce angulato longiorihus. Fl. dan.t. 7. (in siccis arenosis, non procul a Presnenskaja Sastawa, nec non circa Petrowsk, Mai.) 


\section{$-36-$}

66. Primula. Involucrum umbellae. Calyz quinquedentatus. Corolla hypocrateriformis : tubo cylindrico, ore patulo. Capsula unilocularis polysperma, apice dentibus decem dehiscens.

1. P. officinalis: [veris] foliis dentatis rugosis medio contractis, scapo multifloro, coroliae limbo concavo. Fl, dan. t. 433. (in nemorosis et pratis argillosis. Mai.)

b. Primula rubra: corollis rubicundis. (in pomariis et hortis. IMai.)

2. P. elatior: foliis dentatis rugosis medio contractis, scapo multifloro, corollae limbo plano. Fl. dan. t. 434. (in hortis graminosis et in arborum umbra. Mai.)

67. Menyanties. Calyx quinquepartitus. Cosolla infundibuliformis, interne hirsuta vel margine tantum ciliata. Stigma bifidum. Capsula unilocularis polysperma bivalvis seu evalvis. Semina receptaculis linearibus, parieti internae adnatis, inserta.

1. M. trifoliata: foliis ternatis. Fl. dan. t. 54 1. (in uliginosis et paludosis. Maa.)

68. Ноттолia. Calyx quinquepartitus. $\mathrm{Co}$. rolla hypocrateriformis. Stamina tubo corollae imposita. Capsula unilocularis polysperma. Semira receptaculo centrali affixa.

1. II, palustris: floribus verticillatis pedunculatis. Fl. dan. t. 487. (in fossis, stagnis, paludibusque, e. g. versus monasterium St. Simeonis, st alibi, Mai, Jun.) 


\section{- $37-$}

69. Lysimachia. Calyx quinquepartitus. Corolla rotata. Capsula globosa unilocularis decemvalvis polysperma.

1. L. vulgaris: racemis terminalibus compositis, foliis oppositis binis, ternis, quaternisve, oblongo-lanceolatis. Fl. dan. t. 689. (in humidis, 'umbrosis, nemorosis. Jun. Jul.)

2. L. thyrsiflora: [Naumburgia guttata] racemis axillaribus pedunculatis ovatis folio brevioribus. Fl. dan. t. 517. (in paludibus et fossis, circa fontes. Jun.)

3. L. Nummularia: foliis oppositis subrotundis, pedunculis axillaribus uniforis, caule glabro repente. $F l$. dan. t. 493. (in pascuis et nemorosis humidis. Jul.)

70. Convolvulus. Calyx quinquedentatus. Corolla bilocularis, loculis dispermis.

1. C. arvensis: foliis sagittatis utrinque acutis, pedunculis subunifloris. Fl. dan. t. 459. (in agris, cultis et hortis. Jun. Aug.)

b. Convalvulus carneus: floribus carneis. (in solo argillaceo et lutoso.)

2. C. sepium: foliis cordatis, lobis truncatis, pedunculis subtetragonis unifloris, bracteis cordatis acutis adpressis, calycinis dentibus acutis. $F l$. dan. t. 4.58. (ad sepes inque fruticetis humidis. Jul. Aug.)

71. Polemonium. Calyx quinquefidus. Corolla rotata quinquepartita, fundo clauso valvulis staminiferis. Stigma trifidum. Capsula trilocularis supera polysperma. 


\section{$-\quad 38$}

1. P. caeruleum: foliis pinnatis, floribus erectis, calycibus corollae tubo longioribus, $F l$. dan. $t$. 255. (in sylvis et nemoribus. Jun. Jul.)

b. Polemonium album: corollis albis, (in hortis, Jun. Jul.)

72. Jasjone. Involucrum decaphyllum. Calyx quinquepartitus. Corolla pentapetala'regularis. Antherae basi cohacrentes. Capsula infera bilocularis polysperma.

1. J. montrna: foliis lineari-lanceolatis basi angustioribus hispidis undulato-crispis, $F l$. dan. t. 319. (in collibus siccioribus circa pagum Kunzowa. Jun. Jul.)

73. Camranula. Calyx quinquepartitus, Co. rolla campanulata fundo clausa valvis staminiferis. Stigma trifidum. Capsula infera poris lateralibus dehiscens.

1. C. rotundifolia: glabra, foliis radicalibus (cito pereuntibus) oblongis reniformibusque serratis, caulinis linearibus integerrimis. Flor. dan. t. 855. (in pascuis, pratis et nemoribus. Jun. Aug.)

2. C. tenuifolia: glabra, foliis radicalibus oblongis, caulinis linearibus, caule elongato gracili. Allion. pedem. t. 6. (in arvis et ad vias. Jul. Aug.)

3. C. patula: foliis strictis, radicalibus lanceolato-ovalibus, panicula patula. Fl. dan. t. 373 . (in pratis siccioribus, pascuis, collibusque. Jun. Sept.) 
4. C. Rapunculus: foliis undulatis, radicalibus lanceolato - ovalibus, panicula coarctata. $\mathrm{Fl}$. clan t. 85. (in locis graminosis, sepibus, sylvisque. Jun.).

5.C. persicifolia: foliis radicalibus obovatis, caulinis lanceolato-linearibus subserratis sessilibus remotis. Fl. dan.t. 1087. (in sylvis et nemoribus. Jun. 6. C. latifolia: caule tereti striato glabro, foliis ovato-lanceolatis duplicato-serratis, pedunculis axillaribus unifloris erectis, calycibus glabris: $F l$. dan. t. 85. (in montosis sylvaticis. Jul. Aug.)

7. C. urticaefolia: caule ạngulato simplicissimo calycibusque solitariis nutantibus hispidis, foliis serratis: inferioribus cordatis petiolatis, șuperioribus oblongis sessilibus. (in locis umbrosis humidiusculis, cum priori. Jul. Aug.)

3. C. rapunculoides: foliis cordato-lanceolatis, caule ramoso, floribus secundis sparsị, calycibus reflexis. Moris. hist. II. t. 3. f. 32. (in nemoribus versus Petrowsk et Zarizina. Jun. Jul.)

9. C. bononiensis: foliis ovato-lanceolatis subtus scabris sessilibus, caule paniculato. Moris, hist. II. t. 4. f. 38. (in collibus sylvaticis circa Axchangelsk. Jun. Jul.)

30. C. Trachelium: caule angulato, foliis petiolatis, calycibus ciliatis, pedunculis trifidis. $\mathrm{Fl}$. dan. t. 1026. (ad margines sylvarum sepiumque. Jul. Aug.)

11. C. glomerata: caule angulato simplici glabriusculo, foliis scabris oblongo-lanceulatis 


\section{$-40^{\circ-}$}

cordatis sessilibus, capitulo glomerato. Engl. bot. t. 90. (in pratis aridis, nemoribusque. Jun.'Jul.)

b. Campanula salviaefolia: caule angulato simplicissimo, foliis orato-lanceolatis : superioribus sessilibus, mediis ac inferioribus longissime petiolatis.(in collibus.)

c. Campanula hirsuta: caule simplici hirsuto, foliis lanceolato - acutis petiolatis. (cum antecedente.)

d. Campanule diffusa: ramosissima, foliis ovato-cordatis sessilibus scabris. (in solo arido calcareo. Jun. Jul.)

12. C. Cervicaria: hispida, floribus sessilibus, capitulo terminali, foliis lanceolato-linearibus undulatis. Fl dan. t. 787. (in sylvis. Jul. Aug.)

74. Lonicera. Calyx quinquepartitus. Corolla monopetala irregularis tubuloso-sublabiata. Bacca infera bilocularis polysperma.

1. L. Xylosteum: pedunculis bifloris, baccis distinctis, foliis integerrimis pubescentibus. $\mathrm{Fl}$. dan. t. 808. (in nemorosis, e. g. montibus passerinis, Perowa, IKuskowa, et alibi. Mai.)

2. L. tatarica: pedunculis bifloris, baccis distinctis, foliis cordatis obtusis. Jacqu. ic.pl.rar.t. 37. (in hortis frequentissime occurrit. Mai. Jun.)

75. Verbascum. Calyx quinquepartitus. Corolla rotata subinaequalis. Capsula bilocularis, bivalvis, polysperma.

1. V. Thapsus: foliis decurrentibus utrinque tomentosis, caule simplici, filamentis tribus bar- 


\section{$-41$}

batis. Fl.dan.t. 631. (in collibus et monticulis glareosis et arenosis. Jul. Aug.)

2. $V$. phlomoides: foliis ovatis utrinque tomentosis, inferioribus petiolatis, superioribus sessilibus. Mönch. flor. hass. t. 4. (in monticulis asperis arenosis. Jun. Jul.)

3. V. nigrum: foliis inferioribus petiolatis coidatis ovatis, superioribus ovatis sessilibus, caule subramoso, filamentis omnibus barbatis. $\mathrm{Fl}$. dan. t. 1083. (ad pagos, sepes, viasque. Ju!́. Aug.)

76. Datura. Calyx tubulosus angulatus deciduus. Corolla infundibuliformis plicata. Capisula inferne quadrilocularis, superne bilocularis quadrivalvis polysperma.

1. D. Stromonium: pericarpiis spinosis erectis ovatis, foliis ovatis glabris angulato-dentatis.. $F l$. dan. t. 436. in ruderatis pinguibus et circa pagos, in montibus passerinis versus Wassiliewsli, et ad amnem IMosquam. Jul. Arg.)

77. Hroscramus. Calyx quinquedentatus, Corolla infundibuliformis olstusa. Stamina inclinata. Capsula operculata, bilocularis, polysperma.

2. H. nigger: foliis amplexicaulibus subsinuatis, angulatis, radicalilus pinnatifido-sinuatis, floribus sessilibus, corollis reticulatis. Engl. bot. t. 591. (arl vias et sepes, circa pagos et ruinas, in ruderatis et fimcis. Jul. Aug.)

78. Solaxum. Calys quinquepartitus. Corolla rotata. Antherae subcoalitae, apice poro gemino dehiscentes. Eacca bilocularis polysperma. 
2. S. Dulcamara: caule inermi fruticoso srandente, foliis cordatis glabris: superioribus au. riculatis; corymbis oppositifoliis. Ft. dan.t. 460. (in locis humentibus et fossis, ad sepes, molasque etc. Jul. Aug.)

2. S. nigrum: caule inermi herbaceo, foliis ovatis dentato-angulatis glabris, racemis subumbellatis extra foliaceis pedunculatis $\mathrm{Fl}_{0}$ dan. $\mathrm{t}$. 460. (in ruderatis et cultis. Jun. Aug.)

3. S. villosum: caule inermi herbaceo, ramis teretibus hirtis, foliis dentato-angulatis villosopubcscentibus, racemis sulumbellatis extrafoliaceis pedunculatis (cum priori)

79. Cminoña, Calyx quinquepartitus. Corolla rotata. Stylus declinatus. Stamina tubo corollae insidentia. Antherac demum spirales. Capsula biJocularis polysperma.

1. C. Centaurium: [Gentiana Centaurium] caule dichotomo tetragono corymboso, foliis ellipticis trinerviis, calycinis laciniis subulatis subpatulis, corollae limbo plano. $\mathrm{Fl}$. dan. t. 617 . (in pratis et arvis. Jul. Aug.)

80. Rimanxus. Calyx tubulosus quinquedenta" tus. Corolla squamae quinque stamina munientes calyci insertae. Bacca tri-seu tetrasperma.

2. $R$. catharcticus: spinis terminalibus, floribus quadrifidis dioicis, foliis ovatis serrulatis. $F l$. dan. t. 850. (in Astankina et Zarizina. Jun.)

\&. R. Frangula: inermis, floribus monogynis hermaphroditis, foliis ellipticis utrinque acutis 


\section{$-43$}

integerrimis. Fl. dan. t. 278. (in nemoritưs humidiusculis. Bis in anno floret. Mai, Aug.)

81. Evonynus. Calyo quinquepartitus. Corolla pentapetala. Capsula pentagona quinquelocularis quinquevalvis colorata, loculis monospermis. Semina calypirata.

1. E. vulgaris: [europaeus] pedunculis compressis subtrifloris, floribus tetrandris, capsulis acute pentagonis glabris, foliis oblongo-lazceolatis glabris. $\mathrm{Fl}$. dan. t. 1089. (in fruticetis ac sepibus. Mai. Jun.)

2. E. verrucosus: pedunculis filiformi-teretibus subtrifloris, floribus tetrandris, capsulis obtuse pentagonis glabris, foliis ovatis acuminatis glabris, ramis verrucosis. Jacqu. auștr. I. t. 289. (in nemoribus omnibus haud infrequens. Mai. Jun.)

82. Rrbes. Calyx campanulatus quinquefidus. Petala quina. Stamina calyci inserta. Stylus bifidus. Bacca infera polysperma.

i. R. rubrum: inerme, racemis glabris nutantibus, floribus planis, foliis obtuse quinquelobis, caule erecto. Fl. dan, t. 967. (omnes hujus generes species in hortis ubique frequenter occurrunt. Mai.)

2. R. nigrum: inerme, foliis subtus punctatis, racemis laxis, floribus campanulatis, bracteis pedicellis brevioribus. Fl. dan. t. 556.

3. R. Grossularia: ramis aculeatis, petiolis pilosis, pedunculis unifloris, bracteis binis, fructu hirsuto, Blackw, t. 277. 


\section{- $44-$}

4. R. Uva crispa: ramis aculeatis, pedunculis uniforis, bracteis connato - tubulosis, fructu glabro. Fl. dan. t. 546.

83. Vroza. Calyx pentaphyllus. Corolla pentapetala irregularis, postice cornuta seu ecalcarata. Antherae cohaerentes. Capsula supera unilocularis trivalvis polysperma.

\section{* Acaules.}

1. V. hirta: acaulis, foliis cordatis petiolisque piloso-hispidis, calycibus obtusis, $F l$. dan. t. 618. (in nemorosis umbrosis humidiusculis. Mai.)

2. V. palustris: acaulis, foliis reniformibus repandis, glabris, calycibus obtusis. $F l$. dan. t. 8 J. (in paludibus, udisque. Mai. Jun.).

j. V. odorata: acaulis, stolonibus reptantibus, foliis cordatis petiolisque glabriusculis, calycibus obtusis. Fl. dan. t. 309, (in xystis et pomariis. Mai )

b. Viola alba: corollis albis, (in hortis, pomariisque.)

c. Viola magna: grandiflora plena. (ibid. Mai; et non raro iterum Sept.)

4. V. canina: caule adultiore adscendente, foliis oblongo-cordatis, calycibus lanceolatis acutis. Engl. bot. t. 620. (in montosis siccioribus, umbrosis, nemorosis. Mai. Jun.)

5. V. montana: caulibus erectis, foliis cordatis oblongis, calycibus lanceolatis acutis. $\bar{S} c h k u h r$. t. 269. (in montibus passerinis, Líunzowa, $\mathrm{Pe}$ trowsk et alibi, Jun.) 
b. Viola persicifolia: caule erecto, foliis ovato-lanceolatis serratis. (in montibus passeriuis) corollae albae.

** Caulescentes.

6. V. mirabilis: caule triquetro, foliis renifor$\mathrm{m}_{\mathbf{i}}$-cordatis, floribus caulinis apetalis. Jacqu. austr. t. 19. (in montibus passerinis et Gorenki. Mai )

7. V. tricolor: caule angulato diffuso foliisque oblongis dentato-crenatis glabris, stipulis lyrato-pinnatifidis, calycibus pilosis. $F l$. dan. t. 623. (in arvis, agris, cultis, inter segetes, ad sepes et circa domos. Jun. Aug.)

6. Viola bicolor: crecta, calyce stipulisque ciliatis. Hoffmann. (in pratis et canpis.)

c. Viola hortensis: floribus maximis sammetinis, calycibus nudis corolla multa minoribus. (in hortis, aestate.)

\%. $V$. arvensis: caule angulato sulcato, foliis ovato-lanceolatis serratis, stipulis basi incisis, calyce pubescente corolla sublengiore. (in arvis et inter segetes. Jun. Aug.)

84. Impatiens. Calyx diphyllus, Corolla pentapetala irregularis, nectario cucullato. Antherae connatae. Capsula supera quinquevalvis.

1. I. Noli tangere: pedunculis multiforis solitaris, foliis ovatis, geniculis caulinis tumentibus. Fl. dan. t. 588. (in nemorum umbra, in liumidiusculis. Jul. Aug.)

85. Vraca. Calyx quinquepartitus. Corolla hypocrateriformis, Folliculi bini erecti. Sesmina nurla. 


\section{$-46-$}

1. V. minar: caulibus fruticosis procumbentibus, foliis oblongo-lanceolatis margine glabris, floribus pedunculatis. Engl. bot. t. 917. (ad muros in hortis. Maai.)

\section{I G Y N I A.}

86. Hersiaria. Calyx quinquepartitus, Corolla nulla. Stamina quina sterilia. Capsula monosperma.

2. II glabra: glabra, glomerulis multifloris. Fl. dan. t. 529. (in glareosis apricis siccis. Jul. Aug.)

67. Atriplex. Hermaphroditi: Calyx pentaphyl_ lus. Corolla nulla. Stamina quina. Stylus bipartitus. Scmen singulum, depressum.

Feminei: Calyx diphyllus. Corolla nulla. Stamina nulla. Stylus et semen ut supra..

1. A. hortensis: caule erecto herbaceo, foliis triangularibus dentatis concoloribus, calycibus fructus ovatis reticulatis integerrimis. Blackiw. t. 99 et $55^{2}$. (in ruderatis, hortorum rejectamentis. Aug.)

2. A. hastata: caule erecto herbaceo, foliis triangulari- hastatis profunde dentatis concoloribus, calycibus fructus sinuato-dentatis, dente intermedio elongato. Trioris. hist. II. t. 32. f. 14 . (in locis ruderatis. Jul, Aug )

3. A. patula: caule patulo herbaceo, foliis triangulari-hastatis acuminatis subdentatis, calycibus fructus rhombeis apice denticulatis, disce 
submuricatis. Engl. bot. t, 936. (in ruderatis, viis. Aug. Sept.)

83. Cincoponum. Calyx pentaphyllus, pentagonus. Corolla nulla. Semen unum lenticulare superum.

* Foliis planis angulosis.

1. C. Bonus Henricus: foliis triangulari-hastatis integerrimis, spicis compositis glomeratis aphyllis axillaribus terminalibusque. Fl. dan. t. 579. (in ruderatis et fimetis. Jun. Jul)

2. C. urbicum: foliis triangularibus subdentatis, racemis confertis strictissimis cauli approximatis longissimis. Fl. clan t. 13/48. (in plateis. Jun. Jul,)

3. C. rubrum: foliis cordato-triangularibus obtusiusculis dentatis, racemis erectis compositis subfoliosis caule brevioibus, $F$. dan. t. 1149. (in cultis et ruderatis, circa pabula, in fimetis. Jul. Aug.)

4. C. murale: foliis oratis inaequaliter dentatis acutis nitidis, racemis corymbosis nudis, caule ramoso patulo. Fl. Lond. t. 5. (in muris, aggeribusque. Jul. Augr.)

5. C. album: foliis rhombnideo-ovatis erosis postice integris, superioribus oblongis integerrimis, seminibus laevilus. (in agris, cultis, ruderatis. Jul, Aug.)

6. C. viride: foliis rhomboideis dentato sinuatis, racemis ramosis subfoliatis. Fl, dan. t. 1150. (in agris, hortisquec. Jun Jul.) 
7. C. hybridum: foliis ovatis acuminatis subcordatis angulato-dentatis, racemis paniculatis nu dis terminalibus axillaribusque. Barrel, icon. t. 540. (in agris et hortis. Jun. Aug.)

8. C. glaucum: foliis oblongis repandis subtus glaucis, spicis glomeratis nudis simplicibus axillaribus terminalibusque. $F l$. dan. t. 1151. (in fimetariis. Jul. Aug.)

* Foliis planis, integerrimis.

9. C. olidum: [Vulvario $]$ foliis integerrimis rhombeo-ovatis, floribus conglomeratis axillaribus. Fl. dan. t. 1152. (in fimetis, soloque pingui in ruderatis et muris; frequentissime in vallo urbano prope tres inontes, nec non in Perowa, Wassiliewsk. Aug.)

10. C. polyspermum: foliis integerrimis ovatis, caule decumbente, cymis dichotomis aphyllis axillaribus, Fl. dan, t, 1153. (in hortis et agris. Jul. Aug.)

39. Urnuss. Calyx quinquefidus, Corolla nulla. Samara monosperma.

1. U. campestris: foliis duplicato-serratis basi inaequalibus, floribus subsessilibus conglomeratis pentandris, fructibus glabris. Schkultr. I. t. 57. (ad pagos et vias. NTai.)

2. U. cilinta: [effusi $a]$ foliis duplicato-serratis basi inaequalibus, floribus octandris pedunculatis effusis, frictibus margine ciliatis. Schkuhr. I. t. 57. b. (in nemoribus, hortisque. Mai) 
90. Gentrana, Calyx quinquepartitus. Corolla monopetala. Capsula bivalvis unilocularis: receptaculis duobus longitudinalibus.

1. G. cruciata: corollis quadrifidis hypocrateriformibus nudis verticillatis sessilibus, caulibus ancipitibus basi attenuatis. Jacqu. austr.t. 372 . (in pratis montosis, arvis, sylvarum marginibus et vallis: Jun. Jul.)

2. G. Pneumonanthe: corollis quinquefidis campanulatis acuminatis axillaribus pedunculatis, foliis sublinearibus obtusis. $F l$, dan. $\mathrm{t} 269$. (in pratis, nemoribusque humidiusculis. Jul. Aug.)

3. G. Amarella: corollis quinquefidis hypocrateriformibus barbatis, laciniis limbi lanceolatis acutis, calycinis subaequalibus, foliis lanceolatis, internodiis ramorum brevioribus. Röm. Arch. I. t. 5. f. 13. (in pratis siccioribus, Aug. Sept.)

4. C. campestris: corollis quadrifidis hypocrateriformibus obtusis fauce barbatis, calycis laciniis duabus maximis. Engl. bot. t. 237. (in pratis, arvis, marginibusque sylvarum. Aug. Sept.)

91. Erragium. Flores capitati. Calyx pentaphyllus. Corolla uniformis. Fructus ovatus. Receptaculum paleaceum.

1. E. campestre: foliis radicalibus amplexicaulibus pinnato-laciniatis ternatis, caule superne ramosissimo. Fl. dan. t. 554. (in tribus montibus versus lacum. Jul. Hoffmann.) 


\section{$-50$}

2. E. planum: foliis radicalibus ovalibus planis crenatis, capitulis pedunculatis. Jacqu. austr. t. 391. (in campis, vallis, collibusque. Jul. Aug.)

92. Sa nicula. Umbellae confertae subcapitatae. Fructus scaber. Flores disci abortientes.

2. S. europaea: foliis quinquelobis, lobis trifidis dentatis, caule aphyllo, flosculis omnibus sessilibus. Fl. dan. t. 233. (in sylvis montosis et vallis, in montibus passerinis et Kuskowa. MIai. Jun.)

93. Caucalis. Corollae radiatae: disci masculae. Petala inflexo-emarginata. Fructus setis hispidus. Involucra integra.

1. C. Anthriscus: [Tordylium Anchriscus] involucris polyphyllis, seminibus ovatis, stylis reflexis, foliis decompositis, foliolo extimo lineari-lanceolato. Fl.dan. t. 919. (in ruderatis, sepilus, nemorumque marginibus. Jun. Jul.)

94. Daucus. Corollae subradiatae. Flosculi disci abortivi. Fructus pilis hispidus.

1. D. Carota: seminibus hispidis, petiolis subtus nervosis. Fl. dan. t. 723 (in pascuis, nemoribusque. Jun. Jul.)

b. Daucus satimus: radice crassiore succulenta dulci. Blachw. t. 54 б. (cultus.)

95. Conzux. Involucella dimidiata subtriphylla. Iructus subglobosus quinquestriatus utrinque crenatus.

1. C. maculatum: seminibus striatis, involucellis umbellulae radiis multo brevioribus lanceo- 


\section{$-51$}

latis. Jacqu. austr, t. 156. (in cultis et ruderatis. Jul. Aug.)

96. Se cinur. Involucrum reflexum. Petala cordata aequalia. Tructus ovali-oblungus compressoplanus, in medio striatus.

2. S. sylvestre: caule laevi, radice fusiformi multiplici. Moris. hist. Ilr. t. 17. f. 2. (in humidiusculis, umbrosis. Jul. Aug.)

2. S. palustre: caule angulato striato, radice fusiformi subdivisa, radiis umbellae scabris, foliis triplicato - pinnatis, pinnis pinnatifidis, la. ciniis lanceolatis. Engl. bot. t. 229. (in paludibus sylvarum, aliisque umbrosis humidis; in tribus montibus, circa Petrowsk, Semenowsk, et alibi. Jun. Jul.)

3. S. carvifulium: [Carvifolia] caule sulcato acu tangulo, involucro universali nullo, foliolis lanceolatis incisis apice calloso-mucronatis. Jacqu, austr. t. 16. (in pratis paludosis, collibusque umbrosis. Jul. Aug.)

b. Selinum sylvaticum: caule altiori, angulis membranaceis, involucro universali minus deciduo. Sprengel. (in montibus passerinis et Archangelsk. Aug.)

97. Atmamanta. Petala inflexa emarginata. Fructus ovato-oblongus striatus.

1. A. Libanotis: foliis bipinnatis planis, umbella hemisphaerica, seminibus hirsutis. Jasqu, austr. t. 302. (in pratis, collibusque siccis apricis. Aug.) 


\section{$-52-$}

2. A. sibirica: foliis pinnatis inciso - angulatis. Gmel. sib. I. t. 40. f. 1. 2. (in sylvis et collibus ad Jausam fluvium. Jul. Aug.)

3. A. Oreoselinum: foliis triplicato-pinnatis, petiolis partialibus flexuoso-divaricatis. Jacqu. austr, t. 63. (in collibus apricis. Jul.)

98. Peucedanum. Involucra brevissima. Fructus ovatus utrinque striatus ala cinctus.

1. P. Silaus: foliolis pinnatifidis: laciniis oppositis, involucro universali diphyllo. Jacqu. austr. t. 15. (in pratis humidiusculis. Jun. Jul.)

99. Iter a Clevm. Involucrum caducum, Corolla difformis inflexo - emarginata. Fructus ellipticus emarginatus compressus striatus marginatus.

1. H. Sphordylium: foliis pinnatis: foliolis quinis pinnatifidis. Engl. bot. t. 939. (in hortis graminosis, pratisque succulentioribus. Jul. Aug.)

b. Heracleum flavescens: foliis septemlobis angustioribus. Stephan.

2. H. angustifolium: [longifolium] foliis cruciatopinnatis: foliolis linearibus, corollis flosculosis. (in pratis et cultis frequens. Jul)

3. H. sibiricum: foliis pinnatis, foliolis quinis: intermediis sessilibus, corollis uniformibus. Gmel. sib. I. t. 50. (in sylvis humidiusculis. Jun. Aug.)

4. Il. Panaces: follis pinnatis, foliolis quinis: intermediis sessilibus, floribus radiatis. (in pratis. Jul. Stephan.) 


\section{- $53-$}

100. I.rgusticur. Corollae aequales, petalis involutis integris. Fructus oblongus quinquesulcatus utrinque.

1. L. Levisticum: foliis pinnatis : pinnis inferioribus ternatis, foliolis oblongis basi cuneatis, apice acuminatis subincisis. Blackw. $\mathbf{t} 275$. (in hortis olitoriis frequentissimum. Jun. Jul.)

101. Avgerica. Corollae aequales, petalis incurvis. Fructus subrotundus angulatus solidus, stylis reflexis.

1. A. Archangelica: foliolorum impari lobato. Fl. dan. t. 206. (in nemoribus et umbrosis humidiusculis. Jun. Jul.)

102 Srum. Involucrum polyphyllum. Petala cordata. Fructus subovatus striatus.

1. S. latifolium: foliis pinnatis, pinnis radicalium subbipinnatifidis, caulinorum simplicibus, umbellis terminalibus. $F l$. dan. t. 246. (in rivulis et fossis. Jul.)

103. Pineluandrum. Flosculi disci minores. Fructus ovatus laevis coronatus perianthio et pistillo.

1. Ph. aquaticum: foliolorum ramificationibus divaricatis. $F l$. dan. t. 1154. (in lacubus, stagnis, fossis. Jun. Jul.)

10\%. Cicuta. Fructus subovatus sulcatus. Involucrum nullum; involucella tri - usque pentaphylla.

1. C. virosa: umbellis oppositifoliis, petiolis marginatis obtusis: $F l$, dan. t. 208. (in paludibus profundis, ad lacus et fossas. Jun. Jul) 


\section{$-54$}

105. Aethusa. Involucella dimidiata triphylla pendula. Fructus striatus.

1. A. Cynapium: foliis conformibus, foliolis pinnatifidis: laciniis linearibus, Eng. bot. t. $119^{2}$. (inter olera, in hortis spontanea. Jun. Aug.)

106. Conanonum. Involucrum unitersale monophyllum; partialia dimidiata. Corolla radiata. Pitala inflexo-emarginata. Fructus sphaericus.

1. C. sativum: scminibus globosis, Eng. bot. t. 67. (ut anteccrlens, Jul, Aug.)

107. Scandix. Flusculi disci saepius masculi. Corolla radiata, Fetala emarginata. Fructus subu. latus.

1. S. Ccrefolium: [Chacrophyllum sativum] seminibus nitiris ovato-subulatis, umbellis ses. silibus lateralibus. Engl. bot. t. 1268. (in cultis sponte. Jun. Jul.)

108. Ciraenopiyluum. Involucrum reflexum concavum. Petala inflexo-cordata. Fructus oblongus laevis.

1. C. sylvestre: caule striato, geniculis tumidiusculis. Jacqu. austr. t. 149. (in nemoribus et umbrosis, ad sepes et in hortis. Mai. Jun.)

2. C. bulbosum: caule laevi geniculis tumido, basi hirto. Jacqu. austr. t. 3r. (in sylvis et dumetis. Jun. Jul.)

3. C. temulum: caule scabro, geniculis tumidis. Jacqu. austr. t. 65. (in fruticetis, sepibus, viisque. Mai. Jun.) 


\section{$-\quad 55$}

4. C. aromaticum: caule aequali, foliolis cordatis serratis integris, fructibus biaristatis. Jacqu. austr. t. 150. (in montibus passerinis et in Archangelsk. Jun.)

109. Imperatoria. Petala inflexo-emarginata. Fructus subrotundus compressus medio gibbus, margine cinctus.

1. J. sylvestris: [Angelica sylvestris] foliolis aequalibus ovato-lanceolatis serratis. $\mathrm{Pl}$. med. t. 366. (in pratis subhumidis sylvaticis, Jul. Aug.)

110. Pastinaca. Petala involuta integra. Fructus ellipticus compresso - planus.

1. P pratensis: foliis pinnatis glabris, foliolis ovato-lobatis: exterioribus trilobis. Fl. dan. t. 1206. (in ruderatis, pascuis, vallisque. Jul. Aug.)

b. Pastinaca sativa: radice crassiore, dulciore. Blackw. t. 379. (culta.)

111. Anethum. Petala involuta integra. Fructus subovatus compressus striatus.

1. A. graveolens: annuum, fructibus compressis. Blackiv. t. 54.5. (in cultis sponte. Jun Aug.)

112. Carum. Involucrum monophyllum. Petala carinata inflexo-emarginata. Fructus ovato-oblongus striatus.

1. C. Carvi: caule ramoso, vaginis foliorum ventricosis, involucro partiali nullo. $F$. clan. $t$. 1ng1. (in pratis et graminosis. Jun.)

113. Primprecla. Fructus ovato-oblongus. Petala inflexa. Stigmata subglobosa. 


\section{$-56-$}

1. P. Saxifraga: caule striato glabro, foliis pinnatis glabris, radicalium foliolis subrotundis argute dentatis, caulinis bipinnatis linearibus. Fl.dan. t. 669 (in pascuis, collibusque siccis, ad vias. Jul. Aug,)

2. P. nigra: caule striato pubescente, foliis pinnatis pubescentibus, radicalium foliolis subcordatis incisis obtuse dentatis, caulinis bipinnatis linearibus. Jacfu, austr. t. 395. (in siccioribus, in Petrowsk, Sokolnika. Aug.)

114. Aprum. Involucrum monophyllum. Petala aequalia. Fructus ovato-striatus.

1. A. graveolens: foliis caulinis cuneiformibus. Engl. bot. t. 1210. (in cultis Jul.)

b. Apium dulce: foliis erectis, petiolis longissimis, foliolis quinquelobatis serratis. (cultum.)

15. AEgorodium. Fructus ovato-oblongus striatus.

1. A. Podagraria: foliis caulinis summis ternatis ovatis. Fl. dan. t. 670. (in pomariis, sepibus et sylvaticis. Mai. Jun.)

\section{T R I G Y N I A.}

116. Vinurnum. Calyx quinquepartitus superus. Corolla quinquefida. Bacca monosperma.

1.V. Opulus: foliis trilobis acuminato-dentatis, petiolis glandulosis glabris, $F l$. dan, t. 661. (in nemoribus humidiusculis, ad sepes. IMai.) 
b. Viburnum roseum: 'cyma globosa, flore pleno. Innorr. del. hort. II. t. S. 6. (in hortis.) corollulae roseae et albae variant.

117. Sambúcus. Calyx quinquepartitus. Corolla quinquefida. Bacca trisperma.

1. S. Ebulus: cymis tripartitis, stipulis foliaceis ovatis, caule herbaceo. Fl. dan. t. 1156. (in loco deserto ad sepem horti botanici sponte. Jul.)

2. S. nigra: cymis quinquepartitis, stipulis duabus utrinque setaceis, foliis pinnatis: foliolis ovatis serratis, caule arboreo. Fl. dan.t. 545. (in hortis, ad sepes. Jun.)

b. Sambucus laciniata: foliis bipinnatis, pinnis ternatis: foliolis lanceolatis incisis. Kniph. cent. VIII. (in hortis.)

118. Alsine. Calyx quinquepartitus. Petala quina aequalia. Capsula unilocularis trivalvis polysperma.

1. A. media : petalis bipartitis, foliis ovato - cordatis. $F l$. dan. t. 438. et 525. (in cultis et hortis. IVIai. Oct)

\section{T E T R A G Y N I A.}

119. Parnassia. Calyx quinquepartitus. Petala quina. Nectaria quina cordata ciliata: apicibus globosis.

I. P. palustris: foliis radicalibus cordatis, nectariis multisetis. Fl. dan. t. 584. (in pratis humidis et paludosis. Jul.Sept.) 


\section{- 58 \\ P E N T A G Y N A.}

120. Irnum. Calyx pentaphyllus. Petala quina: Capsula quinquevalvis decemlocularis. Semina solitaria.

2. I. usitrtissimum: calycibus capsulisque mucronatis, petalis crenatis, foliis lanceolatis alternis, caule subsolitario. Mart. rust. t. 133. (in campis. Jun.)

2. L. flavum : calycibus acuminatis serrulato-scabris, foliis basi biglandulosis margine glabris, paniculae ramis dichotomis, corollis monopetalis, caule herbaceo. Jacqu. austr. t. 214. (in unbrosis haud frequens, in Swirlowa et Kupawna, Jun.)

3. L. monopetalum: corollis monopetalis quinquefidis. (in sylvis trans Occam. Jun. Stephan.)

4. L. catharcticum: foliis oppositis ovato-lanceolatis, caule dichotomo, corollis acutis. Fl. dan. t. 351 . (in pratis pinguibus humidiusculis ad Mosquam fluvium. Jul, Aug.)

121. Drosera. Calyx quinquefidus. Petala quina. Capsula unilocularis apice quinquevalvis. Semina plurima.

1. D. rotundifolia: scapis radicatis, foliis orbiculatis. Fl. dan. t. 1028. (in paludosis turfosis. Jun. Jul )

¿. D. Longifolia: scapis radicatis, foliis ovalioblongis. Fl. dan. t. 1093. (cum praecedente, rarius. In Gorenki et Archangelsk. Jul.) 


\section{$-\quad 59$ \\ P O L Y G Y N I A.}

122. Mrosurus. Calyx pentaphyllus basi adnatns. Corolla nulla. Nectaria quina lingulata petaliformia. Semina numerosa.

2. M. minimus: foliis linearibus integerrimis. $F l$. dan. t. 406. (in agris, ruderatis, pascuisque arenosis, Mai. Jun.)

\section{H E X A N D R I A.} IIONOGYNIA.

193. Altiuns. Umbella congesta. Spatha bivalvis multiflora. Corolla hexapetala patens. Capsula supera.

2. A. rotundum: caule planifolio umbellifero, staminibus tricuspidatis, umbella globosa, floribus lateralibus nutantibus, (inter segetes circa pagum Tokarewa, nec non ad sylvarum margines versus Kunzowa. Jul.)

2. A. carinatum: caule planifolio bulbifero, umbella patula, pedunculis subnutantibus, staminibus subulatis, spathis longissime cuspidatis. Hall. monogr. t. 2. f. 2. (in montosis circa Iunzowa, et in montibus passerinis. Jun.)

3. A. vineale: caule tereti folio bulbifero, staminibus tricuspidatis. Moris. hist. II. t. 15. f. 4. (in campis ad urbem Colomna. Jul. Stephan)

4. A. olernceum: caule teretifolio bulbifero, foliis scabris semiteretibus subtus sulcatis, sta- 


\section{$-60$}

minibus simplicibus. Hall. monogr. t. 26. f. 2. (in campis. Jun.)

5. A. Schoenoprasum: scapo nudo adaequante folia teretia subulato-filiformia. $F l$. dan. $t$. 971. (circa Petrowsk. Jun. Sine dubio cum solo urbano quondam transplantatum.)

124. Ornithogalum. Spatha nulla. Corolla hexapetala erecta persistens supra medium patens. Filamenta basi dilatata. Capsula trilocularis supera. Semina subrotunda nuda.

1. O. sylvaticum: scapo anguloso basi diphyllo, pedunculis simplicibus triquetris glabris. Uster. nov. annal. V. t. 1. f. 1. (in sylvis. Mai.)

2. O. pratense: [luteum] scapo anguloso basi monophyllo, foliis radicalibus linearibus, pedunculis umbellatis glabris, petalis lanceolatis. Uster. nov. annal. V. t. 2. f. 1. (in pratis, graminosis, sylvarumque marginibus. Mai.)

3. O. spathaceum : folio radicali solitario planiusculo: floralibus alternis, imo maximo spathaeformi, pedunculis ramosis corymbosis, petalis actitiusculis glabris. Uster. ibid. XV. t. 1. (in sylvaticis humidis, pratis, pomariis. Mai.)

4. O. villosum: [minimum] foliis radicalibus geminis : floralibus imis oppositis, pedunculis ramosis corymbosis petalisque hirsutis. Uster. $l$. c. V. t. 1. f. 2. (in campis, agris, oleraceis. In Ismailowa versus vivarium. MTai.)

5. O. umbellatum: racemo subcorymboso paucifloro, pedunculis fructiferis elongatis patentis- 


\section{$-61$}

simis, foliis linearibus glabris. Jacqu. austr. t. 343. (in pomariis, hortisque. Mai.)

125. Asparagus. Calyx nullus. Corolla hexapetala erecta, petalis tribus interioribus apice reflexis. Bacca trilocularis, loculis dispermis.

1. A. officinalis: caule herbaceo tereti erecto, foliis setaceis fasciculatis, stipulis paribus basi inucronatis. $F l$, dan. t. 805. (in campis arenosis ad Mosquam fuvium. Jun.)

126. Convallaria. Calyx nullus Corolla hexafida. Bacca trilocularis maculosa supera.

2. C. majalis: scapo nudo semicylindrico laevi, floribus racemosis canpanulatis nutantibus, foliis ovatis. Fl. dan. t. 584. (in sylvis, nemoribus, hortisque. Mai.)

2. C. Polygonatum: foliis alternis amplexicaulibus, caule ancipiti, pedunculis axillaribus subunifloris $\mathrm{Fl}$. dan. t. 377. (in nemorosis. Juin.)

3. C. multiflora: foliis alternis amplexicaulibus, caule tereti, pedunculis axillaribus multifloris. Fl. dan.t. 152 (in nemoribus et fruticetis. Jun.)

127. Acorvs. Spadix cylindricus tectus flosculis Calyx nullus. Corolla hexapetala nuda. Stylus nullus. Capsula trilocularis.

1. A. Calamus: scapi mucrone longissimo foliaceo. Fl. dan. t. 1158. (in paludibus, lacubus, stagnisque. Jun.)

1:8. Juncus. Calyx nullus. Corolla hexapetala. Stigmata tria. Capsula trilocularis trivalvis 
polysperna, valvulis medio septiferis. Semina dis. sepimento affixa.

\section{* Culmis nudis.}

1. J. conglomeratus : culmo nudo sricto, panicula laterali conglobata, capsulis retusis, floribus triandris. Host. gram. III. t. 32. (in humidis et uliginosis. Jun. Jul.)

2. J. effusus: culmo nudo stricto, panicula laterali supradecomposita effusa, capsulis clavatis apice truncatis. Host. gram. III. t. 83. (in locis paludosis, ad fossas. Jun.)

3. J. filiformis: culmo nudo filiformi nutante, umbella laterali subsimplici paucifora, pedunculis subbifloris, capsulis obtusis. Host. gram. III. t. 84. (in turfosis uliginosis. Jun.)

4. J. squarrosus: culmo nudo, foliis setaceis subdistichis, capitulis terminalibus glomeratis aphyllis. Fl. dan. t. 430 . (in collibus, pascuisque arenosis. Jun. Jul.)

\section{* Culmis foliosis.}

5. J. obtusiflorus: [adscendens] culmo adscendente, foliis nodoso-articulatis subcompressis, panicula composita, petalis aequalibus obtusiusculis. Host. gram. III. t. 37. (in lacubus et fossis. Jun. Aug.)

6. J. acutiflorus: [sylvaticus] culmo erecto, folits modoso-articulatis teretibus, panicula supradecomposita, petalis aristatis: interioribus longioribus. Host. gram. III. t. 86. (in nemuribus humidis. Jul. Aug.) 


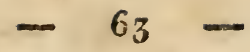

7. J. Gulbo us : culmo folioso simplici compressinsculo, foliis canaliculatis, corymbo terminali foliis fluralibus breviore, capsula subrotunda obtusa petalis longiore. Host. gram. III. t. 89. (in pascuis sterilibus, ad vias. Jun. Jul.)

8. J. bufonius: culmo folioso subramoso, foliis linearibus canaliculatis,-panicula dichoroma, ramis multifloris, petalis acuminatis aequalibus capsula obtusa longioribus. Host. gram. III, t. 90. (in humidiusculis et inundatis arenosis, ad sepes et vias. Jun. Jul.)

229. Luzura. Calyx nullus. Corolla herapetala. Stignmata tria, Capsula unilocularis trivalvis trisperma. Semina receptaculo centrali affixa.

1. L. pilosa: [Juncus pilnsus] foliis planis pilosis, corymbo terminali subcomposito, pedunculis unifloris nutantibus, petalis ovatis capsula brevioribus. Host. gram. III, to 100. (in nemoribus et saltubus. MIai. Jun.)

b. Luzula vernalis: foliis planis pilosis, pedunculis simplicibus : inferioribus reflexis, Hoffmann. (in sylvaticis et nemorosis. Mai,)

2. L. campestris: [Juncus campestris] foliis planis pilosis, spicis pedunculatis umbellatis: intermedia sessili, petalis mucronatis capsula longioribus, $\mathrm{Fl}$. Lond, t: 2. (in pascuis, campisque siccioribus. Jun.)

130. Berberis. Calyx hexaphyllus. Petala sena ad ungues glandulis duabus. Stylus nullus. Bacca disperma. 


\section{$-64-$}

2. B. vulgaris: racemis simplicibus pendulis, petalis obtusis integerrimis, foliis obovatis ciliato-serratis. $\mathrm{Fl}$. dan. t. 904. (in dumetis, sepibusque vivis. Mai.)

b. Berberis asperma: baccis aspermis, aculeis multiplicibus.(in hortis passim.)

131. Peplis. Perianthium campanulatum : ore duodecimfido. Petala sena calyci inserta. Capsula bilocularis.

1. P. Portula: floribus hexandris axillaribus solitariis, foliis petiolatis subrotundo - ovatis. $F l$ dan. t. 64. (in locis inundatis, paludosis, inque lacunis. Jul. Aug.)

\section{T R I G Y N I A.}

152. Rumex. Calyx triphyllus. Petala terna conniventia. Semen unum triquetrum.

* Hermaphroditi: valvulis granulo notatis.

2. R. Hydrolapathum: floribus hermaphroditis, valvulis triangulari - ovatis integerrimis vemosis, omnibus graniferis, foliis lanceolatis basi attenuatis. Petiv. brit.t. 2. f, 1. (in fossis, stagnis et piscinis. Jul.)

s. $R$. crispus: floribus hermaphroditis, valvulis integris graniferis, foliis lanceolatis undulatis acutis, Fl. Lond. 2. (in humidis et graminosis, ad sepes, viasque. Jul. Aug.)

5. R. Nemolapathum: [conglomeratus] floribus hermaphroditis, valvulis linearibus obtusis integerrimis graniferis, verticillis remotis, ramis 
patentibus, foliis inferioribus cordato - lanceolatis, superioribus lanceolatis. (in nemoribus humidis. Jul. Aug.)

4. R. maritimus: floribus hermaphroditis, valvulis dentatis graniferis, foliis linearibus. Fl.dan t. 1208. (in humidis, fossis. Jul. Aug.)

5. R. acutus: floribus hermaphroditis, valvulis dentatis graniferis, foliis cordato-oblongis acuminatis. Blackw. t. 49u. (in pratis succulentis, umbrosis. Jun. Aug.)

6. R. obtusifolius: floribus hermaphroditis, valvulis dentatis graniferis, foliis cordato-oblongis obtusiusculis crenulatis. Fl. Lond. 1. (in pascuis, pratis, viisque. Aug.)

** Hermaphroditi: valvulis granulo destitutis.

7. R. bucephalophorus: floribus hermaphroditis, valvulis dentatis nudis, pedicellis planis reflexis incrassatis. Colum. ecphr. I. t. 150. (Excmplaria hujus plantae, hujusque in Italia indigenae visae, ad ripas Jausae fluminis legit. Henning. Jul.)

8. R. aquaticus: floribus hermaphroditis, valvulis integerrimis nudis, fuliis cordatis glabris acutis. Blackw. t. 490. (ad fossas et amnium litora, in paludibus et humidiusculis. Jul.) *** Floribus diclinis.

9. R. Acetosa: floribus dioicis, foliis oblongis sagittatis. Engl. bot. t. 227. (in pascuis, pratis et hortis. Jun. Jul, ) 
10. R. Acetosella: florib $\mathfrak{a}^{\mathrm{s}}$ dioicis, foliis lanceolato-hastatis. Fl. dan. t. 1161. (in pratis, pascuis, arvis, vallisque arenosis. Mai. Jun.)

b. Rumex multifidus: lobis multifidis. Boccon. $m u s, t .26$. (in clivis et arvis. Jun.)

333. Triglochin. Calyx triphyllus inferus. Corolla tripetala calyciformis. Stigmata tria sessilia. Capsula tri-vel hexalocularis basi dehiscens, loculis monospermis.

3. T. palustre: capsulis trilocularibus laevibus linearibus basi attenuatis. Fl dan. t. 490. (in pratie, pascuisque depressis humidis. Jun. Jul.)

134. Veratrumi. Hermaphroditi: Calyx nullus. Corolla hexapetala. Stamina sena. Pistilla terna. Capsulae ternae polyspermae.

Masculi: Calyx nullus. Corolla luxapetala. Stamina sena. Pistilli rudimentum.

1. V. album: racemis paniculatis, bracteis ramorum oblongis, partialibus pedunculum pubescentem subaequantibus, floribus erectis, foliis oyalibus plicatis, $F l$. dan. t, 1120 . (in montosis. Jữ.)

\section{P. O L Y G Y N I A.}

135. Alisma. Calyx triphyllus. Petala terna. Capsulae plures monospermae.

1. A. Plantago: foliis ovatis acutis, fructibus obtuse trigonis. $F l$. dan. t. 561. (in udis, aquesis et paludibus. Jul. Aug.) 


\section{$-67-$}

b. Alisma angustifolium: [lanceolatum] foliis lancenlatis, fructibus trigonis. Hoppe. (in locis siccioribus.)

\section{H E P T A N D R I A. MONOGYNIA.}

136. Trientalis. Calyx heptaphyllus. Corolla septempartita aequalis plana. Bacca exsucca unilocularis.

2. T. europaea: foliis ovato-lanceolatis integerrimis. Steph. icon. t. 8. (in sylvis et juniperetis humidiusculis ad arborum truncos et circa lapides majores. Jun.)

137. Calla. Spatha plana. Spadix tectus flosculis. Calyx nullus. Corolla nulla. Bacca polysperma.

1. C. palustris: foliis cordatis, spadice undique hermaphrodito. Fl. dan. t. 422. (in paludibus et aquis stagnantibus. Jun. Jul.)

\section{O C T A N D R I A.}

\section{MONOGYNIA.}

138. Oenothera. Calyx quadrifidus tuhulosus. Petala quaterna. Capsula tetralocularis quadrivalris cylindrica infera polysperma. Semina nuda.

2. O. biennis: foliis ovato-lanceolatis planis, caule muricato-villoso, staminibus corolla bre- 


\section{$-68$}

vioribus. $F l$, dan. t. 446. (in cultis et hortis. Jul. Aug.)

19. Erroв Petala quaterna. Capsula oblonga infera. Semina comosa.

3. E. spicatum: [angustifolium] foliis sparsis lineari-lanceolatis integerrimis venosis, floribus inaequalibus, staminibus declinatis. Fl.dan. t. 230. (in palurlibus, pratis humidis, fructicetis et nemoribus. Jun. Jul.)

2. E. hirsutum: [grandiflorum] foliis oppositis alternisuque subamplexicaulibus ovato-lanceolatis serratis glabriusculis, venis hirsutis, caule xamosissimo hirsuto, radice stolonifera. Fl.dan. t. 326. (in humidiusculis. Jul. Aug.)

3. E. pubescens: [parviflorum] foliis oppositis alternisque subsessilibus lanceolatis denticulatis utrinque pubescentibus, caule simplici villoso. Fl. dan.t. 347. (in pratis et ad fossas. Jul.)

4. E. montrnum: foliis oppositis ovatis dentatis, caule tereti, stigmate quadripartito. Fl dan. $t$. 922. (in collibus, vallis et nemoribus, Jun. Jul.)

5. E. roseum: foliis oppositis alternisque ovato. lanceolatis petiolatis serratis glabris. Engl. bot. t. 693. (iu nemoribus humidis. Jul.)

6. F. tetrigonum: foliis lanceolatis denticulatis: imis oppositis, caule tetragono. $\mathrm{Fl}$. dan. t. 1029. (in paludosis et uliginosis, Jul. Aug.) 


\section{$-6_{9}-$}

7. E. palustre: foliis oppositis lanceolatis integerrimis, petalis emarginatis, caule erecto. Engl.but. t. 346. (in paludibus. Jul. Aug.)

140. Acen. Hermaphroditi: Calyx quinquefidus. Corolla pentapetala. Stamina octona. Pistillum singulum. Samarae binae ternaeve monospermae ala terminatae.

Masculi: Calyx quinquefidus. Corolla pentapetala. Stamina octona.

1. A. tataricum: foliis cordatis subincisis inaequalibus serratis, corymbis erectis. Pall. fior. ross. I. t. 3. (in hortis frequens. Mai.)

2. A. platanoides: foliis quinquelobis utrinque glabris, lobis dentibusque acuminatis, corymbis erectis, pedunculis glabris. Ferner. III. t. 17. (in sylvaticis montosis. Mai.)

b. Acer laciniatum: foliis quinquepartitopalmatis laciniatis crispis. (in hortis. Mai.)

3. A. campestre: foliis quinquelobis integerrimis, lobis obtusis: majoribus obsolete subsinuatis, corymbis erectis. Engl. bot. t. 304. (in sylvis, nemoribusque montosis, ad sepes. Mai.)

141. Oxycoccus. Calyx superus quadrifidus. Corolla quadripartita, laciniis sublinearibus revolutis. Filamenta conniventia. Antherae tubulosae bipartitae. Bacca polysperma.

1. O. palustris: [Vaccinium Oxycoccos] foliis ovatis integerrimis revolutis, caulibus filiformibus repentibus nudis. $F l$. dan. t. 80. (in paludibus sphagno phagno repletis. Mai. Jun.) 


\section{$-70$}

142. Vaccinium. Calyx superus quadridentatus. Corolla monopetala. Filamenta receptaculo inserta. Bacca quadrilocularis polysperma.

2. V. Myrtillus: pedunculis unifloris, foliis ovatis serratis deciduis, caule angulato. $F l$. dan. t. 974. (in sylvis umbrosis. Mai.)

2. V. uliginosum: pedunculis unifloris, foliis integerrimis ohovatis obtusis laevibus. Fl. dan. $t$. 231. (in uliginosis nemorosis : circa Butirki et Archangelsk. Jun.)

3. V. Vitis Idaea: racemis terminalibus nutantibus, foliis obovatis revolutis integerrimis subtus punctatis. Fl. dan. t. 40. (in sylvis siccioribus sterilibus. Mai.)

143. Calluna. Calyx duplex tetraphyllus. Corolla campanulata quadripartita. Filamenta receptaculo inserta. Antherae bifidae. Capsula quadrilocularis. Dissepimenta receptaculo centrali affixa.

1. C. vulgaris: [Erica vulgaris] foliis oppositis sessilibus sagittatis. Fl. dan. t. 677. (in campestribus, collibusque sterilibus et sic dictis ericetis. Jul. Sept.)

b. Calluna hirsuta: foliis pubescenti-incanis. (in paludosis ad IKuskowa. Aug.)

144. Daphne. Calyx nullus. Corolla quadrifida marcescens stamina includens. Drupa monosperma.

1. D. Mezereum: floribus sessilibus ternis caulinis, foliis lanceolatis deciduis. Fl. dan. t. 268 . (in sylvis, praesertim in sylva St. Annae, in 


\section{$-71$}

Astankina, Swirlowa, Kuskowa, Petrowsk. IMai,)

\section{T R I G Y N I A.}

145. Polygonum. Calyx nullus. Corolla quin. quepartita calycina. Semen unum angulatum.

$$
\text { * Bistortae: spica unica. }
$$

3. P. Bistorta: caule simplicissimo monostachyo, foliis ovatis in petiolum decurrentibus. Fl, dan. t. 421. (in pratis montusis. Jul.) * Persicariae: pistillo bifido, aut stamina

$$
\text { minus octo. }
$$

2. $P$. amphibium: floribus pentandris semidigynis, spica ovata, ochreis margine laceris, foliis oblongis lanceolatisve.

a. Polygonum aquaticum: foliis oblongoellipticis obtusis natantibus, ochreis glabris, staminibus flore brevioribus. $F l$.dan. to 28. (in lacubus, fluviis, fossis. Jul. Aug.)

b. Polygonum terrestre: foliis ovato - lanceolatis acuminatis, ochreis pilosis, staminibus corolla longioribus. Engl. bot. t. 436. (in humidiusculis ad fossas et ripas, in paludibus. Jul. Aug.)

3. P. Hydropiper: floribus hexandris semidigynis distantibus, ochreis setoso-ciliatis, spicis filiformibus cernuis, foliis lanceolatis. Fl. dan. t. 282. (in subliumidis, ad fossas, fonticulos et paludes. Jul. Aug.)

4. P. minus: [intermedium] floribus hexandris submonogynis, foliis lineari-lanceolatis pla- 
nis, spicis erectiusculis, caule basi repente. Engl. bot, t. 2048. (in uliginosis et umbrosis: in montibus passerinis, tribus montibus haud procul a fonte, circa Petrowsk in fossis. Jul.)

5. P. lapathifolium: floribus hexandris digynis, ochreis muticis, pedunculis scabris, seminibus utrinque concavis. Fl. Lond. I. (in fossis et lacubus. Jun. Aug.)

6. P. Persicaria: floribus hexandris digynis, spicis ovato-oblongis, petalis subtrinerviis, foliis lanceolatis glabris, ochreis abbreviatis laceris ciliatis. Fl. dan. t. 702. (in humidis et ad vias. Jul. Aug.)

7. P. incanum: floribus hexandris digynis, spicis oblongis, petalis subenerviis, foliis oblongolanceolatis subtus pubescentibus, ochreis abbreviatis laceris ciliatis. Schranti, bavar. I. t. 3. (in agris et humidiusculis. Jul. Aug.)

*** Polygona: foliis indivisis, floribus octandris.

3. $P$. aviculare: floribus octandris trigynis axillaribus, foliis lanceolatis caule procumbente herbacco. Fl. dan.t, 803. (in cultis et ruderatis, ad vias et sepes. Jun. Aug.)

b. Polygonum erectum: foliis latioribus, caule erecto.

**** Helxine: foliis subcordatis.

9. P. Fagopyrum: foliis cordato-sagittatis, caule erectiusculo inermi, seminum angulis aequalibus. Mart. rust. t. 46. (inter segetes et in caṇpis. Jul. Aug.) 
10. P. Convolvulus: foliis cordatis, caule volubili angulato, floribus obtusis. Fl.dan, t..744. (in dumetis, agris, hortisque. Jun. Jul.)

11. P. dumetorum: foliis cordatis, caule volubill laevi, floribus carinato-alatis. $\mathrm{Fl}$. dan. t. 756. (in fruticetis sepibusque vivis, in horto Imperiali. Jul. Aug.)

\section{TE T R A G Y N I .}

146. PAris. Calyx tetraphyllus. Petala quaterna angustiora vel nulla. Bacca quadrilocularis.

2. P. quadrifolia: foliis quaternis, flore corollato. Flor. dan. t. 139. (in locis humidis umbrosis. Mai. Jun.)

b. Paris quinquefolia: [pentaphylla] folis quinis senisve. (cum priore.)

147. Adoxa. Calyx bifidus inferus. Corolla quadrifida seu quinquefida supera. Bacca quadrivel quinquelocularis calyce coalita.

1. A. Moschatellina: foliis radicalibus biternatis, caulinis ternatis oppositis, capitulo terminali quinquefloro, $F l$. dan. t. 94. (in nemoribus h... midis, MIai.)

\section{E N N E A N D R I A.}

H E X A G Y N I A.

148. Butomus. Calyx nullus. Petala seria. Capsulae senae polyspermae. 
2. B. umbellatus: foliis triquetris radicalibus, caule simplicissimo nudo. Fl. dan. t. 604. (in fluviis, fossis, lacubus. Jul. Aug.)

\section{E C A N D R I A.' M O N O G Y N I A.}

149. Monotropa. Calyx nullus. Petala dena: quina exteriora basi cxcavato-inellifera. Capsula quinquevalvis.

1. M. Hypopithys: floribus glabris: lateralibus octandris, terminali decandro. Fl. dan.t. 2.32 . (in sylvaticis umbrosis, in pini quercique radicibus parasitica; in Gorenli, Petrowsk, Archangelsk et Kuskiowa Jul.)

150. Ledum. Calys quinquefidus. Corolla plana quinquepartita. Capsula quinquelocularis basi dohiscens polysperma.

1. L. palustre: [Rosmarinus sylvestris] foliis linearibus margine revolutis subtus tomentosis. Du Ham. arb. I. t. 67. (in paludibus, udis et uliginosis turfosis, e. $g$. in Butirki, Jun.)

151. Andromeda. Calyx quinquepartitus. Corolla ovata, ore quinquefido, Capsula quinquelocularis, valvulis dissepimento contrariis.

1. A. polifolia: pedunculis aggregatis, corollis ovatis, foliis alternis lanceolatis revolutis. $F l$. dan. t. 54. (in turfosis uliginosis, in Gorenki, Archangelshi, Butirli et Swirlowa. Mai. Jแn.) 
2. A. calyculata: pedunculis axillaribus solitariis secundis, bracteis binis, foliis ovalibus squamoso - punctatis obsolete serratis. Pall. flor. ross. I. t. 72. f. 1. (cum praecedente. Jun. Aug.)

152. Arsutus. Calyx quinquepartitus. Corolla ovata, ore basi pellucida. Bacca quinquelocularis supera.

2. A. Uva ursi: caulibus procumbentibus, foliis obovatis coriaceis integerrimis reticulato-venosis nitidis. Fl. dan.t. 33. (in sylvis arenosis. Mai.) 153. Prnora. Calyx pentaphyllus. Petala quina. Capsula quinquelocularis, angulis dehiscens.

1. P. rotundifolia: staminibus adscendentibus, pistillo declinato, foliis obovalibus. Fl. dan. t. 110. (in sylvis. Jun. Jul.)

2. $P$. virens: staminibus adscendentibus, pistillo declinato corolla vix longiore, foliis orbiculatis. Rivin. pent. t. 496. f. 1. (in sylvis cum praecedente. Jun. Jul.)

3. P. minor: floribus racemosis dispersis, staminibus pistillisque rectis. Fl.dan. t. 55. (cum priori, rarius. Jul.)

4. P. secunda: racemo unilaterali, foliis ovatis -erratis, pistillo recto longissimo. $F l$. dan, $t_{\text {。 }}$ 402. (in fruticetis et sylvis. Jun. Jul.)

5. P. umbellata: pedunculis subumbellatis, foliis lanceolatis. Steph. icon: II. t. 9. (cum reliquis generis sui occurrit in Gorenki, Archangelsk et Kuskowa. Jun.)

6. P. uniflora: scapo unifloro, foliis suborbiculatis. Steph. icon.II. t. 13. (cum antecedente.) 


\section{$-76-$ \\ D I G Y N I A.}

154. Cinrsosplenium. Calyx quadri-senquinquefidus coloratus. Corolla nulla. Capsula birostris unilocularis polysperma.

1. C. alternifolium: foliis alternis. Fl.dan. t. 336, (in opacis humentibus. Mai.)

15.5. Sclerantirus. Calyx monophyllus quinquedentatus. Córolla nulla. Semina bina calyco inclisa.

1. S. annuus: calycibus fructus patulis acutis, caulibus patentibus. Fl, dan. t. 504. (in arenosis. Mai. Jun.)

2. S perennis: calycibus fructus clausis obtusis margine membranaceis, caulibus procumbentibus. Fl, dan.t. 563 (in campis apricis arenosis. Jun. Jul.)

156. Gypsopinca. Calyx monophyllus campanulatus angulatus. Petala quina ovata sessilia. Cápsula globosa unilocularis.

1. G. muralis: foliis linearibus planis internodiis brevioribus, calycibus aphyllis, caule dichotomo, petalis crenatis. Schkuhr. t. 120. (in siccis arenosis, inter segetes, fad vias, in muris. Jun. Sept.)

157. Saponaria. Calyx monophyllus nudus. Petala quina unguiculata. Cansula oblonga unilocularis.

2. S. officinalis: calycibus cylindricis, foliis ovatolanceolatis. $\mathrm{Fl}$. dan. t. 543 . (in pratis, circa domos, ad sepes. Jul. Aug.) 


\section{$-\quad 77$}

b. Saponaria hortensis: flores rubro albove pleno. (in hortis.)

158. Diantrus, Calyx cylindricus monophyllus, basi squamis quatuor munitus. Petala quina unguiculata. Capsula cylindrica unilocularis polysperma.

1. D. collinus: [ruthenus] floribus aggregatis subgeminato-fasciculatis, squamis ovatis cuspidatis tubo brevioribus, foliis lineari-lanceolatis quinquenerviis cauleque scabris. Waldst et $T i$ tnib. pl. hung. I. t. 38. (in collibus arenosis. Jun. Jul.)

2. D. deltoides: floribus solitariis, squamis calycinis ovato-lanceolatis binatis, foliis linearibus acutis cauleque pubescentibus, petalis crenatis. Fl. dan.t. 577. (in pascuis, campis et nemoribus. Jun.Jul.)

b. Dianthus reptans: ramis longe reptantibus. (in collibus arenosis.)

5. D. arenarius: caulibus subunifloris, squamis calycinis ovatis obtusis, corollis multifidis, foliis linearibus. (in graminosis siccioribus arenosis. Jul.)

\section{T R I G Y N I A.}

259. Cucubalus. Calyx inflatus. Petala quina unguicnlata absque corona ad faucem. Capsula trilocularis.

2. C. Beken: calycibus subglobosis glabris reticulatu-venosis, capsulis trilocularibus, corol- 
lis subnudis. $F l$. dan, t. 914 . (in pratis et nemoribus. Jun. Jul.)

b. Cucubalus pallidus: foliis ovato-acuminatis, calycibus inflatis decoloribus, corollis albis. (in pascuis.)

2. C. viscosus: floribus lateralibus undique decumbentibus, 'caule indiviso, foliis basi reflexis. (in tribus montibus, montibusque passerinis et Kupawna. Jul.)

3. C. tataricus: petalis bifidis, floribus secundis decumbentibus, pedunculis oppositis solitariis erectis, caule simplicissino. (in montosis arenosis sylvaticis, montibus passerinis, tribus montibus, Kunzowa. Jul.)

260. Silene. Calyx ventricosus. Petala quina unguiculata coronata ad faucem. Capsula trilocularis.

1. S. nutans: floribus paniculatis secundis nutantibus, petalis bifidis, caule adscendente, foliis lanceolatis scabris. $F l$. dan. t. 242. (in sylvis, nemoribus, pratis, arvisque aridis. Mai.Jun.)

2. S. baccifera: [Cucubalus bacciferus] calycibus fructiferis cernuis inflatis laevibus, capsulis coloratis, ramis divaricatis. Gmel. in act. petropol. 1759. Vol. XIV. t. 17. f. 1, (in nemoribus et fluvium amnibus, in Kunzowa, Perowa et montibus passerinis. Jul. Aug.)

3. S. noctiflora: calycibus decemangularibus, dentibus tubum aequantibus, caule dichotomo, petalis bifidis. Engl. bot. t. 291. (in locis incultis, ruderatis, nemoribusque. Jun. Aug.) 


\section{$-79$}

161. Steliaria. Calyx pentaphyllus patens. Petala quina bipartita. Capsula unilocularis polysperma.

1. S. nemorum: foliis cordatis petiolatis, panicula pedunculis ramosis, Fl. dan, t. 271 . (in nemoribus et umbrosis. Jun. Jul.)

2. S. Holostea: foliis lanceolatis serrulatis, petalis bifidis. Fl. dan. t. 698. (in nemoribus et sylvis. Mai. Jun.)

3. S. arvensis: [oraminea] foliis lineari - subulatis margine laevibus, panicula divaricata, petalis bipartitis longitudine calycis. Fl.dan t. 414 . (in hortis, pomariis et sylvis, ad sepes et domos. Jun. Jul.)

4. S. palustris: [glauca] foliis lineari-lanceolatis integerrimis, floribus paniculatis, ipetalis bipartitis calyce majoribus. Gmel, flor. sib. IV. t. 61 f. 2. (in paludibus. Jun. Aug.)

5. S. uliginosa: foliis elliptico-lanceolatis, pedunculis subgeminatis paucifloris, petalis calyce brevioribus, caule quadrangulo decumbente. Fl. dan. t. 415. (in paludosis et uliginosis. Jun. Jul.)

162. Arenaria. Calyx pentaphyllus patens. Petala quina integra. Capsula unilocularis polysperma.

1. A. trinervia: foliis ovatis acutis petiolatis nervosis. Fl. dan. t. 429. (in sylvis, ad vias et in hortis. Jun. Aug.)

8. A. serpyllifolia: foliis subovatis acutis sessilibus, corollis calyce brevioribus. Fl. dan. t. 877 . (in arvis et sylvis arenosis. Mai. Sept.) 


\section{$-80$}

3. A. campestris: [rubra] foliis filiformibus mu. cronulatis inteinodio brevioribus, caulibus prostratis glabris, seminibus compresso-angulatis scabriusculis, Loesel. pruss, t. 63. (in collibus arenosis, inter segetes. Jun. Aug.)

b. Arenaria urbana: ramosissima, caulibus adscendentibus, calycibus pilosis. (in arenosis, ad sepes et in hortis. Jul. Aug.)

\section{P E N T A G Y N I A.}

163. Sedum. Calyx quinquefidus. Corolla pentapetala. Squamae quinae nectariferae ad germinum basin.Capsulae quinae uniloculares polyspermae.

1. S. Telephium: foliis oblongis serratis, corymbo composito folioso, caule erecto. Fl dan.t. 686. (in sylvis collibusque siccissimis arenosis, in vallis, muris, tectisque. Jul. Aug.)

6. Sedum purpureum: foribus purpureis. (in arvis et campis aridis arenosis, inter segetes.)

2. S. acre: foliis subovatis adnato-sessilibus gibbis erectiusculis alternis, cyma trifida. Engl. bot. $t, 839$. (in campis vallisque siccissimis sterilissimis, in muris et tectis. Jun. Aug )

3. S. sexangulare: foliis subovatis adnato-sessilibus gibbis erectiusculis sexfariam imbricatis. Decand. t, 228. (in campis apricis. Jun. Jul.) 264. Oxaris. Calyx pentaphyllus. Petala quina unguibus connexa. Stamina inaequalia: quina exteriora breviora basi connata. Cansula angulis debiscens pentagona. 


\section{$-81$}

8. O. Acetosella : acaulis, scapo unifloro foliis lons giore, foliis ternatis obcordatis, stylis longi* tudine staminum interiorum, radice articulata. Fl. dan. t. 980. (in sylvis umbrosis ad arborum adultiorum truncos. Mai.)

b. Oxalis purpurascens: corollis purpurascentibus. (in Solkolnika.)

165. Agrostemia. Calyx monophyllus coriaceus. Petala quina unguiculata, limbo obtuso indiviso. Capsula unilocularis.

2. A. Githago: hirsuta, calycibus corollam aequantibus, petalis integris nudis. $F l$. dan, t. 576. (inter segetes. Jul. Aug.)

b. Agrostemma alba: corollis albis. (in hortis. Jul. Aug.)

266. Luycirnss. Calyx monophyllus oblongus laevis. Petala quina unguiculata, limbo saepe bifido. Capsula quinquelocularis.

1. L. Flos cuculi: petalis quadrifidis, fructu subrotundo. Fl. dan. t. 590. in pratis humidiusculis. Jun. Jul.)

2. L. Viscaria: petalis integris, caule geniculis viscoso. Fl. dan. t. 1032. (in nemoribus, pratisque siccis. Jun.)

3. L. pratensis: [dioica] petalis (albis) bifidis, floribus dioicis, capsulis conicis, caule foliisque pubescentibus. Fl. dan.t. 792. (in agrorum versuris, inter segetes, ad domos. Jun. Aug.)

4. L. sylvestris: petalis (rubris) bifidis, floribus dioicis, capsulis subrotundo-ovatis, caule pedurculisque hirsutis, foliis pubescentibus. 
Schkuhr. t. 124. (in sylvis et graminosis humidiusculis. Jul. Aug.)

167. Cerastium. Calyx pentaphyllus. Petala guina bifida. Capsula unilocularis apice dehiscens.

1. C. vulgatum: erectiusculum hirsutum superne subviscosum, foliis lanceolatis, calycibus acutiusculis petala subaequantibus, capsulis pedicello brevioribus. Fl.Lond. 2. (in siccioribus, cultis et hortis. Mai. Jun.)

2. C. semidecandrum: procumbens villoso-viscosum subincanum, foliis ovato-oblongis, calycibus acuminatis petala aequantibus, capsulis pedicello brevioribus. Fl. ‘lan. t. 1212. (in pascuis sterilibus apricis. Mai Jun )

3. C. arvense: caulibus declinatis, foliis linearilanceolatis subpubescentibus, petalis calyce longioribns, capsula oblonga dentibus obliquis. dehiscente. Fl, dan. t. 626. (in arvis et campis. IMai Jun.)

4. C. aquaticum: foliis cordatis sessilibus, floribus solitariis, fructibus pendulis. Engl. bot. t. 538. (in humidis, pratis paludosis, ad lacuum fossarumque ripas. Jun. Sept.)

168. Spergula. Calyx pentaphyllus. Petala quina integra. Capsula ovata unilocularis quinqueval vis.

2. S. arvensis: foliis verticillatis, pedunculis fructiferis reflexis, seminibus reniformibus $\mathrm{Fl}$. dan. t. 1033. (in arvis arenosis siccis, inter segetes. Juir. Aug.) 
2. S. nodosa: foliis oppositis laevibus subulatis, superioribus fasciculatis, calyce inermi, Fl.dan. t. 96. (in pascuis arenosis humidis, in paludibus. Jul, Aug.)

\section{O D E A N D R I A.}

\section{MONOGYNIA.}

169. Asanum. Calyx tri - quadrifidusve germini insidens. Corolla nulla. Capsula coriacea coronata subsexlocularis polysperma.

2. A. europaeum; foliis reniformibus obtusis glabris geminatis, calyce trifido. Fl.dan. t. 633 . (in nemoribus umbrosis, praesertim ad caudices coryli. Mai.)

17o. Lythrum. Calyx duodecimdentatus. Petala sena calyci inserta. Capsula bilocularis polysperma.

2. L. Salicaria: foliis oppositis cordato-lanceolatis, floribus spicatis dodecandris. $F l_{\text {. dan. }}: t_{\text {. }}$ 671. (in humidis, ad fossas. Jun.)

b. Lythrum quadrifolium: foliis quaternis lanceolatis (circa Kupawna,)

\section{T R I G Y N I A.}

171. Euphorria. Calyx monophyllus ventricosus. Corolla tetra-seu pentapetala. Germen pedicellatum. Capsula tricocca.

2. E. Peplus: umbella trifida: dichotoma, invoJucellis ovatis, foliis integerrimis obovatis pe- 
tiolatis. Fl. dan. t. 2100 . (in cultis, oleraceis, hortis, Mai, Aug.)

2. E. helioscrpia : umbella quinquefida: bifida: dichotoma, involucellis obovatis, foliis cuneiformibus serratis glabris, ca sulis laevibus. $\mathbf{F l}$. dan. $t$ 725. (in cultis Jun. Jul)

3. E, Esula: umbella multifida: bifida, involucellis subcordatis, petalis subbicornibus, tamis sterilibus, foliis uniformibus Blackw. t. 163. (in agris, viis, campis, vallisque arenosis. Maai. Jul.)

b. Euphorbia latifolia: major, foliis latioxibus. (in paludosis umbrosis.)

4. E. palustris: umbella multifida : bi - trifida: bifida involucellis ovatis, foliis lanceolatis, ramis sterilibus, $F l$. dan. t. 866. (in humidis et paludosis. Mai. Aug.)

\section{DODECA GY N IA.}

272. Sempervivum. Calyx duodecimpartitus. Petala duodena. Capsulae duodenae polyspermae.

1. S. tectorum: foliis ciliatis, propaginibus patulis, floribus dodecandris dodecagyniis, nectariis cuneiformibus carunculatis, $F l$ dan. t. $60 x$. (in collibus, siccis, muris, tectisque. Jul.)

2. S. globiferum: foliis ciliatis, propaginibus globosis. Schmid. icon, t. 26. (in collibus arenosis. Jul.) 


\section{$-85$ \\ I C O S A N D R I A. M O N O G Y N I A.}

173. Pnunus. Calyx quinquefidus inferus. Petala quina. Drupae nux suturis prominulis.

1. P. Padus: floribus racemosís, racemis pendulis, foliis deciduis duplicato-serratis subrugo. sis, petiolis biglandulosis. Fl. dan. t. 205. (in nemcribus et hortis Maai.)

2. P. spinosa: pedunculis solitariis, foliis elliptico-lanceolatis subtus pubescentibus, fructibus rectis, ramis spinosis. Fl.dan. t. 926. (in sepibus vivis, ad vias, in desertis. Mai.)

3. P. insiticia: pedunculis geminis, foliis lanceolato-ovatis convolutis subtus villosis, rainis spinescentibus, fructibus subrotundis. Kern. IV. to 29. (in sepibus et hortis. Mai. Jun.)

\section{I G Y N I A.}

174. Agrmonia. Calyx hypocrateriformis: tu. bo fauce constricto, limbo quinquepartito. Petala quina calyci inserta. Semina bina calyce inclusa.

2. A. Eupatoria: calycibus fructiferis hispidis, foliis caulinis pinnatis, foliolis oblonga-ovatis, spicis elevatis, petalis calyce duplo longioribus. Fl. dan, t, 588 (in sylvis, nemoribus, se. pibus, vallisque. Jul. Aug.)

$$
\text { T R I G Y N I A. }
$$

175. Sonsus. Calyx quinquefidus. Petala quina. Pomum triloculare, loculis monospermis. 


\section{- 86}

1. S. aucuparia: foliis pinnatis, foliolis duplicatoserratis glabriusculis, petiolo communi pubescente, Fl. dan. t. 1034. (in nemorosis, hortisque. Jun.)

\section{P E N T A G Y N I A.}

176. Mespilus. Calyx quinquefidus. Petala quina. Bacca di-seu pentasperma.

1. M. Oxyacantha: [Crataegus Oxyacantha] foliis obtusis subtrifidis serratis glabris, floribus digynis, pedunculis calycibusque subglabriusculis, calycinis segmentis lanceolatis acutis, $F l$. dan. t. 634. (in sepibus vivis. Jun.)

2. M. monogyna: foliis acutis subtrifidis serratis glabris, floribus monogynis, pedunculis calycibusque subpubescentibus, calycinis segmentis lanceolatis acuminatis. Fl. dan.t, 1162 . (cum priore. Jun.)

177. Sprraea. Calyx quinquefidus. Petala qui. na. Capsulae quinae pluresve bivalves polyspermae.

1. S. salicifolia: foliis oblongo-lanceolatis serratis basi cuneatis glabris, racemis conferto-paniculatis. Pall. fl. ross. I. t. 21. (in sylva Astankina. Jul. Aug.)

2. S. Filipendula: foliis pinnatis, foliolis uniformibus serratis, caule herbaceo, floribus corymbosis. Fl. dan. t. 635. (in pratis, pascuisque montosis, in sylvis. Jul.).

3. S. Ulmaria: foliis pinnatis subtus tomentosis, impari majore trilobo, lateralibus indivisis, 


\section{$-87$}

corymbis proliferis. Fl. dan, t. 547. (in pratis uliginosis umbrosis. Jun. Jul.)

\section{P O L.Y G Y N I A.}

178. Rosa. Calyx urceolatus quinquefidus carnosus, collo coarctatus. Petala quina. Semina plurima hispida calycis interiori lateri affixa.

2. R. cinnamomea: [majalis] germinibus globosis pedunculisque glabris, caule aculcis stipularibus, petiolis subinermibus. Fl. dan. t. 1214 . (in sylvaticis, circa Gorenki, Kuskowa, et Archangelsk. Jun.)

2. R. canina: germinibus ovatis pedunculisque glabris, caule petiolisque aculeatis. Fl. dan. t. 551. (in dumetis, sepibus, ad vias. Jupn.)

179. Rubus. Calyx quinquefidus. Petala quina. Bacca composita aciuis monospermis.

1. R. Idaeus: foliis quinato - pinnatis ternatisque, caule aculeato, petiolis canaliculatis. Fl.dan. t. 788 (in nemoribus, hortisque. Juns)

b. Idaeus albus: fructibus albidis, Du Ham. arb. t. 10. (in hortis.)

2. R. caesius: foliis ternatis subnudis, lateralibus bilobis, caule aculeato tereti. Fl. dan. t. 1223. (in dumetis et sylvis. Jul $\Lambda$ ug.)

5. R. corylifolius: foliis subquinatis subtus pilosis, lateralibus sessilibus, aculeis rectiusculis, calycibus fructus infiexis. Engl. bot. t. 827 . (in montibus passerinis, Zarizina, Swiulowa, Jun. Jul.) 
4. R. fructicosus: foliis subquinatis subtus tomentosis, foliolis petiolatis, aculeis aduncis, ' caule angulato, calyce reflexo, Fl.dan.t. 1163. (in nemoribus et sylvis. Jun. Sept.)

5. R. 'saxatilis: foliis ternatis, flagellis reptantibus herbaceis. $F l$, dan. t, 134. (in sylvis nemeribusque, locis saxosis. Jun. Jul.)

180. Fragaria. Calyx decemfidus. Petala quina, Receptaculum scminum ovatum, baccatum deciduum.

1. F. vesca: calyce fructus reflexo, pubescentia petiolorum patentissima, pedunculorum ad: pressa. Blackw. t. 77. (in sylvis, nemoribus, pascuis, collibusque siccis sterilibus. Maai. Jul.)

b. Fragaria sylvestris: serratura terminali proximis paulo longiore. Schkuhr. t. 45. (in pascuis pratisque. Mai.)

c. Fragaria semperflorens: pedunculis nonnullis radicalibus. (in hortis. Mai. Sept.)

d. Fragaria alba: fructibus albis. (in hor, tis. Jun.)

2. $F$. collina: calyce fructus erecto, foliis acute serratis utrinque pubescentibus, pubescentia pedunculorum erecta, petiolorum patentissima, (in sylvaticis siccis circa Gorenki et in Perowa, Jun.)

3. F. elatior: calyce fructus reflexo, pubescentia pedunculorum et petiolorum patentissima, Lobel, icon. I. t. 677. (in locis desertis graminosis et in hortis, Mai, Jun.) 


\section{$-89$}

181. Potentilla, Calyx decemfidus. Petala quina. Semina subrotunda nuda, receptaculo par. vo exsucco affixa.

* Foliis pinnatis.

7. $P$. Anserina: foliis interrupte pinnatis sériceis, foliolis argute serratis, caule repente, pedunculis unifloris. (in fossis siccis, pascuis sterilibus, ad vias et. sepes. Jun. Aug.)

b. Anserina sericea: [cana] foliis utrinque sericeis, (in solo argilloso occurrit.)

2. P. supina: foliis pinnatis, foliolis oblongis pror funde dentatis, caule decumbente dichotomo, pedunculis axillaribus solitariis. Pluk, alm. t. 106. f. 7. (in inundatis, ad fluvios. Jun, Aug.) ** Foliis digitatis.

3. obscura: [salisburgensis?] foliis septenatis quinatisque, foliis lanceolatis grosse dentatis, petalis obcordatis calycem aequantibus, caule erecto. (in Sokolnika. Jul.Aug.)

4. P. argentea: foliis quinatis cuneiformibus incisis subtus tomentosis, caule erecto. $F l$. dan. t. 865. (in ruderatis, ad vias. Jun. Aug.)

5. P. intermedia: foliis radicalibus quinatis, caulinis ternatis, caule erectiusculo ramosissimo. (in ruderatis, ad sepes. Jul..)

6. P.verna: foliis quinatis obovatis dentatis pubescentibus, petalis obcordatis calyce majoribus, caulibus declinatis. Engl. bot. t. 37. (in nemoribus, pascuis editioribus et collibus aridis, Mai.) 
7. P. reptans: foliis quinatis cuneiformibus argute serratis, stipulis lanceolatis integerrimis, pedunculis axillaribus unifloris, caule procumbente sarmentoso. $\mathrm{Fl}$.dan. t. 1164 . (in ripa declivi Occae. Jun. Aug. Stephan,)

$$
\text { *** Fuliis ternatis. }
$$

8. P. norvegica: foliis ternatis, caule dichotomo, pedunculis axillaribus. $F l$. dan. $t_{0} 17 \mathbf{1}$. (in agris arenoso-glareosis Jul Aug)

9. P. ruthenica: foliis radicalibus subpinnatis, caulinis ternatis, foliolis ovatis profunde serratis, utrinque cauleque adpresso-pilosis, pedunculis alarıbus solitariis. Moris. hist. II. t. 20, f. 2 . (in arvis, ad sepes. Jul. Aug.)

132. Tormentilla. Calyx octofidus. Petala quaterna. Semina subrotunda nuda receptaculo parvo exsucco affixa.

1. T. erectu: [officinalis] caule erectiusculo, foliis sessilibus. Fl. dan. t. 589 (in pascuis, campis, versurisque sterilibus. Jun. Jul )

183. Geum. Calyx decemfidus. Petala quina. Semina arista geniculata.

2. G. urbanum: floribus erectis, aristis uncinatis nudis, foliis caulinis ternatis, radicalibus lyrato-pinnatis. Fl. dan. t 672. (in umbrosis et dumetis, ad sepes et domos. Jun.)

s. G. intermedium: floribus nutantibus, petalis longitudine calycis, aristis uncinatis nudis, seminibus pilosis, foliis radicalibus lyrato - pinnatis, caulinis ternatis, Petiv brit. t. 40. f. 2. (in ruderatis, umbrosis, sepibusque. Jun. Aug.) 


\section{$-91$}

3. G. rivale: floribus nutantibus, petalis longitudine calycis, aristis plumosis medio tortis, foliis radicalibus lyrato - pimnatis, caulinis simplicibus trifidis. Fl. dan. to 722 . (in pratis humidis, nemoribus. Jun.)

184. Conarum. Calyx decemfidus. Petala quina. Receptaculum seninum ovatum spongiosum persistens.

1. C. palustre: foliis pinnatis, petalis calyce minoribus. Fl, dan. t. 636. [(in pratis uliginosis. Jun. Aug.)

\section{P O L Y A N D R I A. M O N O G Y N I A.}

185. Actaed, Calyx tetraphyllus, Corolla tetrapetala. Bacca unilocularis. Semina semiorbiculata.

1. A. spicata: racemo ovato, petalis staminibus longioribus, fructibus baccatis. Fl. dan, t. 498. (in nemoribus montosis. Mai. Jun.)

136. Cienidonium. Calyx diphyllus. Petala quaterna. Siliqua supera bivalvis unilocularis. Semina plurima cristata.

3. C. majus: pedunculis umbellatis, foliorum pinnis sublobatis obtuse dentatis, ppetalis integerrimis. $\mathrm{Fl}$. dan. t. 542, (in ruderatis et hortis. Jun. Aug.)

2. C. laciniatum: [quercifolium] pedunculis umbellatis, foliorum pinnis pinnatifido-laciniatis 
acute dentatis, petalis incisis. Mill. dict. t. 92. (in ripa utraque Mosquae et Jausae amnis. Jul.) 187. Papaver. Calyx diphyllus Corolla tetrapetala. Capsula unilocularis, sub stigmate persistente poris dehiscens.

1. P. Rhoeas: capsulis glabris globosis, caule piloso multifloro, foliis pinnatifidis incisis. Engl. bot. t. 645. (inter segetes, in hortis. Jun. Jul.)

\&. P. somniferum: calycibus capsulisque glabris, foliis amplexicaulibus incisis glaucis. Blackw. . $_{\text {. }}$ 482. (in oleraceis, hortisque. Jun. Aug.)

b. Pajaver plenum: petalis numerosis omnium gradationum rubicundis albisque. Blackw. t. 483. (in hortis)

188. Nympilaea. Calyx tetra - pentaphyllusve. Corolla polypetala. Bacca multilocularis, loculis polyspermis.

1. N. lutea: foliis cordatis integerrimis, lobis approximatis, calyce pentaphyllo petalis longiore. $F l$. dan. t. 603. (in stagnis, fluviis, la. cubus. Jul. Aug.)

2. N. alba: [Casialia speciosa] foliis cordatis integerrimis, lobis imbricatis rotundis, calyce tetraphyllo. $F l$. dan. t. 602. (in aquis stagnantibus. Jun. Aug )

189. Tilia. Calyx quinquepartitus. Corolla pentapetala. Capsula coriacea evalvis quinquelocularis, loculis quaternis abortientibus, monosperma. 1. T. microphylla: [parvifolia] foliis cordatosubrotundis acuminatis argute serratis, nuce 
subglobosa vix costata fragili. $F l$. dan. t. $55 j$ i (in sylvis, nemoribusque. Jul)

2. T. platyphylla: [grandifolia] foliis cordatosubrotundis acuminatis inaequaliter serratis, nuce turbinata costata lignosa. Schkuhr. t. 141 . (ad pagos, in hortis. Jun.)

\section{T R I G Y N I A.}

290. Delphinitur. Calyx corollinus submonophyllus quinquepartitus, lacinia superiore calcarata. Petalum unicum seu duo, nectario calcarato terminatum. Capsulae tres seu una.

1. D. Consolida: germine glabro solitario, calcare calycem excedente, caule ramoso, foliis linearibus multipartitis. $\mathrm{Fl}$. dan. t. 683. (in agris arvisque restibilibus Jul. Aug.)

£. D. elatum: nectariis diphyllis, labellis ovatis emarginatis, laciniis brevissimis inaequalibus, foliis subpeltatis tripartitis, laciniis multifidis. Mil. ic. t. 250. f. 2. (circa monasterium St. Simeonis Adam; et in campis trans pontem Dragomilovensem. Jun. Henning.)

191. Aconitum. Calyx corollinus pentaphyllus, foliolo superiori concavo galeato. Petala bina superiora ungue longissimo incurvo canaliculato nectariis calcaratis terminato, inferiora linearia. Capsulae ternae seu quinae erectae.

2. A. Lycoctonum: cuculli calcare spirali, labio emarginato ovato, calycis galea conica elongata, foliis palmatis pubescontibus, laciniis tri- 


\section{$-\quad 94$}

* fidis dentatis. Jasqu, austr. t. 380. (in sylvis montosis. Jul. Aug.)

2. A. septentrionale: cuculli calcare revoluto, labio subemarginato spathulato, calycis galea conica elongata, foliis palmatis pubescentibus, laciniis trifidis divaricatis dentatis. $F l$. dan. t. 123. (in nemorosis umbrosis. Jul.)

\section{P E N T A G Y N I A.}

192. Apurlegia. Calyx nullus. Corolla pentapetala. Nectaria quina, foliolis calcaratis, inter petala. Capsulae quinae distinctae.

1. A. vulgaris: nectariis incurvis corollam subaequantibus, foliis ternatis, foliolis tripartitis subrotundis crenatis. Fl. dan, t. 695. (in nemoribus hortisque. Jun.)

Variat corollis caeruleis rubris, albisque, nec non floribus plenis.

\section{P O L Y G Y I A.}

193. Pursatilixa, Calyx nullus. Corolla hexapetala. Semina plura caudata, cauda plumosa.

1. P. vulgaris: [Anemone Pulsatilla] scapo involucrato unifloro, petalis rectis, nectariis pedicellatis, folis bipinnatis incisis. $F l$. dar. t. 153. (in collibus apricis, montibus passerinis. Nai.) \&. P. pratensis: scapo involucrato unifloro villosissimo, petalis apice reflexis, nectariis pedicellatis, foliis bipinnatis incisis. Fl. dan. t. 611. (in campis apricis umbrosis circa Kupawna, Mai.) 


\section{$-95-$}

294. Anemone. Calyx nullus. Corolla penta. usque enneapetala. Seminá plura caudata.

2. A. sylvestris: caule bifloro folioso, foliis tripartitis, laciniis trifidis dentatis, seminibus sub. rotundis lanatis, stigmate persistente. Kniph. cent. V.n. 12. (in sylvaticis montosis circa equariam Pachrinae. IMai)

2. A. nemorosa: caule unifloro, 'foliis caulinis ternis ternatis, foliolis lanceolatis trifido-den-' tatis, corolla hexapetala. Fl. dan, t. 549. (in nemoribus, dumetis, pratisque aquosis. Mai.)

b. Anemone violacea: corollis violaceo-lilacinis. (cum praecedente.)

3. A. ranunculoides: caule subbifloro, foliis caulinis ternis ternatis, foliolis subtrifidis apice dentatis, petalis oblongis obtusis patentibus. $F l$ dan. t. 140. (in nemorosis, dumetis. Mai)

195. Thalictruns. Calyx nullus. Petala quaterna vel quina. Semina ecaudata.

2. T. minus: foliolis subrotundis trifidis incisis, floribus cernuis. Fl. dan. t. 732 . (in pratis, collibusque herbidic, rarius Jul.)

2. $T$. angustifolium : foliolis lanceolato-linearibus integerrimis. Pluk. almag. t 65. f. 6. (in pratis humidis, sylvarumque marginibus. Jun. Jul.)

3. T. flavum: caule folioso sulcato, panicula multiplici erecta $\mathrm{Fl}$ dan. t. 939. (in pratis, nemoribusque subhumidis. Jul. Aug.)

4. T. aquilegifolium: fructibus pendulis triangularibus rectis, caule tereti. Jacqu, austr, $t, 5\llcorner 8$. (in pratis et umbrosis. Jul.) 


\section{$-9^{6}$}

196. Ficaria. Calyx triphyllus. Petala octona vel novena, ungue nectarifero. Semina compressa obtusa nuda.

2. F. verna: [Ranunculus-Ficaria] radice tuberibus fasciculata, caule decumbente, foliis cordatis angulatis petiolatis. $F l$. dan. t. 499. (in dumetis umbrosis, udisque. Mai.)

197. Ranunculus. Calyx pentaphyllus, Petala quina, intra unguem poro mellifero. Semina nuda. * Foliis simplicibus.

1. R. Flammula: foliis ovato-lanceolatis obtusiusculis pctiolatis, caule declinato. Fl. dan. t. 575. (in pascuis udis, ad margines lacuum fossarumque. Jul. Sept.)

2. R. Lingua: foliis lanceolatis acuminatis, caule erecto multifloro. $\mathrm{Fl}$. dan. t. 755 ) in fossis, lacubus et paludibus. Jul. Aug.)

* Foliis dissectis et divisis.

3. $R$. cassubicus: foliis radicalibus subrotundo-: cordatis crenatis, caulinis digitatis dentatis, caule multifloro, Loesel. priss. t. 72. (in nemoribus et sylvis, in Petrowsk, Astankina, SwirJowa, sylva St. Mariae, et alibi. Mai.)

4. R. auricomus: foliis rarlicalibus reniformibus crenatis incisis, caulinis digitatis linearibus, caule multifloro. $F l$. dan.t. 665 . (in nemoribus, pascuisque humidis. Mai.)

5. R. sceleratus: foliis inferioribus palmatis, superioribus digitatis, floralibus lanceolatis petiolatis, fructibus oblongis. $F l$. dan, t. 57r. (in 


\section{$-97-$}

paludibus, fossis, locis inundatis vadosis. Jul. Aug.)

6. R. aconitifulius: foliis quinquelobis dentatis, lobis acuminatis, intermediis trifidis, floralibus summis digitatis sessilibus lanceolatis. Curt. mag. t. 204. (in montibus passerinis, monticulisque ad Kunzowa. Jun.)

7. R. bulbosus: calycibus retroflexis, pedunculis sulcatis, caule erecto multifloro, foliis compositis, radice bulbosa. $\mathrm{Fl}$. dan. t. 551. (in pascuis, pratis, hortisque. IMai. Jun.)

b. Ranunculus campestris: bulbo radicalicarente. (in campis.)

8. R. hirsutus: [Philonotis] foliis ternatis, superioribus trifidis linearibus, caule erecto multifloro hirsuto, calycibus acuminatis demum retroflexis, radice fibrosa. Fl. Lond. n. 15. (in locis udis prope Astankina, in sylva St. Mariae et Sokolnika. Jun. Jul.)

9. R. repens: calycibus patulis, pedunculis sulcatis, sarmentis repentibus, foliis compositis. Fl. dlan. t. 795. (in pascuis, agris, cultis, hortisque. Jun. Aug.)

10. R. acris: calycibus patulis, pedunculis teretibus, foliis tripartito-multifidis, summis linearibus. Engl. bot. t. 652. (in pratis et pascuis. Jun. Jul.)

b. Ranunculus hortensis: corolla saturate citrina, flore pleno. (in hortis.)

11. R. lanuginosus: calycibus patulis, pedunculis teretibus, caule petiolisque hirsutis, foliis 


\section{$-98$}

trifidis lobatis crenatis holosericeis. $F l$, dan. $\varepsilon$. 397. (in nemorosis, ad Perowa et Kunzowa. Jul. Aug.)

22. R. polyanthemos: calycibus patulis hirsutis, pedunculis sulcatis, foliis semiseptemlobis, laciniis tridentatis acutis, radice fibrosa. Steph. ic. pl. MII. t. 29. (in pratis, versuris, campisque herbidis. Jun. Jul.)

13. $R$. arvensis: foliis trifido-decompositis, laciniis linearibus, seminibus aculeatis. Fl. dan. t. 219. (inter segetes et in agris, in hortis, cul(isque. Jun. Aug.)

24. R. aquatilis: foliis submersis capillaceis, emersis subpeltatis. Engl. bot.t. 101. (in aquis segnibus, fossisque. Jul. Aug.)

15. R. fluviatilis: foliis omnibus dichotomo-capillaceis, caule dichotomo. Fl. dan. t. 376. (in fluviis et rivulis. Jul. Aug.)

198. Troucius. Calyx nullus. Petala decem usque quatuordecim. Nectarium : corona polyphylla, foliolis linearibus. Capsulae "plurimae ovatae polyspermae.

3. T. europaeus: corollis conniventibus, nectariis staminum longitudine. $F l$. dan. t. 133. (in prais herbidis subhumidis et in nemorosis. Mai.)

199. Caltra. Calyx nullus. Petala quina. Nestarium nullum. Capsulae plures polyspermae.

2. C. palustris: foliis cordato-reniformibus, caule erecto. $F l$. dan. t. 668. (in pratis humentibus et paludosis. Mai. Jun.) 


\section{$-\quad 99$ \\ D I D Y N A IM I A. GY INOS PERMTA.}

200. Ajuga. Calyx quinquefidus, Corollae labium superius minimum bidentatum. Stamina labio superiore longiora.

x. A. pyramidalis: tetragono-pyramidalis villosa, foliis radicalibus maximis. Engl. bot. t. 1270' (ad margines sylvarum. Jul. Aug.)

b. Ajuga alba: corollis candidis. (in monticulis. Jun. Jul.)

2. A. lanata: [genevensis] foliis radicalibus caulinis minoribus. Bull, herb. t, 361 . (in pratis, collibusque nemorosis. Jun. Jul.)

3. A. reptans: glabra, stulonibus, reptantibus Fl. dan.t 925. (in nemoribus, pratisque. humimidiusculis. Jun. Jul.)

b. Ajuga carnea: corollis carneis. (in umbrosis, ad sepes.)

201. Nepeta. Calyx inaequaliter quinquedentatus. Corollae labium inferius lacinula intermedia crenata, faux margine reflexa. Stanina approximata.

2. N. Cataria: floribus spicatis, verticillis subpedicellatis, foliis petiolatıs cordatis dentato. serratis. Fl. dan.t. 580. (in ruderatis prope Slobodam Germanorum, nec non in vallo arcem (Kreml) cingente. Jul. Aug.)

b. Catarin suaveolens: odorata. (variat in hortis, Jul. Aug.) 
202. Mentia. Calyx quinquedentatus. Corolla subaequalis quadrifida, lacinia latiore emarginata. Stamina erecta distantia.

1. M. sylvestris: spicis cylindraceis basi interruptis, foliis ovato-oblongis subsessilibus argute inaequaliter serratis canescentibus subtus tomentosis, calycibus pedunculisque hirsutis. $F$. dan. t. 484. (in ruderatis humidiusculis, collibus sylvaticis circa Pachrina. Aug.)

2. M. viridis: spicis cylindraceis interruptis, foliis lanceolatis subsessilibus basi cuneatis argute serratis utrinque glabris, calycis dentibus subhirsutis. Sole monogr. t. 5. (in fossis et paJudibus. Jul. Aug.)

3. M. aquatica: spicis capitatis subinterruptis, foliis ovatis serratis petiolatis subtus pubescentibus, calycibus hirsutis, pilis pedunculorum reflexis. Sole monogr. t. 10.11. (in aquosis. Jul. Aug.)

4. M. arvensis: floribus verticillatis, foliis ovatis petiolatis serratis hirtis, calycibus pedunculisque hirsutis, caule ramosissino. Fl. dan. t.512. (in agris subhumentibus messe finita, nec non ad fossarum margines. Aug. Sept.)

5. M. austriaca: floribus verticillatis, foliis ovatis petiolatis serratis hirtis, calycibus hirsutis, pedunculis glabris, caule erecto. Jacqu. austr. V. t. 430. (in udis et fossis frequentissime. Jul.Aug.) 203. Gricroma. Calyx quinquefidus. Corolla ringens. Antherarum singulum par in formam crucis connivens. 


\section{$-101$}

1. G. hederacea: glabra, foliis reniformibus cre. natis, calycinis laciniis ovatis acutis, $F l$, dan. t. 789. (in hortis, cultis, pratis, sepibus, dumetis, fructicetis. Mai.Jun.)

b. Glechoma grandiflora: corollis calyce duplo longioribus. (in hortis, ad vias. Jun.)

204. Lamivm. Calyx quinquedentatus. Corollae labium superius integrum fornicatum, labium inferius bilobum, faux inflata utrinque margine dentata.

1. L. maculatum: foliis cordatis acuminatis serratis petiolatis, junioribus maculatis, petiolis aequalibus, verticillis decemfloris, labio superiori acuto denticulato. Hayne et Drewes. t. 8. (in nemorosis, ad sepes, in hortis. Mai. Jul.)

s. L. album: foliis cordatis acuminatis serratis petiolatis, petiolis dilatatis, verticillis vigintifloris, labio superiore obtuso integerrimo. $F l$. Lond. t. 20. (in cultis et ruderatis. Jun. Jul.:

b. Lamium carneum: floribus carneis. (cum praecedente.)

3. L. purpureum: foliis cordatis obtusis crenatis petiolatis, superioribus confertis. Fl. dan. t. 523. (in cultis, hortis, ad sepes. Mai. Jun.)

4. L. amplexicaule: [Pollichia amplexicaulis] foliis subrotundis obtusis crenatis, floralibus sessilibus amplexicaulibus. Fl. dan. t. 752. (in cultis, agris, pomariis, hortis. Jun. Jul.)

205. Galeopsis. Calyx quinquedentatus. Corollae labium superius subcrenatum fornicatum, la. bium inferius supra bidentatum. 
1. G. latifolia: [Ladanum] foliis ovato-lanceos latis aequaliter dentato - serratis, calycibus hirsutis, dentibus rectis inaequalibus: ternis calyce brevioribus. Schkuhr. t, 160. (in arvis et agris. Jul. Sept.)

2. G, angustifolia: foliis lineari-lanceolatis denticulatis, calycibus villosis: pilis adpressis, dentibus inaequalibus: ternis longitudine calycis. Eirh. heib. n. 137. (in agris, hortisque. Jul. Sept.)

3. G. Tetrahit: internodiis caulinis superne incrassatis, verticillis summis subcontiguis, calycibus pungentibus, corollis calyce parum longioribus, caule hirto. Engl. bot. t. 207. (in arvis, ad sepes, inter segetes. Jun. Aug.)!

4. G. versicolor: [cannabina] internodiis caulinis superne incrassatis, verticillis summis subcontiguis, calycibus pungentibus, corollis calyco quadruplo longioribus, galea ventricosa, caule hirto. $F l$. dan. t. 929. (inter segetes et in nemorosis, dumetis, sepibus. Jul. Aug.)

206. Galeordolon: Calyx quinquefidus inaequalis aristatus, Corollae labium superius integerrimum fornicatum, inferius trifidum, laciniis omnibus acutis.

1. G. luteum: [Galcopsis Galeobdolon] foliis omnibus ovatis, involucro tetraphyllo. Fl. Lond. t. 40. (in nemorosis et sylvaticis umbrosis. Jun. Jul.) 


\section{$-103$}

207. Beronica, Calyx quinquedentatus aristatus. Corollae labium superius adscendens planius. culum, tubus cylindricus.

1. B. officinalis: spica interrupta, corollae galea integra, lacinia media labii inferioris emarginata, caly cibus glabriusculis. Fl. dan.t. 726 . (in nemoribus et pratis. Jun. Jul.)

b. Betonica alba: corollis albis. (in Astanlina et Petrowsk. Juí.)

208. Stacirys. Calyx quinquefidus. Corollae labium superius fornicatum, labium inferius lateri. bus reflexum, lacinia intermedia majore emarginata. Stamina deflorata versus latus reflexa.

1. S. sylvatica: verticillis sexfloris, foliis rugosis cordatis petiolatis. Fl dan. t. 1202 . (in nemoribus umbrosis. Jul. Aug.)

2. S. palustris: verticillis sexfloris, foliis linearilanceolatis semiamplexicaulibus sessilibus. $F l$. dan. t. 1103. (in humidis rivulis et ripis, nec non in cultis humidiusculis. Jul.)

3. S. annua: verticillis sexfloris, foliis ovatolanceolatis trinervibus laevibus petiolatis, caule erecto. Jacqu. austr, t. 360 . (in siccis, agris, glareosis. Jun. Jul.)

209. Lennurs. Calyx quinquedentatus. Corollae lobium superius planum integrum, inferius tsipartitum, lacinia media indivisa.

1. L. Cardiaca: foliis cuneiformi-ovatis trilobis dentatis, corollis calyce pungente majoribus, lacinia media labii inferioris acuta. $F l_{\text {, dan, t. }}$ 727. (in ruderatis et hortis. Jul. Aug.) 
2xo. Phronis. Calyx angulatus. Corollae labium superius incumbens compressum villosum.

1. P. tuberosa: foliis radicalibus cordatis scabris, floralibus oblongo - lanceolatis, bracteis subula. tis hispidis, caule glabro. Buxb. cent. I. t. 6. (in ripa Occae. Jul. Stephan.)

21. Curnopodrunr. Involucrum multisetum, verticillo subjectum. Calyx bilabiatus. Corollae labium superius planum obcordatum rectum.

1. C. vulgare: capitulis verticillatis, bracteis setaceis hispidis, foliis superne pilosis remote dentatis, caule subsimplici Fl.dan. t. 230. (in ruderatis, dumetis, nemoribus. Jul.)

b. Clinopodium variegatum: foliis variegatis minoribus subintegerrimis, corollis niveis. (cum priore, rarius.)

212. Origanumi. Spica tetragona. Corollae labium superius erectum planum, inferius tripartitum, laciniis aequalibus.

1. O. vulgare: spicis longis pedunculatis aggregatis, bracteis longitudine calycum, Engl. bot. t. 2143. (in nemoribus montosis, umbrosis. Jul. Aug.)

b. Origanum humile: [album] panicula densa coarctata, spiculis oblongis, corollis albis. (cum antecedente, rarius.)

223. Trymus. Calycis bilabiati faux villis clausa. Corollae labium superius emarginatum.

1. T. Serpyllum: floribus capitatis, caulibus repentibus, foliis planis obtusis basi ciliatis. $\mathrm{Fl}$. dan. t. 2365. (in collibus apricis arenosis, ver- 
sus monasterium St. Simeonis, in sylva St. Annae, nec non in Petrowsli. Jul. Aug.)

214. Acrnos. Calyx bilabiatus sulcatus pilosohispidus, basi gibbus, fauce villosus. Corolla ringens, fauce subinfata: labio superiore erecto emarginato, inferiore tripartito patente: lacinia intermedia concava. Stamina omnia fertilia.

1. A. vulgaris: ['Thymus Acynos] caule erecto basi ramoso, foliis ovatis acutis antice serratis, verticillis sexfloris. Engl. bot. t. 411 . (in campis siccis glareosis. Jul. Aug.)

215. Dieacocepinalum. Calyx quinquedentatus vel bilabiatus. Corollae faux inflata, labium superius concavum.

1. D. hyssopifolium: [Ruyschiana] floribus spicatis, foliis bracteisque lanceolatis indivisis muticis. Moris. hist. III. t 5. f. 9. (inter frutices, inque umbrosis humidis. Jun.)

2. D. nutans: floribus verticillatis, bracteis oblongis ovatis integerrimis, corollis calyce duplo longioribus nutantibus. Gmel. fl. sib. IIl. t. 49 . in arvis et pratis, tribus montibus. Jun. Jul.) 3. D. thymiflorum: floribus verticillatis, brateis oblongis integerrimis, corollis vix calyce majoribus, $\mathrm{Gmcl}$. fl. sib. III. t. 5o. (in aggeribus, siccisque, in vallo urbano magno, sicut et in vallo arcis (Freml) Ju 1.)

216. Scutrelcaria. Calyx ore integro, post florescentiam clauso; operculato. Corollae faux trigono - compressa.

1. S. galericulata: foliis cordato-lanceolatis crenatis, floribus axillaribus, $F l$. dan. t. 637. (in 
pratis humidis umbrosis, ad fossas, rivulos et lacuum ripas. Jul. Aug.)

217. Prunella. Calyx bilabiatus. Filamenta bifurca, altero apice antherifero. Stigma bifidum.

ג. P. vulgaris: calycis labio superiore truncato triaristato, corollis calyce duplo majoribus. $\mathrm{Fl}$. dan. t. 910. (in pratis, pascuis, sepibus, sylvis, viis, hortisque. Jun. Aug.)

2. P. grandiflora: calycis labio superiore trifidn, corollis calyce quadruplo majoribus. Schkuhr.

t. 168. (in collibus herbidis. Jul. Aug.)

b. Prunclla alba: floribus albis. (in nemoribus ad Podolsk, nec non in Zarizina,)

\section{A N G I O S P E R M I A.}

218. Rirnanturus. Calyz quarlrifidus ventricosus. Capsula bilocularis obtusa compressa.

1. R. major: [Crista galli] caule glabro ramoso maculato, calyce glabro, corollae labio superiore compresso apice bidentato: dentibus pistilloque exserto violaceo-caloratis. Ehrh. herb. n. 56. (in pascuis, pratisque humidis. Jun.Jul.)

2. R. minor: caule glabro inmaculato, calyce glabro, corollae labio superiore compresso breviore pistilloque incluso unicoloribus. Ehrh. herb. n. 46. (in pratis et pascuis. Jun. Jul.)

3. R. villosus: [Alectorolophus] caule calyceque villoso, corollae labio superiore compresso breviore, pistillo exserto. Bull. herb. t. 185. (inter segetes et in agris. Jul.)

219. M.etampsrum. Calyx quadrifidus. Corollae labium superius çompressum, margine replicato. 
Capsula bilocularis obliqua hinc dehiscens. Semina bina gibba.

2. M. cristatum: spicis quadrangularibus, bracteis coloratis cordatis imbricatis compactis den. ticulatis. Fl.sclan. t. 1104. (in sylvis, nemoribus et pratis, Jin. Jul.)

2. HI. arvense: spicis conicis laxis, bracteis coloe ratis lanceolatis pinnato-dentatis. Fl. dan. t. 911. (inter segetes. Jun. Jul.)

3.- $M$. nemorosum: floribus secundis lateralibus, bracteis cordato-lanceolatis dentatis, summis sterilibus coloratis, calycibus lanatis. Fl. dan. t. 305. (in nemoribus. Jun. Jul)

4. M. pratense: floribus secundis lateralibus remotis, foliis lanceolatis, floralibus hastatis, corollis clausis. Engl. bot. t. 113. (in nemorosis et dumetis, Jul.)

5. M. sylvaticum: floribus secundis lateralibus remotis, foliis omnibus lanceolatis, corollis hiantibus. Fl, dan. t. 14,5. (in nemorosis et sylvaticis. Jun.)

280. Eupma sia. Caly quadrificus cylindricus. Antherae inferiores altero lobo basi spinosae. Capsula bilocularis ovato - oblonga.

1. E. officinalis: foliis ovatis obtuse dentatis, laciniis labii corollae inferioris emarginatis. $F l$. dan. t. 1037. (in pratis et pascuis aridis, cam. pis herbidis, versuris. Jul. Aug.)

2. E. nemorosa: [sylvestris] caule elongato ramosissimo, foliis glabris subnitidis ovatis argute 
serratis. Bull. herb. t. 233 . (in sylvis, nemoribus, pratisque. Jun. Aug.)

b. Euphrasia gigantea: caule simplicissimo ultrapedali. (in sylvaticis.)

221. Odontrtes, Corollae galea recta antheras includens, labium inferius trifidum: laciniis linearibus. Antherarum lobi omnes spinosi. Capsula ovata, immarginata.

2. O. rubra: [Euphrasic Odontites] caule ramosissimo piloso-scabro, foliis lineari-lanceolatis serratis, floribus secundis. Fl. dan. t. 625. (in arvis, agris, pascuis, pratisque. Jul. Aug.) 222. Pedicularis. Calyx quinquefidus. Capsula bilocularis mucronata obliqua. Semina tunicata.

2. P. palustris: caule ramoso, foliis pinnatis, pinnis pinnatifido-dentatis, calycibus inflatis bipartitis cristatis, corollae galea ohtusa truncata. Engl. bot. t. 399. (in paludibus, uliginibus. Jul. Aug.)

2. P. Sceptrum Carolinum: caule simplici, foliis pinnatifidis, pinnis repandis crenulatis, calycibus quinquefidis cristatis, corollis clausis. $F l$. clan. t. 26. (in pratis paludosis umbrosis, in Perowa. Jun.)

3. P. comosa: caule simplici, foliis pinnatis, pinnis pinnatifidis subdentatis, spica foliosa, calycibus quinquefidis, corollae galea bidentata. Steph. monogr. ic. (in pratis et pascuis, in montibus passerinis, ad amnem Mosquae Jausaeque, in vallo urbano magno, Petrowsk, Tiuskowa, etc. Jun.) 
283. Linaria. Calyx quinquepartitus. Corolla personata calcarata, palato bipartito. Capsula ovata Bilocularis apice multivalvis polysperma.

1. L. minor: [Antirrhinum minus] foliis linearilanceolatis obtusis cauleque ramoso diffuso glanduloso-pilosis, pedunculis axillaribus calyce multoties longioribus. Fl, dan.t. 502. (in arvis et ruderatis sabulosis et glareosis, in vallo urbano magno. Jul. Aug.)

2. L. vulgaris: [Antirrhinum Linaria] foliis lanceolato-linearibus confertis glabris, caule erecto spicato, spicis terminalibus sessilibus, floribus imbricatis, calycibus glabris calcari brevioriljus. Fl. dan. t. 98z. (in sepibus, aggeribus, versuris, viis, campis herbidis, nemoribus. Jun. Aug.)

b. Antirrhinum Peloria: corolla regulari quinqquefida, Engl. bot. t. 260, (in hortis. Jul. Aug.)

22年. Scrophularia. Calyx quinquefidus. Corolla subglobosa resupinata. Capsula bilocularis.

1. S. nodosa: foliis cordatis serratis glabris subtrinerviis, caule acutangulo. Fl. dan. t. 1167 . (in sepibus et dumetis succulentis. Jun. Aug.)

2. S. aquatica: foliis cordatis serratis petiolatis decurrentibus, caule mernbranis angulato, racernis terminalibus. Fl.dan. t.507. (in humidis, ad fossas. Jun. Aug.)

225. Linnaea. Calyx superus duplex: fructus tetraphyllus, floris quinquepartitus. Corolla campanulita. Bacca sicca trilocularis. 
1. L. bnrealis: floribus geminatis. Fl, dan. t. 3 . (in sylvis, Gorenki et Archangelsk. Jun. Jul ) 226. Limoserca. Calyx quinquefidus, Corolla campanulata quinquefida aequalis. Capsula unilocularis bivalvis polysperma.

1. L. aquatica: foliis lanceolato-spathulatis, scapis foliis brevioribus. Fl. dan, t, 69. (in inundatis et lacunis. Jul. Sept.)

b. Limosella tenuifolia: foliis linearibus an. gustissimis vix apice dilatatis, scapis foliis aequalibus. (cum praecedente.)

c. Limosella diandra: [silesiaca] staminibus duobus. Frock. siles. t. 27. f. B. (cum antecedente passim.)

227. I.atiraxa. Calyx quadrifidus. Glandula depressa ad basin suturae germinis, Capsula unilocularis, receptaculo fungoso.

1. I. Squamaria: caule simplicissimo multifloro, floribus pendulis, labio inferiore trifido. $F l$. dan.t. 136. (in nemoribus, sylvisque umbrosis, ad radices Coryli. IVIai.)

2.28. Ововалсне. Calyx diphyllus, foliolis bipartitis lubatis lateralibus. Corolla ringens, laciniis subaequalibus. Glandula sub basi germinis. Capsula unilocularis bivalvis polysperma.

1. O. caryophyllacea: caule simplici, calycis foliolis bipartitis, corolla tubulosa, labii inferioris laciniis obtusis, limbo fimbriato - crispo, starninibus intus hirsutis, stylo glabriusculo. Sabbat. hort. III. t. 11, (in nemoribus circa Kuskowa, Jun.) 


\section{$-111$ \\ TETRADYNA MIA. S I L I C U I O S A.}

229. Mrachum. Silicula subglobosa evalvis: immatura bilocularis, matura unilocularis monosperma.

1. II. paniculatum: caule erecto, foliis lanceolatis subdentatis sagittatis amplexicaulibus, staminibus simplicibus, siliculis subrotundo - globosis reticulato-rugosis. Fl. dan. t. 204. (juxta agros, interque segetes, in vallo circa murum album [Fitaigorod] Jun. Jul.)

230. Bunras. Silicula subtetraëdra evalvis biseu quadrilocularis rugosa.

1. B. orientalis: siliculis ovatis gibbis verrucosis, foliis inferioribus runcinato-Jyratis, superioribus lanceolatis. Gmel. fl. sib. III, t. 57. (in pratis, campis, agrorum versuris. Jun. Jul.)

231. Draba. Silicula integra ovali-oblonga, valvulis planiusculis dissepimento parallelis. Stylus nullus.

2. D. verna: foliis oblongis acutiusculis subserratis subhirtis, scapo nudo, petalis bifidis, stigmate sessili. Fl. dan. t. 983. (in agris, arvis, collibus, aridis. Mai.)

2. D. muralis : caule ramoso, folis ovatis amplexicaulibus dentatis hirtis, siliculis patentibus glabris. Engl. bot. t. 912. (in ruderatis, collibus, muris. Jun. Jul.)

b. Draba intermedia: caule ramoso, ramis longissinis, foliis maximis grosse dentatis hir- 
tis, siliculis patentibus glabris. (in ruderatis, sterilioribus.)

3. D. nemoralis: caule ramoso, foliis ovatis amplexicaulibus dentatis, siliculis patentibus pubescentibus. Houttuyn. syst. IV. t. 6o. f. 1. (in nemoribus, pascuis, arvis, solo glareoso. Jun. Aug. Londes.)

232. Lepidrum. Silicula emarginata cordata po. lysperma, valvulis carinatis dissepimento contrariis.

1. L. sativum: floribus tetrarlynamis, foliis oblongis multifidis. Blackw. t. 23. (in agris et cultis. Jun, Jul.)

\&. L. ruderale: floribus diandris apetalis, foliis racícalibus dentato - pinnatis, ramiferis linearibus integerrimis. Fl. dan. t. 184. (in ruderatis, agrisque limosis, ad vias. Mai. Aug.)

233. Tiraspr. Silicula emarginata obcordata polysperma, valvulis navicularibus marginato-carinatis.

1. T. arvense: siliculis orbiculatis compressis lacvibus, foliis oblongis dentatis glabris. $F l$. dan. t. 793. (in agris, cultis, hortis. Jun.)

2. T. campestre: siliculis subrotunđis glandulosopunctatis, foliis sagittatis subdentatis incanis. Fl. dan. t. 1£21. (in arvis, campisque editioribus apricis et montosis, ad vias, solo argilJoso. Mai. Jun.)

3. T. Bursa pastoris: siliculis deltoideo-obcordatis, foliis radicalibus lyrato-pinnatifidis hirsutis. Fl. dan. t. 729 . (in hortis, cultis, agris, ruderatis. Mai. Sept.) 
b. Thlaspi simplicifolium: foliis indivisis. Bauh. pin. 108. (cum praecedente.)

234. Iberis. Corolla irregularis, petalis binis exterioribus majoribus. Silicula polysperma emarginata.

1. I. nucticaulis: herbacea, foliis radicalibus lyrato-pinnatifidis, caule centrali nudo simplici, filamentis basi appendiculatis. Engl. bot, t. 327 . (in agris, arvisque arenosis sterilissimis, atque in campis editioribus. Mai. Jun.)

23.5. Alyssunr. Silicula subintegra ovata bilocularis bivalvis, loculis polyspermis, valvulis concavis dissepimento parallelis, stylo coronata.

1. A. incanum: caule erecto, foliis lanceolatis incanis integerrimis, floribus corymbosis, petalis bifidis calyce duplo longioribus. Schkuhr. t. 181. (in apricis siccis, ad sepes et vias. Jun. Aug.)

2. A. calycinum: caule herbaceo, foliis spathulatis stellato - pubescentibus, floribus corymbosis, petalis integris calycem subaequantibus, filamentis brevioribus basi appendiculatis. Jacqu. austr. t. 338. (in campis aridis, montosis. Jun. Jul. Stephan.)

3. A. sativum: [Myagrum sativum] caule erecto, foliis amplexicaulibus pilosis integerrimis', petalis integris, staminibus simplicibus, siliculis obovatis inflatis. Fl. dan. t. 1038. (inter segetes [Linum praesertim] et in hortis. Jun. Jul.) 


\section{$-114$}

236. Lunaria. Silicula elliptica compresso-plasa pedicellata, valvulis dissepimento aequalibus $\mathrm{pa}$ xallelis planis. Calyx foliolis saccatis.

z. L. rediviva: foliis cordatis mucronato-dentatis, siliculis utrinque attenuatis. Lam.ill.t. 562 . (in montibus passerinis et Kunzowa, Jun.)

\section{S I L I Q UOSA.}

257. Cardamine. Calyx subhians. Stigma in. regrum. Siliqua elastice dissiliens, valvulis revolutis.

3. C. impatiens: foliis pinnatis, foliolis lanceolatis incisis, stipulis ciliatis, petalis quaternis cito percuntibus, caule simplici, Engl. bos. t. 80. (in montibus passerinis, Archangelsk et Kunzowa. Jun.)

2. C. hirsuta: [parviflora] foliis pinnatis exstipulatis: foliolis rotundatis repando-dentatis petiolatis, summis oblongis incisis petiolatis, flosibus tetrandris. Fl. dan. t. 735. (in Gorenki. Jun.)

3. C. sylvatica: foliis exstipulatis pinnatis: $f_{0}-$ liolis petiolatis oblongis lanceolatisque incisodentatis: extimo ovali, floribus tetradynamis. Fl. dan. t. 148. (in Kunzowa, montibusque pass( rinis. Jul)

4. C. pratensis: foliis pinnatis, foliolis radicalibus sublyrato - rotundatis dentatis, caulinis lanceolatis. Fl.dan.t. 1039. (in pratis et pascuis aquosis. MIai. Jun.) 
5. C. amara: foliis pinnatis, foliolis inferioribus elliptico-oblongis repandis dentatis, caule basi stolonifero radicante. Engl. bot. t. 1000. (in nemoribus humidis, ad montium passerinorum radicen, in Gorenki, Petrowsk, Archangelsk. MTai )

238. Sismibrium. Calyx patens. Corolla pa. tens. Siliqua dehiscens valvulis rectiusculis.

1. S. Nasturtium: siliquis declinatis, foliis pinnatis, foliolis cordato - subrotundis dentatorepandis glabris, caule basi radicante. $\mathrm{Fl}$. dan. t. 69o. (ad scaturigines, rivulosque puriores. Jun. Jul.)

2. S. sylvestre: siliquis declinatis, foliis pinnatis, foliolis elliptico-lanceolatis inciso-serratis, $\mathbf{F l}$. dan. t. 931. (in pascuis humidis, ruderatis, ad ripas fluviorum. Jun. Aug.)

3. S. palustre: siliquis declinatis oblongo ovatis, foliis pinnatifidis serratis, petalis calyce brevioribus, $\mathrm{Fl}$. dan. t. 409. (in locis udis. paludibusque. Jun. Jul.)

4. S. amphibium: siliquis declinatis oblongoovatis, foliis oblongo-lanceolatis pinnatifidisque serratis, petalis calyce longioribus. $F l$. dan t. 984. (ad ripas fluviorum, fossarumque margines. Jul. Aug.)

5. S. Sophia: foliis decompositis, laciniis sublinearibus glaucis pilosis, petalis calyce minoribus. $F l$. dan. t. 528. (in ruderatis, pagis, muris, viisque limosis. IIai, Aug.) 


\section{$-116$}

6. S. Loeselii: foliis runcinatis acutis hirtis, caule retrorsum hispido, Jacqu. austr. $t_{\text {. }}$ 324. (in cultis et ruderatis. Jun.)

239. Erysinum. Calyx clausus. Siliqua columnaris exacte tetraëdra.

1. E. officinale: siliquis spicae adpressis, foliis lyrato-runcinatis, Fl. clan. t. 560. (in ruderatis, ad vias. Jun. Aug.)

2. E. Barbarea: foliis inferioribus lyratis, lobo terminali rotundato, superioribus obovatis dentatis. Engl. but. t, 443. (in nemorosis, pratis humidis, ad ripas et fossas. Mai.)

3. E. Alliaria: foliis cordatis dentatis Fl.dan.t. 934. (in sepibus, dumetis, cultis, hortis. Jun. Aug.) 4. E. cheiranthoides: foliis lanceolatis obsolete denticulatis, siliquis patulis stylo obtusiusculo terminatis. $\mathrm{Fl}$. dan. t. 731 . et 923 . (in sepibus, dumetis, arvisque. Jun. Jul.)

840. Ававгs. Glandulae nectariferae quaternae, singulae inter calycis foliola, squamae instar reflexae.

1. A. thaliana: foliis radicalibus oblongis petiolatis, caulinis lanceolatis sessilibus, caule erecto basi hirto, petalis calyce duplo longioribus. Fl: dan. t. 1106. (in agris sabulosis, circa Kuskowa et alibi. Jun, Aug.)

241. Turritis. Calyx connivens erectus, Corolla erecta. Siliqua longissima angustata.

1. T. glabra: foliis radicalibus dentatis hispidis, caulinis integerrimis amplexicaulibus glabris. 
Fl. dan. t. 809. (in pascuis siccis apricis, in vallis pratisque umbrosis. Jun. Jul.)

2. T. hirsuta: foliis omnibus cauleque hirsutis, $F l$. dan. t. 1040 (in montibus passerinis aliisque nemorosis montosis. Jun, Jul.)

242. Brassica. Calyx erectus connivens. Glandulae inter stamina breviora et pistillum, interque longiora et calycem. Semina globosa.

1. B. campestris: radice cauleque tenui, foliis cordato-acuminatis amplexicaulibus, inferioribus lyratis dentatis subhispidis. Fl.dan. t. 5.50. (in agris, non argillosis, inter segetes. Jun.)

2. B. Napus: radice caulescente fusiformi, foliis laevibus, superioribus cordato-lanceolatis amplexicaulibus, inferioribus lyratis dentatis. Blackw. t. 224. (inter segetes, solo arenoso. Mai. Jun.)

3. B. Rapa: radice caulescente orbiculari depressa carnosa, foliis radicalibus lyratis scabris, caulinis integerrimis laevibus. Blackw. t. 226. (inter segetes passim. Ju1.)

243. Sivapis. Calyx patens. Corollae ungues recti. Glandula inter stamina breviora et pistillum, interque longiora et calycem. Siliquae rostratae.

1. S. arvensis: siliquis multangulis toroso-turgidis rostro ancipiti longioribus, foliis ovatis sublyratis. $F l$. dan. t. 753. (in agris, inter se: getes. Jun. Aug.)

2. S. alba: siliquis hispidis, rostro obliquo longissimo ensiformi. Blackiw. t. 29. (in agris interque segetes. Jun.) 
3. S. nigra: siliquis glabris tetragonis racemo adpressis, foliis ramulorum deflexis, summis linearibus integerrimis glabris Engl. bot. t. 969. (in agris, ruderatis. Jun. Jul.)

244. Raphanus. Calyx clausus. Glandulae melJiferae binae inter stamina breviora et pistillum, totidem inter stamina longiora et calycem. Siliqua torosa subarticulata teres rostrata.

1. R. Raphanistrum: foliis lyratis, siliquis teretibus articulatis laevibus unilocularibus. $F l$. dan. t. 678. (in agris, inter segetes. Jun. Jul.)

2. R. sativus: foliis lyratis, siliquis teretibus torosis bilocularibus. Lam. ill. t. 566. (in oleraceis Jun )

b. Raphanus niger:' radice ovato-oblonga compacta nigra, sapore acerrimo. (cultus.)

c. Raphanus Padicula: radice globosa amoene rubra albave. (in hortis et agris.)

\section{IM O N A D E L P H I A. P E N T A N D R I A.}

245. Erodium. Calyx pentaphyllus, Corolla pentapetala regularis. Nectarium: glandulae quinae ad basin staminum; nectarilymata quina squamaeformia. Semina quina arillata aristata, aristis spiralibus introrsum barbatis.

1. E. cicutarium: [Geranium cicutarium] pedunculis multifloris, foliis pinnatis, pinnis pinnatifidis incisis, corollis calyce majoribus, caule 
hirto prostrato. Cavan. diss. IV. t. 95. f. 1. (in agris, hortis, viis, sterilibus. Jun. Aug.)

\section{E C A N D R I A.}

246. Geranium. Calyx pentaphyllus. Corolla pentapetala regularis. Nectarium: glandulae quinae melliferae, basi longiorum filamentorum adnatae. Arilli quini monospermi aristati ad basin receptaculi rostrati: aristis nudis simplicibus.

\section{* Pedunculis unifloris.}

1. G. sibiricum: pedunculis unifloris, caule erecto ramoso, foliis quinquelobo-palmatis, lobis oblongis inciso-dentatis. Gmel. fl. sib. III. t. 67. (in collibus trans Occam. Jul. Aug. Stephan.)

2. G. sanguineum: pedunculis unifloris, foliis quinquepartitis trifidis orbiculatis. $F l$. dan. $t$. 1207. (in sylvis et nemoribus. Jul. Aug.)

* Pedunculis bifloris: perennia.

3. G. sylvaticurn: pedunculis bifloris, foliis subpeltatis quinquelobis inciso-serratis, caule erecto corymboso, petalis subemarginatis. Engl. bot. t. 122. (in sylvis, nemoribusque montosis. Jun. Jul.)

4. G. palustre: pedunculis bifloris longissimis declinatis, folis "quinquelobis dentatis, caule decumbente adscendente, petalis integris. $F l$. dan. t. 596. (in paludosis umbrosis. Jun. Jul.)

5. G. pratense: pedunculis bifloris, foliis sub. peltatis multipartitis rugosis acutis, petalis 
integris. Engl. bot. t. 404. (in pratis. Mai。 Jul.)

*** Pedunculis bifloris: annua.

6. G. rotundifolium: pedunculis bifloris, foliis omnibus mollissime villosis: radicalibus reniformibus septemlobis, caulinis subrotundis basi truncatis quinquelobis trifidis, petalis integris longitudine calycis aristati, arillis hirsutis. Iingl. bot. t. 157. (in cultis, agris, arvis, versuris. Jun. Aug. Sicphan.)

7. G. molle: pedunculis bifloris, foliis reniformibus: radicalibus novemlobis, caulinis septemlohis, lobis trifidis, petalis bifidis longitudine calycis mutici, arillis glabris rugosis. Fl. dan. t. 679. (in plateis, pascuis, ruderatis, hortisque. Jul. Aug )

8. G. pusillum: pedunculis bifloris, foliis subseptemlobis trifidis, floribus pentandris, petalis emarginatis longitudine calycis mutici, arillis pubescentibus. Engl. bot. t. 385. (in ruderatis, arvis, agris, cultis. Jun. Aug.)

9. G. robertianum: pedunculis bifluris, foliis ternatis quinatisque trifido-pinnatifidis, petalis integris calyce aristato duplo longioribus, arillis reticulatis. $\mathrm{Fl}$. dan. t. 69/4: (in nemorosis, umbrosis, ruderatis, muribus, ad domos.Jul. Aug.)

$$
\text { P O L Y A N D R I A. }
$$

247. Malva. Calyx duplex : exterior triphyllus. Capsulae plurimae monospermae. 
2. $M$, rotundifolia: caule prostrato, foliis cordato - orbiculatis obsolete quinquelobis, pedunculis fructiferis declinatis. Fl. dan, t. 721. (in ruderatis, collibus, viis, plateis. Jun..Aug.)

b. Malva pusilla: toto habitu minor teneriorque. Engl. bot. t. 2/\}1. (in ruderatis.)

2. M1. sylvestris: caule erecto herbaceo, foliis septemlobatis acutis, pedunculis petiolisque pilosis. Fl. dan. t. 1223. (in campestribus, sepibus, viis. Jul. Aug )

3. M. mauritiana: caule erecto herbaceo, foliis quinquelobatis obtusis, pedunculis petiolisque glabriusculis. Cavanill. II, t. 25. f. 2. (in cultis, hortisque sponte, etiam in vallo arcis. (Irremlin) Jun. Aug.)

4. M. crispa: caule erecto, foliis angulatis crispis, floribus axillaribus glomeratis. Cavanill. I1. t. 23. f. 1. (ad sepes, in hortis et pomariis. Jul. Aug.)

248. Lavatera. Calyx duplex: exterior trifidus. Capsulae plurimae monospermae.

1. L. vulgaris: [thuringiaca] caule herbaceo tomentoso, foliis subtomentosis: inferioribus angulatis, superiobus trilobis, lobo intermedio longiore obtuso, pedunculis axillaribus solitariis. Jacqu. austr. t. 311 . (in nemoribus et dumetis. Jul. Aug.) 


\section{- $122-$ \\ D I A D E L P H I A. H E X A N D I A.}

249. Corydaris. Calyx diphyllus, Corolla ringens. Filamenta bina nembranacea, singulum antheris ternis. Siliqua bivalvis polysperma.

2. S. bulbosa: [Fumaria bulbusa] caule simplici, racemo terminali, bracteis oblongis pedunculo longioribus, foliis biternatis oblongis acutiusculis, radice tuberosa cava. $\mathrm{Fl}$. dan. t. 605 . (in dumetis et nemoribus umbrosis. Mai.)

b. Corydalis alba: floribus albis. (cum praecedente et sequente. IMai.)

2. C. Halleri: caule simplici, racemo terminali, bracteis cuneatis digitatis pedunculo longioribus, foliis biternatis, radice tuberosa. Fl. dan.

t. 1224. (cum reliquis generis sui. Mai.)

250. Fumarxa. Calyx diphyllus. Corolla ringens. Filamenta bina membranacea, singulum antheris ternis. Silicula monosperma evalvis.

2. F. officinalis: caule ramoso diffuso, siliculis globosis retusis, foliis supradecompositis, foliolis cuneiformi-lanceolatis incisis. $F l$. dan. t. 940. (inter getes, in agris, cultis, hortis. Jun. Jul,)

\section{O C T A N D R I A.}

251. Polygala. Calyx pentaphyllus, ffoliolis duobus' alaeformibus coloratis. Legumen obcorda. tum biloculare. 
1. P. vulgaris: floribus cristatis racemosis, alis calycinis trinerviis obtusis longitudine corollae, caulibus procumbentibus, foliis lineari-lanceolatis acutiusculis. $F l$. dan. t. 516. in pascuis, pratis, montosis, umbrosis. Jun. Aug.)

b. Polygala elongata: major, caule simpliciusculo adscendente. Vaill. paris. t. 32. f. 1. (in pascuis et sylvis.)

c. Polygala carnea: corollulis carneis (in pratis et herbidis.)

2. P. amara: floribus cristatis racemosis, caulibus erectiusculis, foliis subspathulatis, radicalibus obovatis. $F l$. dan. t. 1269. (in pascuis, nemorosis, montosis siccis. Jun. Jul,)

b. Polygala alba: corollulis albis. (ad Mosquam fluvium.)

\section{DECA N D R I .}

252. Genista, Calyx $\frac{2}{3}$ bilabiatus: dentibus binis superioribus brevissimis. Vexillum oblongum a pistillo staminibusque deorsum deflexum.

1. G. tinctoria: foliis lanceolatis glabris, ramis tcretibus striatis erectis, leguminibus glabris. Fl. dan. t. 526. (in sylvaticis montosis, circa Kuskowa. Jun. Jul )

253. Antriylurs. Calyx ventricosus. Legumen subrotundum tectum mono-vel trispermum.

1. A. Vulneraria: herbacea, foliis pinnatis inaequalibus, capitulo duplicato. Fl. dan. t. 988. 
(in pratis, campisque apricis sabulosis, circa Petrowsk et Tokarewa. Jun. Jul.)

254. Оrовиs. Calyx basi obtusus: laciniis superioribus profundioribus brevioribus. Stylus linearis.

1. O. vernus: foliis pinnatis trijugis ovatis acuminatis, stipulis semisagittatis integerrimis, caule simplici. $F l$. dan. t. 1226 . (in nemoribus. IMai.)

2. O. tuberosus: foliis pinnatis tri-quadrijugisve lanceolatis, stipulis semisagittatis integerrimis, caule alato. $F l$. dan. t. 781 . (in sylvaticis et pratis. Mai. Jun. Steplan.)

255. Lathyrus. Calycis laciniae superioribus binae breviores. Stylus planus, supra villosus, superne latior.

1. L. tuberosus: pedunculis nultifloris, cirrhis diphyllis, foliolis ovalibus, internodiis nurlis. Rivin. tetr.t. 42. (inter segetes, humo argilloso. Jun. Aug.)

2. L. pratensis: pedunculis multifloris, cirrhis diphyllis simplicissimis, foliolis lanceolatis. $F$ dan. t. 527. (in pratis, ad sepes. Jun. Aug.)

3. L. sylvestris: pedunculis multifloris, cirrhis diphyllis, foliolis ensiformibus, internodiis membranaceis. $F l$. dan. t. 325. (in sylvaticis et pratis montosis, in Petrowsk, Swirlowa. Jun. Jul.)

4. L. latifolius: pedunculis multifloris, cirrhis diphyllis, foliolis lanceolatis, internodiis mem- 


\section{$-\quad 125$}

branaceis. Engl. bot. t. 1108. (in nemoribus subhumidis, ad sepes. Jun. Jul )

5. L. palustris: pedunculis multifloris, cirrhis polyphyllis, foliolis lineari lanceolatis acutis, stipulis semisagittatis"lanceolatis, internodiis membranaceis Fl. dan. t. 399. (in pascuis paludosis, dumetis humidis, montibus passerinis Jul. Aug.)

256. Vicia. Stigma latere inferiore transverse barbatum. Calyx superne emarginatus bidentatus, inferne dentibus tribus rectis longis. Vexillum emarginatum.

\section{* Pedunculis elongatis.}

1. V. dumetorum: pedunculis multifloris, foliolis ovatis mucronulatis reflexis, stipulis lanceolatis serratis. Spreng. hal. t. 7. (in nemoribus montosis. Jun )

2. $V$. sylvatica: pedunculis multifloris folio longioribus, foliolis ellipticis, stipulis lunatis setaceo-dentatis. Fl dan. t. 277. (in sylvaticis et nemorosis montosis. Jul )

3. $V$. cassubica: pedunculis multifloris folio brevioribus, foliolis oblongis subpubescentibus, stipulis semisagittatis integerrimis lanceolatis. Jacqu austr. III. $\mathbf{t} 289$ (in nemoribus umbrosis arenosis, in Gorenki, Astankina. Jul)

4. $V$. Cracca: pedunsulis multifloris folio longioribus, floribus imbricatis, foliolis lanceolatis obtusis, stipulis semisagittatis lineari-subulatis integerrimis. $\mathrm{Fl}$. dan. t. 804 . (inter se- 


\section{$-126-$}

getes, ad sepes, in pratis, versuris, dumetis. Jun. Aug.)

5. V. tenuifolia: pedunculis multifloris folio lon. gioribus, floribus imbiicatis, foliolis linearibus glabriusculis trinerviis, stipulis linearibus integerrimis. Roth. (cum praecedente. Jun. Aug.) * Floribus axillaribus subsessilibus.

6. $V$. sativa: leguminibus sessilibus subbinatis, foliolis oblongo.ovatis truncatis mucronatis, stipulis dentatis notatis. $\mathrm{Fl}$. dan. t. 522. (inter segetcs. Jun. Aug.)

7. V. angustifolia: leguminibus sessilibus subbinatis " patentibus, foliolis imis ovatis retusis emarginatis, superioribus linearibus apice integerrimis, stipulis dentatis, seminibus globosis. Schkuhr. t. 201. (inter segetes, in campis arenosis, nemoribusque. Jun. Jul.)

3. V. sepium: leguminibus pedicellatis subquaternis erectis, foliolis ovatis integerrimis, exterioribus decrescentibus. $F l$, dan. t. $6_{99}$. (in pratis, sepibus, nemoribus, hortis. Mai. Jun.)

257. Envum. Calyx quinquepartitus. Stigma eapitatum undique pilosum. Legumen oblongum.

1. E. tetraspermum: pedunculis subbifloris, leguminibus glabris tetraspermis, foliolis oblongis truncatis. Fl. dan. t. 95. (in agris, arvis, cultis, hortis. Jun. Aug.)

2. E. hirsutum: pedunculis multifloris, leguminibus hirsutis dispermis, foliolis linearibus obtusis. Fl.dan. t. 639. (in agris, arvis, cultis.

Jul. Aug.) 
258. CrCer. Calyx quinquepartitus longitudine corollae, laciniis quaternis superioribus vexillo decumbentibus. Legumen turgidum dispermum.

2. C. Lens: [Ervum Lens] pedunculis subbifloris, seminibus compressis, foliolis integerrimis. Kniph. cent. IX. (inter segetes, in cultis, hortisque, Jun. Jul.)

b. Cicer macrospermum: seminibus majoribus, leguminibus succulentis dulcibus. (in hortis.) Jun. Jul)

259. Cytrsus Calyx bilabiatus, labio superiore bidentato. Carina erecta. Legumen basi attenuatum compressurn.

1. C. supinus: floribus pedunculatis subbinatis axillaribus, caule decumbente, foliolis obovatis obtusis Jacqu. austr. I. t. 20. (in collibus apricis sylvaticis, circa pagum Tokarewa. Jul Henning.)

260. Rовгіл. Calyx quadrifidus, lacinia superiore bipartita. Legumen gibbum elongatum.

2. R. Caragana: pedunculis simplicibus plurimis, foliis abrupte pinnatis subquadrijugis, petiolis inermibus, leguminibus cylindricis. $D u$ Ham. I. t. 19. (in hortis et sepibus vivis. Mai. Jun.)

261. Coronilla. Calyx bilabiatus, dentibus superioribus connatis. Petala unguiculata. Vexillum vix alis longius. Lomentum teres articulatum rectum.

2. C. varia: herbacea, foliolis plurimis lanceo. latis glabris, loraentis teretibus erectis. $R$ - 


\section{$-128$}

vir. t. 219. (in sepibus, dunetis, nemoribus, interque segetes。 Jul.)

202. Astragulus. Carina obtusa. Legumen plerumque biloculare gibbum. Semina biserialia.

1. A. glycyphyllos: caulescens prostratus, foliolis glabris ovatis obtusis mucronatis, stipulis ovato-lanceolatis, racemis pedunculatis folio brevioribus, leguminibus subtriquetris arcuatis. Fl. dan. t. 1108 . (in nemoribus, circa Kunzowa et Zarizina. Jul.)

263. Menzotuus. [Trifolium Linn.] Calyx tubulosus quinquedentatus. Corolla decirlua, Carina arlpressa. Legumen oligospermum dehiscens calyce longius.

1. MI. cacrulea: racemis oblongis pedunculatis, leguminibus ventricosis seminudis dispermis mucronatis, caule erecto, stipulis lanceolatis membranaceis. Blackw. t. 184. (in cultis, hortis. Jul.)

2. M. officinalis: [lutea] leguminibus racemosis nudis dispermis subrogosis ovatis subcompressis acutis, stipulis subulatis, caule erecto. Fl. dan. t. 934. (in campestribus, pratis, arvis, sepibus, ruderatis. Jun. Jul.)

3. M. vulgaris: [alba] leguminibus racemosis nudis monospermis rugosis obovatis acutis, stipulis setaceis, caule erecto. (in ruderatis et cultis. Jun. Jul.)

264. Trifolrum. Calyx tubulosus quinquedentatus. Corolla persistens. Carina adpressa, Legumen oligospermum evalve calyce tectum. 
* Lotoidea: leguminibus tectis, polyspermis.

2. T. hybridum: capitulis umbellaribus, leguminibus tetraspermis, calycinis dentibus subaequalibus, foliolis ovato-oblongis emarginatis serrulatis, caule adscendente prostrato. Sturm. I. t. 25. (in cultis, pratis, ad vias. Jun. Jul.)

\&. T. repens: capitulis umbellaribus, leguminibus tetraspermis, calycinis dentibus superioribus brevioribus, foliolis ovato-oblongis emarginatis serrulatis, caule repente. Fl. dan. t. 990. (in pratis, pascuis, campis, versuris, hortisque. Jun. Aug.)

b. Trifolium pentaphyllum: foliolis quaternis, quinis, senisve fusco-maculatis, (in hortis ).

* La gopoda: calycibus villosis.

3. $\boldsymbol{T}$. pratense: spicis densis ovatis, calycis dente infimo tubo corollae monopetalae inaequalis breviore stipulis aristatis, foliis ovalibus integerrimis, caule adscendente, $F l$. dan. t. 989. (in pratis, versuris, campis, hortisque, Jun. Aug.) b. Trifolium sativum: multicaule elatius, foliolis lanceolato-oblongis, capitulis nudis pedunculatis subgeminis Sturm. I.t, 15. (cultum.)

4. T. flexuosum: [medium] spicis laxis subglobosis solitariis, calycis dente infimo tubum corol. lae monopetalae subaequalis aequante, stipu. lis subulatis, foliolis ellipticis tenuissime serrulatis striato-venosis, caulibus ramosis flexuo- 


\section{$-130$}

sis. Jacqu. austr. IV. t. 316. (in nemorosis montosis, e. g. montibus passerinis et Kunzowa. Jun. Jul.)

b. Trifolium carncum: corollulis carneis. (cum antecedente.)

5. T. alpestre: spicis densis 'subglobosis subgeminatis, calycis dente infimo tubum corollae monópetalae subaequalis aequante, stipulis'setaceis, foliolis lanceolatis tenuissime serrulatis striato-venosis, caulibus simplicissimis strictis. Sturm. I. t. 15. (in collibus nemorosis。 Jul. Aug.)

6. T. arvenise: spicis villosissimis subcylindraceis, dentibus calycinis setaceis corolla longioribus, foliolis obovato-linearibus. Fl. dan. t. 724. (in arvis campisque sterilibus, inter setes. Jun. Aug.)

** Lupulina: vexillis corollae inflexis.

7. T. montanum: spicis subimbricatis subtribus; vexillis subulatis emarcescentibus, calycibus nudis, caule erecto. Fl dan. t. 1172. (in collibus aridis, nemoribusque montosis. Jun. Aug.)

8. T. spadiceum: spicis cylindricis imbricatis, rexillis deflexis persistentibus, calycinis dentibus inaequalıbus subpilosis, foliolis infinis obcordatis, supremis ellipticis scrrulatis, petiolo apice incrassato marginato, stipulis lanceolatis erectis cauleque erecto pubescentibus. Sturm. I. t. 16. (in pratis montosis siccioribus. Jun. Jul.) 


\section{1}

9. T. agrarium: [aureum] spicis ovalibus imbricatis, vexillis deflexis persistentibus, calycinis dentibus inaequalibus glabris, foliolis lanceolatis serrulatis, stipulis lanceolatis erectis glabris, caule erecto $F l$. dan. t. 558. (in pratis, arvisque siccis. Jul. Aug.)

2o. T. campestre: spicis ovatis imbricatis, vexillis deflexis persistentibus, pedunculis folia obovata obtusa aequantibus, stipulis oblique reflexis ciliatis, caule decumbente. Fl dan.t. 796. (in agris cultioribus post messem. Jul. Aug.)

11. I procumbens: [minus] spicis ovatis imbricatis, vexillis deflexis persistentibus, foliolis obovatis petiolatis emarginatis, calycibus pubescentibus, stipulis brevi-ovatis glabris, caule ramisque procumbentibus Engl. bot. t. 1256. (in pratis, campisque herbosis. Jun. Jul.)

12. T. filiforme: spicis capitatis hemisphaericis paucifloris, vexillis deflexis persistentibus laevibus, foliolis obcordatis denticulatis, calycibus glabris, caule procumbente. Engl. bot. t. 12.57 (in pratis argillosis. Jun. Jul.)

265. Lotus. Calyx tubuloșus. Alae sursum longitudinaliter conniventes. Filamenta cuneiformia. Legumen cylintricum strictum.

1. L. corniculatus : capitulis depressis multifloris, calycibus erectis pilosis, caule subangulato solido decumbente, leguminibus teretibus patulis. Fl. dan. t. 991. (in pratis, graminosis et versuris siccioribus. Jun. Aug.)

8. L. uliginosus: [sylvaticus] capitulis depressis multifloris, calycibus recurvis barbatis, caule 


\section{2}

tereti fistuloso decumbente, leguminibus teretibus. Schkuhr.t. 211. (in herbidis, sylvaticis, umbrosis humentibus. Jul. Aug.)

266. Medicago. Carina corollae a vexillo deflectens. Legumen compressum cochleatum.

2. M. falcata: pedunculis racemosis, leguminibus contorto-falcatis pubescentibus, foliolis oblongis apice dentatis. Fl. dan.t. 233. (in aggeribus, pratis apricis siccis, ad vias. Jun. Aug.)

2. M. Lupulina: spicis ovalibus, leguminibus uniformilsus monospermis, stipulis integerrimis, foliolis obovatis. Fl. dan.t 992. (in pratis, pascuis, agrisque siccioribus.' Jun. Jul.)

\section{P O L Y A E L P H I A. P O L Y A N D R I A.}

267. Irpenicum. Calyx quinquepartitus. Petala quina. Filamenta multa in quinque phalanges basi comata. Capsulae tri-seu quinqueloculares polyspermae.

1. H. quadrangulare: floribus trigynis, caule quadrangulo herbaceo, foliis pellucido - punctatis, foliolis calycinis lanceolatis. Fl.dan. t. 640. (in pratis humentibus, ad sylvarum margines, in montosis Jun. Jul)

2. H. dubium: floribus trigynis, caule obsolete quadrangulo, foliis obtusis epunctatis, foliolis calycinis ellipticis. Allion. pedım. t. 83. f.. 


\section{$-133$}

(in pratis, aggeribus, sylvaticis, montosis. Jun. Jul.)

3. H. per'oratum: floribus trigynis, caule ancipiti, foliis obtusis pellucido-punctatis, foliolis calycinis lanceolatis. $F l$. dan. t. 1043. (in nemoribus, dumetis, sepibus, campis herbidis. Jul. Aug.)

4. H. montanum: floribus trigynis corymbosopaniculatis terminalibus, calycibus serratoglandulosis, foliis oblongis amplexicaulibus impunctatis, margine nigro-maculatis, caule tereti erecto. Fl. dan. t. 173. (in sylvaticis et nemorosis inontosis. Jul.).

5. H. hirsutum: floribus trigynis, calycibus serrato-glandulosis, caule tereti erecto pubescente, foliis oblongis basi attenuatis pellucidopunctatis subtus pubescentibus, $\mathrm{Fl}$. dan.t 302 . (in collibus sylvaticis ad Kunzowa, et in montibus passerinis. Jun. Jul.)

\section{S Y N G E N E S I A. A E Q U A L I S.}

268. Tragopogon. Receptaculum nudum. Calyx simplex polyphyllus. Pappus plumosus stipitatus.

1. T. pratense: calycibus corollae radium subaequantibus, pedunculo tereti, foliis integris strictis. Fl. dan.t. 906. (in pascuis, pratis apricis, aggeribus. Jun. Aug), 


\section{$-13 / 4_{-}$}

2. T. orientale: calycibus corollae radio brevioribus, foliis integris subundulatis. (in pratis. circa Tolsarewa. Jul Henning.)

3. T. majus: calycibus corollae radium superantibus, pedunculo superne incrassato, corollulis apice rotundatis. Jacqu, austr. t. 29. (in montosis arenosis ad monasterium St. Simeonis. Aug.)

269 Sonchus. Receptaculum nudum. Calyx imbricatus ventricosus. Pappus pilosus sessilis.

1. S. palustris: pedunculis calycibusque hispidis subumbellatis, foliis runcinatis basi sagittatis. Fl. dan. t. 1109. (in pratis paludosis. Jun. Jul,)

2. S. arvensis: pedunculis calycibusque hispidis. subumbellatis, foliis runcinatis basi cordatis. $F l$. dan. t. 6o6 (in agris humidiusculis argillosis, inter segetes. Jul. Aug.)

3 S. oleraceus: pedunculis subtomentosis umbellatis, calycibus glabris, foliis oblongo-lanceoJatis amplexicaulibus denticulatis subsinuatis. $F l$. dan. t. 682. (in cultis, agris, hortis. Jun. Aug.)

4. S. asper; [rigiclus] pedunculis calycibusque glabris, foliis ovato-oblongis integris dentatis: dentibus alternis minoribus, seminibus glabris. Fl. dan. t. 843. (in agris, arvisque. Jul Sept.)

270. Lactuca. Receptaculum nudum. Calyx imbricatus cylindricus, margine membranacea. Pappus simplex stipitatus. Semina laevia. 
1. L. Scariola: foliis verticalibus carina aculeatis runcinato-sinuatis denticulatis acutis. $F l$. dan. t 1227. (in ruderátis, aggeribus, ad vias, marginesque fossarum. Jun. Aug.)

b. Lactuca sanguinea: caule foliisque maculis sanguineis adspersis. Herm. parad. t. 191. (in agris, Aug.)

271. Prenanties. Receptaculum nudum. Calyx calyculatus. Pappus simplex subsessilis. Flosculi simplici serie.

1. P. muralis: foliis lyrato-pinnatifidis dentatis, Jobo terminali quinquangulari, floribus paniculatis. Fl. dan. t. 509. (in nemoribus umbrosis, ruderatis, circa ruinas. Jun. Jul.)

27․ Leontodon. Receptaculum nudum. Calyx duplex. Pappus stipitatús pilosus.

1. L. Taraxacum: calyce exteriore reflexo, scapo unifloro, foliis runcinatis glabris, laciuiis lanceolatis dentatis. Fl. dan. t. 574. (in pascuis, pratis, viis, sepibus, versuris, cultis, hortis. Mai. Oct.)

b. Leontodon laciniatum: foliis minoribus runcinato-laciniatis. (cum antecedente.)

273. Apargia. Receptaculum nudum. Pappus plumosus sessilis. Calyx imbricatus.

1. A. incana: [Hieracium incanum] scapo uniforo subnudo calyceque pubescente, foliis lanceslatis acutis subdenticulatis cano-scabris, pilis multifidis. Jacqu. austr. t. 287. (in montosis sylvaticis, ad urbern Kaluga. Jul. St phan ) 


\section{$-136$}

2. A. autumnalis: [Hedypnois autumnalis] scapis ramosis declinatis squamosis, folii's lanceolatis runcinato-pinnatifidis glabriusculis. Engl. bot. t. 83o. (in pratis, pascuis, aggeribus, versuris. Jul. Sept.)

3. A. hispida: [Iseontodon hispidum] scapo nudo unifloro, calyce hirto, foliis runcinato-denta. tis hirtis, pilis furcatis. Fl.dan.t. 862. (in pratis, pascuisque montosis. Jun. Jul.)

274. Thrincia. Receptaculum favosum. Pappus difformis: marginalis membrana multifida, centralis stipitatus plumosus, Calyx octangularis octophyllus.

1. T. hirta: [Apargia hirta] scapo unifloro, calyce glabriusculo squamulis aucto, foliis lanceolatis sinuato - dentatis, pilis simplicibus, Engl. bot. t. 55.5. (in marginibus agrorum aridis, collibusque siccis. Jul.)

275. Prcris. Receptaculum nudum. Pappus plumosus stipitatus. Semina transversim striata. Calyx calyculatus.

1. P. hieracioides: caule erecto scabro, foliis amplexicaulibus lanceolatis dentatis, floribus corymbosis, calyce exteriore laxo. Engl. bot. t. 196. (in pratis, versuris, ad sylvarum limites. Jun. Jul.)

276. Hir racrum. Receptaculum nudum. Calyx imbricatus ovatus. Pappus simplex sessilis.

1. If. Pilnsella: scapo unifloro, foliis integerrimis ovatis subtus tomentosis, stolonibus repen. tibus. Fl. dan. t. 1110 (in pascuis aridis, cols 
libus apricis, aggeribus, versuris, ad vias. Mai. Aug.)

2. H. dubium: scapo subquadrifloro nudio, foliis oblongis obtusis integerrimis, stolonibus repentibus. $F l$ dan, t. 1111. (in pascuis subudis, sylvisque. Jun. Jul.)

3. H. cymosum: scapo folioso hispido, floribus corymboso-paniculatis, pedunculis propriis glomeratis, calycibus hispidis, foliis oblongolanceolatis integris hirtis. Spreng. hal. t. 10. (in sylvaticis, pascuis, montosis. Mai. Jun.)

4. H. praemorsum: scapo nudo racemoso, foliis ovatis pubescentibus subdentatis, floribus superioribus primoribus. $\mathrm{Fl}$. dan. t. 942. (in collibus herbidis, nemorosis, sylvaticis. Jul.)

5. H. murorum: caule recto folioso pilosissimo simplici, floribus paniculatis, foliis ovatis basi profunde dentatis, Fl. dan, t. 1113. (in siccis, ruderatis, apricis, muris, Jun. Jul.)

b. Hieracium nemorosum: [sylvaticum] caule folioso subramoso, foliis aequalibus ovatis dentato - sinuatis submaculatis. Blackw. t. 533. (in nemoribus et sylvis arenosis. Jun. Jul.)

6. II. paludosum: caule simplici, foliis glabris oblongis basi attenuatis runcinato - dentatis, caulinis amplexicaulibus, floribus paniculatis, calycibus hispidis, $F l$. dan, t. 923. (in nemoribus umbrosis humidis. Jun. Jul.)

7. H. sibiricum: [Crepis sibirica] caule erecto paniculato sulcato pubescente, foliis rugosis, radicalibus oblongis dentatis, caulinis amplexicaulibus, basi inaequaliter profunde dentatis, 
Bummis lanceolatis, calycibus laxis hispirlis, Gmel. $f l$ sib. III. t. 10. (in sylvaticis gramino. sis. Jun. Jul.)

8. II: sabaudum: caule erecto sinplici, foliis ovato - oblongis subglabris acutis sessilibus subamplexicaulibus basin versus dentatis, floribus corymbosis. Fl. clan.t. 872 . (in nemoribus, humidiusculis, in montibus passerinis, tribus montibus, Ḱunzowa. Jul. Aug.)

9. H. umbellatum: caule erecto simplici, foliis linearibus subdentatis, floribus corymbosoumbellatis, calycibus squarrosis. Fl. dan. t. 680. (in pascuis editioribus siccis, ad scaturigines sylvarum. Jul Aug.)

b. Hieracium lineare: foliis angustis linearibus. (in sylvula prope monasterium St, Simeonis. Aug.)

277. Crepis. Receptaculum nudum. Calyx caJyculatus, squamis deciduis.

2. C. tectorum: foliis glabriusculis lanceolatoruncinatis, laciniis adscendentibus, summis linearibus filiformi-sagittatis amplexicaulibus, floribus corymbosis, calycibus pubescentibus. (in pascuis editioribus arenosis, aridis tectis, interque segetes. Jun. Jul.)

2. C. biennis: foliis hispidis runcinato-pinnatifidis, sunmis sessilibus lanceolatis dentatis carina hispido-aculeatis, calycibus pubescentibus muricatis. Engl. bot t. 149. (in pratis, pascuis, ruderatis, nemoribus. Jul. Aug.)

278. Hrrocroenis. Receptaculum, paleaceun, Calyx inbricatus. Pappus plumosus. 
1. H. maculata: [hirsuta] caule subnudo, ramo solitario, foliis ovato-oblongis integris dentatis Fl. dan. t. 149. (in 'nernorosis montosis, pratis asperis, ad vias. Jun. Aug.)

279. Lapsana. Receptaculum nudum. Calyx subcalyculatus, squamis singulis interioribus canàliculatis, Pappus nullus.

1. L. communis: caulescens ramosa, foliis ovatis petiolatis angulato-dentatis. $\mathrm{Fl}$. dan. t. 500, (in cultis, hortis, ruderatis, sepibus. Jun. Jul.) 280. Crcirorium. Receptaculum subpaleaceuu. Calyx calyculatus. Pappus polyphyllus paleaceus.

2. C. Intybus: floribus axillaribus geminis subsessilibus, foliis runcinatis. Fl. dan. t. 907. (in versuris, pratis, viis, ruderatis. Jul dug.)

b. Cichorium sativum: radice crassiore suc. culenta. (cultum.)

c. Cichorium variegatum: foliis variegatis, (in hortis, cultum.)

281. Arctrum Receptaculum paleaceum. Calyx globosus, squamis apice hamis inflexis. Pappus actoso - paleaceus.

1. A. Lappa: foliis caulinis cordatis petiolatis denticulatis, calycibuslaevibus. Engl. bot. t 1228. (in ruderatis, ad vias et sepes.Jul. Aug.)

a. Arctium majus: squamis calycinis mar: gine paleaceis : paleis obtusis clavatis. Schkuhr. II. t. $₫ 27$.

b. Artium minus: squamis calycinis margi= ne paleaceis: paleis acutis cylindraceis. Schhuhr. ibid. 


\section{$-140$}

2. A. Bardana: foliis caulinis cordatis petiolatis intègerrimis, calycibus arachnoideo-tomentosis. Fl. dan. t. 642 (cum prioribus. Jul. Aug.)

232. Serratula. Receptaculum paleaceum seu villosum. Calyx imbricatus cylindraceus inermis. Pappus plumosus sive dentatus.

1. S. tinctoria: foliis argute serratis basi subpinnatifidis, corymbo fastigiato. $F l$. dan. t. 281 . (in pratis et nemoribus. Jun. Jul.)

ع. S. arvensis: foliis lanceolat is pinnatifido-dentatis undulatis spinosis glabris, caule paniculato. Engl. bot. t. 975. (in agris, cultis, arvis, viis Jul. Aug.)

3. S. setosa: foliis oblongis glabris serrulatis setaceo-ciliatis obtusis mucronatis, caule corymboso. Secliger (in ruderatis, hortis ubique. Jul. Aug.)

283. Carduus. Calyx imbricatus ventricosus, squamis spinosis. Pappus capillaris seu scaber. Receptaculum villosum.

1. C. nutans: foliis semidecurrentibus spinosis, floribus cernuis, squamis calycinis superne patentibus. Fl. dan t. 675. (in ruderatis, ad vias, pagosque. Jul. Aug.)

2. C. acanthoides: foliis decurrentibus sinuatospinosis, calycibus globosis subpedunculatis, squamis linearibus recurvatis. Engl. bot. t. 973. (in ruderatis, viisque. Jul. Aug.)

3. C. crispus: foliis decurrentibus oblongis sinuatis margine spinosis subtus lanuginusis, floribus pedunculatis aggregatis termiualibus, caly- 


\section{$-141$}

cinis squamis lineari-subulatis mucronatis patulis. Fl. dun. t. 621. (1n agris, cultis, sepibus. Jul, Aug.)

4. C. marianss: foliis amplexicaulibus hastatopinnatifidis spinosis, calycibus aphyllis, spinis canaliculatis duplicato-spinosia. Engl. bot. t. 976. (in cultis, hortisque Jul. Aug.)

284. Cinicus. [olim ad Carduum] Calyx imbricatus ventricosus, squamis spinosis. Pappus plumosus. Receptaculum villosum

1. C. palustris: foliis decurrentibus nudis lanceolatis dentatis margine spinosis, floribus racemoso-glomeratis, squamis calycinis ovatolanceolatis mucronatis adpressis. Engl. bot. t. 974. (in pratis humidis subpaludosis. Jul. Aug.)

2. C. lanceolatus: foliis decurrentilus hispidis pinnatifidis, laciniis bilobis divaricatis spinosis, calycibus ovatis araclinoideo-pubescentibus, squamis lanceolatis spinosis patentibus $\mathrm{Il}$ dan. t. 1173. (in ruderatis, agris, ad vias. Jul. Aug.)

3. $C$ eriophorus: foliis sessilibus pinnatifidis liispidis, laciniis geminatis. divaricatis spinosis, calycilus globosis arachnoideo-villosis, squamis oblongis apice linearibus elongatis mucro-' natis reflexis. Engl. bot. t. 386. (in sterilibus, montosis. Jul. Aug.)

4. C. heterophyllus: foliis amplexicaulibus cordatis lanceolatis serratis ciliatis subtus tomentosis, inferioribus subincisis, calycinis squamis 


\section{$-142$}

lanceolatis adpressis submucronatis. Allion. pe. dcm.t. 34. (in pratis montosis nemorosis, Jun. Jul.)

5. C. helenioides: foliis subcordatis amplexicaulibus lanceolatis ciliatis subtus tomentosis, inferioribus subincisis, floribus aggregatis, squamis calycinis lanceolatis adpressis inucronatis. Mill. dict. t, $94^{2}$ (in ruderatis, Jul.)

- 6. C. serratuloicles: foliis lanceolatis sessilibus ciliatis subtus strigosis, radicalibus sinuatis, caule ramoso, squamis calycinis oblongo-lanceolatis mucronatis apice recurvatis. Jacqu. austr. t. 127. (in ruderatis, ad vias. Jul. Aug.)

7. C oleraceus: folis amplexicaulibus cordatis pinnatifidis ciliato-senratis, floribus terminalibus subraccinosis bracteatis, bracteis subcoloratis ovatis, squamis calycinis lanceolatis spinosis. Schliuhr.t. 229. (in pratis umbrosis, subnemorosis humidis. Jun. Aug.

235. Oropordon. Receptaculum favosum. Pap. pus capillaris. Calyx imbricatus, squamis mucronatis.

1. O. Acanthium: squamis calycinis patentissimis, foliis decurrentibus tomentosis sinuatis dentatis spinosis. Fl dan, t 909. (in ruderatis, pagis, collibus, sepibus, viisque. Jun. Aug ) 286. Carlina Receptaculum paleaceo-setosum. Corollae flosculosae. Calyx radiatus, squamis marginalibus longis coloratis. Pappus paleaceo-plumosus. 


\section{- $143-$}

1. C. vulgaris: caule multifloro corymboso pube* scente, foliis lanceolatis déntatis spinosis subtus pubescentibus $F l$. dan. t. 1174 . (in sylvaticis montosis arenosis asperis. Ju\}. Aug)

287. Bidexs. Receptaculum paleaceum planum. Semina tetragona. Pappus aristis hinis seu quaternis erectis scabris. Calyx subaequalis calyculatus. (Corolla rarius flosculo uno alterove radiante instruitur.)

1. B. tripartita: floribus discnideis, calycibus exterioribus flore majoribus, seminibus erectis, foliis tripartitis lanceolatis dentatis. Engl. bot, t. 1123. (in inundatis, ad fossas, Jul. Aug.)

2. B. ccrnua: floribus subradiatis cernuis, calyce exteriore flore longiore, foliis lanceolatis subconnatis dentatis. Fngl. bot. t. 1214 . (in udis, humidis, paludosis Jul. Aug.)

b. Bidens radiata: [Coreopsis Bidens] floribus radiatis. Moris hist. III. t 5. f. 25. (in paludosis profundioribus, inundatisque. Jul. Aug )

c. Bidens pumila: [minima] foliis lanceola. tis sessilibus, floribus seminibusque erectis. Fl. dan. t. 312. (in sphagnetis, uliginosisturfosis, paludibus Jul.Aug.)

288. Eupatonum. Receptaculum nudum. Pap. pus pilosus seu scaber. Calyx imbricatus. Stylus senribifidus longus.

1. E. cannabinum: foliis petiolatis tripartitis, laciniis lanceolatis sorratis, intermedia longiore. 


\section{$-144-$}

Fl. dan. t. 745. (in pratis paludosis, ad aquarum rivulos. Jul. Aug.)

\section{S U P E R F I U A.}

289. Tanacetum. Receptaculum nudum, Pappus submarginatus. Calyx imbricatus. hemisphaericus. Corollulae radii obsoletae, trifidae.

1. T. vulgare: foliis bipinnatis incisis serratis. Fl. dan. t. 871. (in aggeribus versuris, sepibus, nemorosis, fruticetis. Jun. Aug.)

b. Tanacetum crispum: foliis crispis. Do. dan. pempt. 36(in hortis. Jul. Aug.)

290. Artemista. Receptaculum subvillosum vel nudiusculum. Pappus nullus. Calyx imbricatus, squamis rotundatis conniventibus. Corollae radii nullae.

x. A. campestris: foliis caulinis setaceis pinnatis glabris, radicalibus pinnatis: laciniis trifidis incanis, caule procumbente ramoso virgato, floribus oratis pedunculatis. Fl. dan. t. 1175 . (in collibus aridis, canpis apricis, ad pagos et coemeteria. Jul, Ayg.)

2. A. Absinthium: foliis multipartitis sericeo-incanis, laciniis lanceolatis obtusiusculis, floribus racemosis hemisphaericis pendulis, receptaculo piloso. Engl. bot. t, 1230. (in sepulcris, ruderatis, aggeribus, viisque. Jun. Aug.)

3. A. vulsaris: foliis pinnatifidis subtus tomentosis!, laciniis lanceulatis acutis, calycibus 
subsessilibus racemosis ovatis tomentosis. $F l_{\text {。 }}$ dan. t. 1176 . (in cultis, ruderatis, versuris; pagis. Jun. Jul.)

b. Artemisia rubra: caule floribusque rubris. (cum praecedente)

291, Giaphalium. Receptaculum nudum. Pappus pilosus vel plumosus. Calyx imbricatus, squanis marginalibus rotundatis scariosis coloratis.

1. G. dioicum: sarmentis procumbentibus, caule simplicissimo, foliis radicalibus spathulatis, corymbo coarctato, floribus dioicis, calycinis squamis interioribus elongatis obtusis coloratis. Fl. dan. t. 1228. (in pascuis editioribus, versuris apricis, aridisque sylvaticis. Jun. Jul.)

a. Gnophalium masculum: corollulis albis

b. Gnaphalium femineum: corollulis roseis.

2. G. rectum: caule herbaceo' ferecto simplici, foliis lineari-lanceolatis subtus sericeis, floribus terminalibus et axillaribus sessilibus spicatis. Fl. dan. t. 1229. (in sylvaticis montosis. Jul. Aug.)

3. G. sylvaticum: caule herbaceo erecto simplicissimo, foliis lanceolatis utrinque attenuatis lanatis, floribus terminalibus sessilibus spicatis. Fl. dan. t. 254. (in sylvis. Jul.)

4. G. uliginosum: caule herbaceo ramoso diffuyo lanato, foliis lineari-lanceolatis utrinque angustatis tomentosis, floribus terminalibus congestis. Fl. dan. t. 859. (in humidiusculis, inundatis, uliginosis. Jul. Aug.) 
6. Gnaphalium nudum: caule ramoso diffuso, floribus confertis foliisque utrinque nudis (in uliginosis, inundatis. Jul. Aug.)

292. Conyza. Receptaculum nudum. Pappus simplex. Calyx imbricatus subrotundus. Corollae radii trifidae.

1. C. squarrosa: foliis scabris, caulinis ovatooblongis serratis, rameis oblongo-lanceolatis subintegerrimis, caule herbaceo corymboso, calycibus squarrosis. Fl. dan. t. 622. (in siccis montosis. Jul Aug.)

293. Erigerow. Receptaculum nudum. Pappus pilosus. Corollae radii lineares angustissimae.

1. E. canadense: caule floribusque paniculatis hirtis, foliis lanceolatis ciliatis. Fl. dan.t. 298. (in arvis, ruderatis, cultis, hortis, sylvis. Jul. Aug.)

2. E. acre: caule racemoso piloso, pedunculis alternis uniforis, foliis lanceolato-ligulatis. Engl. bot. t. 1158 (in montosis apricis arenosis calcareis siccis Mai. Jul.)

294. Tussilaco. Receptaculum nudum Pappus simplex. Calycis squamae aequales discum aequantes submembranaceae.: Corollae femineae ligulatae sive edentulae.

1. T. Farfara: scapo unifloro subnudo bracteato, flore radiato, foliis cordatis angulatis dentatis subtus pubescentibus. $F l$. dan. t. 595. (in aggeribus, agrisque limosis argillosis subhumidis, in ruderatis, sylvaticis. Maai.) 
2. T. Petasites: thyrso oblongo, floribus discoideis, foliis oblongo - cordatis inaequaliter denticulatis subtus pubescentibus, lobis approximatis. Fl. dan. t. 842. (ad margines fossarum et torrentum. Mai.)

b. Tussilago hybrida: thyrso oblongo, flosculis femineis nudis plurimis. Hort. cliff. 412. 295. Senecro. Receptaculum nudum. Pappus simplex. Calyx cylindricus calyculatus, squamis apice sphacelatis.

1. S. vulgaris: corollis nudis, foliis amplexicaulibus pinnatifidis dentatis, floribus corymbosocoarctatis. Fl. dan. t. 513. (in ruderatis, agris, cultis, hortisque. Mai. Aug.)

\&. S. sylvaticus: corollis revolutis, foliis pinnatifidis lobatis denticulatis subpilosis, calyculis brevissimis, caule corymboso erecto. Rupp. fl. jenens. t. 3. (in sylvis caeduis. Jul. Aug.)

b. Senecio pumilus: caule floreque simplici. Schkuhr. t. 267. (in ericetis montanis sterilibus. Jul. Aug.)

3. S. Jncubaea: radio patente, foliis lyrato-bipinnatifidis divaricatis dentatis glabris, caule erecto. Engl. bot. t, 2135. (in pascuis, pratisque editioribus nemorosis. Jul. Aug.)

4. S. paludosus: corollis radiantibus, foliis semiamplexicanlibus lanceolatis argute serratis subtus subvillosis, corymbo terminali divaricato, caule stricto $\mathrm{Fl}$. dan. t. 385. (in paludibus, aquis stagnantibus. Jun. Jul.)

5. S. saracenticus: corollis radiantibus, foliis lan- 


\section{8}

Ceolatis basi cuneatis' argute serratis subsessilibus glabriusculis. Jacqu. austr. t. 186. (in paludibus nemorosis,montosis umbrosis. Jul. Aug.) 296. Solidago: Receptaculum nudum. Pappus simplex. Corollae radii circiter quinae. Calycis squamae imbricatae clausae.

-1. S. Virgaurca: caule erecto tereti superne ramoso et pubescente, foliis caulinis lanceolatis utrinque attenuatis serratis, inferioribus ellipticis pilosiusculis, racemis erectis, ligulis elongatis. Fl. dan. t. 663. (in nemoribus montosis, pascuis siccis, ad sylvarum margines. Jul Aug.) 297. Ixura. Receptaculum nudum. 'Pappus simplex. Antherae basi in setas duas desinentes.

3. I. Helenium: foliis amplexicaulibus ovatis ru. gosis subtus tomentosis, calycum squamis oratis. $F l$. durn. t. 718 . (ad pagos, in sylvaticis liumidiusculis, et paludosis. Jun. Jul)

2. If dysenterica: foliis amplexicaulibus cordatooblongis incano-tomentosis repandis obsolete denticulatis, ramis lateralibus medios superantibus patulis, squamis calycinis setaceis. $F l$. dan. t. 410. (in pratis humidis, fossisque exsiccatis. Jul. $\Lambda$ ug )

3) I. salicina: [Buphthalmum salicinum] foliis $\therefore$ anplexicaulibus lanceolatis recurvis nudis, serratis scabriusculis, ramis angulatis, inferioribus altioribus. $F l$. dan. t. 786. (in pratis nemorosis. Jul. Ang.)

4. I. hirta: foliis sessilibus lanceolatis obsolete serratis rigidis hirtis, caule subunifloro, caly- 


\section{$-149$}

cinis squamis lanceolatis ciliatis. Jacqu. [austr. t. 358. (in pratis montosis nemorosis. Jum. Jul.)

298. Chrysantinenum. Receptaculum, nuurlum: Pappus nullus. Calyx hemisphaericus imbricatus, squamis marcinalibus membranaceis.

1. C. Leucanthernum: foliis amplexicaulibus lanceolatis serratis basi inciso-dentatis, caule erecto ramuso. Fl.tan. t. 994. (in pratis, arvis, pascuis, inter segetes. Jun. Jul)

b. Chrysanthemum sylvestre: tota planta liir. suta atque robustior. (in arvis et sylvis. Jul)

2. C. montanum: foliis inferioribus petiolatis spathulatis serratis, superioribus lineari-lanceolatis serratis, caule subuniforo, Allion. pedemont. t. 37. f. 2. (in collibus siccioribus ad oppodium Podolsk. Jul.)

299. Prretinua. Receptaculum nndumplaniusculum. Pappus marginatus. Calyx hemisphaiericus imbricatus, squamis acutiusculis margine scariosis.

2. P. corymbosum: [Chrysanthemum corymbo. sum] foliis pinnatis, pinnis lanceolatis pinuatifidis argute serratis, summis confluentibus, pedunculis corymbosis Jacqu. austr. t. 379. (in sylvaticis montosis, in marginibus sylvae St. Annae, et in Kunzowa. Jun. Jul.)

2. P. Parthenium: [Alatricaria Parthenium] folii pinnatis, pinnis oblongis obtusis pinnatifidis dentatis, sumnis confluentibus, caule rasnoso, floribus corymbosis, radio calyce fere duplo 


\section{- 150}

longiore, pappo dentato. Fl.dan.t. 674. (in cultis, hortisque. Jun. Jul.)

3. P. inodorum: [Chrysanthemum inodorum] fo, liis bipinnatis, pinnis lineari-filiformibus bivel tripartitis, caule diffuso ramoso, pappo gerrimo. Fl. dan. t. 696. (in ruderatis, arvis, agris, cultis. Jul. Aug.)

300. Matricaria. Receptaculum nudum cylin. draceo-conicum, Pappus nullus. Calyx planus imbricatus, squamis margine scariosis,

1. M. sunveolens: foliis triplicato-pinnatis, squa= mis calycinis acutis. (in ruderatis, circa pagos. Jul. Aug )

\&. M. Chamomilla: foliis bipinnatifidis linearibus glabrir, radio patente, squamis calycinis obtusiusculis, Engl.bot, t. 1232. (in agris, cultis, inter segetes. Jul.)

301. Antremis. Receptaculum paleaceum. Pap. pus nullus sive margo membranaceus. Calyx hemisphaericus subaequalis, Flosculorum radii plus quain quinque.

1. A. arvensis: receptaculis conicis, paleis lanceolatis, seminibus coronato-marginatis, fo= liis bipinnatis, laciniis lanceolato-linearibus. $F l$. dan. t. 1178. (inter segetes, in agris, hor. tis, viis. Jun. Jul.)

2. A. Cotula: receptaculis conicis, paleis setaceis, seminibus nudis, foliis bipinnatis, foliolis subulatis tripartitis. Fl. dan.t. 1279. (in agris et ruderatis, Jun, Jul.) 


\section{$-151$}

3. A. tinctoria: foliis bipinnatifidis argute serratis subtus pubescentibus, caule erecto ramoso, pappo membranacen integerrimo. $F l$ dan t. 742 . (in collibus et aggeribus, arvis, dumetis, sepibusque. Jul. Aug.)

302. Acirllea. Receptaculum paleaceum. Pappus nullus. Calyx ovatus imbricatus. Flosculi radii circiter quaterni.

2. A. Ptarmica: foliis linearibus acuminatis aequaliter argute serrulatis glabris, caule paniculato, corymbis compositis, paleis integris. $F l$. dan. t. 643. (in pratis humidiusculis, ad sylvam St. Annae, in Kunzowa et Perowa. Jul.)

2. A. Millefolium: foliis bipinnatis multifidis glabriusculis, pinnarum laciniis linearibus incisodentatis suberectis. Fl. dan. t. 737. (in pratis, pascuis, versuris, viigque. Jun. Aug.)

b. Millefolium purpureum: corollulis purpureis. (in aggeribus, coemeteriis et sylyis. Jul. Aug.)

\section{F R U S T R A N E A.}

303. Heliantius. Receptaculum paleaceum planum. Pappus diphyllus. Calyx imbricatus subsquarrosus.

1. H. tuberosus: foliis triplinerviis scabris, inferioribus cordato-ovatis, superioribus ovatis acuminatis alternis, petiolis basi ciliatis. Jacqlø. hort.t. 162 . (in campis et cultis peremuans) 
304. Centaurea. Receptaculum setosum. Pappus simplex. Corollae radii infundibulifornes longiores irregulares.

1. C. phrygia: calycibus recurvato-plumosis, foliiș oblongis indivisis scabris mucronato-serrulatis. Fl. dan t. 520 . (in pratis montosis sylvaticis. Jun. Jul.)

2. C. Cyanus: calycibus serratis, foliis linearibus sessilibus integerrimis, infumis basi pinnatifidis. Fl. dan. t. 993. (inter segetes. Jun. Jul.)

Variat in hortis corollis coeruleis, cyancis, violaceis, lilacinis, ptirpureis, sanguineis, rubris, incarnatis, roseis et albis.

3. C. paniculata: calycibus ciliatis ovatis adpressis, foliis inferioribus bipinnatifidis, superioribus pinnatifidis, caule paniculato. Moris. hist. III. t. 23. f. 15. (in collibus, ruderatis, versuris, agris, arvis, viis. Jun. Jul.)

4. C. Scabiosa: calycibus ciliatis pubescentibus, foliis pinnatifidis scabriusculis, laciniis lanceolatis acutis basi pinnatifidis. Fl. dan, t, 1231. (in pratis, versuris, arvis, aggeribus, nemoribus. Jun. Jul.)

5. C. Jacea: calycibus scariosis, squamis ovatis apice laceris, foliis lanceolatis integerrimis, radicalibus subdentatis, ramis angulatis. $F \vec{l}$ dan. t. 519. (in pratis, graminosis, pascuis, sylvaticis. Jun. Aug.) 


\section{N E C E S S A R I A.}

305. Fifago. Calyx imbricatus Receptáculum nullum. Pappus nullus. Flosculi ferninei inter squamas calycis locati.

1. F. arvensis: [Gnaphalium arvense] caule erecto herbaceo paniculato, foliis oblongo-lanceolatis lanuginosis, floribus congestis subspicatis mollissime tomentosis. (in campis et arvis sterilibus. Jul, Aug.)

\section{G Y N A N D R I A.}

\section{IM O N A N D R I A.}

306. Orchis. Corolla pentapetala, petalo superiore fornicato. Lahellum basi subtus calcaraturn. Antliera terminalis adnata

\section{* Radicibus testiculatis.}

1. O. bifolia: labello lineari integerrimo obtuso, cormu germine duplo longiore, foliis caulinis vaginantibus brevissimis, radicalibus binis oblongis basi attenuatis. Fl. dan. t. 235. (in nemaribus, pascuis hurnidis. Mai. Jun.)

2. O. cucullata: labello trifido, laciniis acutis, calcare germine breviore incurvato, spica laxa secunda, foliis radicalibus binis ovatis. Gmel. sıbir. I. t. 3. f. 2. (in montibus passerinis, Archangelsk, Perowa, Gorenki, Kúskovia, $\mathrm{P}_{\mathrm{e}}$ trowsk. Jun. Jul.)

3. O. coriophora: labello trifirlo, lacinia media angustiore integerrima, lateralibus reflexis de: 
ticulatis, calcare brevissimo, petalis conniven. tibus Hall. stirp.t 34. (in pratis. Jun.)

4. O. Morio: labello trifido, lobis crenatis obtusis : medio emarginato, petalis adscendentibus obtusis, cornu conico adscendente germine breviore Schkuhr. t. 271. in pratis humidiusculis. Mai. Jun.)

5. O. mascula: labello trifido crenulato obtuso, lobo medio bifido, cornu obtuso adscendente germen aequante, petalis acutis: exterioribus reflexis, foliis lato-lanceolatis, Jacqu. ic. rar, t. 180 (in pratis humidis nemorosis. Jun. Jul.) 6. O. militaris: labello tripartito punctato sca. bro, Jaciniis lateralibus linearibus, intermedia biloba obtusa cum nucrone interjecto, petalis acutis conniventibus, comnu recto germine duplo breviore, bracteis obsoletis. Hall. stirp. t. 28. (in nemoribus, sylvaticis. MIai. Jun.)

$$
\text { ** Radicibus palmatis. }
$$

7. O. latifolia: labello leviter trilobo lateribus reflexo, petalis superioribus conniventibus, bi* nis lateralibus reflexis, cornu conico germine breviore, bracteis flore longioribus, $\mathrm{Fl}$. dan. t. 2G6. (in pratis humidis. Jun. Jul.)

Variat corollis violaceis, sanguineis, purpureis, rubris, incarnatis, roseis, albisque, neo won foliis fusco-maculatis.

b. Orchis angustifolia: foliis lineari-lanceolatis canaliculatis, spica conferta, labello subcuneato, lobo intermedio obsoleto, bulbo bipartito divaricato. (in pratis paludosis. Jun, Jul.) 


\section{$-155-$}

8. O. maculata: labello plano trilobo crenato, petalis superioribus conniventibus, lateralibus patentibus, cornu cylindraceo germine breviore, bracteis longitudine germinis. Fl. dan. t. 933. (in nemoribus, pratisque succulentis. Jun. Jul.)

b. Orchis alba: corollis albis.

9. O. conopsea: labello obtuse trilobo, petalis lateralibus patentissimis, cornu subulato germine duplo longiore. $F l$. dan. t. 224. (in pratis nemorosis montosis. Mai. Jun.)

307. NeоттiA. Corolla pentapetala ringeris, petalis exterioribus lateralibus antice circa basin labelli ventricosi connexis. Anthera stylo acuminato parallela, postice inserta.

1. N. repens: [Satyrium repens] foliis radicalibus ovatis petiolatis reticulatis, scapo vaginata floribusque pubescentibus, floribus secundis, labello petalisque lanceolatis. $\mathrm{Fl}$. clan, t. 810 . (in sylvis sterilibus, versus Butirki, Petrowsk. Jun. Jul.)

8. N. spiralis: [Ophrys spiralis] labello ovato crispato crenulato, spica tortili, floribus secundis, foliis radicalibus subpetiolatis oblongis, $\mathrm{Fl}$. dan. t. 387. (in nemorosis montosis, herbidisque sylvaticis. Jul. Aug.)

308. Satroium. Corolla pentapetala ringens, petalo superiore fornicato. Labellum lineare, partitum vel subintegrum. Calcar breve subinflatum aut nullum. Anthera orchidis.

1. S. viride: bulbis palmatis fibrosis, foliis oblongis obtusis, labello lineari trifido, lacinia in. 


\section{- $560-$}

termedia breviore. Engl. bot. t. 94. (in pratis sylraticis montosis, in Perowa et Kunzowa. Jul. Aug.)

2. S. Monorchis: [Ophrys Monorchis] bulbo globoso, scapo nudo, labello trifido cruciato basi subgibboso. Fl dan. $t$ 22. (in collibus graminosis, pratisijue subhumidis. Jun)

309. Eripactis. Corolla pentapetala erecto-patens. Labelluń ecalcaratum. Anthera opercularis persistens. Pollen pulvereo-granulatum.

1. E. latifolia: [Serapias latefolia] foliis ovatis amplexicaulibus, bracteis inferioribus flore longioribus, floribus pendulis, labello integerrino acuminato petalis breviore, germinibus pubescentibus. Fl, dan. t. 81. (in sylvis montosis. Jun. Jul.)

2. E. palustris: [Serapias longifolia] foliis lanceolatis amplexicaulibus, bracteis flore brevioribus, floribus pendulis, labello crenato obtuso petalis aequali, germinibus pubescentibus. Fl. dan. t. 267. (in pratis udis sylvaticis prope Kuskowa. Jul.)

3. E. grandiftora: [Serapias lancifolia] foliis oblongo-lanceolatis sessilibus, bracteis germine longioribus, floribus erectis, labello obtuso petalis breviori, germine glabro. Engl. bot.t. 271. (in sylvaticis montosis, solo calcareo. Jul.) 4. L. rubra: [Serapias rubra] foliis lanceolatis, bracteis gemine glabro longioribus, floribus ercetis, labello acuto lineis undulatis notato. Fl. dan.t. 345. (cum praccedcrite. Jul.) 


\section{$-157-$}

5. E. Nidus avis: [Ojhrys Nidus avis.] raule, aphyllo vaginato, labello ohrordato petala obtusa duplo superante. $F$, dan, t, 18e. (in nenoribus umbrosis, ad radices querci. Jun)

6. E. ovata: [Ophrys ovata] caule bifolio', foliis ovatis oppositis, labello lineari petalis obtusis triplo longiore. Fl. dan. t. 237. (in nemorusis. Mai. Jun.)

7. E. cordaca: [Ophrys cordata] caule bifolio, foliis cordatis, labello basi utrinque unidentato. Engl.bot. t. 358: (in sylvis hunentibus montosis, circa Gurenki. Jul.)

310. MALAxis. Corolla pentapetala patens resupinata. Labellum concavo-patulum adscendens. Anthera opercularis.

1. Mi. munophylla: [Ophrys monoplylla] folio subsolitario ovato acuto, scapo triquetro, labello conçavo acuminato. Jacyu. coll. IV. t. 23 . f o. (in paludibus sylvaticis. Jul.)

b. Malaxis bifolia: major, foliis binis. Buxb. cent. III $\mathrm{t}$ 26. (in umbrosis. Jul.)

311. Crmbinium. Corolla pentapetala erecta vel patens. Labellum basi concavum ecalcaratum, lamina patula. Anthera opercularis decidua.. Pollen globosum.

1. G. Corallorhiza: [Ophrys Corallorhizn] cäule aphyllo vaginato, floribus erectis, petalis lanceolatis, infimis deflexis, lahello oblongo integro. $F l$. dan. t. 451. (in sv]vaticis paludosis, Kunzowa et Kuskiowa, Jun, Jul) 


\section{- 158}

\section{DIANDRIA.}

312. Cypripedium. Corolla tetrapetala patens. I tabellum ventri cosum inflatum. Stylus superne-lobo petaloideo appendiculatus.

1. C. guttatum: caule diphyllo, foliis alternis ovato-oblongis obtusis, loho styli ovato emarginato deflexo, Jabello petalis obtusis longiore. Amm. ruth. t. 22. (in montibus passerinis. Jul. Fortunatow.)

\section{H E X A N D I A.}

313. Anrstolocria. Calyx nullus. Corolla monopetala ligulata basi ventricosa. Capsula sexlocularis infera polysperma.

1. A. Clematitis: foliis subrotundo-cordatis obtusiusculis petiolatis, caule erecto, pedunculis unifloris aggregatis, corollis erectis, labio oblongo. Fl.dan. t. 1235. (in sylvaticis et nemorosis. Jun.)

\section{O N O E C I A.} MONANDRIA.

324. Chara. Mas. Calyx nullus. Corolla nulla. Anthera glohosa sessilis.

Femina: Calyx nullus. Corolla nulla Stylus nullus. Stigmata quina. Bacca unilocularis poly. sperma. 
¿. C. vulgaris: caulibus ramulisque hasinudis, $\mathrm{ra}$ mulis teretibus, articulis foliosis, foliolis oblon. go - suhulatis, hracteis bacca brevioribus. Engl. bot. t. 336. (in aquis stagnantibus, Jun. Aug.)

\section{I A N D R I A.}

31.5. Lemia. Mas: Calyx monophyllus. Cos rolla nulla.

Femina: Calyx monophyllus. Corolla nulla. Stylus singulus. Capsula unilocularis disperma.

1. L. trisulca: foliis lanceolatis in petiolum attenuatis cruciatim cohaerentibus, radicibus solitariis. Engl bot. t. 926. (in agris stagnantibus, lacubus et fossis. Jun.)

2. L. minor: foliis ellipticis utrinque planis basi cohaerentibus, radicibus solitariis. Engl. bot. t. 1095. (cum priore. Jun)

3. L. gibba: foliis ellipticis subtus hemisphaericis basi cohaerentibus, radicibus solitariis. Engl. bot. t. 1233. (cum antecedentibus.)

4. L. polyrhiza: foliis ellipticis planis basi cohaerentibus, radicibus fasciculatis Schkuhr. $t_{\text {o }}$ 837. (cum ceteris generis sui. Jun.)

\section{T R I A N D R I A.}

316. Trpira. Mas: Amentum cylindricum. Ca. lyx obsoletus triphyllus Corolla nulla.

Femina: Amentum cylindricum sub-masculo. Calys nullus. Corolla nulla. Semen unicum pe- 


\section{$-160$}

dicellatum, pedicello basi pilis longis pappi instar cincto.

x. T. latifolia: foliis linearibus planis, spira mascula femineaque approxinatis, utraque $\mathrm{cy}-$ lindrica Fl. dan. t. 645. (in paludibus, piscinis, fossisque profundioribus Jul).

2. T. angust folia: foliis linearibus canaliculatis, spica mascula femineaque remotis, utraquecylindrica. Fl. dan. t. $8^{\circ} 5^{\circ}$ (in paludibus, stagnisque Jul.)

317. Spanganium, Mas: Amentum subrotumdum. Calyx triphyllus. Corolla nulla.

- Femina: Amentum subrotundun. Calyx triphyllus. Corolla nulla. Stigma bifidum. Drupa exsucca monosperma.

2. S. rumosum: foliis basi triquetris, lateritus concavis, pedunculo commini ramoso, stigmate lineari, Engl. bot. t. 744. (in aquis lente fluentibus. Jul)

2. S. simplex: foliis hasi triquetris, lateribus planis, perlunculo communi simplici, stigmate lineari. Engl. bot. t. 745 (in aquosis, paludosis. Jul)

318. Canex. Mas: Amentum imbricatum. Calyx squama solitaria., Corolla rulla.

Femina: Anentum imbricatum: Calyx squama solitaria. Corolla ventricosa monopetala apice bidentata. Stigmata bina ternave. Nux triquetra corolla persistenti inclusa.

* Spicis dioicis. 
1. C. dioica: [Linnaenna] spica dioica simplici, stigmatibus hinis, fructibus erectiusculis ovatis nervosis, foliis culmisque glabris, radice repente. Schkuhr. t. A. f. 1. (in pratis spongiosis paludosis. Mai.)

\section{** Spica unica androgyna.}

e. C. pulicaris: spica androgyna simplici superne mascula, stigmatibus binis, fructibus oblongis teretiusculis glabris reflexis utrinque attenuatis, squama oblonga persistente longioribus. Schkuhr. t. A. f. 3. (in pratis, pascuisque li- mosis. Mai.)

$$
\text { ** Spicis androgynis sessilibus alternis. }
$$

3. C. Chordorhiza: spicis androgynis superne masculis in formam ovatam aggregatis, fructibus ovatis acuminatis, foliis culmeis adpressis, culıno basi subramoso. Schkuhr, t. G. f. 31. (in paludibus, circa Gorenki. Mai. Londes.)

4. C. arenaria: spica androgyna composita, spiculis alternis confertis: superioribus masculis, inferioribus femineis, intermediis apice masculis, stigmatibus binis, fructibus ovatis marginatis bifidis ciliato - serratis, culmo incurvo. Schkuhr. t. B. f. 6. (in arenà mobili, Jun.)

5. C. intermedia : [disticha] spica androgyna composita, spiculis alternis confertis, inferioribus remotiusculis: superioribus et inferioribus $f e$ mineis, intermediis masculis, stigmatibus binis, fructibus ovatis marginatis bifidis ciliato-serratis, culmo erecto. Schkuhr. t. B. f. 7. (in pratis udis et paludibus. Jun. Jul.) 
6. C. Schreberii: [praecox] spica androgyna composita, spiculis ovatis alternis confertis inferue masculis, stigmatibus binis, fructibus ovatis bidentatis. Schkuhr. t B. f. 9. (in collibus herbidis, siccis graninosis. MTai. Jun.)

7. C. leporina: [Lrchonalii] spica androgyna, spiculis tribus subrotundo-ellipticis inferne masculis alternis congestis, fructibus ellipticis compressis acuminatis, ore integris. Schkuhr. t. Fff. f. 129. (in pratis. IMai.)

8. C. ovalis: [leporina] spica androgyna composita, spiculis subsenis subrotundo-ellipticis alternis subapproximatis inferne masculis, stigmatibus binis, fructibus ovatis marginatis bidentatis ciliato-serratis. Schkuhr. t. B. f. 8. (in pratis udis circa Butirki. Mai. Jun.)

9. C. vulpina: spica androgyna composita, spiculis numerosis ternatim quinatimve aggregatis oblongis confertis superne masculis; stigmatibus binis, fructibus ovatis bidentatis compressotriquetris patentibus, bracteis setaceis. Schliuhr. t. C. f. 10. (in paludibus, ad fossas. Mai Jun.) 10. C. brizoides: spica androgyna composita subdisticha, spiculis subquinis alternis curvatis oblongo-lanceolatis approximatis inferne masculis, stigmatibus binis, fructibus ovatis marginatis bifidis. Host. gram. I. t. 47. (in graminosis umbrosis. Mai, Jun.)

11. C. mucicata: [cancscens] spica androgyna composita, spiculis ovatis superne masculis approximatis, stigmatibus binis, fructibus hori- 
zontalibus ovatis plano'- convexis bidentatis basi marginatis, margine ciliato-serratis. Schkuhr. t. E. f. 22. (in sylvis, pratisque humidis. Mai )

22. C. stellulata: [echinata] spica androgyna composita, spiculis subquaternis remotiusculis inferne masculis, stigmatibus binis, fructibus ovato - acuminatis bidentatis margine ciliatoserratis horizontalibus, squamis ovatis acutis. Schluhr. t. C. f. 14. (in pratis humidis versus Butirki. Jun.)

13. C. remota: spica androgyna composita, spiculis alternis remotis inferne masculis, bracteis foliaceis longissimis suffultis, fructibus ovatis acuminatis bifidis compressiusculis. Schkuhr. t. E. f. 23. (in sylvis, nemoribusque subhumidis. Mai. Jun.)

14. C. clongata: [multiformis] spica androgyna composita, spiculis subduodenis alternis approximatis cylindraceis inferne masculis, stigmatibus binis, fructibus ovato-acuminatis emarginatis nervosis patulis squama ovata obtusa longioribus Schkuhr, t E. f. 25. (in paludosis, nemoribus humidis. Jun.)

*** Spicis androgynis paniculatis.

15. C. paniculata: spicis androgynis paniculatis superne masculis, stigmatibus binis, fructibus ovatis superne marginatis bidentatis margine ciliato-serratis, culmo triquetro. Schkuhr. t. D. f. 20. (in paludibus, nemoribus udis. Mai. Jul.) 
** * * Spicis sexu distinctis: mascula solitar.a, femineis sessilibus seu incluse pedunculatis.

36 C. pilulifera: [montana] spica mascula solitaria, femineis subternis approximatis ellipticosubrotundis sessilibus, stigmatibus ternis, fructibus subrotundis breve rostratis pubescentihus squama oblonga acuta brevioribus, culmo decumbente. Schkuhr. t. I. f. 39. (in nemoribus subudis. MIai.)

17. C. collina: [montana] spica mascula solitaria, femineis subgeminis approximatis ellipticis stessilibus, fructibus oblongis brevissime rostratis pubescentibus, foliis radicalibus annotinis culmo longioribus. Schkuhr. t. F. f. 29. (in collibus apricis et montosis. Mai. Jun.)

28. C. cilinta: [ericetorum] spica mascula solitaria, femineis subgeminis approximatis oblongis sessilibus, fructibus subrotundo-obovatis pubescentibus squama oblonga obtusa majoribus. Schkuhr. t. I. f. 48. (in ericetis, collibusque arenosis. Mai.)

19. C. digitata: spica mascula solitaria sessili, femineis subternis linearibus remotiusculis, stigmatibus ternis, fructibus obovatis rostratis triquetris pubescentibus squamam obovatain mucronatam aequantibus, bracteis vaginatis obliquis mucronatis margine membranaceis. Schkuhr. t. H. f. 38. (in collibus herbidis nemorosis, sylvisque umbrosis. Jul. Ang.)

80. C. flava: spica mascula solitaria, femineis - ubternis subapproximatis ellipticis incluse pe- 
dunculatis, stigmatibus ternis, fructibus ovatis reflexis rostratis, rostro curvato bidentato, squan!a ovato-lanceolata longioribus. Schliuhr. t. H. f. 36. (in pratis pascuisque humidis. Mai.) ***** Spica mascula solitaria. femineis plus minusve pedunculatis.

\&. C. pilosa: spica mascula solitaria, femineis subternis distantibus, binis inferioribus remotis, stigmatibus ternis, fructibus ovatis rostratis, ore membranacen obliquo emarginato, -squama ovata majoribus, foliis ciliatis. Schkuhr. ז. M. f. 49. (in sylvis montanis. Mai. Jun.)

22. C. panicea: spica mascula solitaria, femineis subbinis remotiusculis, suprema subinclusa pedunculata, infima longe pedunculata, stigmatibus ternis, fructibus ovatis obtusis squama ovata majoribus. Schkuhr. t. L l. f. 100. (in pratis udis, nemoribusque humentibus. Jun. Henning.)

e3. C. sylvatica: [Drymeja] spica mascula solitaria, femineis quaternis remotis filiformibus pedunculatis cernuis, stigmatibus ternis, fructibus ovati-rostratis bifidis. squamam ovatam membranaceam mucronatam subaequantibus. Schkuhr. t. L1. f. 102. (in nemoribus, sylvisque humentibus. Jun. Jul.)

24. C. Pseudo-Cyperus: spica mascula solitaria, femineis quaternis geminatis pedunculatis pendulis cylindricis, stigmatibus ternis, fructibus ovato-lanceolatis bicuspidatis reflexis squaman 
setaceam aequantibus. Schkuhr. t. M m.f. 102. (in fossis, praesertim in tribus montibus et montibus passerinis. Mai.)

Var: spica androgyna. Henning.)

25. C. pallescens: spica mascula solitaria, femineis subternis pedunculatis cernuis ellipticis, stigmatibus ternis, fructibus ovato-oblongis obtusis squamam oblongam cuspidato - mucronatam aequantibus, foliis pubescentibus. Sclikulur.t. Kk. f. 99. (in pratis, pascuis, sylvisque paludosis. Mai. Jun.)

26. C. limosa: [elegans] spica mascula solitaria, femineis binis ovatis pedunculatis pendulis, fructibus ellipticis compresso - triquetris brevissime rostellatis, ore integro. Schkuhr.t. X. f. 78. (in pratis udis, paludibusque turfosis. Mai )

27. C. caespitosa: spica mascula subsolitaria, femineis cylindraceis obtusis subternis distantibus, infima brevissine exserte pedunculata, stigmatibus binis, fructibus ovatis obtusis ore pertusis squama oblonga obtusa majoribus, foliis patulis. Schkuhr, t. A a. et B b. f. 85 . in pratis paludosis turfosis. Mai. Jun.)

******* Spicis masculis pluribus.

28. C. filiformis: spicis masculis geminis, femineis geminis ovato-oblongis sessilibus distantibus, stigmatibus ternis, fructibus ellipticis bifurcatis lanatis squamam oblongo-lanceolatam subaristatam aequantibus. Schkuhr.t. K. f. $4,5$. (in paludibus nemorum profundis. Mai. Jun.) 


\section{$-\quad 167$}

29. C. acuta: [ racilis] spicis masculis binis ternisve, femineis subquaternis subpedunculatis subnutantibus cylindraccis remotis, stigmatibus binis, fructibus oblongis brevissime rostellatis, ore integro pertuso, 'squamam oblongam acutam subaequantibus. Schluhr t. Ee. f. g2. (in paludibus, pratis udis, inundatis, ad fossas. Mai. Jun.)

b. Carex nigra: spicis masculis nigris, femineis erectis. Schkuhr. t. Ff. 92. (cum praccedente. Jun )

30. C. paludosa: $[r u f a]$ spicis masculis binis, femineis ternis erectis cylindraceis attenuatis, inferioribus pedunculatis, stigmatibus ternis, fructibus ovatis nervosis bidentatis squama lanceolata aristata latioribus camque aequantibus. Schkuhr. t. Oo. f. 203. (in fossis et paludibus. Mai)

31. T. vesicaria: [inflata] spicis masculis subquaternis, femineis binis erectis pedunculatis cylindraceis, stigmatibus ternis, fructibus oblongis inflatis rostratis bicuspidatis squama lanceolata majoribus, culmo acute triquetro. Schkuhr. t. Ss. f. 106. (in paludibus, udisque sylvaticis. IIai. Jun.)

32. C. ampullacea: [bifurca] spicis masculis tribus, femincis binis cylindraceis breve pedunculatis erectis, fructibus subglobosis inflatis rostratis bifurcatis, culmo obtuse triquetro. Schkuhr. t. Tt. f. io7. (in paludosis. Mrai. Jun.) 


\section{$-\quad 168$}

33. C. hirta: spicis masculis binis, femineis tribus obtongis remotis, inferioribus breve pedunculatis, stignatibus ternis, fructibus oblongis acuminatis bicuspidatis squama oblonga aristata majoribus, vaginis foliisque hirtis. Schkuhr. t. Uu. f. 108. (in pratis et versuris sabulosis udisque. Mai.)

\section{T E T R A N D R I A.}

310. Arvus. Mas: Amentum receptaculis cuneiformibus truncatis trifloris compositum. Calyx squanı. Corolla quadripartita.

Femina: Amentum. Calyx squamae biflorae. . Corolla nulla. Semina compressa ovata nuda.

1. A. glutinosa: [Betula Alnus] foliis subrotundocuneatis obtusis subretusis glutinosis, axillis venarum subtus villosis. Kern. Wïrt. II. t. 14 . (in pratis udis, ad fossas. Apr. Mai.)

320. Untrca. Mas: Calyx tetraphyllus, Corolla nulla. Nectarium centrale cyathiforme.

Femina: Calyx hivalvis. Corolla nulla. Semen unicum nitidum.

1. U. urens : foliis oppositis ellipticis subquinquenerviis argute serratis, spicis glomeratis geminatis. $F l$. dan. t. 739 . (in cultis ruderatis, ad sepes. Jun. Aug )

8. U. dioica: foliis oppositis cordatis ovato-lanceolatis grosse serratis, floribus dioicis, spicis paniculatis glomeratis geminatis petiolo longio- 


\section{$-\quad 169$}

ribus. Fl. dan. t. 746. (in ruderatis, sepibus, hortis. Jun. Augs.)

\section{P E N T A N D R I A.}

321. X.1xтnum. Mas: Calyx communis imbricatus. Corollae monopetalae quinquefidae infundibuliformes. Receptaculum paleaceum.

Femina: Calyx involucrum diphyllum uniflorum. Corolla nulla. Lrupa sicca muricata bifida. [Nux bilocularis.

2. X. strumarium: caule inermi, foliis cordatis trinervatis lobato-serratis. $F l$. dan. t. 970. (in ruderatis, arvis, ad vias. Jul.)

322. Amarantius. Mas: Calyx tri-seu pentapliyllus. Corolla nulla. Stamina terna quinave.

Femina: Calyx maris. Corolla nulla. Styli terni. Capsula unilocularis circumscissa. Semen unicum.

2. A. Blitum: glomerulis triandris subspicatis, floribus triphyllis, foliis ovatis retusis, caule diffuso. Pluken. phyt. t. 212, f. 2. (in cultis, lıortis. Jul. Aug.)

\section{P O L Y A N D R I A.}

323. Ceratophylum. Mas: Calyx multipartitus. Corolla nulla. Stamina sena, dena, usque vicena, brevissima. Antherae tricuspidatae.

Feinina: Calyx hexaphyllus imbricatus. Corolla nulla. Pistillum singulum. Stylus flifermis. Nux monusjerma, 
x. C. demersum: foliis dichotomo-bigeminis, firctibus trispinosis. Engl. bot. t. 947. (in aquis stagnantibus, lacubus, fossis. Jun. Jul.)

324. Mrropmylum. Mas: Calyx quadrifidus bractcatus. Corolla tetrapetala, caduca. Stamina quaterna, sena, octonave,

Femina: Calyx et Corolla maris. Pistilla quaterna. Stylus nullus. Semina quaterna corticata. 1. M. spicatum: foliis omnibus pinnatis capillaceis, spica terminali verticillata nuda. Fl. dan. t. 681. (in fossis et stagnis. Jul. Aug.)

2. $M$. verticillatum: foliis pinnatis capillaceis, sumnis pectinato-pinnatilidis, floribus axillaribus verticillatis. $1 \%$. dan. t. 1046. (in aquis quietis, in montibus passerinis et tribus montibus. Jul. Aug.)

325. Sagittaria. Mas: Calyx triphyllus. Co: rolla tripetala. Filamenta fere vicena quaterna.

Femina: Calyx et Corolla maris. Pistilla multa. Semina plurima nuda.

1. S. sagittijolia: foliis lanceolatis acuminatis sagittatis, lobis Janceolatis rectis, scapo simplici petiolisque sulcato-angulatis. Fl. dan. t. 172 . (in fluviis, lacubus, piscinis, fossis. Jun. Jul.)

b. Sagittaria natans: foliis longissimis natantibus. (in aquis profundis.)

326. Ротеrium. Mas: Calyx tetraphyllus. Corolla quadripartita. Stamina tricena lusque quadragena Femina: Calyx et Corolla maris. Pistilla bina. Bacca e tubo corollae indurato.

3. P. Sanguisorba: inerme, caulibus subangulo- 
sis. Engl. bot. t. 806. (in pratis montosis asperis calcareis. Jun)

327. Quencus. Mas: Calyx subquinquefidus. Corolla nulla. Stamina quina ad dena usque.

Eemina: Calyx monophyllus integerrimus scaber. Corolla nulla. Styli bini usque quini. Nux coriacea calyce persistente basi cincta.

2. Q. Robur: fcliis oblongis petiolatis glabris sinuatis, lobis rolundatis, fructibus oblongis sessilibus. Engl. bot. t. 1342. (in nemoribus et sylvis. Mai,)

2. Q. pedunculatus: foliis oblongis subsessilibus glabris sinuatis, lobis rotundatis, fructibus oblongis pedunculatis. Fl. dan. t. 2280 . (cum priore. Mai.)

328. Berula. Mas: Amentum imbricatum squamis peltatis trifloris. Calyx squama. Corolla nulla. Stamina dena usque duodena.

Femina: Amentum imbricatum. Calyx squama biflora. Corolla nulla. Semen singulum alatum.

1. B. alba: foliis ovato - deltoideis acuminatis duplicato-serratis glabris. Blackw. t. 240. (in nemoribus, sylvis, propriisque betu?etis Mai.)

b. Bctula pendula: foliis deltnideis acuminatis inciso-duplicato-serratis glabris, strobilorum siquamis subtrilobis. Sckilihr. III. t. 283. (cum priore. NIai.)

2. B. nana: foliis orbiculatis crenatis glabris subtus reticulato-venosis. Fl. dan. t. 9r. (in pa. ludibus inontosis sylvaticis, ad urbem Klin. Mai. Stephar.) 
329. Conycus. Mrs: Amentum imbricatum. Calyx squama. Corolla nulla. Stamina octona.

Feminu: Calyx bipartitus lacerus. Corolla nulla. Styli bini. Nux ovata calyce persistente cincti. 1. C. Avellana: stipulis oblongis obtusis, calycibus fructus campanulatis apice patulis lacerodentatis, foliis subrotundis condatis acuminatis. Engl. bot. t. 723. (in nemoribus, sepibus, hortis. April Mai.)

b. Corylus maxima: calycibus patentissimis inciso-dentatis, nuce depressa ovata. (in hortis. Mai.).

\section{O NA D ELPHIA.}

330. Prnus. Mas: Calyx tetraphyllus. Corolla nulla. Stamina plurima. Antherae nuảae.

Femina: Calyces strobili: squama tiflora. Co, rolla nulla. Pistillum singuluen. Nux ala membra. nacea excepta.

1. P. sylvestris: foliis geminis rigidis, strobili ovato-conicis longitudine foliorum subgeminis basi rotundatis, Lamb. pin.t. 1. (in sylvis, pinetisque propriis. Mai.)

2. P. Abies: foliis solitariis tetragonis, strobilis cylindraceis, squamis rhombeis complanatis margine repandis erosis. Lamb. pin. t. 25. (in sylvis et hortis. Mai.)

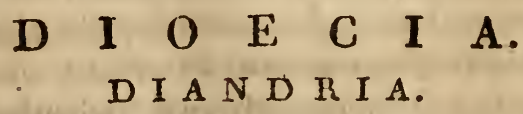

33x.Salxx. Mas: Amentum cylindraceum, Calyx squama. Corolla nulla, Glandula baseos nectarifera. 


\section{$-\quad 173$}

Femina: Amentum, Calyx, Corolla inaris. Stylus bifidus. Capsula unilocularis, bivalvis. Semina papposa.

* Foliis serratis, glabriusculis.

2. S. hermaphroditica: foliis serratis glabris, floribus hermaphroditis diandris. (habitat circa Gorenki. Mai. Londes.)

\&. S. triandra: triandra arborea, foliis oblongolanceolatis subtus glaucescentibus serratis serraturis inflexo-glandulosis, stipulis glabris ovatis crenatis deciduis, amentorum squamis villosis, capsulis glaberrimis pedicellatis. Hoffmann. salic.t. 9. t 1o. et t. 23.f. 2. (in pratis, salicetis, ad fossarum ripas. Mai.)

3. S. amygdalina: triandra fruticosa, foliis ovato-acuminatis basi inaequalibus serratis subtus glaucescentibus, stipulis semicordatis crenatis maximis, amenti squamis glabris, cap1 sulis pedicellatis glaberrinis. Linn. lappon. t. 8. f. 8. (in palustriluus, ad ripas. Mai.)

4. S. pentandra: pentandra amborescens, foliis ovalibus basi attenuatis crenulatis glabris subtus glaucis, stipulis subrullis, amenti squamis rotundatis basi villosis, capsulis glabris pedicellatis. Fl. dan. $t$ 943. (in paludosis montosis sylvaticis. Mai)

5. S. vitellinn: triandra arborescens, foliis serratis ovato-lanccolatis acutis supra glabris, serraturis cartilagineis, petiolis calloso-punctatis. Hoffm. salic. t. 12. t. 22. et t. 24. f. 1. (in humidis, salicetis, ad vias. Mai.) 
6. S. fragilis: [decipiens] diandra arborescens, foliis lanceolatis acuminatis glaberrimis serratis, serraturis inflexis glandulosis, petiolis dentatoglandulosis, stipulis rotundatis obsolete dentatis deciduis, nectario gemino. Hoffm. salic. t. 3. (in pratis, ad ripas Mai.)

7. S. monandra: [Helix] monandra arborescens, foliis lanceolatis utrimque attenuatis serrulatis glabris subtus glaucescentibus, stipulis nullis, stylo-elungato filiformi, stigmatibus linearibus, capsulis lanatis. Hoffm. salic. t. 1. f. 1. 3 . et t. 5. f. 1. et t. 23. f. 1. (in aquosis, salicetis. Mai )

8. S. myrsinites: frutescens, foliis ellipticis ovatis undique serrulatis utrinque glabris nitidis concoloribus, ranulis hirtis, amentis praecocibus, capsulis lanceolatis sericeo-pubescentibus. $F l$. dan. t. 1054. (in frutticetis humidis montosis. Mai.)

* Foliis serratis, pubescentibus.

9. S. incubacea: [angustifolia] frutescens, foliis lanceolatis utrinque attenuatis integerrimis convexis supra glabris subtus incanis subsericeis, germinibus lanccolatis sericeis, stigmatibus subsessilibus. (in locis humidis arenosis. Mai.)

1o. S. rosmarinifolia: frutescens, foliis linearilanceolatis subintegcrimis planis, supı pubescentilus, subtus sericeis, germinibus lanceolatis villusis, stylis elongatis. (in arenosis et turfosis udis, in Gorenki. Mai. Londes.)

11. S. aurita: diandra fruticosa, foliis oboratis adunce mucronatulis utrinque villosis reticula- 
to- venosis, stipulis polymorphis, capsulis longius pedicellatis subulatis villosis. Hoff in. salic. t. 5. f. 3. et. t. 22. f. 1. (in sepibus humidiusculis, nemoribusque udis. Mai.)

12. S. caprea: diandra arborea, foliis ovatis acuminatis undulatis repando-serratis, supra glabriusculis, subtus dense tomentosis venosis, stipulis sublunatis, capsulis pedicellatis ovatis birostratis villosis. $H$ offm. salic. t. 3 . et $t .21$. f. a. b. c. (in sepibus nemoribusque siccis. Mai.)

23. S. acuminata: diandra arborescens, foliis oblongo-lanceolatis acuminatis repandis apice dentatis, supra'glałris, subtus tomentosis venosis, stipulis reniformibus dentatis, capsulis pedicellatis subulatis pubescentibus. Hoffm. salic. t. 6. et t. $22 \mathrm{f}$. 2. (in nemoribus locisque humidiusculis Mai.)

24. S. viminalis: diandra fruticosa, foliis lancealato-linearibus longissime acuminatisintegerrimis subtus sericeis, ramis virgatis, stylo elongato. Hoffm. salic. t. 2. t. 5. et t. 2 x. f. e. f. g. (ad fluviorum ripas. Mai)

15. S. alba: triandra arborea; foliis lanceolatis acuminatis serratis utrinque sericcis, scrraturis infunis glandulosis, capsulis subsessilibus glabratis birostratis. Hnffm. salic. t. 7. t. 8 . et t. 24: f. 3. (ad pagos et urbes, in pratis et ad ripas fluviorum. Mai.)

332. Fraxinus, Hermaphroditi:-Calyx nullus seu quadiipartitus. Corolla tetrapetala vel nulla. Stamiua bina. Pistillum unicum. Samara mono- 
sperisa ala lanceolata terminata.

Feminei: Calyx quadripartitus sive nullus. Corolla tetrapetala vel nulla. Pistillum singulum. Samara ut supra.

2. F. excelsior: foliolis subpetiolatis lanceolatis acuminatis serratis glabris basi cuneatis, floribus nudis. Fl din. t. 969. (in sylvis, sepibus, ad pagos. Mai.)

6. Fraxinus simplicifolia: foliis simplicibus serratis ternatisque.

c. Fraxinus pendula: ramis pendulis. (cum seteris. Mai.)

\section{T E T R A N D R I A.}

337. Viscum. Mas: Calyx quadripartitus. Corolla nulla. Filamenta nulla. Antherae calyci adnatae.

Femina: Stylus nullus. Bacca infera monosperma. Semen cordatum.

1. $V$. album: foliis lanceolatis obtusis enerviis, caule dichotomo, floribus quinis terminalibus glomeratis sessilibus. Schkuhr. t. 320. (in vivario Inperiali, parasiticum in quercubus. Mai.)

\section{P E N T A N D R I A.}

334. Cannabrs. Mas: Calyx quinquepartitus, Corolia nulla.

Femina: Calyx monophyllus integer, latere hians. Corolla nulla. Styli bini. Nux bivalvis, intra calycem clausum.

1. C. sativa: foliis digitatis, caule erecto. Lam. ill. t. 814. (in culis. Jun, Jul.) 


\section{$-177-$}

335. Humuevs. Mas: Calyx pentaphyllus. Co. rolla nulla.

Femina: Calyx monophyllus, oblique patens integer. Corolla nulla. Styli bini. Semen singulum inter calycem foliatum.

1. H. Lupulus: foliis cordatis lobatis integrisque grosse serratis, caule volubili. Fl.dan. t. 2239. (in nemorosis, dumetis, sepibus. Jul. Aug.)

$$
\text { O C T A N D R I A. }
$$

336. Popurus. Mas: Amentum cylindraceum. Calyx squama lacera. Corolla turbinata obliqua integra.

Femina: Amentum, Calyx, Corolla maris. Stigma quarrifidum. Capsula bilocularis. Semina multa comosa.

1. P. tremula: foliis orbiculatis dentatis utrinque glabris, petiolis compressis, ramulis hirtis, [stigmate purpurascente] Kerner. t. 27. (in sylvis, arenosis, ad pagos. Mai.)

2. P. nigra: foliis deltoideis utrinque glabris acuminatis serratis, diametro longitudinali longiore, [stigmate nigrescente.] Kerner. t. 28. (in pratis, humilis, ad ripas. Mai.)

\section{E N N E A N D R I $A$.}

337. Mercurialis. Mas: Calyx tripartitus. Corolla nulla. Stamina novena vel duodena. Antherae globosae didymae.

-Femina: Calyx et Corolla maris. Styli bini. Capsula dicocca bilocularis, loculis monospermis. 0. Ih. perennis: caule simplicissino, foliis scabris, radice serpente. Fl.dan. to 400. (in nemo- 
ribus montofis, e. g. in montibus passetinis, Kunzowa. Mai.)

338. Hrdrocharis. Mas: Spatha diphylla. CaJyx trifidus. Corolla tripetala. Filamenta terna interiora stylifera.

Fomina: Calyx trifidus, Corolla tripetala. Styii seni, Capsula sexlocularis infera polysperma.

1. II. Morsus ranae: foliis reniformibus integris petiolatis, Fl. dan. t. 878 (in fluminibus, stagnis, fossisque limosis. Jul)

\section{O D E C A N D R I A.}

339. Stratrotes. Mas: Spatha diphylla. Ca$I_{y x}$ tripartitus. Corolla tripetala. Nectaria vicena antheriformia. Stamina undena, duodena vel terna dena.

Femina: Spatha, Calyx, Corolla, Nectariumque maris. Styli senii bipartiti, Bacca sexlocularis poJysperma.

1. Aloidcs: foliis ensiformi-triangulis ciliatoaculeatis carinatis. Fl. dan, t. 337. (in aquis pigris, praesertim in tribus montibus. Jun. Jul.) II O N A D E L P H I A.

340. Junipreus. Mas: Amentum ovatum. Calyx squama. Corolla nulla. Stamina terna.

Femina : Calyx tripartitus. Petala terna. Styli terni. Bacca trisperma, tribus tuberculis calycia inaequalis.

1. J. communis: foliis ternis patentibus mucronato-spinosis bacca longioribus. $\mathrm{Fl}$. dan. t. 1119. (in sylvaticis sterilioribus arenosis, pro. priisque juniperetis. Mai. 


$$
\text { PARS SECUNDA. }
$$

PLANTAE CRYPTOGAMAE. 



\section{GONOPTERIDES.}

1. $\mathrm{E}_{\text {QUUrseturr. Receptacula peltata plana polygona }}$ spicata, subtus indusiis quaternis usque septenis corniculatis clausis, tandem longitudinaliter rumfentibus et fructificationes occultantibus obsita. Stamina quaterna. Germen ovatum. Stylus nul. lus. Semen unicum.

1. E. arvense: caulibus sterilibus simpliciter ramosis, ramis scabriusculis tetragonis, fructificantibus simplicibus, vaginis cylindraceis inciso-dentatis, dentibus acutis. Bolton. t. 34 . (in agris, arvis et campis stcrilioribus. Maai. Jun.)

2. E. fluviatile: caulibus sterilibus simpliciter ramosis, ramis scabriusculis octogonis, fruct:ficantibus simplicibus, vaginis infundibuliformibus lacero-dentatis, dentibus aristatis. (in fluviorum fossarumque ripis humidis. Jun.)

3. E. sylvaticum: caulibus sterilibus fructificantibusque duplicato-ramosis, ramis scabriusculis deflexis tetragonis, ramulis subtriquetris. Fl dan. $t$ 1182. (in sylvis, nemoribusque umbrosis. Mai.)

b. Equisetum capillare: ramis capillaceis. (cum anteccdente, Mai)

4. E. limosurn: caulibus subramosis, ramis subduodenis pentagonis laevibus glabris, spica 
terminali. Fl. dan. t. 1184. (in fossis ripisquue lacuum et fluviorum, in inundatis. Jun.)

5. E. prlustre: caulibus simpliciter ramosis glae bris sulcatis, ramis pentagonis apice spiciferis. Fl. dan.t. 1283. (in pratis paludoso-spongiosis. Jun.)

6. E. hyemale: caulibus simplicilus erectis scaberrimis apice spiciferis, vaginis discoloribus. basi apiceque sphacelatis, dentibus aristatis omnino caducis. Engl. bot. 915. (in paludibus. Aug. Oct.)

\section{STACHYOPTERIDES.}

2. Lrcopodrum. Capsulae reniformes uniloculares bivalves polyspermae. Semina minutissima pulveriformia.

1. L. clavatum: caule repente, ramis adscendentibus, foliis sparsis enerviis incurvato-setigeris, spicis geminatis cylindricis periunculatis, squamis ovatis acuminatis eroso-denticulatis. (in sylvaticis turfosis. Jul. Aug.)

2. L. complanatum: caule erecto, ramis alternis dichotomis, foliis bifariis connatis apice patentibus, superficialibus solitariis adpressis, pedunculis quadrifidis tetrastachyis, spicis teretibus cyiudricis. $F l$. dan. t. 78 . (in pratis sylvaticis montosis. Jul. Aug.)

3. L. annotinum: caule repente, framis adscendentibus basi his bipartitis, ramulis simplicibus, fuliis quinquefariis lineari-lanceolatis nucronatis apice serrulatis patentibus, ad incrc- 
menta annua contractis, spicis solitariis sessi.

. libus terminalibus. Fl. dan. t. 27. (in nemorihus, sylvisque umbrosis uliginosis. $\Lambda$ ug. Sept.)

4. L. Selago: foliis sparsis octofariis lineari - lanceolatis acuminatis integerrimis imbricato-pa-. "ulis rigidis, caule dichotomo erecto, ramis fastigiatis. Fl. Ian. t. 104. (in nemoribus sabulo. sis humidis. Jul.)

\section{SCHISMATOPTERIDES.}

3. Botnycrum. Capsulae subglobosae, rachi racemi compositi adnatae, discretae nudae uniloculares, valvulis binis postice comnexis transverse dehiscerites.

3. B. Lunaria: [Osmunda Lunaria] scapo superne unifrondoso, fronde pinnata, pinnis lunatio integerrimis. Fl.dan. t. 18: (in collibus pascuisque apricis ac siccis, ad sylvarum margines. IVIai. Jun.)

\&. B. rutaceum : scapo superne unifiondoso, fronde bipinnatifida, laciniis emarginatis $l_{i} \mathbf{i}-\mathbf{s e u}$ tridentatis obtusis. $F l$. dan. t. 13. f. 3. (cum antecedente, in uliginosis prope Butirki, nec non ad aquaeductum versus pagum Alexejewsk. Mai. Jun.)

4. Osmunda. Capsulae subglobosae pedicellatae striatae semibivalves paniculatae: Indusium nullım.

1. O. regalis: frondibus bipinnatis, pinnulis lan. ceolatis subintegerrimis basi inferiore subauri- 
culatis, inferioribus oppositis, panicula bipinnata fructificante in apice frundis. Fl. dan. t. 217. (in paludibus nemolosis. Mai. Jun.)

\section{F I L I C E S.}

5. Polyrodium. Sori subrotundi sparsi. Indusia nulla.

1. P. vulgare: froudibus profunde pinnatifidis, Jaciniis lineari - lanceolatis obtusis crenulatis approximatis, superioribus sensim minoribus, soris solitariis, stipite paleaceo. Fl. dan. t. 1060 (in sylvis umbrosis ad arborum truncos. Mai.)

2. P. Phegopteris: frondibus bipinnatifidis, pinnis duabus infimis deflexis, laciniis lineari - lanceolatis obtusis integerrinis ciliatis, infumis adnato-decurrentibus cum oppositis rhombum fere formantibus, venis birtis, soris solitariis marginalibus. Bolton. t. 2o. f. a. b. (in nemoribus umbrosis. Aug.)

3. P. Dryopteris: frondibus tennatis bipinnatis - patulo-deflexis, laciniis obtusis sulintegerrimis, soris marginalibus, radice filiformi. Engl. bot. t. 616. (in nemoribus montosis. Aug)

6. Asprdium. [Polypodium olim] Sori subrotundi sparsi. Indusium umbilicatum.

2. A. Oreopteris: frondibus pinnatis, pinnis lanceolatis glabris subtus résinoso - glandulosis pinnatifilis, laciniis lanceolatis oltusis integerrimis, infimis sublongioribus, soris marginali- 


\section{$-185$}

bus. Fl. dan, t. 1221, (in montibus passerinis. Jun. Jul.)

2. A. cristatum: frondibus pinnatis, pinnis subcorlato-oblongis pinnatifidis, laciniis oblongis obtusis dentato-serratis, stipite paleaceo. Bolton. t. 23. (in sylvis, nemoribusque humidis. Jun. Jul.)

3. A. aculeatum: frondibus bipinnatis, pinnulis ovatis subfalcatis acutis mucronato-serratis, basi superiore truncatis, inferiore abbreviatocuneatis, superioribus fructificantibus, stipite rachique paleaceis. Bolton, t. 26. (in montibus passerinis, Kunzowa. J11.)

4. A. Filix mas: frondibus bipinnatis, pinnulis oblongis obtusis serratis, serraturis muticis, soris costae mediae approximatis, stipite rachibusque paleaceis. Bolton. t. 24. (in nemoribus saxosis umbrosis, Mai.)

5. A. spinulosum: frondibus bipinnatis, pinnulis oblongis decurrentibus confluentibus incisodentatis, laciniis mucronato - serratis, stipite paleaceo, indusiis glandulosis, Fl. dan. t. 707. (in nemoribus. Mai.)

7. Aтnyrivm. [sub Polypodio] Sori subrotundi sparsi. - Indusium laterale, hinc dehiscens.

1. A. Jragile: frondibus bipinnatis, pinnulis oblongis obtusis inciso-serratis, serraturis obtusis deuticulatis, rachi alata. Bolton. t. 27. (in fissuris viarum cavarum sylvarum. IVTai. Jun.) 2. A. Filix femina: frondibus bipinnatis, pinnulis oblongo-lanceolatis inciso-serratis, serra- 


\section{$-236-$}

turis bi-seu tridentatis acutiuscullis, soris ob:ongis rectis. Bolton. t. 25. '(in nemoribus et syl-ilu: vis umbrosis. Jun. Sept.)

3. A. molle: frondibus bipinnatis, pinnulis lanceolatis pinnatifidis, laciniis linearibus apice conniventi-serratis Ehrh. crypt.t. ox. (in ne. moribus arl arborum radices. Mai. Sept)

p 8. Strutriopteris. Capsulae partem frondis inferiorem dense tegentes. Indusia squaniformia marginalia interius deliscentia.

1. S. germanica: [Osmunda Struthiopteris] frondibus sterilibus bipinnatifrlis, lacinis integerrimis acutiusculis aequalibus. Fi dan. t. 169 . (in nemoribus umbrosis, ad Gorenki et Archange.lsk. Jul Aug )

9. Ásplenium. Sori lineares transversales sparsi. Indusia e venis lateralibus orza costam versus dehiscentia.

1. A. Ruta muraria: frondibus alternatim subdccompositis, pinnulis cuneiformibus apice incisis. Fl. dan, t, 190. (in muris antiquis. Jun. Jul.)

10. Pтens. Sori continui lineares marginales. Indusium e margine frondis inflexum interius dehiocens.

1. P. aquilina: frondibus tripartitis bipinnatis, foliolis inferioribus pinnatifidis, summis ind:visis. Schkuhr. t. 95. (in piuetis et sylvis acero. sis. Ang. Sept.) 


\section{- $139-$ \\ C A L Y P T R A T A E.}

11. Phascum Peristomium nullum.

1. P. cuspidatum: subacaule, foliis ovatis cuspidatis patulis, in imis conniventibus. Dillen. t. 32. f. 11. (in pomariis, hortis, cultis, fossis exsiccatis. IVIai.)

2. P. muticum : acaule, foliis ovato-concavis mu ticis conniventihus. Dillen. t. 32 f. 12 (cum praccedente, et in muris argillosis Mai. Sept.)

3. P. subulatum: caulescens, foliis lineari-subulatis patulis, perichaetialibus longissimis. Fl. dan.t. 249. (in arenosis sylvaticis, ad aggeres et vias. ITTai, Jun.)

12. Siragnum. Calyptra medio transversim rupta.

1. S. latifolium: [palustre] foliis ovatis concavis obtusis, ramis apice turgidis. Dillen. t. 32, f. 2 . (in paludibus turfosis, propriisque sphagnetis. Sept. Oct.)

2. S. capillifolium: foliis ovato-lanceolatis pla. niusculis acuminatis, ramis apice capillaceis. Dillen, t. 32. f. 2. (cum antecedente, in rivulis. Sept. Oct.)

3. S. cuspidatum: foliis subulatis patentiusculis planis undulato-acuminatis. Dillen. t. 32. f. a. B. (in aquosis fluitans et pedalem longitudinem superans. Jul. Aug.)

13. Grmostonur. Calyptra integra secedens. Peristomium nudum.

1. G. truncatum: [Bryum truncatulum] foliis oratis acuuinatis planis integerrimis, capsula ob- 


\section{$-183$}

ovata truncata. Dillen. t. 45. f. 7. (in hortis, cultis, muris, ad fossas, viasque. M[ai.)

\&. G.ovatum: [Pottia cavifolia] foliis ovatis obtusis integerrimis concavis aristatis, capsula ovata. Hedw. musc. t. 6. (in muris, agrisque Jimosis. Mai.)

14. Texnapurs. Peristomium dentibus quaternis liberis.

2. T. pellucida: [Mnium pellucidum] trunco erecto, foliis ovato-lanceolatis integris, capsula cylindrica. Dillen, t. 31. f. 2. (in sylvaticis udis et paludosis, ad arborum radices. Aug. Sept.)

15. Spracinum. Peristomium dentibus octonis geminis. Capsula cum apophysi.

1. S. ampullaceum: apophysiampullaeformi capsulam excerlente, foliis ovato-lanceolatis acuminatis, superioribus denticulatis. Dillen. t. 44. f. 3. (in paludibus turfosis, raro. Aug.)

16. Encalypta. Peristomium dentibus sedecim simplicibus integris. Seta terminalis. Calyptra campaniformis maxima.

1. E. vulgaris: [Bryum exstinctorium] caule simplici, foliis spathulato-lanceolatis, calyptra basi integra. Dillen.t. 45. f. 8. (in locis arenosis, collibus, muris. Mai.)

17. Leensia. Peristomium dentibus senis denis angustis erectilibus integris.

1. L. cirrhata: [Mnium cirrhatum]! trunco erecto ramoso, foliis linearibus siccitate tortilibus carinatis, capsula orata. Fl. dan. t. 538. f. 4 . (in colliculis arenosis. Mai. Jun.) 
8. L. lanceolata: [Bryum lanceolatum] trunco erecto, foliis lanceolato-concavis acuminatis, capsula ovata. Hedw, musc. II. t 23. (ad margines fossarum in muris argillaceis. Sept)

18. Grimmia. Peristomium dentibus senis denis simplicibus integris. Seta terminalis. Calyptra exilis.

1. G. apocarpa: [Bryum apocarpum] trunco ramoso diffuso, foliis ovatis acuminatis: perichaetialibus piliferis, capsula ovata sessili. Fl dan. t. 480. (super arborum truncos. Mai. Sept.)

19. Werssia. Peristomium dentibus senis denis latiusculis reflexilibus integris.

1. W. viridula: [Grimmia crispa] subacaulis, foliis subulatis siccitate tortilibus, capsulae ellipticae operculo subulato. Hedw. musc. III. t. 5. (ad vias cavas, in locis submontosis. Mai.)

2. W. Dicksonii: [Bryum Dicksonii] trunco ramoso, foliis linearibus carinatis siccitato subcrispis, capsulis erectis ovato-cylindraccis. Dicks. III. t. 7. et IV. t. 7. (in arborun truncis emortuis. Oct.)

20. Fissinens. Peristomium dentibus senis denis brevioribus inflexis.

1. F. bryoides: [osmundoides] trunco simplici adscendente, foliis distichis oblongis obtusiusculis, seta terminali. Hedw. posthum. t. 40 . (in viis cavis, ad aggeres fossarum, in sylvis umbrosis. Oct.)

2. F.taxifolius: [Hypnum taxifolium] trunco simplici, foliis distichis oblongo-lanceolatis, seta 
subradicali. Dillen. t. 34. f. 2. (in sylvaticis et nemorosis umbrosis. Sept:)

3. F. pulvinatus: [Dicranum pulvinatum] foliis obtusis oblongis piliferis, seta arcuata. Dillen. t. 50. f. 65. (in muris et saxis. Mai. Oct.)

21. Dicranum. [Bryum olim] Peristomium dentibus senis denis simplicibus flexis solidis fissis.

1. D. purpureum: trurco subdichotomo, foliis lanceolato - acuminatis erecto-patulis carinatis, capsula cylindrica. Dillen. t. 49. f. 52. (in sterilibus, ericetis montosis, muris. Mai.).

2. D. glaucum: trunco erecto ramoso, foliis imbricatis ovato - lanceolatis enerviis glaucis, operculo curvirostro. Dillen. t. 46. f. 20. (in sylvaticis et ericetis humidis. Mai.)

3. D. scoparium: trunco ramoso, foliis lanceoIato-subulatis secundis, seta solitaria, operculo obliquo. Dillen. t. 46. f. 16. A. B. (in nemoribus ad arborum truncos et radices. Mai)

4. D. heteromalluin: trunco simpliciusculo, folis subulatis falcatis secundis, capsulae cernuae operculo curvirostro Dillen. t. 47.f. 37. (in scrobibus, fossarum marginibus, viis cavis et muris. Jun.)

5. D. fastigiatum: trunco ranoso, ramis fastigiatis, foliis linearibus carinatis obtusiusculis apice serrulatis adpressis, capsulae cylindricae rectae operculo subulato. (in turfosis, sphagnetis. Mai.)

22. Tricrostonuvi. Peristomium dentibus senis denis simplicibus recis capillaribus fissis.

1. T. canescens: [Bryum canescens] trunco ra- 
moso, foliis ovato-lanceolatis striatis reflexis apice incanis, capsulae ellipticae operculo subulato. Dillen, t. 47 . f. 27. B. C. D. E. (in montosis sterilibus. Mai. Sept.)

23. Polytricirum. Peristomium dentibus trice. nis, binis brevibus apice epiphragmate nexis.

1. P. yuccatfolium: [commune] trunco simplici erecto, foliis lancenlato-acuminatis serrulatis reflexis, capsula oblonga tetraëdra. Dillen. t. 54. f. 2. (in sylvaticis humidis turfosis. Maai. Jun.)

2. P. juniperinum: [juniperifolium] trunco simplici, foliis lanccolato - acuminatis integerrimis carina scabris, capsula ablonga tetraëdra. Dil. len. t. 54. f. 2. (in ericetis, pascuisque sterilibus. Jun.)

3. P. piliferum: trunco subsimplici, foliis lanceolatis integerrimis revolutis apice piliferis, cafsula tetraëdra. Dillen. t. 54. f. 3. (in ericotis, umbrosis. Mai. et Sept)

4. P. hanum: subacaule, foliis lanceolatis obtusis apice serrulatis, seta flexuosa, capsula turbinata cernua, Dillen. t. 55. f. 6. (in ericetis sylvaticis. Mai. et Sept)

5. P. aloicles: trunco simplicissimo, foliis lanceolatis obtusis serrulatis, capsula cylindrica subobliqua. Dillen, t. 55. f. 7. (in ericetis sterilibus umbrosis. Mai. et Sept.)

6. P. undulatum: [Bryum undulatum] truncs erecto subsimplici, foliis lanceolat is scrratis undulatis siccitate tortilibus, capsula cylindrica 
cernua, calyptra infra apicem laevi. Hoffḿ. crypt. t. 2. (in sylvaticis umbrosis humidis. Mai. Aug.)

2.4. Banbula. Peristomium ciliis numerosis tortilibus.

1. B. unguiculata: [Bryum unguiculatum] trunco subramoso, foliis lanccolatis carinatis mucronatis nervosis, capsula oblonga. Dillen. t. 48. f. 48. (in campis aridis, viis, muris et ericetis. Mai.)

2. B. ruralis: [Bryum rurale] trunco ramoso, foliis ovato-oblongis carinatis reflexis piliferis, operculo oblique conico. Dillen, t. 45. f. 12. (in tectis, aridis, truncis. Mai.)

3. B. murnlis: [Tortula muralis] trunco subsimplici, foliis oblongo-spathulatis patulis piliferis, operculo acuminato. Dillen. t. 45. f. 14. 15. (in tectis, muris, saxisque. Maai.)

4. B. subulata: [Tortula subulata] trunco subsimplici, foliis oblongo-lanceolatis patulis mucronulatis, capsulae cylindricae maximae operculo subulato. Dillen. t. 45. f. 10. (in argillaceis humidis et siccis, Maai.)

25. Ontrotricium. Peristomium figuratum duplex: externum dentibus senis denis acutis, internum ciliis fornicatis basi liberis.

2. O. striatum: [Bryum striatum] trunco erecto ramoso, foliis lanceolatis carinatis revolutis, capsulae pedunculatae ovatae striatae operculo obtusiusculo, peristomii interni ciliis senis de- 


\section{$-193-$}

nis. Fl. dan. t. 537. f. 3. (ad saxa et sepes, in truncis arborun putridis. Mai. Jun.)

2. O. ancmalum: trunco erecto subramoso, foliis lanceolat 15 carinatis revolutis obtusiusculis, capsulae priunculatae ovatae sulcatae operculo oltuso, peristomio externo nullo. Dilíen t. 55. f. 9. (in muris antiquis, ad saxa arborumque truncos Mai.)

26. Necrera. Peristonium figuratum duplex: extermum dentibus senis denis acutis, internum ciliis rectis basi liberis.

1. N. crispa: [Hypnum crispum] trunco zamoso,

- folirs distichis oblongis transverse rugosis, capsulis pedunculatis. Dillen. t. 30. f. 12. (in ne. morosis montosis ad arborum truncos solo calcareo. Sept.)

2. N. viticulusa: [Hypnum viticulosum] trunco repente ramoso, ramis erectis simpliciusculis, foliis ovatis obtusis subreflexis, capsulis pedunculatis. Dillen. t. 39. f. 43. (in siccioribus, ad saxa, Oct.)

27. Chima crum. Peristomium duplex: externum dentibus senis denis acutis, internum ciliis rectis basi liberis, trabeculis transversalibus nexis.

2. C. dendroides: [Hypnum aendroides] trunco erecto basi nudiusculo, ramis fasciculatis terminalibus, foliis oblongis apice serrulatis nervosis. Dillen. t. 40 . f. 48 . (in nemorosis montosis, ad arborum radices. Maai, et Sept.) 


\section{$-194$}

28. Leskea. [Hypnum olim] Peristomium externum dentibus senis denis acutis, internum ciliis uniformibus basi membrana connatis.

1. L. trichomanoides: trunco ramoso, ramis apice obtusis, foliis distichis oblongis obtusis sublunulatis enerviis. Dillen. t. 34. f. 8. (ad arborum truncos. Mai.)

2. L. complanata: trunco ramoso repente, ramis apice attenuatis, foliis ovato-oblongis apiculatis enerviis. Dillen. t. 34. f. 7. (ad truncos et radices arborum. Mai.)

3. L. sericea : trunco ramoso repente, ramis erectis incurvis, foliis lanceolato-acuminatis tristriatis, seta muriculata, capsula erecta.Dillen. t. 42. f. 59. (ad truncos. Mai.)

29. Bartramra. Peristomium externum dentibus senis denis acutis, internum membrana plicata dentibus geminis uniformibus coronata. Capsula subglobosa.

2. B. pomiformis: [Webera pomiformis] trunco ramoso, ramis brevioribus incrassatis, foliis lineari-subulatis argute serrulatis siccitate tortilibus. Dillen. t.44. f. 1. (in viis cavis, ad sylvarum margines. Mai.)

8. B. fontana: [Mnium fontanum] trunco erecto, ramis terminalibus subverticillatis, foliis imbricatis ovato-lanceolatis apice serrulatis subsecundis. Dillen. t. 44.f. 2. (in paludibus adscaturigines. Mai. Jun.) 


\section{$-195$}

50. Trenteporrida. Corpuscula sessilia, inter axillas foliorum ovata, perichaetio cincta, clausa, decidua.

1. T. erecta: [Bryum annotinum] trunco erecto subramoso, foliis sparsis ovato-lanceolatis serratis, capsulae pendulae pyriformis operculo obtuso. Hofin. crypt.t 14. (in pratis arenosis, locisque inundatis. Jul. Sept.)

31. Bryun. Peristonium externum dentibus senis denis acutis, internum membrana plicata dentibus integris et interpositis ciliis coronata.

1. B. caespiticium: [Mnium caespiticium] trunco erecto subramoso, foliis lanceolato-cuspirlatis nervosis strictis, capsulae pendulae pyriformis operculo mammillari. Dillen. t. 50. f. 05 A. B. C. D. E. (in ericetis, sylvaticis, arenosis, caespite denso. Mai.)

2. B. argenceum: [M[nium argenteum] trunco erecto subramoso, foliis dense imbricatis ovatis obtusis mucronulatis argenteis, capsulae obovatae pendulae operculo obtuso. Dillen. $t$ 50. f. 62. (in muris, tectis, saxis, viis, ruderatis, collibus apricis. Sept. Oct.)

3. B. capillare: [Mnium capillare] trunca brevissimo, foliis substellatis ovatis nervosis piliferis siccitate involutis, capsulae obovatae pendulae operculo acuminato. Dillen. t. 5o., f., 67. (in umbrosis humidis. Mai.)

32. 'Mnxum. Peristomium externum dentibus șe nis denis acutis, internum membrana plicata denti- 
bus foratis et interpositis ciliis coronata. Seta ter. minalis.

1. $M$. palustre: trunco erecto apice diviso, foliis lanceolato-acuminatis integerrimis patulis, capsulae subcernuae operculo obtusiusculo. Dillen. t. 31. f. 3. (in paludibus et scaturiginibus. Mai. Jun.)

2. M. hornum: trunco erecto subsimplici, foliis oblongo - lanceolatis serratis nervosis patulis, capsulae pendulae operculo mammillari. Dillen. t. 51. f. 71. (in nemorosis ad rivulos paludum. Mai.)

3. M. cuspidatum: [Bryum cuspidatum] trunco sterili reptante, foliis ovato-lanceolatis serratis cuspidatis, capsulae fendulae operculo convexo. Dillen. t. 53. f. 79. (in sylvaticis umbro. sis et pomariis, ad fossas. Mai. Jun.)

4. M. junctrtum: [serpyllifolium] trunco sterili reptante, foliis subrotundis integerrinis, capsulae ovatae operculo acuminato. Dillen, t 53. f. 81. (ad fossas et in 6ylvaticis unbrosis, ad arborum radices. Mai. Jun.)

5. M. roseum: [Bryum roseum] trunco erecto simplici, foliis rosaceo-congestis ovato-lanceolatis acuminatis tenuissime serrulatis, capsulae pendulae operculo convexo. Dillen. t. 52. f. 77. (in nemoribus umbrosis ad fossas. Mai. Jun.)

6. M. undulntum: [Bryum ligulatum] trunco ste- rili reptáate, foliis oblongis undulatis serratis, 
oapsulae pendulae operculo acutiusculo. Dillen.

t. 52. f. 76. (ad fossas nemorum. Mai. Jun.)

33. Hypnum. Peristomium externum dentilus senis denis acutis, internum membrana plicata dentibus foratis et interpositis ciliis coronata. Seta axillaris.

1. H. myosuroides: [Leshea vivipara] trunco repente, ramis recurvis, foliis ovato-acuminatis integerrimis, [nervo vix conspicuo] capsula erecta. Dillen. t. 41. f. 50. (ad arborum radice. in sylvaticis udis. Mai.)

2. H. abietinum: trunco decumbente ramoso, ramis pinnatis attenuatis rigidis, foliis imbricatis adpressis ovato- lanceolatis striatis, capsula cernua. Dillen. t. 35. f. 27 . (in siccis syluaticis montosis. Mai.)

3. H. proliferum: [delicatum] trunco decumbente ramoso pinnato, ramis apice convolutis, foliis ovato-acuminatis, summis enerviis papillosis, capsula subcernua, Dillen, t. 35. f. 14. (in sylvaticis ad arborum radices. Mai.)

4. H. praelongum: trunco decumbente, ramis laxis, foliis ovato-lanceolatis remotiusculis denticulatis, seta muriculata, capsulae cernuae operculo rostrato. Dillen. t. 35. f. 15. (in po. mariis et hortis ad arborum truncos et radices. Mai.)

5. H. serpens: trunco repente ramosissimo, foliis ovato-acuminatis basi nervosis, capsulae cernuae operculo mammillari. Dillen, t. 48. f, 6 / 
(ad truncos, praesertim Oxyacanthae, ad saxa et in muris vetustis. Mai et Sevt.)

6. H. velutinum: trunco repente, ramis erectis simplicibus, foliis confertis ovato-lanceolatis subserratis, perichaetialibus crinitis, capsula cernua ovata. Dillen. t. 42. f. 61. (in muris, ruderatis, sylvaticis, ad arborum truncos. Mai.)

7. H plumosum: trunco reptante, ramis bifariis depressis, foliis ovato-lanceolatis striatis, seta laevi, capsulae cernuae operculo conico. Dillen. t. 35. f. 26 . (in sylvaticis ad saxa et truncos. Mai.)

8. H. puruim: [elegans] trunco adscendente pinnato, foliis imbricatis ovalibus concavis mucronulatis nitilis, capsulae cernuae operculo mucronulato. Dillen t. 40. f. 45. (in pratis, nenorosisque úmbrosis. Mai.)

0. H. rutabulum: trunco ramosissimo, foliis ovatis acuminatis patulis serrulatis, seta muriculata, capsulae cernuae operculo conico. Dillen. t. 38. f. 29. (in sylvaticis humidis. Mai. Jun.)

10. H. denticulatum: trunco subsimplici, foliis bifariam positis lanceolatis integerrimis, seta subbasilari, capsulae cernuae operculo conico. Dillen. t. 54. f. 5. (in umbrosis sylvaticis ad arborum radices. Mai.)

11. H. triquetrum: trunco pinnato, ramis sparsis subrecurvis, foliis deltoideo-lanceolatis patulis serrulatis striatis, capsulae cernuae oper- 


\section{- 299}

oulo conico. Dillen. t. 38. f. 28. (in sylvis ad arhorum truncos. Mai. et Oct.)

2. H. squarrosum: trunco erecto pinnato, foliis ovatis acuıninatis recurvis, capsulae subnutantis operculo conico. Dillen t. 39. f. 38. (in pomariis, nemorosis et sylyaticis sterilibus. Mai. et Sept.)

13. H. cuspidatum: trunco pinnato, foliis lanceolatis patulis, summis convolutis, capsulae cernuae operculo conico. Dillen. t. 39. f. 34. (in pratis paludosis umbrosis. Jun. Jul.)

14. H. compressum: [Schreberi] trunco pinnato subcompresso, ramis subincurvatis, foliis laxe imbricatis ovatis concavis. Dillen t. 40. f. 47. (in sylvaticis et nemorosis declivibus. Mai. et Oct.)

15. H. parietinum: [splendens] trunco bipinnato, foliis arlpressis ovato-acuminatis apiculatis, capsulae cernuae operculo rostrato. Dillen. t. 35 . f. 43. (in ericetis et sylvis, ad arborum truncos. Mai. Jun.)

16. H. commutatum: trunco exacte pinnato, foliis ovato-subulatis tortilibus, setis rameis, capsulae cernuae operculo conico. Hedu' musc. IV. t. 26. (in sylvaticis udis, palustribus, rivulisque. Jul. Aug.)

17. H. molluscum: [Crista castrensis] truneo pinnato, ramis distichis suboppositis, foliis linearibus falcatis subdenticulatis. Hedw. posth. t. 76. (in sylvis ad arborum truncos et radices Mai, et Sept.) 
18. H. cupressiforme: trunco prostrate pinnato, ramis simpliciusculis subincurvatis, foliis ovatoaeuminatis arcte imbricatis, capsulac cernuae operculo rostrato. Heaiw: musc. IV. t. 23. (in arboribus, praesertim salicibus vetustis. Mai.) 19. 11. extenuatum: ramis filiformibus, foliis ovato-acuminatis incurvatis secundis enerviis. Ditlen. t. 37. f. 23. B. C. D. (ad terram, arborum truncos et saxa. Mai.)

34. Webera. Peristomium externum dentibus senis denis acuminatis, internum membranaceum carinatum, cum et absque cilis.

1. W. pyriformis: [Mnium pyriforme] foliis planis acutis apice serrulatis, capsula pyriformi. Dillen. t. 44. f. 6. (ad margines fossarum, in muris, ruderatis, fodinis calcareis. Mai. et Sept.) 35. Buxbaumia. Peristomium externum rlentibus senis denis truncatis brevissimis, internum filis multiplicibus conicis.

1. B. aphylla: pedunculo elongato, capsula altero latere depressa marginata. Bu.xb. f. 11. 12. (in ericetis et sylvaticis arenosis umbrosis, ad collium margines. Mai.)

36. Fontracis. Peristomium externum dentibus senis denis, internum reticulum conicum.

1. F. antipyretica: trunco triquetro ramosissimo, foliis ovatis acutis complicato - carinatis enerviis, capsula subsessili. Dillen.t. 33. f. 1. (in fluviis, fontibus, fossis, ad aggeres moletrinarum. Mai.) 37. Funaria. Peristomii externi dentes apice cohaerentes, interni cilia fornicata. 
1. F. hygrometrica: [Koelreutera hygrometrica] trunco subsimplici, foliis oblongis acuminatis, capsulae nutartis operculo plano. Dilien. t. 52. f. 75. (in humidis umbresis limosis ac montium rimis, nec non ad vias. Mai. Sept.)

\section{H E P A T I C A E.}

38. Jungerima via. Capsula quadrivalvis. Semina filis spiralibus nexa.

1. J. asplenioides: trunco ramoso adscendente, foliis distichis ovatis denticulato-ciliatis, Dillen. t. 69. f. 5. (in nemoribus umbrosis humidiusculis. IMai.)

2. J. viriculusa : trunco ramoso adscendente, foliis distichis subrotundis integerrimis. Dillen. t. 69. f. 7. (in nemorosis udis montosis. Mai.)

3. J. pusilla: trunco brevissimo repente, foliis distichis imbricatis obovatis undulatis apice crenulatis. Dillen. t. 71. f. 22. (in apricis humidis glareosis sylvaticis. Jul. Sept.)

4. J. bicuspidata: trunco procumbente diffuso, foliis distichis subquadratis apice emarginatobicuspidatis, calycibus lateralibus. Dillen. $t$. 70. f. 13. (in syliaticis umbrosis. Mai.)

5. J. bidentata: trunco prostrato radicante, foliis ovatis apice emarginatis bidentatis, stipulis pipartitis quadridentatis. Dillen. t. 70. f. 11. (in locis umbrosis. Mai. et Sept.)

6. J. ciliaris: trunco repente glabro, foliis stipulisque oratis incisis dentato ciliatis imbri- 
catis, calycibus glabris. Dillen. t. 69. f. 3. (in locis udis sylvaticis. Mai. Jun.)

7. J. complanata: trunco repente complanato, foliis stipulisque rotundatis planis integerrimis densissime imbricatis, calýcibus oblongis compressis. Dillen. t. 72. f. 26. (ad arborum truncos. Mai.)

3. J. platyphyllı: trunco procumbente, foliis ovatis imbricatis stipulisque integerrimis triplici ordine, intermediis duplo maioribus. Dillen. $t$. 72. f. 32. (ad radices arborum. Mai.)

9. J. dilatata: trunco repente dense caespitoso, foliis rotundatis imbricatis arcte adpressis, stipulis lateralibus ovatis, intermediis bifidis margine revolutis approximatis. Dillen. t. 72. f. 27 • (ad truncos. MIai.)

10. J. epiphylla: fronde obverse ovata obtuse lo. bata, medio fructifera. Dillen. t. 74. f. 14. (ad fossas et rivulos atque in udis umbrosissimis. Mai. Jun.)

11. J pinguis: frondibus carnosis oblongis dichotomis laciniatis, latere fructiferis. Dillen. t. 74. f. 42. (ad rivulorum parietes, inque locis udis umbrosis. Mai. Jun.)

39. Marchantia. Capsula multivalvis sub peltis radiatis pedicellatis. Semina filis spiralibus nexa. Gemmulae duplices in cyathis et peltis.

2. M. polymorpha: frondibus obtuse lobatis, receptaculo gemmifero duplici, scyphiformi et peltato, seminifero radiato. Dillen. t. 76. et 77. 


\section{$-203$.}

(in locis umbrosis humidis, in ruinis, ad scaturigines et fontes aquarum. Maai. et Sept.)

\section{HOMALLOPHYLLAE.}

40. Riccra. Capsula glohosa intra frondis substantiam latens, apice demurn forata. Semina nuda, utriculis diaphanis subtrilocularibus primum inclusa.

3. R. glauca: frondibus dichotomis apice emarginatis obtusis sulcatis. Dillen, t. 73. f. 1 o. (in agris' sabulosis limosis post messem. Aug.)

2. K. fluitan's: frondibus planis dichotome multifidis divaricatis furcatis apice obtusis reticulatovenosis. (in fossis, piscinis et aquis stagnantibus. Jun. Jul.)

\section{A L $G$ A E.}

41. Confenva. Tubuli subgeniculati, utriculis cylindricis massam granulosam continentibus. .?

1. C fontinalis: filamentis simplicissimis aequalibus brerissimis lubricis viridi - ferrugineis caespitosis. Fl. dan. t. 651. f. 3. (in rivulis umbrosis ad lapires. Mai.)

2. C muralis: [Oscillatoria parietina] filamentis viridi - sericeis curvato-implexis capillaribus. Dillw. cónf. t. 7. (in muris vetustis versus septemtrionem. Mai.)

3. C. vaginata: [amphibia] filamentis nigricantibus vaginatis, ramulis subsimplicibus divergentibus. Vauch, conf. t. 15. f.13. (in muris vetustis pluvia humectatis. Mai.) 


\section{$-204$}

4. C. furcata: [Ceramium caespitosum] filamentis viridibus geniculatis divaricato ramosis,; articulis cylindricis, globulis gemmiferis atropurpureis tuberculato-arillatis. (in fossis et aquis sègnibus. Mai.)

5. C. velutina: [Byssus velutina] filamentis viridibus erectiusculis subramosis hinc inde hyalinis, geniculis fasciatis contractis. Michel. t. 89 . f. 5. (in ollis floralibus hortorum Mai.)

6. C. glomerata: [cristata] filamentis viridibus ramosissimis rectis geniculatis, ramis fasciculatis, articulis cylindricis granulosis. Fl. cian. t. 652. f. 2. (ad cataractas rivulorum molarum. INiai.)

7. C. fluviatilis: filamentis viridibus ramosis subnodulosis, articulis angulatis, geniculis dilatatis. Dillen. t. 7.f. 47. (in fluviis ad ligna vetusta. IVai.)

8. C. gelatinosa: [Chara gelatinosa] flamentis viridibus gelatinosis ramosissimis, ramulis fasciculatis dichotomis articulatis, articnlis ellipticis, geniculis setis contractis. Lillen. t. 7. f. 42. (in rivulis et aquaeductibus. Mai.).

9. C. reticulata: filamentis reticulato-anastomosantibus Dillen: t. 4. f. 14 . (in fossis stagnantibus, rivulisque paludosis. Mai.)

42. Ulva. Membrana diaphana, granulis sparsis innatis.

i. $U$. intestinalis: tubulis simplicibus continuis inflatis anfractuosis. Dillen. t. 9. f: 7. (in fluminibus. Mai. Jun.) 


\section{$-205$}

43. Frvelaria. Substantia gelatinoso-cartilaginea hyalina, nuda. Filamenta articulata recta subrainosa per totam substautiam.

2. R. encivinefolia: fronde suborbiculata planiuscula lacunosa palmato-multifida, ramulis teretibus truncatis crinitis, flamentis genicula-

i tis brevibus crystallinis. (ad culmos graminum majorum in aquis segnibus putrescentium. Jun. Jul.)

2. R. dura: globosa solida dura, filamentis radiatis subdichotomis, articulis ovalibus. (ard caules Myriophyllorum et Potamogetonum. Jun. Jul.)

44. Linkx Substantia gelatinosa hyalina membrana obvoluta. Filamenta articulata curvata per totam substantiam.

2. L. Nostoc: ['Tremella Nostoc] subrotunda difformis plicato-undulata virescens, demum membranacea et fugax. Dillen. t. 10. f. 14. (in campis et arvis colliculosis post pluvias. Jul. Sept.)

\section{S C U TELLA TA E.*}

45. Opegrapma. Apothecia lirellae. Thallus crustaceus.

1. O vulgata: crusta tenui effusa albo-virescente subpulverulenta, lirellis oblongo-linearibús

") Otnhia haec genera olim sub nomine fichen fuerunt. Omni tempore 


\section{- $\operatorname{so6}$}

simplicibus confertis. Fl. dan, t. 1242. f. 2. (in cortice Abietum.)

2. O. pulverulenta: [Squamaria pulvcrulenta $]$ crusta effusa alloa membranacea, lirellis connatosubramosis flexuosis linearibus pulverulentis. Pers. annal, bot. t. 1. f. \&. B b. (in cortice Alni.)

3. O. scripta: [Verrucaria scripta] crusta tenuissima albo - virescente nigro limitata, lirellis flexuosis simplicibus ramosisque glabris. (in cortice Querci et Coryli.)

46. Lecidra. Apothecia patellae. Thallus erustaceus, foliaceus.

1. L. geographica:' [Verrucariageographica] crusta flavescente areolata, margine petellulisque atris. Hoffm. lich. t. 54. f. 2. (in saxis ubique.)

2. L. aurantiaca: $[$ Verrucaria aurantiaca $]$ crusta detcrminata rimosa cinerascente, patellulis confertis convexis aurantiacis, margine dilutiori. Fl. dan. t. 955. f, x. (in truncis Ulmorum, Populorum.)

3. L. lapicida: [Lichen pertusus] crusta tartarea cinerea areolato-subrugosa, patellulis depressis confertis subconfluentibus angulosis atris. Hoffm. lich. t. 57. f. 2. (in truncis, saxisque.) 47. Calicrum. Apothecia pilidia. Thallus crustaceus.

1. C. claviculare: [salicinum] crusta leproso-granulosa cinereo-olivacea, pilidiis ferrugineoatris. Dillen. t. 24. f. 3. (in cortice Quercus, Uilmi et Salicum.) 


\section{- $207-$}

48. Vrrrucalina. Apothecia tubercula. Thallus crustaceus.

1. V. nitida: [Sphaeria nitida] crusta effusa cartilagineo - membranacea laevigata pallide - virescente, tuberculis confertis papillatis atris nitidis. Weig. obs. t. 2. f. 14. (ad truncos Quercuum )

49. Cladonta. Cephalodium non marginatum -membrana seminifera obductum, nucleo thallode, podetiis suffultum. Thallus foliaceus, fruticulosus.

1. C. coccifera: [coccinea] podetiis brevibus cinereo-virescentibus, scyphis dilatatis integris clausis, cephalodiis marginalibus coccineis. Dillen, t, 14. f. A. D. (terrestris, in abietinis sabulosis.)

8. $C_{\text {: }}$ pyxidata: podetiis brevibus, scyphis cyathiformibus clausis integris, cephalodiis marginalibus fuscis, Dillen. t. 14. f. 6. A. (in lignorum caedibus et ericetis.)

3. C. gracilis: podetiis elongatis filiformibus acuminatis sterilibus scyphiferisque, scyphis clausis subulato-dentatis, cephalodiis pedicellatis fuscis, Dillen. t. 14. f. 13, C. D. (in ericetis colliculosis.)

4. C. uncialis: podetiis caespitoso-aggregatis tubulosis albo-virescentibus, ramulis brevibus patulis stellato-radiatis denticulatis perforatis, cephalodiis minutis globosis spadiceis. Dillen. t. 16. f. 22. (in ericetis sylvaticis.)

5. C. paschalis: [Stereocaulon paschale] podetiis suprafoliaceis, cephalodiis ab initio marginatis 


\section{$-208$}

subfuscis. Hoffm. lich, t. 5. f. x. (in ericetis montosis.)

6. C. rangiferina: podetiis teretibus tubulosis ramosissinis cinerascentibus, axillis perforatis, ramulis apice cernuis, cephalodiis globosis. Dillen. t. 16. f. 29. (in sterilibus pinetis montosis.)

50. Usnea. Orbillae planae ambitu radiatae. Thallus loreus, filamentosus, fruticulosus.

1. U. florida: thallo subcrustaceo fruticuloso tereti exasperato fibrulloso, fibrillis horizontalibus, ramis sparsis subfastigiatis simpliciusculis, orbillis terminalibus albo-virescentibus, tuberculss gemmiferis luteis. Dillen, t. 13. f. 13. (in cortice Quercuum annosarum.)

2. U. hirta: thallo magis caespitoso gracilioreque praecedente. Dillen. t. 13. f, 12. (in arborum cortice, praesertim Pinuum, ad dumeta, sepes, saxa.)

51. Cornicularia. Orbillae scutellaeformes convexiusculae. Thallus cartilagineus fruticulosus.

1. C. spadicea: [tenuissima] thallo cartilagineo fruticuloso glabro castaneo, ramulis plano-compressis sublacunosis flexuosis denticulatis. Dillen. t. 27. f. 31 . (in ericetis, sterilibusque montosis )

2. C: islandica: thallo cartilagineo castaneo, ramulis compressis canaliculatis laciniatis: laciniis bicornibus scutellisque ciliatis. Hoff $m$. lich. t. 9, f, x. (in montosis sylvaticis et ericetis.) 
52. Parmelia. Apothecia scutellae. Semina tu. bulis inclusa. Thallus crustaceus, foliaceus, filamentosus

2. P. candelaria : [Byssus candelaris $]$ crusta imbricato-lobata, lobis confertissimis lacerogranulatis viridi-flavis, scutellis planis concoloribus. Fl. dan. t. 899. f. 2. (in parietibus, saxis, arborumque corticibus.)

2. P. murorum: [Psora saxicola] crusta plicatorugosa rimosa virescenti-flava, lobis incisis, scutellis subconcoloribus, margine dilutiori. Hoffm. lich. t. 17. f. 3. (in saxis, muris, lignis, tectis, parietibus.)

3. P. saxatilis: [Usnea cranii] thallo cinereoglaucescente scabro lacunoso, subtus nigro fibrilloso, scutellis badiis. Dillen. t. 24. f. 83. (in saxis et corticibus.)

4. P centrifuga: [Squamaria centrifuga] thallo subcoriaceo virescente glabro punctato, sorediis subramosis, scutellis centralibus spadiceis, margine inflexo integro. Hoffm. lich.t. 26. f. 2. (in saxis.)

5. P. stellaris: [Squamaria stellaris] thallo cinereo, laciniis sublinearibus stellatis subtus cinereo-fibrillosis, scutellis caesiis, demum nigris. Fl. dan t. 857. (in tectis ligneis, variarumque arborum cortice.)

6. P. pulverulenta: [Squamaria pulverulenta] thallo humectato viridi-fusco, sicco cinereopruinoso, subtus nigro tomentoso, scutellis 
caesiis. Hoffm. lich. t. 8. f. 2. (in salicum, aliarumque arborum truncis.)

7. P. parietina: [Platisma parietinum] thallo ste]lato flavo subtus subfibrilloso, laciniis rotundato-lobatis crispis, scutellis concoloribus. Dillen.t.24.f.76. (in parietibus, muris, arboribusque fructiferis.)

8. P. olivacea: [Platisma olivaceum] thallo ste]lato olivaceo-fusco nitido, centro rugoso plicato, subtus subfibrilloso, scutellis brunneis margine crenulato. Dillen. t. 24. f. 77. 78. (in saxis, Betularumque cortice.)

9. P. caperata: [Platisma Gaperatum] thallo subcoriaceo sulphureo-virescente subtus atro hispido, scutellis subcentralibus rufescentibus margine pulverulento. Hoffm. lich.t. 38. et 39. (ad saxa et arbores.)

20. P. pulmonaria: [Pulmonaria reticulata] thallo subcartilagineo lacunoso-reticulato flavidofusco subtus hirto, laciniis sinuatis truncatis, scutellis submarginalibus rufo-fuscis. Dillen. t. 29. f. 113. (in cortice Quercus annosae.)

11. P. nigra: [Lichen niger] thallo foliaceo gelatinoso nigro, scutellis immersis concoloribus. Hoffm. lich. t. 3. f. 6. (ad saxa.)

2. P. tenella: [Lichen hispidus] thallo cinerascente, laciniis ciliatis obtusis apice fornicatis, scutellis caesio-nigris. Fl. dan. t. 1186. f. 1. (ad arborum corticem.)

13. P. physodes: [Physcia physodes] thallo glahro albicante subtus nigro-fusco, laciniis sinuato- 
multifidis, scutellis rubris. Dillen.t. 2o. f, 49. (in sylvis ad corticem arborum.)

14. P. furfuracea: [Platisma furfuraceum] thallo cinereo puiverulento subtus fusco nudo, scutellis lateralibus concavis, Dillen. t. 21. f. 52. (in Pinuum cortice, saxisque.)

15. P. ciliaris: [Platisma ciliare] thallo virescen. ti-glauco subtus nudo albicante, laciniis apice fibrillosis, scutellis nigro-caesiis. Hoffm. lich. t. 3. f. 4. (ad arborum corticem.)

16. H. prunastri: [Lichen corniculatus] thallo molli rugoso - lacunoso exalbido, laciniis divaricatis attenuatis, scutellis concavis badiis Dillem.t. 21. f. 54. (in cortice arborum, praesertim Prunorum.)

17. P. fraxinea: [Platisma fraxineum] thallo caespitoso albo - cinerascente rugoso-lacunoso, laciniis laciniatis, scutellis planis concoloribus. Dillen.t. 21.f 55. A. (in arborum cortice.) 18. P. farinacea: [Platisma farinaceum] thallo cacspitoso cinereo, sorediis confertis marginalibus scutellisque pedicellatis concoloribus. Dillen t. 23. f. 63. (in cortice Salicum et Betulae.) $19 P$. jubata: [Usnea jubata] thallo cartilagineo tereti laevi cinereo, lorulis filiformibus ramosis, axillis compressis, scutellis concoloribus. Dillen. t. 12. f. 7. (ad corticem Abietis.)

53. Peltigera. Apothecia peltae. Semina tubulis inclusa. Thallus foliaceus lobatus subtus fibrillosus.

2. P. crnina: thallo coriaceo expanso cinerascente subtus albidiori, venis fibrillıque fu- 
scescentibus, lobis oblongis, peltis verticalibu anticis revolutis badio-rufis. $F l$. dan. t. $76 \%$. 2. (terrestris, ad arborum truncos musco obtectos, in umbrosis.)

2. P. aphthosa : thallo coriaceo expanso laete viridi, sorediis sparsis glaucis fuscis, subtus avenio nigro fibrilloso, peltis anticis rotundis rubris. Engl. bot. t. 1119. (in urnbrosis pinetis, terrestris.)

54. Cetrania. A pothecia peltae scutellaeformes centro arlnatae. Thallus foliaceus margine crispus utrinque nudus.

1. C. juniperina: $[S q u a m a r i a ~ j u n i p e r i n a]$ thallo membranaceo pallide flavo subtus flavissimolacero-laciniato, laciniis adscendentibus complicatis eroso-crispis, peltis elevatis badiis. $\mathrm{Fl}$. dan. t. 1004. (ad truncos Juniperi.)

\section{Y L, O M Y C I.}

55. Spinamia. Sclerocarpus. Perithecia sphaerica intus gelatinosa thecis spermatophoris farcia.

1. S. militaris: [Clavaria militaris] carnosa flavescente-rubra, clavula sphaerulis prominentibus tuberculosa. Fl. dan. t. 337. f. 1. (in sylvis arl truncos putrescentes, inter muscos, etc. post largas pluvias. Sept. Oct.)

2. S. Hypoxylon: [Clavaria Hypoxylon] gregaria ramosa compressa basi hirta. Sowerb. fung.t. 55. (in sylvis et hortis ad arborum putrescentium truncos. Jul. Aug.)

3. polymorpha: [Clavaria digitata] gregaria, forma varia, clavulis ventricosis sphaerulis un- 
dique cinctis. Sowerb. fung. t. 69. (ad truneos Qucrcuum annosarum. Aug. Sept.)

4. S. fiscil: [fragiformis] difformis subconfuens fusca, intus subconcolor, sphaerulis umbilica. tis subprominulis. Hoffm. crypt. I. t. 5. f. 1. (ad ramos exsiccatos Coryli, Alui et Oxyacan. thae. Jul. Aug )

5. S. ribesia: erumpens mollis elliptica subdepressa, sphaerulis dissectis albicantibus. (in ramis exsiccatis Ribis rubri. Hyeme.)

6. J. deusta: [versipellis] late effusa crassa undulato-rugosa pustulata, primo carnosa cinereoalbida pulverulenta, demum nigra rigida. Tode mekl. II. t. 17. f. 129. (in sylvis ad truncos vetustos. Jul. Sept.)

7. S. Stigma: [Hypoxylon operculatum] ambiente effusa laevis rimosa, ostiolis inmersis planiusculis. Bulliard. champ. t. 473. f. 2. (ad ramos siccos Oxyacanthae et in sepibus vetustis. Mai.)

8. S. graminis : epiplyylla sublinearis maculacformis nitente-nigra, ostiolis latentibus. Pers. mycol.t. 1. f. 1. 2. (in foliis exsiccatis graminum majorum, praesertim Arundinis Phragmitis. Jun. Jul.)

9. S. salicina: subcomposita erumpens ovalis rugulosa atra, splaerulis connatis. Tode fung.

t. 13. f. 107. (in cortice Salicum. Jul. Aug.)

1o. S. pteridis: [Xyloma pteridis] striata paraltela nigra, sphaerulis minutissimis subprominulis. Rebent. t. 1. $f$. 3 . (in foliis $P$ teridis adhuc virentibus. Aug. Sept.) 


\section{$-214$}

11. S. trifolii: atra parva, magnitudine varia, cespitulo inaequali ruguloso interne subpulverulento. (in foliis arlhuc viridibus Trifolii repentis et hybridi. Oct.)

12. $S$ nebulosa: grisea, sphaerulis minutissimis sparsis maculas nigrescente gribeas interruptas inaequaliter lineatas efformantibus, ostiolis prominulis subacutis. (ad caules umbellatarum aliarumque herbarum inajorum siccatas. Jul. Sept.)

13. S. nivea: [Lichen rosaceus] conica, disco farinaceo niveo, ostiolis prominulis papillatis. Fl. dan. t. 825. f. 1. (ad ramos exsiccatos Populi tremulae. Jul. Aug )

14. S. aucupariue: [cespitosa] cespitosa nigra albido - pulverulenta, sphaerulis farctis elongato - subcylindricis Torle fung. II. t. 14. f. 113. (in ramis exsiccatis Sorbi aucupariae. Jnl. Aug.)

15. S. berberidis: cespitosa nigra, sphaerulis globosis rimoso-rugosis farctis. (ad ramos Berberidis vulgaris. Jul. Oct.)

16. S. Gnumon: simplex epiphylla, sphaerulis utplurimum collapsis ostiolisque clavatis glaberrimis. Unter. Annal. XI. t. 2. f, 6. (in foliis deciduis Coryli Avellanae, locis sylvaticis um. brosis. Mai)

17. S. solani : tecta laevis, ostiolo erumpente filiformi. (sub epidermide tuberum biennium Solani tuberosi putrefactorum. Oct.) 


\section{$-\quad 215$}

18. S. xylostei: [inquinans] atro-inquinans, sphaerulis immersis, ostiolo demum perforato. (ad Lonicerae Xylostei languescentis ramos adhuc semivivos, Jul. Aug,)

19. S. tiliae: sparsa tecta glabra subannulata, ampullaeformis aut circumscissa, orificio largo. (in ramis arefactis Tiliarum. Hyeme.)

20. S. Pulvis pyrius: simplex congesta, sphaerulis ovatis subrotundis tuberculosis rugosis medio sulcatis. (ad truncos et ligna arida, pulveri pyrio disperso similis. Jul. Sept.)

56. Stilbospora. Sclerocarpus. Massa nigra erumpens, e sporulis constans.

2. S. microsperma: sporulis minutissimis subrotundis utrinque subacutis. (in cortice Betulae. Jul. Oct.)

57. Hystenium. Sclerocarpus. Perithecium oblongum, rima longitudinali dehiscens.

1. H. pulicare: [Lichen pulicaris] gregarium oblongum aut ellipticum striatum. Mich. nov. gen. t. 50. f. 2. (ad corticem Ulmorum Quercuumque. Sept. Oct.)

2. H. quercinum: [nigrum] erumpens flexuosum subventricnsum molle nigrescente - cinereum. Tode fung. II. t. 8. f: 64. (ad ramulos juniores Quercuum. Jul. Sept.)

3. H. conigenum: erumpens parrum subovatum rugosum. (in squamis strobilorum abietinorum exsiccatorum. Jul. Aug.) 


\section{$-216,-$}

58. Xruoma. Sclerocarpus. Perithecium applanatum suborbiculare inaeqquale dehiscens, intus farctum.

1. X. salicinum: crassum tuberculosum, intus basi cartilagineum album. Pers. meth. t. 2. f. 4. (in foliis Salicis capreae. Jul. Aug.)

\&. X acerinum: [Sphaeria maculaejormis] maculaeforme tenue contiguum subrugosum. (in foliis Aceris platanoidis et campestris. Aug. Sept.)

3. X. populinum: gregarium forma varium applanatum laeve opacum nigrum. (in foliis Populi tremulae. Mai. Jun.)

59. Naeniaspora. Sclerocarpus, Gelatina fluxilis, sub lente anorpha, in cirrhos prorumpens.

1. N. chrysosperma: [populina] pustulata erumpens nigrescens, cirrhis copiosis tenuibus flavis. Pers. mycul. I. t. 5. f. 8. (in cortice Populi nigrae, Betulae albae, Alni glutinosae. Jul. Sept.)

6o. Tumercurakia. Sclerocarpus. Perithecium - hemisphaericum stipitiforme aut nullum. Latex subrotundus compactus persistens, humectatus subfluxilis.

1. T. vulgaris: [Sphaeria miniata] gregaria amoene rubra sulcato - rugosa, receptaculo stipitiformi crasso pallido. Bolt. fung. t. 127. f, 1. (in ramis emortuis Ribis rubri et Tiliarum. Jul. Sept.)

61. Sphaerobolus. Sarcocarpus, Receptaculum globosum radiatim fissum, vesiculan inclusam elastice protruvens. 


\section{$-217-$}

1. S. stellatus: [Lycoperdon Carpobolus] capitulo glabro, ore acuminato dentato. $F l$. dan. t. 395. (ad ramos putrescentes, in acervulis serraginis. Sept. Oct.)

69. PiLnólus. Sarcocarpus. Receptaculum stipitiforme hydrophorum, cui imposita vesicula nurla elastice desiliens.

3. P.crystallinus: [Mucorurceolatus] receptaculo obovato, vesicula hemisphaerica nigra. Bull. champ. t. 480. f. 1. (ad fimeta equina aut bubulina. Sept. Oct.)

63. Sclerotium. Sarcocarpus. Corpus carnosum connexum, vesiculis farctum.

x. S. complanatum: complanatum erectum substipitatum pallidum. Tode fung. I. t. 5. f. 9. (in fimetis, culmis gramineis putrescentibus adhaerens. NIai)

2. S. brassicae: oblongum depressum nigrum, intus nigro-punctatum (intra folia putrescentia Brassicae oleraceae in cellis asservatae. Hyeme.)

3.-S. Semen: [Sphaeria brassicae] gregarium sphaericum nigrescente-spadiceum, demum corrugatum. Tode fung. I: t. 4. f. 6. (ad stipites subputrescentes Solani tuberosi in agris acervatos. Vere et autumno.)

4. S. Erysiphe: [Dematium Erysiphe] epiphy]lum, granulis aggregatis fusco-nigris, tomento albo insidentibus. (in foliis variarum plantarum v. c. Heraclei Sphondylii, Coryli Avella. nae, etc. Sept.) 
5. S. populneum: epiphyllum congestum subimmersum incarnato-rufum, demurn nigrescens, fórmis varium subrotundum aut angulato-confluens. (in foliis Populi tremulae. Mai.)

64. Tuber. Sarcocarpus. Subrotundum carnosum. Substantia venis seminiferis variegata.

1. T. cibarium: [Lycoperdon Tuber] subterraneum, verrucis exasperatum nigrescens. Bull. champ.t. 356. (sub terra, ubi a canibus eo fine eruditis elfoditur, in vicinitate quercuum annosarum. Jun. Sept.)

\section{G A S TER O M Y C I.}

6.5. Geastrum. Dermatocarpus, trichospermus. Volva tenuis, evanescens. Peridium radiatim fissum demum reflexum, ore piloso.

2. G. hygrometricum: [Lycoperdon stellatum] radio multifido inflectente badio, peridio reticulato sessili subconcolore. Bull. champ.t. 238. (in pinetis sabulosis. Vere et autumno.)

66. Bovista. Dermatocarpus, trichospermus. Peridium laeve sessile, cortice exteriore demum evanescente, apice irregulariter hiscente.

1. B. plumbea: [Lycoperdon ardesiaceum] minor subglobosa plumbeo-caesia. Bull. champ. $t$. 292. (in pratis, locis graminosis, montosis, umbrosis. Aug. Sept.)

67. Lxсоrerdon. Dermatocarpus, trichospermus. Peridium verrucis obsitum caulescens, apice demum ruptum. 
1. L. giganteum: [maximum] subacaule globosuin maximuin ex albido pallescens, squamulis sparsis subobsoletis. Bull. champ. t. 447\% (in graminosis, arvisque. Sept)

\&. L. Bovista: [gemmatum] magnum obconicum molle pallescente-albidum, subtus plicatum, squamis latiusculis. $F l$. dan, t. 1139. (in collibus herbidis. Sept Oct.)

3. L. pratense: [papillatum] candidum molle, peridio hemisphaerico laeviusculo, verrucis parcis, caule brevissimo. Eull. champ. t. 435. f. 2. (in pratis collibusque graminosis, post pluvias. Aug. Sept.)

4. L. pyriforme: [ovoideum] cespitosum pyriforme umbonatum fuligineo-pallidum: squamulis tenuissimis, radiculis fibrosis longis. Bull. champ. t. 435 . f. 3. (ad truncos putridos, in quercetis. Sept. Oct.)

68. Scleroderma. Dermatocarpus, trichospermus. Peridium cortice suberoso duriusculo subtes. selato, indeterminatim demum rupto.

1. S. cervinum: [Lycoperdon cervinum] subterraneum rotundum oblongum durum granulatum. Mich. gen. t. 99. f. 4. (in pinetis subterraneum. Jun. Sept.)

69. Lrcogala. Dermatocarpus, trichospermus. Peridium subrotundum membranaceum laeve, intus primo massa pulposa liquescente, dein fulvere filis raris intertexto farctum.

1. L. miniata: [Lycoperdon Epidendrum] gregaria globosa, primo ininiata, demum fuscescens, 
pulvere roseo. 'Fl. dan. t. 760 . in itruncis putrescentibus vetustis, post pluvias. Aug. Sept) 70. Fuligo. Dermatocarpus, trichospermus. Peridium effusum, primo julposum, dein fibroso eellulosum pilosun, demum in pulverem fatiscens. 1. F. rufa: [Mucor septicus] pulvinata rufa, cortice subrugoso fragili subcompacto. $F l$. dan.t. 778. (in truncis et lignis putrescentibus. Aug. Sept.)

2. F. fiava: [Reticularia lutea] effusa subrotunda flava, cortice celluloso-fibroso. Bolt. fung. $t$. 134. (super truncos, muscos, foliaque decidua, vitelli ovi ad instar effusa. Sept. Oct.)

3. F. vaporaria: primo obtecta venosa repens, matura late cespitosa crassa celluloso-fibrosa flavo-cinnamomea, (in vaporaris intra pulverem coriarium. Hyeme.)

72. Srumaria. Dermatocarpus, trichospermus. Peridium duplex effusum : exterius furfuraceum deciduum, interius persistens ramoso-cornutuin.

1. S. Mucilago: [Reticularia alba] magna, alba, peridiis interne ramoso-cornutis. Bull. champ. t. 126. (super folia et muscos effusa, caulesque plantarum seu ramulos deciduos ambiens. Sept. Oct.)

72. Dideria, Dermatocarpus, trichospermus. Peridium duplex: exterius fragile, interius pellucidum. Fila parca latentia columnulae ovali adnata.

1. D. vernicosum: [Lycoperdon fragile] stipitatum congestum rufescens ovatum nitidum, stipite brevi laxo albido. Dichs. brit. I. t. - 3: f. 5 . 
(in sylvis, muscos, ramulos, foliaque praesertim incolens. Frequenter in Calluna et Myrtillo. Sept. Oct.)

73. Tnicixa. Dermatocarpus, trichospermus. Peridium glabrum inaequaliter ruptum. Capillitium compactum elastice expansum.

2. $\Gamma$. rubiformis: [Lycoperdon vesparium] stipitata fasciculata chalybea nitida, stipitibus connatis subpedatis brevioribus. Batsch. fung. I.

t. 30. f. 172. (in sylvaticis ad truncos subputrescentes, nec non in sepibus vetustis. Sept. Oct.)

\&. T. ovata: [Clathrus turbinatus] congesta sessilis obovata opaca ex ochraceo-alutacea. Bolt. fung. t. 48. f. 7. (in sylvis. Sept. Oct.)

74. Arcrixa. Dermatocarpus, trichospermus. Peridium circunscissum. Capillitium ovatum receptaculo calyculato impositum.

1. A. punicea: [Stemonitis crocata] congesta croceo-punicea, capillitio subcinereo. Bull. champ. t. 502. f. 1. b. c. (in sylvis ad truncos putrescentes. Aug. Sept)

75. Stemonxis. Dermatocarpus, trichospermus. Peridium tenuissimum evanescens. Capillitium reticulatum, subcompactum, columnulae adnatum.

1. S. typhina: [Embolus pertusus] sparsa minor, capillitio cylindrico obtuso subincurvo. Bull. champ. t. 477. f. 2. (ad truncos vetustos, praesertim salicinos. Aug.)

76. Cribraria. Dermatocarpus, trichospermus. Peridium tenuissimum, aut totum aut ad dimidium 
evanescens. Capillitium filis reticulatis cancellatum, pulverem congestum ambiens.

1. C. vulgaris: gregaria, perilio lutoso rotundo subcernuo, stipitelongo purpurascente. Schrad.

t. 1. f. 5 (in sylvaticis ad truncos putridos et muscos. Jul. Oct.)

77. Tubulina. Dermatocarpus, gymnospermus. Peridia tubuliformia in cespitulum connata, stro. mati membranaceo imposita.

1. $\Gamma$. fragiformis: [Stemonitis ferruginea] suborbicularis rubro-spadicea, tubulis incrassatis apice distinctis. Fl. dan. t 659 f. 2. (post pluvias densas, ad truncos. Jul. $\Lambda$ ug.)

73. Mucon. Dermatocarpus, gymnospermus. Peridiun membranaceum subglobosum stipitatum: primo subaquosum pellucidum, dein opacum. Sporulae nudae, subcohacrentes.

2. M. Mucedo: [Mucedo grisea] stipite simplici, peridio inflato nigrescente griseo, ore rotundo circa stipitem dehiscente. Fl. dan. t. 462 . f. 4. (in fructibus putridis Autumno et hieme.)

2. M. caninus: [Hydrophora stercorea] congestus byssoideus albus, peridiis minutis lutescentibus. Pers. mycol. I. t. 6. f. 3. 4. (in muscerda canina, tempestate pluviosa. Oct Nov.)

3. M. herbariorum: [Stemonitis sulphurea] acaulis flavescens persistens, peridiis globosis tomento insidentibus. (in plantis haud bene exsiccatis, vel locis lumidis depositis.)

79. Onygena. Deinatocarpus, gymnospermus. Peridium stipitatum, subrotundum, siccum, per- 
sistens. Pulvis compactus, cohaerens, filis nullis intertextus.

1. O. equina: [Lycoperdon equinum] gregaria albido-pallescens, peridio orbiculari glabro rugoso subfurfuraceo. Pers. mycol. II, t. 6. f. 3. a. b. c. (in unguibus vetustis equorum, cornubusque bovum, locis sylvaticis umbrosis dejectis. Aestate.)

80. Aecidium. Dermatocarpus, gymnospermus. Peridia cylindracea membranacea, ore plerumque dentato dehiscentia. Pulvis farinaceus.

1. A. cornutum: [Lycoperdon corniferum] havescens, peridiis longissimis curvatis olivaceo-griseis. Pers. mycol. II. t. 4. f. 2. 3 (in foliis Sorbi aucupariae. Aug. Sept.)

2. A. cancellatum: [Lycoperdon cancellatum] tuberculatum spadiceum, peridiis in lacinias apice cohaerentes demum fissis. $F l$. dan. t. 704. (in foliis adhuc viridibus Betulae et Pyri languescentis. Aug. Sept.)

3. A. rhamni : cespitosum roseum, peridiis elougatis subdivergentibus demum expallidis. Pers. mycol. I. t. 2. f. 4. (in foliis Rhamni catharctici et Frangulae. Aestate.)

4. A. rubellum: [rumicis] confertum subconfluens cespitosum orbiculare rubrum. peridiis pulvereque albidis. Hoffm. germ. II. t. 2. f. 2. (in foliis Rumicis aquatici et obtusifolii, nec non Rhei undulati et Fragariae vescae. Jul. Aug )

5. A. grossulariae: solitarium cespitosum, macula subinaequali rubra margine peridiisque 
pallidis. (in foliis et petiolis, aut in ipsis luaccis Grossulariae. Jun. Aug.)

6. A. confertum: [ficariae ] subeffusum crassum flavum: forma varia inaequali, peridiis subdistantibus. (in Ficariae vernae et Violae adoratae petiolis et nervis foliorum. Mai.)

7. A. crassum: subeffusum crassum flavo-aurantium. Pers. ic. et descr. II. t. 3. f. 1. 2. (in foliis Rhamnorum, Ranunculorum, Calthae et Aquilegiae, nervos praecipue obdlucens. Mai.) 8. A. asperifolii: cespitosum orbiculare subtus excavatum crassiusculum aurantium, peridiis sparsis. (in plantis variis asperifoliis, e. g. in Cynoglosso, Picride, Symphyto, Urtica urente, etc. Jul. Aug )

9. A. tussilaginis: [Lycoperdon epiphyllum] macula purpurascente-flava, peridiis immersis, cespitulo plano. (in foliis Tussilaginum. Jul. Aug.)

10. A. berberidis: [Lycoperdon poculiforme] cespitosum orbiculare parvum convexum, peridiis subelongatis flavis Jacqu. coll. I. t, 4. f, 1. in foliis Berberidis. Jun. Aug.)

11. A. geranii: macula nulla, cespitulo forma vario, peridiis subelongatis pulvereque brunneo. (in foliis Geranii sylvatici et pratensis. Aug. Sept)

22. A. bifrons: [ranunculi] macula nulla, cospitulo forma vario, peridiis confertis tenuibus flavescentibus. (ad nervos foliorum Ranunculi acris et Aconiti Lycoctoni. Jul. Aug.) 
13. A. tragopogi: [cichoriarum] sparsum, peridiis subellipticis albis, margine inaequali la. cero, pulvere flavo. (in caule foliisque Tragopogi pratensis.Jul. Aug.)

14. A. leucospe mum: [anemones] simplex spa $\mathbf{1}_{1}$ sum, peridiis cylindricis prominulis pallidis utplurimum dentatis, pulvere albo ex toto repletis. (in foliis junioribus Anemones nemorosae. Mai.)

25. A. punctatum: simplex sparsum, peridiis subimmersis, ore subconnivente, pulvere compacto fuscescente. Hoffm germ.II. $t$ 2. f. 1. (in foliis Anemones ranunculoidis. Mai)

31. Puccisia. Dermatocarpus, gymnospermus. Peridia turbinata septulis interstincta.

1. P. anemones: [Aecidium fuscum] sparsa subparallela spadicea inquinans, sporulis uno septulo medio constrictis, utrinque rotundatis. Pers ${ }^{*}$ mycol. II t. 6 f. 5. (in foliis Anemones nemorosae et ranunculoidis $\mathrm{MI}$ ia)

‥ P. betonicae: confluens spadicea inquinans; - capsulis variis, utplurimum oblongo-ovatis mucronatis (in foliis Betonicae officinalis Mai.)

3. P. aethusae: [nitida] sparsa pustulata ferruginea dein fusco spadicea; capsulis obovatis nitıdis, cauda brevi curva instructis (in foliis et caulibus Aethusae Cynapii. Jul. Aug.)

4. P. menthae: sparsa punctiformis obscure spa. dicea, sporulis subquadrangularibus: cauda, brevissima. (in foliis Menthae aquaticae et austriacae. Aug. Sept.) 


\section{- 226}

5. P. acgopodii: [bullata] glometulis minutis fuscis circinatim aggregatis; capsulis subovatis, mucrone curvo. (in foliis Aegopodii Podagrariae Jun. Jul.)

6. P. gentiance: [pneumonanthes] erumpens varia umbrina; capsulis oblongis, cauda brevi curva. (sub epidermide foliorum adhuc viridium Gentianae cruciatae et Pneumonanthes. Sept. Oct.)

7. P. pimpinellae: sparsa subrotunda cinnamomea, capsulis diformibus ovatis obovatisque, cauda brevi curvula. (in foliis 1 impinellae Saxifragae. Aug Sept.)

8. P. hicracii: [flosculorum] sparsa subrotunia cinnamomea; capsulis subovatis. (in foliis Hieracii murorum, sylvatici et sabaudi. Aug. Sept.)

b. Puccinia apargiae: [prenanthidis] subconferta irregularis, capsulis subovatis (in foliis $A$ pargiae autumnalis et Prenanthidis muralis. Sept. Oct.)

9. P. cnici: sparsa rotunda cinnamomea; capsulis subellipticis. (in foliis Cnici lanceolati. Aug. Sept)

10. P. centaureae: conferta fusco-cinnamomea; capsulis ovatis. (in foliorum inferiore pagina Centaurca phrygiae. Sept.)

11. P. polyguni: spadicea depressa, sporulis caudatis oblengo-ovatis.

a. Puccinin bistortae: glnmerulis subrotumdis minutis aurantiis, capsulis ovatis orbatis. 
que. (in foliis Polygoni amphibii et Bistortae. Aug. Sept.)

b. Puccinia persicariae: glomerulis depressis fuscescentibus, variae formae et magnitudinis. (in foliis $\mathrm{P}_{0}$ lygoni Persicariae. Sept.)

22. P. cerealis: [graminis] conferta linearis nigrescens, sporulis subturbinatis medio constrictis (in culmis foliisque graninum variorum, praecipue Secalis et Tritici. Sept.)

13. P. junci: [scirpi] subrotunda linearis nigra; capsulis fusiformibus supra medium constrictis, in caudam desinentibus. (in foliis et culmis scirporum juncorumque. Sept. Oct.)

14. P. tanaceti: [caudata] sparsa rotunda fusca; capsulis oblongis medio coarctatis, cauda longissima rectiuscula. (in foliis Tanaceti vulgaris Sept. Oct.)

15. P. balsamitae: sparsa conferta subrotunda fusca; capsulis ovatis constrictis, cauda capsulae longitudine. (in foliis Balsamitae suaveolentis Sept. Oct.)

16. P. potentillae: [ohtusa] subrotunda sessilis, primum aurantiaca demum nigra, sporulis cylindricis obtusis. (in foliis Potentillae argenteao et Tormentillae erectae. Sept Oct.)

17. P. rubi: [mucronata] conferta nigra villosa, sporulis subattenuatis. (in foliis Rubi corylifolii et fruticosi. Sept. Oct.)

18. P. bulbosa: capsulis cylindricis obtusiusculis septulis quatuor, cauda crassa bulbosa. (in foliis Rubi fructicosi, Sept, Oct.) 
19. P. ficariae: e badio nigrecens, subbullata; cespitulis majusculis solitariis parcis subrotundis, sporulis rotundo-ovatis subcaudatis (in Ficaria verna. Mai.)

20. P. pruni: [acaciae] sparsa minuta punctiformis, sporulis globosis geminis, cauda brevissima. (in foliis Pruni insiticiae et spinosae. Sept. Oct.)

21. P. circaeae: [chrysosplenii] sparsa verrucaeformis badia, sporulis ovato-acutis. (in foliis Circaeae alpinae. Sept. et in Chrysosplenio alternifolio. Mai.)

82. UnEDo. Dermatocarpus, gymnospermus. Peridium effusum ab epidermide formatum, pulvere uniformi globuloso prorumpente.

$$
\text { * Pulvere albo [Alevigo] }
$$

1. U. candida: [Aecidium candidum] prominens candida; capsulis siccitate contractis, ovatis.

a. Uredo thlaspeos: subeffusa. (in foliis Thlaspeos Bursae pastoris. Jul. Aug.)

b. Uredo cheiranthi: [crysimi] sparsa subglo. bosa tumida. (in foliis Cheiranthi incani et Erysimi cheiranthoidis. Aug)

c. Uredo alyssi: sparsa subrotunda latens. (in foliis Alyssi calycini et incani. Jul. Aug )

a. U. cubica: [iragopogi] globosa clausa albida; capsulis siccitate in formam cubicam contractis. (in foliis Tragopogi majoris et pratensis. Aug. Sept)

* Pulvere flavescente. [RvBrgo] 


\section{$-\quad 839$}

5. U. alchemillae: flava conferta, lineasque subpr: rallelas erumpens. (in foliis Alchemillae utriusque. Jun. Jul.)

4. U. frumenti: [linearis] flava linearis longissima inquinans, demum colore obscuriore. (in culmis foliisque frumentorum. Jul. Aug.)

5. U. polypodii: [athyrii] flava linearis longissima tenera. (in stipitibus foliisque Athyrii fragilis et Aspidii spinulosi. Aug. Sept )

6. U. euphorbiae: [helioscopiae] flava subglobosa. sparsa prominens. (in foliis Euphorbia helioscopiac et Pepli. Jul. Aug.)

7. U. pyrolae: flava conferta applanata oblonga. (in foliis Pyrolae rotundifoliae et umbellatae. Jul. Aug.)

8. U. lini: aurantiaco - rubra conferta, cespitulis pulvinatis magnitudine variis. (in foliis Lini usitatissimi et catharctici. Jul. Aug.)

9. U. potentillae: parca laxa rufo-inquinans. (in villo foliorum Potentillae argenteae et in ruthenica. Sept. Oct.)

10. U. rubi: aurea minuta pulverulenta subglobosa. (in foliis Rubi caesii, corylifolii et fruticosi. Jun. Jul.)

12. U. orchidis: [circinalis] aggregata vivide anrea elliptice et aequaliter circinata. (in foliis Orchidis conopseae et maculatae. Mai. Jun )

12. U. mercurialis: [confluens] saturate oclirace applanata circinatim confluens. (in foliis Mercurialis perennis. IMLi. Jun.) 
13. U. evonymi: [ribis] minor colore dilutiore, (in foliis Evonymi verrucosi et in Ribesio alpino. Mai, Jun.)

14. U. senecionis: [farinosa] ochracea irregulariter confluens farinosa. (in foliis Senecionis sylvatici et vulgaris. Aug. Sept )

15. U. tussilaginis: [farfarae] miniato-rubra, punctis subconcentricis. (in foliis Tussilaginis Farfarae et Petasitidis. Aug. Sept.)

16. U. pulsatillae: [tremellosa] crocea clausa pustulaeformis subtrcmellosa. (in foliis Pulsatillae vulgaris. Jul. Aug.)

17. U. campanulae: flavo-rubra rotunda subdepressa, magnitudine varia. (in foliis Campanulae patulae, rapunculoidis, rotundifoliae et Trachelii. Jun. Jul.)

28. U. sonchi: fulva subconfluens conferta, cespitulis planiusculis irregularibus. (in foliis Sonchi arvensis et oleracei. Aug. Sept.)

19. U. ringentium: aurantia inaequalis subsparsa. a. Uredo rhinanthi: subsparsa. (in foliis Rhinanthi majoris et minoris. Jun. Jul.)

b. Uredo melampyri: flavo-rubens effusa, (in foliis Melampyri arvensis et nemorosi. Jul.)

c. Uredo euphrasiae: miniato-aurantia. (in foliis Euphrasiae officinalis et nemorosae. Jul.)

d. Uredo odontitidis: aurantia inaequalis. (in foli is Odontitidis rubrae. Aug. Sept.)

20. U. eglanteriae: [miniatc] miniato-aurantia effusa subrotunda, cespitulis oblongis subrotundisque. (in foliis, petiolis, pedunculis, ca- 


\section{$-231$}

lycibusque Rosae caninae, centifoliae et Eglanteriae. Jun.)

21. U. ulmariae: [spiraeae] miniato - aurantia elongata bullatim prorumbens. (in foliis Spiraeae Ulmariae. Mai. Jun.)

22. U.rosae: [centifoliae] flavo-rubens conferta, basi plana effusa, cespitulis orbicularibus. (in foliis Rosae centifoliae. Jul. Aug.)

23. U. illaei: [gyrosa] flava subconica sparsa, disco foliorum gyrose rupta. (in foliis Rubi Idaei. Mai, Jun.)

24. U. populi: [ovata] fulva minuta globulosa aperta. (in foliis Populi nigrae et trenulae. Sept. Oct.)

25. U. betulae: [betulina] lutescens conferta in. aequalis bullata minuta rotunda clausa. (in foliis Betulae albae. Jul. Aug.)

26. U. epilobii: [pustulata] flavescens subrotunda minuta prominula clausa, in glomerulos collecta. (in foliis Epilobii montani et tetragoni. Jul. Aug )

27. U. cerastii: flava conferta minuta subrotunda prominula clausa, in glomerulos collecta. (in foliis Cerastii vulgati. Jul. Aug.)

23. U. vaccinii: [myrtilli] ochrea conferta minuta in glomerulos collecta subrotunda clausa, demum aperta. (in foliis Vaccinii uliginosi et Myrtilli. Aug)

29. U. ledi: sparsa aggregata miniato-aurantia subcylindrica, pulvere laxo. (in foliis adhuc virentibus Ledi palustris, MLai. Jun.) 
** Pulvere obscuro [Nigredo]

30. U. fabae: [viciae] fusco-spadicea conferta orbicularis subeffusa depressa. (in foliis cauleque Viciae. Fabae et sativae. Aug. Sept.)

31. U. betae: [cincta] sparsa orbicularis, pulvere cinnamomeo epidermide alba cincto. (in foliis Betae vulgaris. Sept. Oct.)

32. U. menthae: pallide fuscescens sparsa orbi- cularis planiuscula. (in foliis Menthae arvensis, austriacae et sylvestris. Sept. Oct.)

33. U. convolviall: [polygoni] dilute cinnamomea sparsa orbicularis convexa (in foliis Convolvuli arvensis et Polygoni Convolvuli. Sept. Oct)

34. U. conii: [nitida] conferta irregularis ferrugineo-spadicea, capsulis oblongis. (in foliis petiolisque Conii maculati. Aug. Sept.)

35. U. oreoselini: [bullata] bullatim prorumpens spadicea, capsulis ovato-oblongis caudatis. (in foliis Athamantae Oreoselini. Jul, Aug.) 36. U. suaveolcns: [serratulae] dilute fusco-purpurea confluens inaequalis odorata. (in foliis Serratulae et Cnici arvensis. Mai. Jun.) 37. U. trifolii: [apiculata] sparsa punctiformis cinnamomea; capsulis globosis mucronatulis. in foliis exsiccatis Trifolii arvensis, hybridi et montani. Jul. Aug.)

b. Uredo arctii: [bardanae] acervulis crebrioribus, modo minoribus modo majoribus. (in foliis Arctii Lappae et Bardanae. Aug. Sept ) 


\section{$-233$}

c. Ureslo violae: colore laetiore in flavum vergente. (in foliis Violae caninae et palustris. Jul. Aug )

38. U. phaseoli: [appendiculata] badia subconfluens conferta pulvinata inquinans, (in foliis Phaseoli vulgaris. Aug. Sept.)

59. U. pisi: sparsa inaequalis dilute fusco-purpurea planiuscula. (in foliis stipulisque Pisisativi. Jul Aug:)

40. U. genistae: sparsa subrotunda clausa dilute badia; capsulis globosis, cauda incurvata. (in foliis Genistae tinctoriae. Sept, Oct.)

41. U. segetum: [Lycoperdon tritici] pulverecopioso fusco-nigro inquinante. Jun. Jul.)

a. Uredo hordei: subclausa. (in Hordeo disticho et vulgari.)

b. Uredo tritici: effusa. (in Tritico aestivo et hyberno )

c. Uredo avenae: in glumis latens. (in Avena sativa.)

d. Uredo panici: effusa magna. (in Panico miliaceo. Jun. Jul.)

42. U. decipiens: pulvere compacto nigro.

a. Uredo graminum: (in Agrostide vulgarị et Panico glauco. Mai. Jun.)

b. Uredo caricis: in Carice brizoide, pilulifera, praecoci, stellulata, aliisque. Mai.)

43. U. violncea: [saponariae] pulvere purpureoviolaceo (in antheris florum Saponariae officinalis. Aug.) 
83. Trichoderma. Dermatocarpus, gymnospermus. Pulvis copiosus, farinaceus, tegmine tomentoso seu villoso cinctus.

1. T.viride: [Sphaeria olivacea $]$ subrotundum effusum, pulvere viridi, villo albido fugaci. Tode fung. I. t. 3. f. 29. (ad ramulos deciduos, aut in caulibus herbarum majorum, post pluvias. Oct.)

-. 'T. tuberculatum: candidum suborbiculare, primo tomentosum, demum tuberculosum, pulvere cinereo. Pers. mycol. I. t. 2. f. 8. (in sylvis umbrosis, post crebras "pluvias, ad terram nudam. Aestate.)

84. Cyathus. Dermatocarpus, sarcospermus. Peridium infundibuliforme aut cupulare coriaceum, drimo epiphragmate clausum, vesiculis lentiformibus repletum.

1. C. striatus [Nidularia hirsuta] hirsutus spadiceus interne striatus. Bolton. t. 102. f. 2. (in locis sylvaticis humidis, ad ramulos dejectos, radices emortuas, et inter folia putrescentia. Sept. Oct )

2. C. lentiferus: [Nidularia vernicosa] externe cinereus aut fuscescens subtomentosus, interne laevis plumbeo-lividus. Bull. champ. t. 488. f. 1. (ad asseres, inter ligna putrida. Mai. Sept.)

\section{F U N G I。}

85. Pinalius. Iytothecius. Volvatus. Pileus oratus stipitatus, hymenio reticulato liquescente. 
1. P. impudicus: volvatus stipitatus, pileo cellu, loso. $E l$. dan. t. 175. (in sylvarum frondosarum umbra. Jun. Sept.)

86. Amanita. Hymenothecia. Volvata. Hymeniuın lamellosum.

1. A. livida: [Agaricus plumbeus] pileo planiusculo umbonato striato plumbeo-livido, lamellis stipiteque longo candidis. Fl. dan. t. 1014. (ad margines sylvarum frondosarum, aut in pinetis, post diurnas pluvias. Jun. Aug.)

2. A. virgata: [Agaricus volvaceus] cespitosa, pileo campanulato conico piloso cinereo nigroque virgato, lamellis pulverulentis rubrocinnamomeis. Bull. herb. t. 261. (in vaporariis, inter pulverem coriarium. Jul. Aug.)

5. A. muscaria: [Agaricus imperialis] pileo aurantiaco - rubro nitido planiusculo, verrucis lamellis stipiteque candidis. Fl. dan. t. 1129 . (in syylvis et pinetis. Jul. Oct)

87. $\Lambda$ garicus. Hymenothecius. Evolvatus. Hymenium lamellosum.

A. Leprota: lamellis arescentibus, stipite annulato.

2. A, squarrosus: [floccosus] cespitosus, pileo carnoso stipiteque squarroso - squamoso ochraceis, lamellis olivaceo-pallidis confertis. $F l$. dan. t. 491 . (ad caudices quercinas. Sept. Oct.)

2. A. caudicinus: [mutabilis] cespitosus, pileo subcarnoso umibonato glabro cinnamomeo, lamellis sulddecurrentibus pallide ferrugineis, 
stipite squamoso subtenui cylindrico Fl. dan. t. 10n8. (ad trunces putrescentes. Sept. Oct.)

B. Cortinaria: lamellis demum cinnamomeis, stipite cortinato s. velo in fila araneosa soluto.

3. A. violaceus: stipitatus, pileo rimoso: inargine violaceo tomentoso, stipite caerulescente: lana ferruginea. Mich.gen. t. 74. f. 1. (ad margines sylvarum. Sept. Oct.)

4. A. vaccinus: [rufus] gregarius, pileo carnoso hemisphaerico umbonato piloso-squamoso rufo, lancllis albis pallescentibus, stipite cavo longo subfibrilloso. Pers, ic. et descr. t. 2. f. $\mathbf{2}$. 2. 3. 4. (in pinetis. Aug. Sept.)

5. A. croceus: [cinnamomeus] gregarius minor, pileo subcarnoso umbonato subtomentoso fulvocinnamomeo opaco, lámellis flavo - croceis, stipite subtenui fibrilloso lutescente: cortina fugaci. Batsch. t. 23. f. 127. (in pinetis. Sept.)

C. Gyninopus: lamellis unicoloribus arescen: tibus, stipite nudo.

6. A. pratensis: [miniatus] fulvo-rubescens subdurus, pileo campanulato seu obtuse urnbonato glabro, lamellis crassis distantibus decurrentibus, stipite brevi subtenui deorsum attenuato. Fl. dan. t. 715 . (in pratis, pascuis, collibus. que herbidis. Sept. Oct.)

7. A. fastibilis: [lateritiuis] cespitosus, pileo carnoso lateritio - rufo aut pallido oftaco fexuoso, lamellis aquose cinnamomeis, stipite 
crasso fibrilloso albilo. Eatsch. t. 33. f. 195. (in sylvis et pinetis. Sept. Oct.)

8. A. coccineus: gregarius, totus coccineus, pileo submembranaceo convexo subviscoso, lamellis distantibus dentatim connexis, stipite cavo subcompresso. Bull. herb. t. 570. f. 2. (in pratis et pascuis colliculosis. Sept. Oct)

9. A. hortensis: cespitosus elasticus, pileo subliemisphaerico planiusculo obsolete umbonato fuligineo subnigrescente, lamellis subdecurrentibus subcontortis albidis, stipite subundulato deorsum incrassato. (in hortis et sylvis. IAug. Sept.)

D. Mrcens: tenelli pileo striato subpellucido, lamellis unicoloribus, stipite elongato fistuloso.

10. A. hypnorum: tenerrimus parvus totus ochraceo-ferrugineus, pileo campanulato sulcato, lamellis distantibus latiusculis, stipite mediøcri. Batsch. t. 19. f. 96. (inter muscos, praesertim hypna, post largas pluvias. Sept. Oct.)

11. A. vulgaris: gregarius confertus parvus, pileo papillato demum subumbillicato subviscosocinereo, lamellis albidis uncinatis, stipite viscoso crassiusculo. $F l$. dan. t 830. f. 2 ? (in pinetis post pluvias largas. Sept. Oct.)

E. Coprraus : pileo membranaceo fugaci,.la. mêllis nigrescenti-liquescentibus, stipite subalbido.

12. A. fimetarius: [comatus] gregarius, pileo conico squamoso albido: squamis flave scentibus, 


\section{$-238-$}

lamellis congestis primo albido-purpurascentio bus, stipite longissimo: annulo mobili. Fl.dan. t. 834. (in locis graminosis, ad sepes, in hortis. Sept.)

13. A. plicatus: cespitosus, pileo campanulato plicato fuscescente - cinerco, apice squamuloso, margine denum revoluto, lamellis confertis latis primo purpurascente-fuscis pruinatis $S_{0}$. werb. t. 188. (in pagis, ad sepes, in pratis. Sept.)

14. A. ferrugineus: [lignorum $]$ cespitosus, pi]co campanulato sulcato ferrugineo, lamellis nitentibus primo roseis, dein cinereis, tandem nigrescentibus. Fl. dan. t. 1070. (in hortis et sylvis, ad truncos. Sept. Oct.)

15. A. vitellinus: fragilis, pileo viscido dilute vitellino, lamellis distinctis argillaceis, stipite fistuloso farinaceo pulverulento nudo. (in fimeto equino gregarie. Mai)

16. A. disseminatus: congestus parvus fugax, pileo scmiovali striato-plicato, primum subochraceo, dein griseo: Jamellis distinctis semi* adnexis albido-fuscescentibus, stipite utplurimum incurvo. Schäff. fung.t. 308. (in salicum truncis cavis. Jul. Sept)

17. A. domesticus: pileo campanulato obtuso undulato sulcato fuligineo: squamulis furfuraceis, lamellis confertis linearibus, primo caesio-rubris, dein brumneis nigricantibus. (in doniciliis ad muros humidos. Aug. Sept.) 
18. A. ephemerus: gregarius minor, pilco crinpanulàto demum partito striato glabro subcihereo: disco rufescente, stipite longo' glabro. Bull. herb. t. 542, f. 1. d. (in stercorariis. Sept. Oct.)

F. Pratella: pileo persistente, lamellis nebulosis aquosis, pulvere seminali demum obscurioribus.

19. A. campestris: pileo carnoso planiusculo rufo squamoso, lamellis rubescente-fuscis, stipite brevi : annulo incompleto. $F$ l. dan.t. 714. (in pratis et pascuis colliculosis, cultis stercoratis, fimetisque. Sept. Oct.)

20. A. sracilis: [cuspiáatus] pileo membranaceo campanulato acuto mollissimo incarnato ochraceo, lamellis nigrescenti-cinereis, stipite longissimo glabro, Eolton. t. 66. (in sylvaticis, inter folia. Sept. Oct.)

G. LactrfuuUs: pileo subdepresso, lameliis lactescentibus.

21. A. piperatus: pileo infundibuliformi, margino expanso glabro albido, lamellis congestis furcatis candidis pallescentibus. Fl. dan. t. 1132. (in sylvis umbrosis. Sept. Oct.)

22. A. deliciosus: [Lactarius lateritius] pileo umbilicato subaurantio: exsiccato sordide pallido, lamellis succoque aurantio-lateritiis, Fl. dan. t. 1131. (in pinetis arenosis. Sept. Oct.)

23. A. ruber: [lactifluus] gregarius majusculus, pileo depresso ochraceo-rubro, lamellis flavescentibuô, stipite crassiusculo, pileo conco- 


\section{$=840$}

lore. Schäff. fung. t. 5. (in pinetis. Sept. Oct.)

H. Russula : pileo carnoso subdepresso, lamellis arescentibus, stipide nudo subalbido.

24. A. rosaceus: pileo convexo-plano sublacvi roseo seu diluto rubro, lamellis stipiteque albis. Fl. dan. t. 1009. (in sylvis frondosis acerosis. Sept. Oct.)

25. A. ochroleucus: pilen flavescenteplaniusculo, nargine laevi, lamellis stipiteque albis. Fl. dan. t. 830. f. 1. (in sylvis abietinis. Sept. Oct.)

I. Omprana : pileo umbilicato infundibuliformi, lamellis exsuccis subdecurrentibus, stipite nudo.

26. A. gilvus: [infundithuliformis] gregarius submagnus flavo-ferrugineus nitidus, pileo infundibuliformi rigido margine rellexo, stipite crasso subtuberoso. Fl. dan t. 1011 . (in sylvis abietinis gregarie. Sept.)

27. A. androsaceus: [perforans] gregarius persistens, pileo planiusculo subplicato albido obsolete umbonato, lamellis simplicibus totis adnexis, stipite nigrescente-badio. $F l$. dan. t. 1134. (in pinetis supra folia abietira. IMai. Sept.)

K. Pleunopus: pileo dimidiato, stipite nudo laterali aut nullo.

28. A. mollis: gregarius mollis, pileo glabro gibboso pallido, lamellis aquose cinnamomeio. 
Schäf. fung. t. 213. (ad truncos cariosos. Sept. Oct.)

99. A. sepiarius : [hirsucus] coriaceus durus utrinque planus, pileo strigoso-tomentoso spadiceo, laminis confertis ramosis lutescentibus Schiff. fung. t. 76. (ad truncos et in sepibus pineis. Aug. Sept.)

83. Mrrelius. Hymenothecius. Hymenium venosum, venis superficialibus tumidulis.

1. M. Cantharellus: [Agaricus Cantharellus] gregarius, totus vitellinus, pileo carnoso glabro depresso. Fl, dan. t. 264. (in nemoribus et sylvis. Sept. Oct.)

2. M. cornucopodioidles: [Peziza cornucopodioides] cespitosus nigrescens, pileo membranaceo squamuloso: venis olssoletis. $F l$. dan. t. 384. (in sylvaticis. Sept. Oct.)

3. M. Vastator: orbicularis adultus aureus, venis crispis centrum versus in plicas abeuntibus: tuberculis intus albis utplurimum aggregatis caulescentibus intermediis. Tode in Abhandl. d. Hall. nat. Gics, I. t. 2. f. 1. 2, 3. 4 (in aedificiis, locis suffocatis aut humentibus, in ligno humido, alburno. Mrai, Sept.)

89. Damalea. Hymenothecia. Hymenium sinubus poriformibus reticulatum.

1. D. quercina: [Agaricus qucrcinus] coriacea ligneo-pallens, pileo ruguloso glabro, laminis ramoso-sinuatis: sinulis magnis. Sowerb. fung. t. 181. (ad Quercuum truncos. Sept.) 
2. D. suaveolens: [Boletus suaveolens] coriaceosuberosa sessilis glabra ex niveo subfulva, carne stramineo-fuliginea: tubis longissimis subrufidis. Eull. champ. t. 3 10. (super Salicum annosarum truncos. Mai. Jun.)

90. Boletus. Hymenothecius. Hymenium tubulis porosum.

1. B. subtomentosus: [communis] pileo convexiusculo pulvinato subtomentoso sordide ferrugineo, poris ingentibus. Eolt. fung. t. 87. (in nemorosis. Sept. Oct.)

2. B. piperatus: [gregarius] pileo flexuoso cinnamomeo, poris majusculis convexis rufo - ferrugineis, stipite basi intusque flavo $F l$. dan. t. 1018. (in pinetis. Sept. Oct..)

3. B. edulis: [bulbosis] pileo pulvinato latissimo fuscescente - vaccino: carne immutabili; poris primo farctis albidis, dein dilute flavis, stipite tuberoso subventricoso reticulato rufescentecinereo. Bull. herb. t. 494. (in sylvis, pinetis et ericetis. Sept. Oct.)

4. B. perennis: [ $[$ mbriatus] coriaceus tenax cinnamomeus, pileo tenui zonato velutino. $F l$. dan. t. 1075. (in sylvis arenosis ad truncos. Sept. Oct.)

5. B. badius: [durus] subcespitosus, pileo glabro tenace castaneo, margine pallidiore, poris minutis pallidis, stipite laterali crasso fusco. Fil. dan. t. 1075. f. 1. (in sylvaticis, ad Salices cavas. Sept. Oct.) 


\section{$-243-$}

6. B. suberosus: [salicinus] odoratus crassus suberosus supra tomentosus albus, poris majusculis pallidis. Bolt. fung. t. 162. (ad Salices annosas. Oct, Nov.)

7. B. igniarius: dilatatus laevis, epidermide rugulosa, supra castaneo-aurantiacus, subtus ochroleucus. Fl.dan.t. 953. (ad Abietum truncos caesos. Sept. Oct.)

8. B. betulinus: substipitatus majusculus, pileo carnoso - suberoso reniformi fuligineo - rufescente, subtus albido. Bull. champ. t. 312.' (ad' caudices Betulae albae. Aug. Sept.)

9. B. Meáulla panis: cardidus limitatus crustaceus effusus, poris minutis brevibus, Bole. fung. t. 166. f. a. (ad ligna fubrefacta, e. g. januas vetustas hortorun; tunc in sylvis ad truncos aridos. Sept.)

20. B. versicolur: caespitosus acaulis coriaceus, pileo tenui zonato multicolore caeruleo tomentoso-sericeo, poris albis. Bolt fung.t. 31. (ad truncos aridós Sept Nov.)

91. Sisтотнем. Hymenothecium. Hymenium primum gyroso-porosum, dein dentibus difforinibus lacerum.

1. S. cinereum: [Boletus unicolor] imbricatum suberosum, pileo dimidiato hirsuto subtus cinereo. Bull, champ. t. 501. f. 3, (ad truncos, Sept. Oct.)

2. S. quercinum: [Hydnum candidum] resupinatum glabrum pallidum subrufescens, dentibus. crassis difformibus incisis subudpressis. IVill. 


\section{- 244}

in bot, Mag. I. 4. t. 7. (in ramis exsiccati

Quercorum, Pinuumque. Sept. Oct.)

92. Hуричm. Hymenothecium. Hymenium echinatum seu in dentes subuliformes integros prominens.

1. H. imbricatum: pileo carnoso umbilicato umbrino squamoso, squamis erectiusculis crassis obscurioribus. Fl, dan, t. 176. (in pinetis et sylvaticis montosis. Sept. Oct.)

2. H. repandum : pileo rugoso flexuoso sublobato glabro pallide incarnato seu flavido, stipite tuberoso subexcentrico. Fl. dan. t. 310. (in sylvaticis. Sept. Oct.)

3. II. ouriscalpium: stipitatum spadiceum, pileo dimidiato coriaceo. $F l$, dan, t. 1020. (ad terram in strobilis Pini sylvestris. Mai. Oct.)

4. H. forrugineum: [tomentosum] effusum tomentosum ferrugineum. Schrad, nov, gen, pl. t. 4. f. 3. (intra corticem et lignum, vel ad latera ramorum aridorum. Sept Oct.)

93. Turelpirora. Hymenothecia. Hymenium dilatatum uniforme subpapillosum.

1. T, terrestris: [mesenteriformis] subimbricata obscura fusca, pileo dimidiato applanato fibroso-strigoso. Willd, flor, berol, t. 7. f. 15. (in pinetis s abulosis. Sept )

2. T. ferruginea: [Auricularia tabacina] effusoreflexa fusco-ferruginea, pileo tenui subtomentoso laeviusculo subtus piloso. $F l$, dan, $t$. 1198. (ad ramos dejectos, colore pulveris tabacini, Sept.) 


\section{- $245-$}

3. T. hirsuta: [Auricularia reflexa] cespitosa coriacea lutescens strigoso- hirsuta subtus glabra. Fl, dan, t. 950. (ad truncos et palos. Sept. Oct.)

4. T. purpurea: [mesenterica] imbricata subtremellosa zonata tomentosa albida, subtus pur. purea. Mich. gen, t. 66. f. 4. (ad truncos, praesertim Populi tremulae, putrescentes. Sept.)

5. T. quercina: [carnea] resupinata effusa coriacea rugulosa rimulosa carnea, margine subin. voluto subtusque umbrino. Bull, champ. t. 434 . f. 1. (in ramis quercinis aridis. Sept.)

6. T. papyracea: [laevis] resupinata albido-carnea, late effusa laevissima, margine byssino. (ad ramos aridos varios, praesertim populneos. Sept.)

7. T. incrustans: terrestris resupinata subcarnosa rugoso-tuberculata pallida, subtus ferruginea tomentosa. (in locis sylvaticis' supra terram, folia et ramos effusa, post pluvias. Aug. Sept.) 94. Cravaria. Dermatothecia. Clavula simplex seu ramosa, cum stipite brevi cauleve crassiusculo confluens.

2. C. corniculata: [furcata] subramosa flava, caule gracili elongato furcatim subdiviso, ramulis acutis, $\mathrm{Fl}$, dan, $t, 775$, f, 3, et t, 836, f。 2. (in sylvis ad terram, Jul, Sept.)

2. C. viscosa: [flammea] subramosa vitellina viscosa tenax, ramis ramulisque furcatis, caule tenui radicato. Schäff. fung, t, 174 . (in pinetis ad truncos, Jul, Oct.) 


\section{-2 दु 6}

3. C, pistillaris: simplex solitaria magna clavata aurantiaca vel cinnamomea apice rotundo, $F l$. dan, t. 1255. (in sylvaticis. Sept, Oct.)

95. Geogrossum. Derinatothecium, Clavula carnosa compressa, margine prominente stipiti contigua.

1. G. hirsutum: [Clavaria ophioglossoides] subfasciculatum hirsutum nigrum. Schmid. icon. t. 25. f. 1. - 19. (in sylvis et pratis gregarie. Sept. Oct.)

96. IIelvelua. Dermatothecia, Pileus membranaceus inflatus difformis utrinque dcflexus.

1. H. Mirra: [sulcata] pileo inflato lobato, demum sublibero livido-nigrescente, stipite sulcato-lacunoso allicante. Fl. dan. t, 116. (in pinetis, ad terram. Sept. Oct.)

2. H. brunnea: [infula] pileo inflato ]aevi brunneo, stipite subtomentoso laevi. Schäff. fung. t. 159. (in sylvaticis montosis, ad truncos abietinos. Sept.)

97. Morciner.u. Dermatothecia. Pileus elongatus teres, areolis lacunosus.

1. M. esculenta: [Phallus esculentus] pileo basi contracto brunneo-fuligineo, stipite fistuloso albo-pulverulento. Fl. dan. t. 53. (in sylvis montosis. Mai. Jun.)

98. 'Tremerta. Dermat othecia. Iffusa", gelatinosa, hyalina, plicato-gyrosa. Pileus plerumque distinctus mullus. 


\section{- 247}

1. T. mesenterica: subcompacta plicato-undulata aurantiaca. Jacqu. austr. I. t. 13. (ad ra. mos dejectos. Maai.)

2. T. spiculosa: [arborea] applanata effusa crassiuscula nigra, papillis conicis aspera. $F l$. dan.

t. 884. (ad truncos. Sept. Oct.)

3. T. Aluricula: [Peziza Auricula] cespitosa tenuis flexuosa concava nigrescens, subtus plicata cinerea tomentosa. Bolt. fung. t. 107. (ad truncos Sambuci nigrae. Jul. Aug.)

4. T. caraganae: minor tenerior subcarnosa carneo-rufa. Bull. herb. t. 427. f. 11 ? (ad caudices Robiniae Caraganae. Jul, Aug.)

5. T. juniperina: sessilis magna membranacea subgelatinosa auriformis fulva. Vill. dauph. III. t. 56. (ad ramos juniperinos. Mai. Jun )

6. T. ustulata: exigua vesiculosa gelatinosocarnosa fusco-nigricans, superficie flexuososulcata. Bull. champ. t. 420 . f. 2. (in fructibus carnosis putrescentibus. Aug. Oct.)

7. T. abietina: [miliaria] gregaria subrotunda aurantiaca subplicata. (ad ligna dejecta abietina. Jul. Sept.)

8. T. urticae: [sepincola] gregaria minuta subrotunda oblonga laevis flavo-rubra. (ad caules aridos Urticae dioicae. Mai.)

99. Pezrza. Dermatothecia. Receptaculum hemisphaericum, $i$ concavum. Hymenium thecis spermatophoris farctum.

1. P. inquinans: [Octospora elastica] gregaria magna atro-inquinans, demum conevxa, ob- 
conica, extus rugosa sumbumbrina. Fl. dars. t. 464: (ad caudices caesos, praesertim quercinos. Sept. Nov.)

2. P. sarcoides: [Ociospora carnea] cespitosa subcarnosa firmula carneo-rubra, externe subvenosa. Fl, dan. t. 1017. (ad ramos aridos subputridos. Sept. Oct.)

3. P. aurea: congesta minuta subsessilis planiuscula fulva nitida. (ad arborum truncos in sylvis. Sept. Oct.)

4. P. stcrcoren: [Octospora scutcllata] gregaria sessilis cuncava tota fulva setosa, setis badiis suberectis. Bolt. fung. t. 108. (in fimo equino. Jul. Aug.)

5. P. papillata: minutissima rubescens, disco papillata, margine ciliata. (in fimo vaccino. Sept. Oct.)

6. P. rosae: [Myrothecium hispidum] sparsa sessilis, cupulis concavis siccis spadiceis subtomentosis, tomento concolore insidentibus. To. de fung. I. t. 5. f. 4l. (in ramis aridis Rosaeca-, ninae. Mai.)

7. P. cyathoidea: [Octospora albidula] gregaria p arva albida, cupula cyathiformi nuda tenui, stipite subfiliformi Eatsch. fung. t. 27. f. 151 . (in caulibus exsiccatis herbarum majorum. Ang. Sept.)

8. P. citrina: conferta tota citrina, stipite crasso - brevi obconico. Hedwig. t. 8. f. B. (in sylvis, ad truncos et ramos exsiccatos. Sept. Oct.) 
9. P. lenticularis: [flava] convexa adpressa sub. connexa laete flava, stipite vix ullo papillaefor, mi nigrescente. Bull. champ. t. 300. f. a. b. c, (ad ramos dejectos Ulmorum. Oct.)

10. P. granulosa: [scabra] exigua gregaria aurantio-rubra planiuscula, subtus granulosorugosa. Bull. cliamp. t. 438. f. 3. (super stercus vaccinum. Sept. Oct.)

11. P. Patellaria: [Lichen atratus] gregarianigra applanata subcoriacea distincte marginata. Hedwig. t. 22. f, A. in ramis aridis Tiliarum. Sept.)

22. P. radicta: [Sphaerobolus rosaceus] immersa parva stipitata exalbida, margine setacco-radiata. Fl. dan. t,-1016. (ad ligna, ramos, caulesque herbarum aridas. Sept.)

100. Ascoвolus. Dermatothecius. Receptaculum subcupulaeforme, hemisphaericum, carnosum. Thecae manifestae, prominentes, humore sporulisque [octonis plerumque] refertae.

1. A. Jurfuraceus: [Peziza stercoraria] gregarius subconcavus fuscus aut virescens, externe furfuraceus. Bull. chåmp. t. 376. (in pratis, super stercus vaccinum. Oct.)

101. Henotiun. Dermatothecium. Receptaculum capituliforme, convexo-hemisphacricum utring que laeve.

1. H. galeatum: [Acrospermum galeatum] gregarium subtremellosum carueo-fuligineum fuscatum : capitulo subalbicante. Fl. dan. t. 1100. f. 3. (in uliginosis ad ramulos dejectos. Oct.) 
102. Strubum. Dermatothecium. Capitulum stipitatum, subrotundum, subaquosum, dein compactum.

1. S. rigidum: gregarium, stipite rigilo persistente nigro crassiusculo, capitulo subrotundo primum aquoso lacteo, denum griseo compacto deciduo. Pers. in Uster. Annal. II. t. 2. f. 2. (in 'truncis putrescentibus. Mai.)

2. S. vulgare: capitulo sphaerico, stipite cylindrico crassiusculo. Tode fung. I. t. 2. f. 16. (ad caudices semiputridas. Sept. Oct.)

\section{B $\quad$ Y S S I.}

103. Isaria. Subbyssoidea, simplex, ramosa, molliuscula, alba, pulvere farinaceo obtecta.

1. I. truncata: [Ramaria farinosa] ramosissima, ramis truncatis crenulatis. (inter folia decidua, super larvas insectorum, nec non ad truncos caesos et radices. Sept.)

2. I. mucida: [Byssus fruticulosa] cespitosa effusa, ramulis subdepressis furcatis pruinatis mollibus. $F l$. dan, t. 718 . f. 2. (ad ligna putrescen. tia. Jul. Oct.)

104. Bотвутіs. Erecta, fruticulosa, dichotoma. Sporulae in racenum conglomeratae.

1. B. cincrea : congesta late effusa ramosa cine* rea. Disp. fung. t. 3. f. 9. (in Curcubitis pu. trescentibus et ad caules Brassicae oleraceae. Ang. Sept ) 


\section{$-251$}

105. Moxilia. Fila moniliformia seu articulata, stipitata vel effusa.

1. M. glauca: [Mucor glaucus] cespitosa cinereoglauca. $F l$. dan. t. 777 . f. 2. et t. 480 . f. 3. (in fructibus putrescentibus. Omni tempore.)

2. M digitata: [Mucor penicillatus] glauca, stipite simplici digitato. Bull. champ. t. 504. f. 11. (in variis corporibus putrescentibus. Omni tempore.)

5. M. fructigena: cespitulo subrotundo cinereoalbido: filorum articulis ovatis. (in fructibus putridis, praesertim Pyri communis. Omni tempore.)

106. Deмa trum. Fila brevia erecta aut depressa, cespitosa aut fasciculata.

1. D. ciliare: [Hypoxylon ciliare] subsparsum atrum, filis subbulbosis confertis simplicibus longis filiformibus. Bull. champ. t. 46. f. 1. (ad ramos exsiccatos, Aug. Sept.)

2. D. epiphyllum: erectum fasciculatum olivaceum demum pulveraceum filis intertextis. (in foliis deciduis aridis. Sept. Oct.)

3. D. ollare: effusum sericeo-fulvum 'mollissimum. Mich, gen. pl.t. 9o. f. 4. (in ollis vaporariorum totam terrae superficiem incrustans. Aug. Sept.)

4. D violaceum: [Byssus phosphorea] cespitosum violaceo-caesium phosphoreum. (ad.ligna exsiccata putrescentia. Jul. Aug.)

5. D. virescens: cespitosum laxum subfarinaceum, primo virens, dein sordıde olivaceun 
opacum. (ad ligna et ramos exsiccatos, in unbrosis sylvaticis. Mai.)

6. D. salicinum: epiphyllum effusum rubiginosum tenue. (in foliis Salicis capreae. Jul. Aug.) 107. Enrneum. Fila rigida, grumosa, in cespitulum foliis adpressum conglomerata.

1. E. acerinum: [Mucor forrugineus] deprossum latiusoulum rufo-fuscum. Bull. champ. t. 514. f. 12. (ad folia Acerum dejecta. Sept.)

2. E. betulinum: depressum effusum, primo sulphureo-purpureum, dein rufo-ifuscum. (ad folia Betulac albae. Sept. Oct.)

3. E. tiliaceum: gregarium pulvinatum albidopallidum. (in foliis Tiliarum. Aug. Sept)

4. E. populinum: cupulare immersum subgrumo: sum spadiceum. (in foliis Populorum. Sept. Oct.)

5. E. alneum: pulvinatum grumosum fulvo-ferrugineum. (ad folia Alni glutinosae. Aug. Sept.)

108. Racodium. Filamenta densissime intertexta pannum referentia.

1. R. rupestre: [Byssus antiquitatis.] compactum nigrum erectiusculum subranosum. Dillen. musc. $t$, 1. fo 18. (in muris et saxis arenariis. Omni tempore.)

2. R. cellare: [Byssus mollissima] ]ate expansum mollissimum nigrum simplex. Mich. gen. t. 39 . f. 9 (in cellis vivariis, ad dolia. Omni tempore.) 


\section{- 253}

109. Hinaxtia. Filamenta villosa ramoso-fibrosa.

1. H. thermitrum: [domestica] maxima subviolaceo-fuscescens mollis, in membranam cohaerens. (in domibus ligneis uvidis, praesertim in balneis publicis nostris. Omni tempore.)

8. H. candida: [Byssus candida] tenera candida : apice subplumoso dilatato. Dillen. musc. t. 1. f. 15. (intra folia decidua putrescentia. Aug. Oct.)

110. Rumzomorpis. Filamenta ramosa repentia solida, medulla villosa farcta.

1. R. subcorticalis: [Clavaria phosphorea] compressa ramosa fusco-nigricans. $F$. dan.t. $7 \mathbf{1}$. (ad truncos exsiccatos inter corticem et lignum. Sept. Oct.)

2. R. setiformis: [Lichen setosus] filamentis capillaribus atris subramosis. Rebent. t. 3. f. 12. (in foliis acerosis dejectis, Sept.) 


\section{N D E X.}

Abies.

Absinthium.

A.

Acanthium

Acer

campestre.

laciniatum.

platanoides.

tataricum.

ícetosa.

Acetosella.

Achillea.

Millefolium.

Ptarmica.

Aconitum.

Lycoctonum.

septentrionale.

Acorus.

Calamus.

172 cichoriarum.

344 confortum.

1.42

69

cornutum.

223

$22+$

$6 g$ ficariae.

224

69 fuscum.

69) geranii.

225

69

65

66.81 .

grossulariae.

224

223

225

225

$15 \mathrm{r}$

punctatum.

ranunculi.

224

151

I5I

rhamni.

rubellum.

rumicis.

223

225

94

61

tragopogi.

tussilaginis.

Aegopodium.

224

56

61

Acrospermum galeatum, 249

Actaea.

91

spicata.

Acynos.

vulgaris.

Podagraria.

56

Aethusa.

Cynapium.

54

54

$9^{2}$

Agaricus.

235

240

259

I05

Adoxa.

Moschatellina.

Aecidi um.

anemones.

androsaceus.

campestris.

Cantharellus.

241

candicinus.

235

cinnamomeus. $\quad 236$

225

coccineus.

23 ?

224

comatus.

237

berberidis.

224

bifrons.

Coprirus.

237

224

Cortinaria.

236

cancellatum.

cruceus.

236

canciscum.

cuspidatus. 
deliciosus.

disseminatus.

domesticus.

ephemerus.

fastibilis.

ferrugineus.

fimetarius.

floccosus.

gilvus.

gracilis.

Gymnopus.

hirsutus.

hortensis.

hypnorum.

imperialis.

infundibuliformis.

lactifluus.

lateritius.

Lepiota.

lignorum.

miniatus.

mollis.

mutabilis.

Mycena.

ochroleucus.

Omphalia.

perforans.

piperatus.

Pleuropus.

plicatus.

plumbeus.

Pratella.

pratensis.

quercinus,

rosaceus.

ruber.

rufus.
239 Russula. 240

$23 \mathrm{~S}$ sepiarius. $24 \mathrm{I}$

238 squarrosus. 235

239 vaccinus. 236

236 violaceus. 236

238 vitellinus. 238

237 volvaceus. 235

235 vulgaris. 237

240 Agrimonia. 85

23.9 Eupatoria. 85

239 Agrostemma. 8 .

241 alba, 81

237 Githagu, 8 I

237 Agrostis. 14

255 alba. 15

240 arundinacen. 24

259 caniua. 25

256 compresea. $\times 5$

235 gigantea. 15

258 lispida. 15

236 Spica renti. 14

2 40 tenells. 14

235 vulgaris. $\quad 14$

237 Aira. 15

240 aquatica. 16

240 caespitosa. 15

240 canescens. 16

259 cristata. $\times 5$

240 flexuosa. $\mathbf{5}$

258 praccox. 16

235 Ajuga. 99

239 alba. 99

236 carnea. 99

27 I genevensis. $\quad 99$

2 qo lanata. 99

239 pyramidalis. 99

236 reptans. 99 
Alchemilla. liybrida. pubescens. vulgaris. Alectorolophus. Algae. Alisma.

angustifolium。 lanceolatum. Plantago. Alliaria. Allium. carinatum. oleraceum. sotundun. Schoenoprasurn. rincale.

Aluuś. glutinosas Aloides. Alopecurus. agrestis. bulbosus. Reniculatus. myosuruides. pratensis.

Alsine. niedia.

Alyssum. calycinum. incauun. sativum.

Amanita.

livida. muscaria. virgata. Amaranilus,
31 Blitum。

31 Amarella.

51 Anagallis

5. Andrameda.

Iu6 calyculata.

205 polifolia.

66 Androsace.

67 septentriomalis,

67 Anemone.

66 nemorosa.

116 Pulsatilla.

59

60

49

168 168 778

13

13

I1

13

13

15

$5 ?$

57

113.

I 13 113

113

235

25i

235

235 169 ranunculoides. sylvestris. violacea.

Anethum. graveolens. Angelica. Archangelica. sylvestris.

Anserina. cana. sericea.

Anthennis. arvensis. Cotula. tinctoria.

Anthoxanthum.

$$
\text { odoratum. }
$$

Anthriscus.

Antluyllis.

Vulneraria. minus.

Peloria.

Apargia. lirta. $16 g$

Antirrlinum Linaria. 109

109

309

135

136 
lispida. incana. Aparine, Apium. dulce. graveolens. Aquilegia. vulgaris. Arabis. thaliana. Arbutus.

Uva ursi. Archangelica. Arctium.

Bardana.

Lappa.

majus.

minus.

Arcyria.

punicea. Arenaria.

campestris. rubra, serpyllifolia. trinervia urbana. Aristolochia. Clematitis. Artemisia.

Absinthiun . campestris. rubra. vulgaris. Arundo.

Epigejos. Phragmites. syiralica.

\begin{tabular}{|c|c|c|}
\hline 136 & Asarum. & 83 \\
\hline 355 & europaeum. & 83 \\
\hline 27.29 & Ascobolus. & 849 \\
\hline 56 & furfuraceus. & 249 \\
\hline 56 & Asparagus. & 61. \\
\hline $56 i$ & ofícinalis. & $6 t$ \\
\hline 94 & Asperugo. & 35 \\
\hline 94 & procumbens. & 35 \\
\hline 116 & Asperula. & 27 \\
\hline 216 & Aparine. & 127 \\
\hline $75 i$ & odorata. & 27 \\
\hline 75 & Aspidium. & 184 \\
\hline 53 & aculeatum. & 185 \\
\hline 139 & cristatum. & 185 \\
\hline 140 & Filix mas. & 185 \\
\hline 139 & Oreopteris. & 184 \\
\hline 139 & spinulosum. & 183 \\
\hline 139 & Asplenium. & 386 \\
\hline 221 & Ruta muraria. & 186 \\
\hline 221 & Astragalus. & $\mathbf{2} 28$ \\
\hline 79 & glycyphyllos. & 128 \\
\hline 80 & Athamanta. & 51 \\
\hline 80 & Libanotis. & 51 \\
\hline 29 & Oreoselinum. & 52 \\
\hline 79 & sibirica. & 52 \\
\hline 80 & Athyriam. & 185 \\
\hline 258 & Filix femina. & 185 \\
\hline 158 & fragile. & 185 \\
\hline 144 & molle. & 186 \\
\hline $2 \div 4$ & Atriplex. & 46 \\
\hline $2+1$ & hastata. & tix \\
\hline 345 & hortensis. & 46 \\
\hline 144 & patula. & 46 \\
\hline 23 & Auricula. & 247 \\
\hline 23 & Auricularia reflexa & 245 \\
\hline 23 & tabacins. & 244 \\
\hline & & 172 \\
\hline
\end{tabular}


Avena.

elatior.

fatua.

pratensis.

sativa.

strigosa.

B.

Barbarea.

Barbula.

muralis.

ruralis.

subulata.

unguiculata.

Bardana.

Bartramia.

foutane.

pomiformis.

Beccabunga.

Beckmannia.

erucaeformis:

Behen.

Berberis.

asperma.

vulgaris.

Betonica.

alba.

officinalis.

Betula.

alba.

Alnus.

nana.

pendula.

Biden.

cernua.

minima.

punila:

23 radiata.

17

23 Bistorta.

23 Bistortae.

23 Blitum.

23 virgatum.

Boletus.

badius.

betulinus.

bulbosus.

$19^{2}$ bulbosus.

192

192

192

192

340

194

194

194

5

14

14 suaveolens.

77 suberosus.

63 subtomentosus.

64 unicolor.

64 versicolor.

103 Bonus Henricus.

103 Borage.

105 alba.

17. officinalis.

171 Botrychium.

168 Lunaria.

171

171

143

143

143

143

$$
\text { rutaceum, }
$$

Botrytis.

cinerea.

Bovista.

plumbea.

Brassica.
$2+5$

143

71

71

4. 169

4

242

242

243

242

242

242

$2+2$

242

242

243

243

242

242

243

242

243

$2+2$

273

$2+3$

47

34

34

34

183

183

183

250

250

218. 219

218

ii? 
campestris

Napus.

Rapa.

Briza.

melia.

Bromus.

arvensis.

giganteus.

inermis.

mollis.

multiflorus.

secalinus.

sterilis.

strigosus.

tectorum.

Bryum.

annotinum.

a pocarpum.

argenteum.

caespititium.

canescens.

capillare.

cuspidatum.

Dicksonii.

exstinctorium.

fastigiatum.

glaucum.

heteromallum.

lanceolatum.

ligulatum.

purpureum.

roseum.

rurale.

scoparium.

striatum.

truncatum.

undulatum.
I7 unguiculatum.

117 Bunias.

102

117 orientalis.

II

20 Buphelalmum salicinum. 20

21 Bursa pastoris.

22 Butomus.

22 umbellatus.

22 Buxbaumia.

22 apliylla.

21 Byssi.

21 Byssus antiquitatis.

22 candelaris.

22 candida.

22

195

195

189

195

195

19 ?

I 95

Ig6

189

188

190

190

tgo

189

I 96

190

196

192

190

192

187

fruticulosa.

mollissima.

phosphorea.

velutina.

148

112

73

$7+$

200

200

250

252

209

253

250

252

251

204

Calamus.

Calicium.

claviculare.

salicinum.

Calla.

palustris.

Callitriche. autumnalis.

cespitosa.

intermedia.

minima.

verna.

Calluna.

hirsuta.

vulgaris.

Caltha.

palustris.
62

206

206

206

67

67

5

3

3

3

5

3

20

70

70

98

98 
Calyptratae.

Campanula.

bononiensis.

Cervicaria.

diffusa.

glomerata.

hirsuta.

latifolia.

patula.

persicifolia.

rapunculoides:

Rapunculus.

retundifolia.

salviaefolia.

tenuifolia.

Trachelium.

urticaefolia.

Cannabis.

sativa.

Cantharollus.

Caragana.

Cardamine.

$$
\begin{aligned}
& \text { amara. } \\
& \text { hirsuta. } \\
& \text { impatiens. } \\
& \text { parviflora. } \\
& \text { pratensis, } \\
& \text { sylvatica. }
\end{aligned}
$$

Cardiaca.

Carduus.

acanthoides.

crispus.

criophorus.

helenioides.

heterophyllus.

lanceolatus.

rwarianus. \begin{tabular}{r|l}
182 & nutans. \\
38 & oleraceus. \\
39 & palustris. \\
40 & serratuloides. \\
40 & Carex.
\end{tabular}

39 acuta. I67

40 ampullecen.

39 androgyna.

38

39

39

39

38

40

38

39

39

176

276

$24 \mathrm{I}$

227

214

II 5

114

II 4

II 4

114

114

203

140

140

140

141

142

141

141

141 arenaria.

bifurca.

brizoides.

caespitosa.

canescens.

Chordorlizad.

ciliata.

collina

digitata.

dioica.

disticha.

Drymeja.

echinata.

elegans.

elongata.

ericetorum.

filiformis.

flava.

gracilis.

hirta.

inflata:

intermedia.

Lachenalii.

leporina.

limosa.

Linnaei.

montana.

multiformis.

muricata. $140^{\circ}$

142

$34 \mathrm{I}$

142

160

$16 \%$

166

161

167

x 62

166

162

I6.

I64

164

r 64

i6x

161

165

163

I 66

163

164

166

164

167

168

$\mathbf{x} 67$

162

162

162

166

I6 $\mathrm{x}$

164

163

162 
nigra.

oralis.

pallescens.

paludosa.

panicea.

paniculata.

pilosa.

pilulifera.

jraecox.

Isoudo-Cyperus.

yulicaris.

rernota.

rufa,

Schreberi.

stellulata.

sylvatica.

uliginosa.

vesicaria.

vulpina.

Carlina. vulgaris.

Carota.

Carpobolus,

Car um.

\section{Carvi.}

Carvi.

Carvifolia.

Castalia speciosa.

Cataria.

$$
\text { suaveolens. }
$$

Caucalis.

Anthriscus.

Centaurea.

Cyanus.

Jacea.

panieulata.

plirygia.

Scabiosa.
167 Centaurium.

162 Centunculus.

42

166 minimus.

30

30

167 Ceramium caespitosum. 204

165 Cerastium.

163 aquaticum.

165

164

162

165

161

I63

167

162

163

165

10

167

162

142

143

50

217

55

55

55

51

arvense.

semidecandrum.

vulgatum.

Ceratophyllum.

demersum.

Cerefolium.

Cervicaria.

Cetraria.

juniperina.

Chaerophyllum.

aromaticum.

bulbosum.

82

82

183

82

82

1169

170

54

40

$2 \times 2$

212

54

55

54

54

54

$5 \div$

6

Chamaedrys,

Chamomilla.

Chara.

150

158

204

159

92

92 lanceolatum.

99 quercifolium. 92

50 Chenopodium. 47

50 album. 47

I52 Bonus Henricus. 47

I52 glaucum. 48

I52 lybridum. 48

152 murale.' 47

152 olidum, 43

152 polyspermum. 48 
rubrum.

urbicum.

viride.

Vulvaria.

Chironia.

Centaurium.

Chordorhiza.

Chrysanthemum,

corymbosum.

inoderum.

Leucantiemum.

montauum

sylvesire.

Chrysosplenium. alternifolium.

Cicer.

Lens.

macrospermum.

Cichorium.

Intybus.

sativum.

variegatum.

Cicula.

virosa.

Circaea.

alpina.

lutetiana.

pubescens.

Cladonia.

coccifera.

coccinea.

gracilis.

paschalis.

rangiferina. uncialis.

Clathrus turbinatus. Clavaria.
47 corniculata.

47

47

48

42

42 militaris.

6. ophioglossoides.

149 phosphorea.

I9 pistillaris.

150 viscosa.

149 Clematitis.

1 เ Clisnacium.

$1+9$ dendrcides.

70 Clinopodium.

76 variegalum.

127 vulgare.

127 Cnicus.

127 eriophorus.

139 helenioides.

I39 heterophyllus.

139 lanceolatus.

139 oleracous.

53 palustris.

53 serratuloides.

4 Comarum.

4 palustre.

4 Conferra.

4

207

207

207

207

207

208

207

221

245
245

212

245

245

212

212

$2+6$

253

246

$2+5$

158

193

193

104

104

104

141

141

142

141

142

172

$14 x$

142

91

9I

203

203

204

204

203

204

204

204

203

204

203 


\section{N D EX}

relutina.

Conimu.

maculatum.

Consolida.

Convallaria.

bifolia.

majalis.

multiflora.

Polygonatum.

Convolvulus.

arvensis.

carneus.

sepium.

Conyza. squarrosa.

Coprinu8.

Corallorhiza,

Coreopsis Bideno.

Coriandrum.

sativum.

Cornicularia.

islandica.

spadicea.

tenuis.

Coronilla.

varia.

Cortinaria.

Corydalio.
alba.
bulbosa.
IIalleri.

Corylus.

Avellana.

maxima.

Cotula.

Cracca.

Crataegus Oxyacantha.
204 | Crepis.

50 biennis.

50 sibirica.

93 tectorum.

61 Cribraria.

30 vulgaris.

61 Crista castrensis.

61 Crista galli.

61 Crus galli.

37.73 Cucubalus.

37 bacciferus.

37 Behen.

37

146

146

237

157

143

54 Cyanus.

54 Cyatlius.

208 lentiferus.

208 striatus.

208 Cymbidium.

208 Corallorhiza.

227 Cynapium.

227 Cynoglossum.

236 officinale.

122 Cynosurus.

222

122

122

77

172

172

1172

150

125 cristatus.

Cypripedium. guttatum.

Cytisus.

supinus.

$1 \div 8$

138

137

138

221

223

199

206

12

27

78

77

78

78

78

32

32

' 32

152

25 !

231

231

157

157

54

33

33

so

20

158

158

127

127

20

20

241 
quercina.

suaveolens.

Daphne.

Mezereum.

Datura.

Stramonium.

Daucus.

Carota,

sativus.

Delphinium.

Consolida. olatum.

Domatium.

ciliare.

epiphyllum.

Erysiphe.

ollare.

salicinum.

violaceum.

virescens.

jiantlius.

arenarius.

collinus.

deltoides.

reptans.

ruthenus.

Dicksonii bryum.

Dicranum.

fasigiatum.

glaucum.

heteromallum.

pulvinatum.

purpureum.

scoparium.

Diderma.

vernicosum.

Draba.
2.4 Intermedia.

242

70

70

42 Dracocephalum.

41 hyssopifolium.

50 nutans.

50 Ruyschiana.

5n thymiflorum.

93 Drosera.

93 longifolia.

93 rotundifolia.

251 Drymeja.

25I Jryopteris.

251 Dulcamara.

217

251

252 Ebulus.

251 Echium.

251 vulgare.

77 Elymus.

77 caninus.

77 Embolus pertusus.

77

$x 90$

$x$ go

190

190

190

190

190

220

220

III
I)

112

II 12

111

105

105

205

105

105

58

58

58

165

IS4

42

E.

57

35

35

24

24

221

I 88

188

219

23

68

68

68

68

68

69

68

68

68

68 
tetragonum.

Epipactis.

cordata.

grandiflora,

latifolia.

Nidus aris.

ovata.

palustris.

rubra.

Equisetum.

arvense.

capillare.

fluviatile.

hyemale.

limosum.

palustre.

sylvaticum.

Erica vulgaris.

Erigeron.

aere.

canadense.

Erineum.

acerinum.

alneum.

betulinum.

populinum.

tiliaceum.

Eriophorum.

angustifolium.

latifolium.

polystachion.

vaginatum.

Erodium. cicutarium.

Ervum.

hirsutum.

Lens.
68 retraspermum.

156 Eryngium.

157 campestre.

556 planum.

156 Erysimum.

157 Alliaria.

157 Barbarea.

356 cheiranthoides.

156 officinale.

181 Erysiphe.

$1 S_{1}$ Esula.

181 Eupatoria.

181 Eupatorium.

182

181

182

I 81

70

146

146

176

252

252

252

252

252

252

11

iI

II

11

II

I18 Fagopyrum.

118 Farfara.

I 26 Festuca.

126 decumbens.

127 duriuscula.
126

49

49

50

$3 \times 6$

216

11. 6

116

116

217

84

85

143

I 43

83

84

84

84

84

83

107

108

107

108

107

107

43

43

43

43

F.

72

346

20

21

.20 
elatior.

fluitans.

ovina.

pratensis.

rubra.

Ficaria.

verna.

Filago.

arvensis.

Filices.

Filipendula.

Filix femina.

Filix mas.

Fissidens.

brycides.

osmundioides.

pulvinatus.

taxifolius.

Flaminula.

Flos cuculi.

Fontinalis.

antipyretica.

Fragaria.

alba.

collina.

elatior.

semperflorens.

sylvestris.

vesca.

Frangula.

Fraxinus.

excelsior.

pendula.

simplicifolia.

Finligo.

flava.

rufa.
21 vapnraria.

18 Fumaria.

20 bulbosa.

2 officinalis.

21 Funaria.

96 hygrometrioa.

96 Fungi.

153

153

38

86 Galeopsis.

185 angustifolia.

185 cannabina.

189

189

189

190

189

96

81

200

200

83

88

88

88

88

88

88

43

$\times 75$

176

176

176

220

220

220

Galeobdolon.

Ladanum-

latifolia.

Tetralit.

versicolor.

G.

palustre.

nubescens.

rubioides.

scabrum.

trifidum.

verum.

Geastrum.
223

122

122

122

200

201

234

102

102

$10 \mathrm{r}$

to 2

102

102

102

102

102

102

27

29

29

29

28

27

28

28

28

montanum. 28

sylvaticum. $\quad 28$

28

uliginosum. 28

28

Gasteromyci. 218 
hygrometricum

Genista.

tincroria.

Gentiana.

Anarella.

campestris.

Ceniaurium.

cruciata.

Pneumonanthe.

Geoglossum.

hirsutum.

Geranium.

cicutariumn.

molle.

palustre.

pratense.

pusillum.

robertianum.

rotund ifolium.

sanguineum.

sibiricum.

sylvaticum.

Goum.

intermedium.

rivale.

urbanum.

Githago.

Gladiolus. communis.

Glechoma. grandiflora. hederacea.

Gnaphalium. arvense.

dioicum.

femineum.

masculum.

nudum.
$218 \mid$ rectum.

123 sylvatioum.

123 uliginosum.

49 Gnomon.

49 Gonopterides.

49 Gratiola.

42 officinalis.

49 Grimmia.

49 apocarpa.

276 crispa.

246 Grossularia.

39 Gymnopus.

118 Gymnostomum,

120

119

129

220

120

120

II 9

119

119

90

90

91

90

81

9

9

100

101

101

145

153

145

145

$\times 45$

$\checkmark 46$

ovatum.

truncatum.

Gypsophila. muralis.

\section{H.}

Helenium.

Helianthus.

Helix.

Helotium.

Hepaticae.

Heracleum.
Halleri corydalis.

145

145

145

214

18.

7

7

189

189

189

43

236

187

188

187

76

76

Hedypnois autumnalis. 136

148

151

151

174

249

249

246

246

246

246

246

72

20 I

52

52

52

52

52 
sibiricum.

Sphondylium.

Herniaria.

glabra.

IIieracium.

cymosum.

dubium.

incanum.

lineare.

murorum.

nemorosum.

paludosum.

Pilosella.

praemorsum.

sabandum.

sibiricum.

sylraticurn.

umbellatum.

Himantia.

candida.

domestica.

thermarum.

Hippuris.

minor.

vulgaris.

Holcus.

avenaceus.

mollis.

odoratus,

Holostea.

IIomallophyllae.

Hordeum.

hexastichon.

murinum.

vulgare.

Hottonia.

palustris.
$52 \mid$ Hunulus.

52 Lupulus.

46 Hydnum.

46 auriscalpum.

I36 candidum.

I37 ferrugineum.

137 imbricatum.

155 repand um.

238 tomentosum.

157 Hydrocharis.

137 Morsus ranae.

15 ? Hydrola pathum.

136 Hydrophora stercorea. 222

137 Hydropiper. $\quad$ I

138 Hyoscyarnus. - 41

237 niger. 4 I

137 Hy pericum, $\quad \mathbf{3 2}$

138

253

253

253

253

3

3

3

17

$\mathbf{1} 7$

17

17

79

203

24

25

25

25

36

36 dubium.

hirsutum.

moutanum.

perforatum.

quadrangulare.

Hy pnum.

abictinum.

commutatum.

complanatum.

compressum.

crispum.

Crista castrensis.

132

153

33

133

132

197

397

299

19) 4

199

193

199

200

199

197

193

dendroides.

198

denticulatum.

198

elegans.

extelluatum.

molluscum.
200

199 
myosuroides. parietinuma. plumosum. praclongum. proliferum. purum. rutabnlum. Schreberi, serioeum. serpens. splendens. squarrosum. taxifolium. tricliomanoides. triquetrum. velutinum. viticulnsum. Hypochaeris. hirsuta. maculata. Hypopithys, Hypoxylon. ciliare, operculatum, Hysterium. conigenum. nigrum, pulicare. quercinum.

\section{I.}

Jacea.

Jacobaea.

Jasione.

montana.

Iberis, nudicaulis. rdáeus.
197 albus. 87

199 Inpatiens. 45

198 Noli tangere. 45

197 Inperatoria. 55

I97 sylvestris. 55

398 Intybus.

98 Inula, 248

199 dysenterica. 148

194 Helenium. 178

197 hirta. 148

190 salicina. $\quad 348$

199 Iris. 9

189 paludosa. 9

194 pratensis. 9

198 Pseudacorus. 9

I98 sibirica. 9

193 Isaria. 250

138 mucida. 250

339 truncata. 250

239 Juncus. 61

24 acutiflorus. 62

212 adscendeus. 62

251 bufonius. 63

213 bulbosus. 63

215 campestris. 63

215 conglomeratus. 62

215 effusus. 62

215 filiformis. 62

215 obtusiflcrus. 62 pilosus. $\quad 63$

152 squarrosus. $\quad 62$

147 sylvaticus. 62

38 Jungermannia. 201

38 asplenioides. 20i

113 bicuspidata.. 201

113 bidentata. 201

87 cilinris. 20I 
complanata.

dilatata.

epiphylla.

pinguis.

platyphylla.

pusilla.

veticulosa.

'Juniperus.

communis.

K.

Koelreutera hygrometrica.

201

L.

Lachenalii carex.

Lactarius lateritius.

Lactifluus,

Lactuca.

sanguinea.

Scariola.

Ladanuin.

Lagopoda.

Lamium.

album.

amplexicaule.

carneum.

maculatum.

purpureum.

Lappa.

Lappula.

Lapsana.

communis.

Lathraea.

Squamaria.

Lathyrus.

latifolius.
202 palustris. $12 j$

202 pratensis. 142

202 sylvestris. 124

202 tuberosus. 124

202 Lavatera. $12 \mathrm{I}$

20 I thuringiaca. 121

20r vulgaris. 121

178 Lecidea. 206

178 aurantiaca. 206

206

$2 c 6$

lapicida.

Ledum.

palustre.

Leersia.

cirrhata.

74

74

185

183

189

159

153

159

159

159

127

$13 i$

136

135

135

103

IC3

112

112

112

235

\begin{tabular}{l|ll}
139 & Leskea. & 194 \\
110 & complanata. & t9f
\end{tabular}

110

124

124 serices. 
Leucanthemum.

Levisticum.

Libanotis.

Lichen aphthosus. atratus.

aurantiacus.

candelaris.

caninus.

caperatus.

centrifugus.

ciliaris.

clavicularis.

cocciferus.

coccineus.

oorniculatus.

farinaceus.

floridus.

fraxineus.

furfuraceus,

geograplicus.

gracilis.

lirtus.

hispidus.

islandicus.

jubatus.

juniperinus.

lapicidus.

murorum.

niger.

nitidus.

olivaceus.

parielinus.

pasclialis.

pertusus.

pliysodes.

prunastri.

pulicaris.

\begin{tabular}{r|l}
149 & pulmonarius. \\
53 & pulverulentus, \\
51 & pyxidatus. \\
212 & rangiferinus. \\
249 & rosaceus. \\
206 & salicinus. \\
209 & saxatilis. \\
211 & scriptus. \\
210 & setosus. \\
209 & spadiceus. \\
211 & stellaris. \\
206 & tenellus. \\
207 & uncialis. \\
207 & vulgatus. \\
211 & Liguscicum.
\end{tabular}

210

206

207

208

214

206

209

206

253

208

209

210

208

207

53

55

110

110

110

110

110

109

109

$1 \mathrm{Cg}$

g6

205

205

109

IIO

161

58

53

58

58

58

33

33 
Iobelii melica.

16 corniferum.

Loeselii sisymbrium, 116 Epidendron.

Lolium.

latum.

perenne.

temulentum,

Lonicera.

tatarica.

Xylosteum.

Lotoidea.

Lotus.

corniculatus.

sylvaticus.

nliginosus.

Lunaria.

rediviva.

i.upulina.

Lupulus.

Luzula.

campestris.

pilosa.

vernalis.

Lychnis.

dioica.

Flos cuculi.

pratensis.

sylvestris,

Viscaria.

Lycoctonum.

Lycogala.

miniata.

Lycoperdon.

ardesiacum.

Bovista.

cancellatum.

Carpobolus.

cervinum.

114. 183

\section{4}

130

177

63

63

63

63

$8 \mathbf{x}$

81

81

81

81

81

95

219

219

218

218

219

223

217

219 epiphyllum.

equinum.

fragile.

gemmatum.

giganteum.

maximum.

ovoideum.

papillatum.

poculiforme.

pratense.

pyriforme.

stellatum.

tritici.

Tuber.

vesparium.

Lycopodium.

annotinum.

clavatum.

complanatum.

Selago.

Lycopsis.

arvensis.

Lycopus.

europaeus. .

vulgaris.

Lysimachia.

Nummularia.

thyrsiflora.

vilgaris.

Lythrum.

quadrifolium.

Salicaria,

224

223

220

219

219

219

219

219

224

219

219

218

233

218

221

182

$182^{\prime}$

182

182

183

35

35

7

7

7

37

37

37

37

83

83

83

M.

Majanthenum. 
bifolium.

Malaxis.

bif lia.

monophylla.

Malva.

crispa.

mauritiana.

pusilla.

rogundifolia.

splvestris.

Marchantia.

polymerpha.

Matricaria.

Cliamomilla.

Parthenium.

suaveolens.

Medicago.

falcata.

lupulina.

Medulla panis.

Melampyrum.

arvense.

cristatum.

nemorosum.

pratense.

sylvaticum.

Melica.

caerulea.

Lobelii.

nutans.

uniflora.

Melilothus.

alba.

caerulea.

lutea.

officinalis.

vulgaris.

Mentha.
3.) aquatica.

157 arvensis.

157 anstriaca.

157

120

ז21

181

12 I

122

121

$2 \cap 2$

202

$15^{\circ}$

150

I. 99

150

I3.

132

152

2.43

106

107

107

107

1017

I 7

16

$x 6$

16

26

16

128

128

128

128

128

228

$\infty$

sylrestris.

viridis.

trifoliata.

Mercurialis.

perennis.

Merulius.

Vastator.

Mespilus.

vilium.

effusum.

Mitra.

Mnium.

capillare.

fontanum.

hornum.

palustre.

roseum.
Menvantlies.

Cautharellus,

cornuenpudioides.

monogyna.

Oxyacantha.

Mezereum.

Millefolium.

purpureum.

argenteum.

caespiticium.

cirrhatum.

cuspidatum.

pellucidum:

punctatum.

pyriforme.

serpyllifolium.

undulatum.

Mollugo.
100

100

100

100

100

36

36

177

177

241

241

241

$24 \mathrm{r}$

86

86

86

70

14

14

$15 \mathrm{x}$

351

246

195

195

195

195

188

xij 6

194

196

196

188

196

200

I96

196

$\begin{array}{r}96 \\ \hline\end{array}$

28 
Monilia. digitata. fructigena. glauca. "

Monorchis. Monotropa. IIypopitleys. Morchella. esculenta.

Mnrio.

Morsus ranae. Moschatellina. Mucedo, grisea. Mucilago. Mucor.

caninus.

ferrugineus. glaucus.

herbariorum. Mucedo. penicillatus.

- septicus. urceolatus.

Myagrum.

paniculatum.

sativum.

Mycena.

Myosotis.

arvensis,

collina.

Irapula. palustris.

scabra.

scorpioides. sparsiflorares:

y lvatica.
$251 \mid$ Myosurus.

251 minimus.

25r Myriophyllum.

59

251 spicatum.

170

$\$ 56$ verticillatum.

170

74

Myrotlecium hispidum.243

74 Myrtillus.

70

246

246

154

178

73

222

222

220

222

229. Nasturtium.

N.

Naemaspora.

216

2,6

216

117

Napus.

Nardus.

II

31

115

252 Naumburgia guttata. 57

25, Neckera. 193

222 crispa. 193

222 viticulosa. $\mathbf{1 9 3}$

251 Nemolapathum. 64

220 Neottia. $\quad \mathbf{1 5 5}$

217 repens. 155

11 8piralis. $\mathbf{3 5}$

11 Nepeta. 99

313 Cataria. 99

237 Nidularia hirsuta. 234

32 rernicosa. 234

53 Nidus avis. 157

33 Nigredo. $\quad 232$

33 Noli tangere. . 45

32 Nostoc. 205

32 Nummularia. 37

32 Nympliaea. $\quad 9^{2}$

33 alba. 92

32 lutea. $\quad 9^{2}$ 
o.

Octnspora albidula, carnea. elastica. scutellata.

Odontites. rubra.

Oencthera. biennis.

Omplalia.

Onopordon. Acanthium.

Onygena. equina.

Opegrapha. pulverulenta. scripta. vulgata.

Ophrys Corallorhiza. cordata. monophylla. Monorchis. Nidus avis. orata. spiralis.

Opulus. Orchis. alba. angustifolia. bifolia. conopsea. coriopliora. cucullata. latifolia. maculata. mascula. militaris.

\begin{tabular}{|c|c|c|}
\hline & Morio. & 154 \\
\hline 248 & Oreopteris. & 184 \\
\hline 2.48 & Oreoselinum. & $5^{2}$ \\
\hline 247 & Origanum. & 304 \\
\hline 248 & album. & 204 \\
\hline 108 & humile. & 104 \\
\hline 108 & rulgare. & 104 \\
\hline 67 & Ornithogalum. & 60 \\
\hline 67 & luteum. & 60 \\
\hline 240 & minimum. & 60 \\
\hline 142 & pratense. & 60 \\
\hline 142 & spathaceum. & 60 \\
\hline 222 & sylvaticum. & 60. \\
\hline 225 & umbellatum. & 60 \\
\hline 205 & villosum. & 60 \\
\hline 206 & Orobanche. & 110 \\
\hline 206 & caryophy!!scea. & 110 \\
\hline 205 & Orobus. & 124 \\
\hline 257 & tuberosus. & 124 \\
\hline 157 & vernus. & 124 \\
\hline 157 & Orthotrichum. & 192 \\
\hline 150 & anomalum. & 293 \\
\hline 157 & striatum. & 192 \\
\hline 257 & Oscillatoria parietina. & 203 \\
\hline 155 & Osmunda. & 183 \\
\hline $5^{6}$ & Lunaria. & 183 \\
\hline$x_{53}$ & regalis. & 283 \\
\hline 155 & Struthiopterig. & 186 \\
\hline 254 & Oxalis. & 80 \\
\hline$x_{53}$ & Acetosella. & $8 \mathrm{r}$ \\
\hline 155 & purpurascens. & 82 \\
\hline 153 & Oxyacantha. & 86 \\
\hline 153 & Oxycoccos. & 69 \\
\hline 154 & Oxycoccus. & 69 \\
\hline 155 & palustris. & 69 \\
\hline $\begin{array}{l}154 \\
154\end{array}$ & Padus. & 85 \\
\hline
\end{tabular}


Panaces.

Panicum.

aristaturn.

Crus galli. flavescens. glancum. miliresum. murieum. viride.

Paparer. plersum. Rhıeas. somniferunt.

Pariessria. officinalis.

Paris.

pentaphylls. quadrifolia. quinģuefolia. parmelia. candelaris. caperata. centrifuga. ciliaris. farinacea. fraxinea. furfuracea. jubata. murorum. nigra. olivacea. parietina. physodes. prunastri. pulmonaria. pulverulenta. saxatilis.
52 stellaris. 209

11 tenella. 2 Io

I2 Parnassia. 57

12 palustris. 57

12 Parthenium. $\quad 149$

12 Pastinaca. 55

12 pratensis. 55

12 sativa. 55

12 Patellaria. 249

$19^{2}$ Pedicularis. $\quad 108$

92 cimosa. , 108

$9^{2}$ palustris. 108

$\mathrm{g}^{2}$ Sceptrum. 108

30 Peloria. Iog

30 Peltigera. 211

73 aplitiosa. 212

73 canina. 211

73 Peplis. 64

75 Portula. 64

209 Peplus. 83

209 Persicaria. 72

210 Persicariae. 71

209 Petasites. $\quad \mathbf{1 4 7}$

211 Peucedanum. 52

211 Silaus. 52

211 Peziza. 247

2II aurea. 248

211 Auricula. 247

209 citrina. 248

210 cornucopodioides, 24 I

210 cyathoides. 248

210 flava. 249

210 granulosa. $\quad 249$

211 inquinans. 247

210 lenticularis. 249

209 papillata. 248

209 Patellaria. 249 
radiata.

rosac.

sarcoides.

scabra.

stercoraria.

stercurea.

Phalaris.

arundinacea.

canariensis.

erucaeformis.

picta.

Phallus.

esculentus.

impudicus.

Phascum.

cuspidatum.

muticum.

subulatum.

Phegopteris.

Phellandrium.

aquaticum.

Philonotis.

Plileum.

bulbosinm.

nodosum.

pratense.

Phlomis.

tuberosa.

Phragmites.

Physcia physodes.

Picris.

hieracioides.

Pilobolus.

crystallinus.

Pilosella.

Pimpinella.

nigra.
249 Saxifraga

243 Pins.

245

249

249

248

22

15

12

14

13

254

2,6

235

187

187

187

187

184

53

53

97

13

I3

13

13

104

101

23

210

156

$13^{6}$

217

217

136 6

55

36

Plantago.

altissima.

major.

media.

sylvatica.

Pleuropus.

Poa.

annua.

aquatica.

bulbosa.

distans.

fluitans.

strigosa.

sudetica.

album.
Abies.

sylvestris.

lanceolata.

Platisma caperatum.

ciliare.

farinaceum.

fraxineum.

furfuraceum.

olivaceum.

parietinum.

Pneumonanthe.

angustifolia.

compressa.

nemoralis.

pa!ustris.

pratensis.

retroflexa.

trivialis.

Podagraria.

Polemonium.
56

172

172

172

29. 66

29

29

29

29

29

210

211

211

211

211

210

210

240

43

17

13

39

17

I8

i?

19

I 8

19

39

18

I)

28

28

13

50

37

of 
caeruleum.

38 vulgare.

Pollichia amplexicauliz. 101 Polytrichum.

Polygala.

122

alba.

amara.

carnea.

elongata.

rulgaris.

Polvgona.

Poiygonatum.

Polygonum. amphibium. aquaticum. aviculare.

Bistorta.

Convolvulus.

dumetorum.

crectum.

Fagopyrum.

II ýdropiper.

iucanum.

intermedium.

lapathifolium.

minus.

Fersicaria.

terrestre.

Pulypodium. aculcatum. cristatum.

Dryouteris.

Filix femina.

Filix mas.

fragile.

snolle.

Oryopteris. Pliegopteris. spirulosum. aloides.

commune. juniperifolium. juniperinum.

nanum.

piliferum.

undulatum.

yuccaefolium.

Populus.

nigra.

tremula.

Portula.

Potamogeton.

crispum.

grạnineum.

lucens.

natans.

perfoliatum.

pusillum.

Potentilla.

Anserina.

argentea.

cana.

intermedia.

norvegica.

obsciria.

reptans.

rutlenica.

191

g1

191

19 ?

392

igt

391

192

177

177

177

64

31

32

32

31

31

31

52

89

89

89

8.

89

9o

89

90

90

salisburgensis.

89

sericea.

89

39

89

170

Poterium.

Sanguisorba.

170

Pottia cavifolia. 
Pratella.

Prenanthes. muralis.

Primula. elatior. officinalis. rubra. veris.

Prunella. alba. grandiflora. vulgaris.

\section{Prunus.} insiticia.

Padus. spinosa.

Pseud-Acorus.

Pseudo-Cyperus.

Psora saxicola.

Ptarmica.

Pteris. aquilina.

Puccinia.

acaciae.

aegopodii.

aethusae.

anemones.

apargiae.

balsamitae.

betonicae.

bistortae.

bulbosa.

bullata.

cauclata.

centaureao.

cerealis.

chrysosplenii.

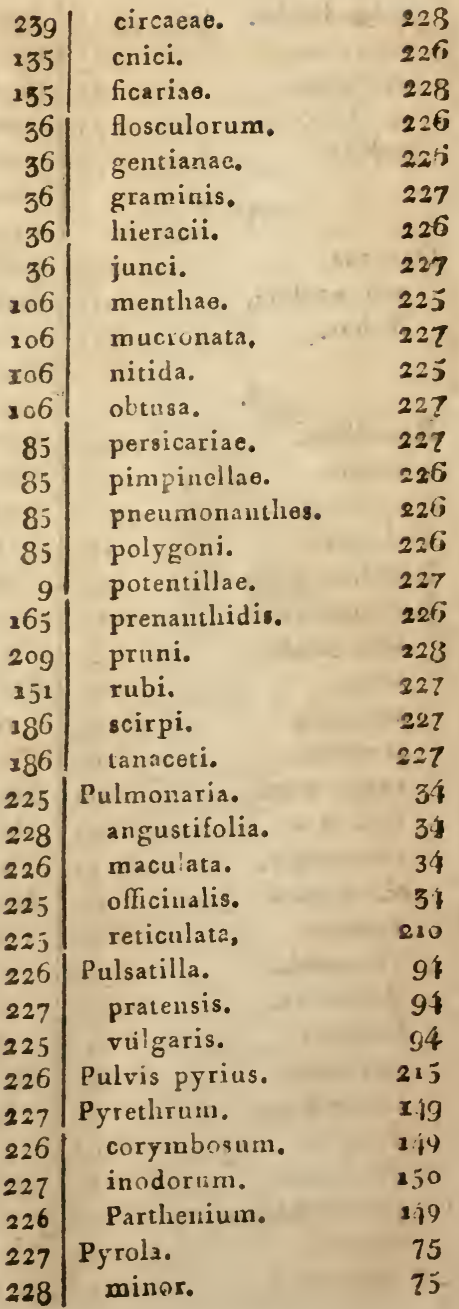


rotundifolia.

secunda.

umbellata.

uniflura.

virens.

\section{Q.}

Quercis.

pedunculata.

Rubur.

R.

Racodium.

cellare.

rupestre.

Radicula.

Ramaria farinosa.

Ranunculus.

aconitifolius,

acris.

aquatilis.

arvensis.

auricomus.

bulbsus.

campestris.

cassuticus.

Ficaria.

Flammula.

fluriatilis.

hirsutus.

hortensis.

lanuginosug.

Lingua.

Philonotis.

polyanthemos.

repens.

sceleratus.
75 Rapa.

25 Raphanistruma.

75 Raphanus.

75 niger.

75

Radicula.

Raphanistrum.

sativus.

\begin{tabular}{l|l}
$I_{\zeta 2}$ & $R a p u n c u l u s$.
\end{tabular}

172 Reticularia alba.

118

I18

171 lutea.

Rhamnus.

catharcticus.

252

252

252

118

250

96

97

97

98

98

Frangula.

Rhinamhus.

Alectorolophus.

Crista galli.

major.

minor.

villosus.

Rhizomurpha. setifurmis.

subcoriticalis.

96 Rhoeas.

92

97

96

96

96

98

97

97

97

96

97

98

92

96

Khynchospora.

Ribes.

Grossularia.

Riccia.

fluitans. 
Caragana.

Robnr.

Rosa.

canina.

cinnamomea.

majalis.

Rosmarinus sylvestris. 74

Rubigo.

Rubus.

albus.

caesius.

corylifolius.

fruticosus.

Idaeus.

saxatilis.

Pumex.

Acetosa.

Acetosella.

acutus.

ayuaticus.

bucephaiophorus.

conglomeratus.

crispus.

Hydrolapathum,

maritimus.

multifidus.

Nemolapathum.

obrusifolius.

Russula.

Ruta muraria.

Ruyschiana.

S.

Sagina.

procumbens.

Sagittaria.

natans.

sagittifolia.
122 Salicaria.

172 Salix.

8? acuminata.

87 alba.

87 anygdalina.

87 angustifolia.

228

87

87

87

87

88

87

88

64

65

66

65

65

65

64

67

67

65

66

64

65

240

136

105

32

32

170

170

170 aurita.

caprea.

decipiens.

fragilis.

Helix.

hermaphroditica.

incubacea.

monandra.

myrsinites.

pentandra.

rosmarinifolia.

triandra,

viminalis.

vitellina.

Salvia.

glutinosa.

pratensis.

rubra.

Sambucus.

Ebulus,

laciniata.

nigra.

Sanguisorba.

officinalis.

Sanicula.

europaea.

Saponaria.

hortensis.

officinalis

Satyrium.

Nonorchis.
83

172

175

275

173

174

174

175

174

174

174

I 73

I:7

$1 ? 4$

174

173

174

I 73

175

273

8

8

8

S

57

57

57

57

50. 170

50

50

50

76

27

76

$\mathbf{1 5 5}$

256 
repens.

viride.

Saxifraga.

Scabiosa.

-3 arvensis.

columbaria.

ochroleuca.

Succisa.

sylvatica.

Scandix.

Cerefolium.

Scariola.

Sceptrum Carolinum. Schismatopterides.

Schvenoprasum.

Schoenus albus.

Sclueberi carex.

hypnum.

Scirpus,

acicularis.

capitatus.

caricinus.

lacustris.

nanus.

ovatus.

palustris.

sylvaticus.

Soleranthus.

annuus.

perennis.

Sclerouerma.

cervinum.

Sclerotium.

brassicae.

complanatum.

Erysiphe.

ropulncum.
155 Semen.

I55 Scrophularia.

26. 152

56 aquatica.

26 Scutellaria.

26 galericulata.

26 Scutellatae.

26 Secale.

26 aestivum.

54 coreale.

57 Sedum.

$13 j$ acre.

108 purpureum.

$1 \$ 3$

60

9

162 Seliuum.

199 Carrifolia.

9

10

10

10

10

10

IO

10

10

76

26

76

219

219

217

$21 ?$

217

217

218

tectorum. carvifolium

palustre.

sylvaticum.

sylvestre.

Semen.

Sempervivum.

globiferum.

Senecio.

Jacobaea.

paludosus.

pumilus.

saracenicus,

sylvaticus.

vulgaris.

Serapias lancifolis.

latifolia.

longifolia.

rubra.
217

109

109

10 ?

105

105

205

25

25

25

so

80

so

80

80

I 83

51

5 I

5 I

$5 \mathrm{I}$

5 I

5 I

217

$8+$

$8+$

$8+$

147

142

147

$1+7$

147

147

147

156

156

I 56

156 
Serpyllum.

Serratula.

arvensis.

sctosa.

tinctoria.

Silaus.

Silene.

baccifera.

noctiflora.

nutans.

Sinapis.

alba.

arvensis.

nigra.

Sistotrema.

cinereum.

quercinum.

Sisymbrium.

amphibiun.

Loeselii.

Nasturtium.

palustre.

Sophia.

sylrestre.

Sium.

latifolium.

Solanum.

Dulcamara.

nigrum.

villosum.

Solidago.

Virgaurea.

Sonchus.

arvensis.

asper.

oleraceus.

palustris.
$104 \mid$ rigidus.

J40 Sophia.

140 Sorbus.

140 aucuparia.

140 Sparganium.

52 ramosum.

78 simplex.

78 Spergula.

78 arrensis.

78 nodosa.

117 Sphaeria.

117 aucupariae.

117 berberidis.

118 brassicae.

$2+3$ cespitosa.

243 deusta.

275 fragiformis.

115 fusca.

115 Fnomon.

116 graminis.

115 Hypoxylon.

134

115

85

86

160

I60

160

82

82

83

212

217

217

217

214

213

213

213

214

$2 \times 3$

212

15 inquinans.

215

II) maculaeformis.

216

II - militaris.

212

53 miniata.

53 nebulosa.

4 nitida.

42 nivea.

42 olivacea.

42 polymorpha.

216

214

257

214

$23+$

212

149 pteridis. 213

149 Pulvis pyrius. 215

$13+$

$13 t$

134 ribesia.

213

213

214

134 Stigma. 213

134

tiliae. 
trifolii. versipellis. xylostei. Sphaerobolus. rosaceus. stellatus. Sphagnum. capillifolium. cuspidatum. latifolium. palustre. spliondylium. Spica venti. Spiraea.

Filipendula. salicifolia. Ulmaria. Splachnum. ampullaceum. Spumaria. Mucilago. Squamaria. centrifuga. juniperina. pulverulenta. stellaris.

Stacliyopterides. Stachys.

annua. palustris. sylvatica. Stellaria.

arvensis. glauca. graminea. Holostea. nemorum.
214 palustris.

213 uliginosa.

215 Stemonitis.

79

216 crocata.

249 ferruginea.

221

221

217 sulphurea.

222

187 typhina.

222

187 Stereocaulon paschale. 207

187 Stigma.

187 Stilbospora.

187 macrosperma.

52 Stilbum.

14 rigidum.

86 vulgare.

86 Stramonium.

86 Stratiotes.

86 Aloides.

188 Struthiopteris.

188 germanica.

220 Succisa.

220 rosea.

110 Symphytum.

209 album.

212

206

209

182

103

103

103

officinale.

patens.

purpureum.

Syringa.

213

215

215

250

250

250

4 I

178

178

I186

186

26

26

34

34

$3+$

34

84

4

4

4

4

IO3

79 Tanacetum.

144

79 crispum. 244

79 vulgare. 144

79 Taraxacum. $\quad \mathbf{1 3 5}$

79 Telephium. 80

79 Tetrahit. 102 
Tetraphis. pellucida.

Tencrium. Thalictrum. angustifolium. aquilegifolium. flavam. ninus.

Thapsus.

Thelephora:

carnea.

ferruginea.

hirsuta.

incrustans,

laevis.

mesenterica.

mesenteriformis.

papyracea.

purpurea.

quercina.

terrestris.

Thlaspi.

arvense.

Bursa pastoris.

campestre.

simplicifolium.

Thrincia.

hirta.

Thymus.

Acynos.

Serpyllum.

Tilia.

grandifolia.

microphylla.

parvifolia.

platyphylla.
285 Tormentilla.

288 erecta.

6 officinalis.

95 Tortula muralis,

95 subulata.

95 Trachelium.

95 Tragopogon.

95 majus.

40 orientale.

2.47 pratense.

245 Trapa.

24-3 natans.

$2+5 \mid$ Tremelia.

275 abietina.

245 arborea.

245 Auricula.

$2+7$ caraganae.

$2+5$ juniperina.

245 mesenterica.

245 miliaria.

274 Nostoc,

112 sepincola.

112 spiculosa.

112 urticae.

112 ustulata.

113 Trentepolilia.

130 erecta.

136 Trichia.

Iof ovata.

10; rubiformis.

107 Trichoderma,

92 tuberculatum.

03 viride.

92 Trichodium.

92 caninum,

93

Trichostomura.

Tordylium Anthriscus. 
Trientalis. europaea.

Trifolium.

agrarium.

album.

alpestre.

arvense.

aureum.

caeruleum.

campesire.

carnelim.

filiforme.

flexuosum.

hybridum.

luteum.

medium.

Melilothus.

minus.

montanum.

officinale.

pentaphyllum.

pratense.

procumbens.

repens.

sativum.

spadiceum.

vulgare.

Triglochin.

palustre.

Tritigum.

aestivum.

liybernum.

repens.

Trollius.

europaeus.

Tuber.

cibarium.
$67 \mid$ Tubercularia. 216

67 vulgaris. 216

128 Tubulina. 222

131 fragiformis. 222

128 Turritis. $\quad 126$

I3 glatra. 116

I3 hirsuta. 127

31 Tussilago. If6

128 Farfara. $1+6$

$13 i$ hibrida. $\quad 1+7$

130 Petasites. 142

131 Typha. 159

229) angustifolia, 160

129 latifolia. 160

128

129

128 Ulmatia. 86

131 Ulmus. 48

130 campestris. 48

128 ciliata. 48

129) effusa. 48

129 Ulva. 204

131 intestinalis. 204

129 Ureáo. 228

129 alchemillae. 224

130 alyssi. 228

128 apiculata. 232

66 appendiculata. 233

66 arctii. 232

25 atinyrii. . 229

25 avenae. 233

25 bardanae. 232

26 betae. $23^{2}$

98 betulae. $23^{\mathrm{I}}$

98 betulina. 232

218 bullata. 232

218 canipanulae. 250 
candida.

caricis.

centifoliae.

cerastii.

cheiranthi.

cincta.

circinata.

confluens.

conii.

convolruli.

cubica.

decipiens.

eglanteriae.

epilobii.

erysimi.

eupliorbiae.

euphrasiae.

evonymi.

fabae.

farfarae.

farinosa.

frumerti.

genistae.

graminum.

gyrosa.

helioscopiae.

hordii.

idaei.

ledi.

linearis.

lini.

melampyri.

mentluae.

mercurialis.

miniata:

myrtilli.

nitida.

odontitidis.

orcliidis.

oreosclini.

ovata.

panici.

phaseoli.

pisi.

polygoni.

polypodii.
$228 /$ populi.

233 potentillac.

231 pulsatillae.

231 pustulata.

223 pyrolae.

232 rhinanthi.

220

229

232

232

229

233

230

231

228

229

230

230

232

230

230

229

233

233

231

229

233

231

231

229

229

230

232

229

230

231

532

230

229

232

231

233

253

233

232

229 ribis.

ringentiam,

rosac.

rubi.

saponariae.

segetum.

senecisnis.

serratulae.

sonchi.

spireso.

siaveolens.

thlaspeos.

tragopogi.

trenuellosa.

trifolii.

tritici.

tussilaginis.

ulmariae.

vaccinii.

viciae.

violacea.

violae.

Urtica.

dioica.

urens.

Usnea.

cranii.

florida.

hirta.

jubata.

Utrienlaria.

minor.

vulgaris.

Ura crispa.

Uva ursi.

Vacciniúm.

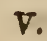

Myrtillus.

Oxycoceos.

uliginosum.
251

229

230

231

229

230

2.30

230

231

229

233

233

230

232

230

231

232

228

228

230

232

233

230

231

231

232

233

233

168

168

168

208

209

208

208

211

7
7

7

44

75

70

70

69

78 
Vitis Idaea.

Valeriama.

officinalis.

Vastator.

Veratrum.

album.

Verbascum.

nigrum.

phiomoides.

Tha?sus.

Verrnica.

agrestis.

Anagallis

arvensis.

ausiriaca.

Jeccabunga.

Chamaedrys.

latifnlia.

longitolia.

maritima.

officinalis.

parmularia.

rosea.

scurellata.

serpyilifolia.

8 yicata.

Teucrium.

triphliyllos.

verna.

Verrucaria.

aurantiaca.

ge'graphica.

nitida.

scripta.

Viburnum.

Opulıs. roseum.

Vicia.

angustifolia. cassubica.

Cracca. dumetorum, sativa.

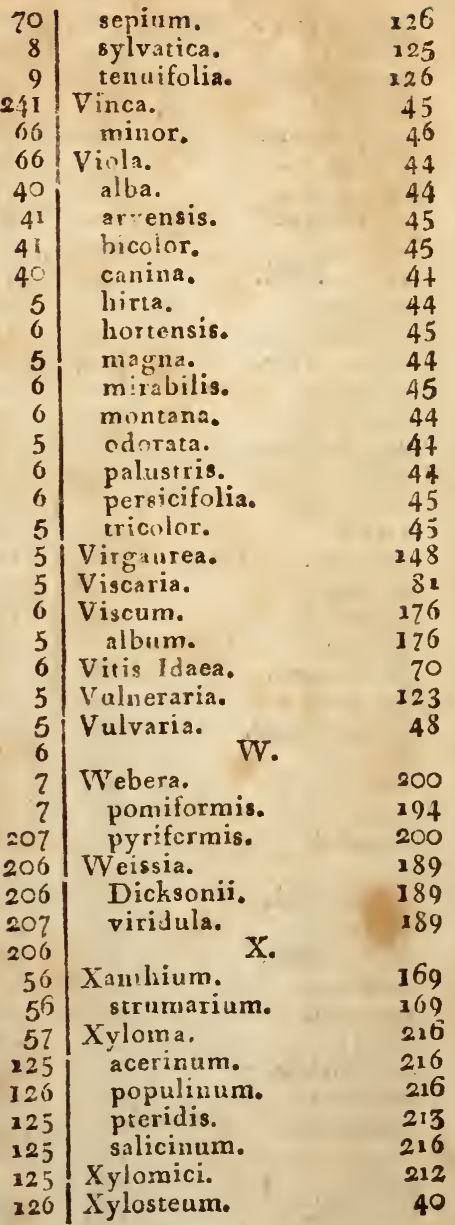






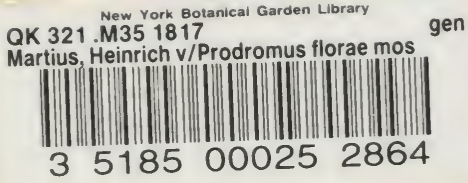




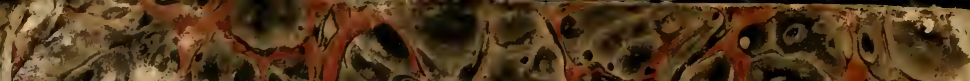

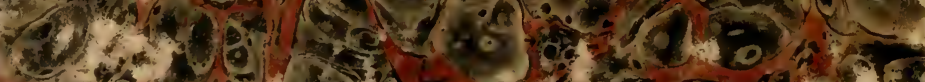
2)

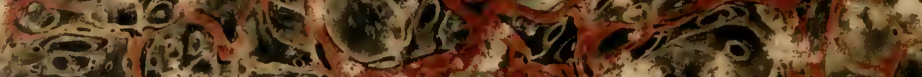

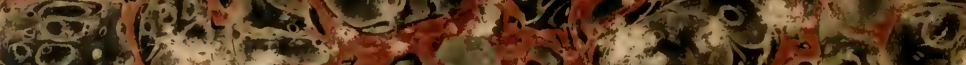

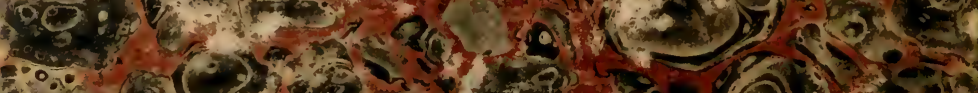

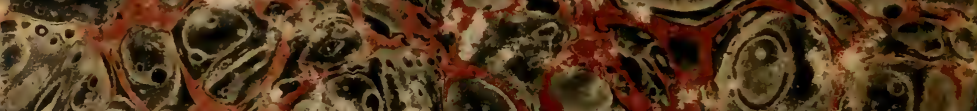

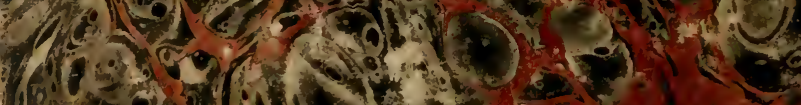

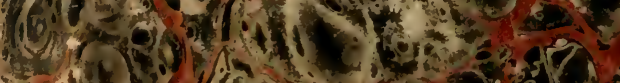

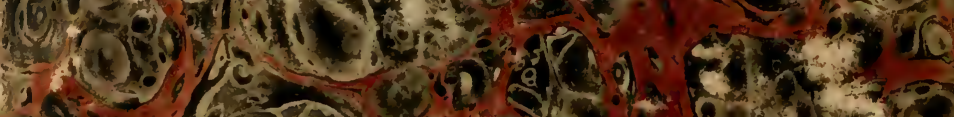
1.

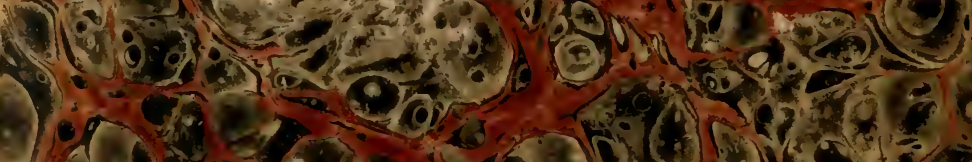

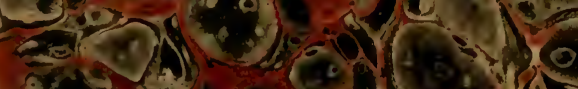

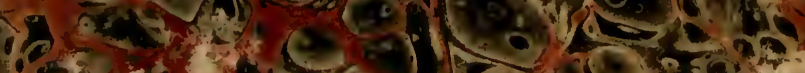
1.

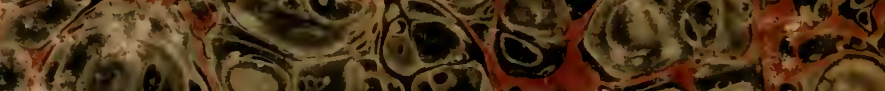

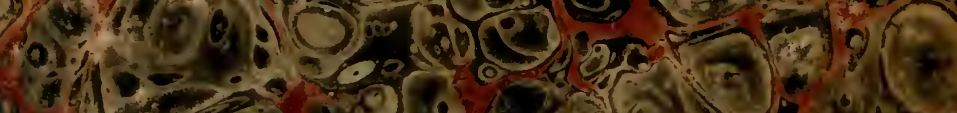
12

s.6. 2. 8 - 11 260 a 3 atsom.

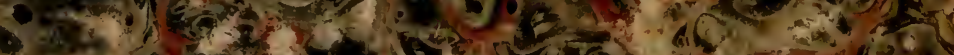
(9)

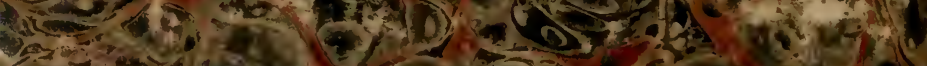

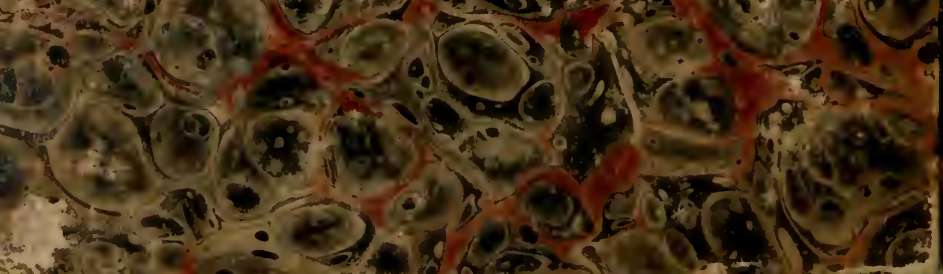

